\title{
Scoping the Emissions Gap Report 2017
}

\author{
Olhoff, Anne; Christensen, John M.
}

Published in:

The Emissions Gap Report 2017: A UN Environment Synthesis Report

Publication date:

2017

Document Version

Publisher's PDF, also known as Version of record

Link back to DTU Orbit

Citation (APA):

Olhoff, A., \& Christensen, J. M. (2017). Scoping the Emissions Gap Report 2017. In The Emissions Gap Report 2017: A UN Environment Synthesis Report (pp. 1-2)

\section{General rights}

Copyright and moral rights for the publications made accessible in the public portal are retained by the authors and/or other copyright owners and it is a condition of accessing publications that users recognise and abide by the legal requirements associated with these rights.

- Users may download and print one copy of any publication from the public portal for the purpose of private study or research.

- You may not further distribute the material or use it for any profit-making activity or commercial gain

- You may freely distribute the URL identifying the publication in the public portal

If you believe that this document breaches copyright please contact us providing details, and we will remove access to the work immediately and investigate your claim. 


\section{UN environment}

\section{The Emissions Gap Report 2017}

A UN Environment Synthesis Report 
Published by the United Nations Environment Programme (UNEP), November 2017

Copyright @ UNEP 2017

ISBN: 978-92-807-3673-1

Job Number: DEW/2136/PA

This publication may be reproduced in whole or in part and in any form for educational or non-profit services without special permission from the copyright holder, provided acknowledgement of the source is made. UNEP would appreciate receiving a copy of any publication that uses this publication as a source.

No use of this publication may be made for resale or any other commercial purpose whatsoever without prior permission in writing from the United Nations Environment Programme. Applications for such permission, with a statement of the purpose and extent of the reproduction, should be addressed to the Director, Communication Division, UNEP, P. O. Box 30552, Nairobi 00100, Kenya.

\section{Disclaimers}

Mention of a commercial company or product in this document does not imply endorsement by UNEP or the authors. The use of information from this document for publicity or advertising is not permitted. Trademark names and symbols are used in an editorial fashion with no intention on infringement of trademark or copyright laws.

The views expressed in this publication are those of the authors and do not necessarily reflect the views of the United Nations Environment Programme. We regret any errors or omissions that may have been unwittingly made.

(C) Images and illustrations as specified.

Citation This document may be cited as: UNEP (2017). The Emissions Gap Report 2017. United Nations Environment Programme (UNEP), Nairobi

A digital copy of this report along with supporting appendices are available at www.unenvironment.org/resources/emissions-gap-report

Supported by:

Federal Ministry for the Environment, Nature Conservation, Building and Nuclear Safety

\section{UN Environment}




\section{The Emissions Gap Report 2017} A UN Environment Synthesis Report November 2017 


\section{Acknowledgements}

UN Environment (UNEP) would like to thank the members of the steering committee, the lead and contributing authors, reviewers and the secretariat for their contribution to the preparation of this assessment report.

Authors and reviewers have contributed to the report in their individual capacities. Their affiliations are only mentioned for identification purposes.

\section{Project steering committee}

John Christensen (UNEP DTU Partnership), Navroz K. Dubash (Centre for Policy Research, India), Thelma Krug (Brazilian National Institute for Space Research), Uwe Leprich (German Federal Environment Agency), Jian Liu (UN Environment), Simon Maxwell (Climate and Development Knowledge Network), Surabi Menon (ClimateWorks Foundation), Bert Metz (European Climate Foundation), Yacob Mulugetta (University College London), Katia Simeonova (United Nations Framework Convention on Climate Change), Oksana Tarasova (World Meteorological Organization), Merlyn van Voore (UN Environment)

\section{Chapter 1}

Lead authors: Anne Olhoff (UNEP DTU Partnership), John Christensen (UNEP DTU Partnership)

\section{Chapter 2}

Lead authors: Michel den Elzen (PBL Netherlands Environmental Assessment Agency), Taryn Fransen (World Resources Institute), Takeshi Kuramochi (NewClimate Institute)

Contributing authors: Jasmin Cantzler (Climate Analytics), Hanna Fekete (NewClimate Institute), Jos Olivier (PBL Netherlands Environmental Assessment Agency), Paola Yanguas Parra (Climate Analytics)

\section{Chapter 3}

Lead authors: Michel den Elzen (PBL Netherlands Environmental Assessment Agency), Niklas Höhne (NewClimate Institute), Kejun Jiang (Energy Research Institute, China)

Contributing authors: Jasmin Cantzler (Climate Analytics), Philip Drost (UN Environment), Taryn Fransen (World Resources Institute), Hanna Fekete (NewClimate Institute), Takeshi Kuramochi (NewClimate Institute), David Lee (Manchester Metropolitan University), Kelly Levin (World Resources Institute); Joeri Rogelj (International Institute for Applied Systems Analysis), Fu Sha (National Center for Climate Strategy and International Cooperation), Michiel Schaeffer (Climate Analytics) and Zoi Vrontisi (E3M Lab)

\section{Chapter 4}

Lead authors: Kornelis Blok (Ecofys), Angélica Afanador (Ecofys), Detlef van Vuuren (PBL Netherlands Environmental Assessment Agency)

Contributing authors: Tom Berg (Ecofys), Christian Breyer (Lappeenranta University of Technology), Oreane Edelenbosch (PBL Netherlands Environmental Assessment Agency), Ann Gardiner (SQ Consult), Danny Harvey (University of Toronto), Atul Kumar (TERI University), Roberto Schaeffer (Universidade Federal do Rio de Janeiro), Pete Smith (University of Aberdeen), Lynn Price (Lawrence Berkeley National Laboratory), Irina van der Hoorn (Ecofys), Paul Waide (Waide Strategic Efficiency), Hans Joosten (Greifswald University)

\section{Chapter 5}

Lead authors: Amit Garg (Indian Institute of Management Ahmedabad), Jan Christoph Steckel (Mercator Research Institute on Global Commons and Climate Change)

Contributing authors: Jesse Burton (University of Cape Town), Julio Friedmann (Energy Futures Initiative), Frank Jotzo (Australian National University), Gunnar Luderer (Potsdam Institute for Climate Impact Research), Pao-Yu Oei (German Institute for Economic Research/Berlin Technical University), Michiel Schaeffer (Climate Analytics), Samantha Smith (Just Transition Centre), Fabby Tumiwa (Institute for Essential Services Reform), Adrien Vogt-Schilb (InterAmerican Development Bank), Paola Yanguas-Parra (Climate Analytics), Xianli Zhu (UNEP DTU Partnership)

\section{Chapter 6}

Lead authors: Zbigniew Klimont (International Institute for Applied Systems Analysis), Drew Shindell (Duke University)

Contributing authors: Nathan Borgford-Parnell (UN Environment), Lena Höglund-Isaksson (International Institute for Applied Systems Analysis), Steffen Kallbekken (CICERO Center for International Climate Research), Johan Kuylenstierna (Stockholm Environment Institute at York), Luisa Molina (Molina Center for Energy and the Environment/ Massachusetts Institute of Technology), Leena Srivastava (TERI University), Shu Tao (Peking University), Chandra Venkataraman (Indian Institute of Technology Bombay) 


\section{Chapter 7}

Lead authors: Pete Smith (University of Aberdeen), Julio Friedmann (Carbon Wrangler, LLC)

Contributing authors: Sabine Fuss (Mercator Research Institute on Global Commons and Climate Change), Noah Deich (Center for Carbon Removal), Giana Amador (Center for Carbon Removal), Jan Minx (Mercator Research Institute on Global Commons and Climate Change), Mark G. Lawrence (Institute for Advanced Sustainability Studies, Potsdam), Mercedes Bustamante (Departamento de Ecologia, Universidade de Brasília), Omar Masera (Institute for Ecosystem Research and Sustainability, Universidad Nacional Autónoma de Mexico), Annette Cowie (New South Wales Department of Primary Industries/University of New England), Oliver Geden (German Institute for International and Security Affairs)

\section{Reviewers}

Alan David Lee (World Bank), Asbjørn Torvangers (CICERO Center for International Climate Research), Ayyoob Sharifi (Global Carbon Project - Tsukuba International Office), Benoit Gabrielle (INRA - AgroParisTech), Chandra Shekhar Sinha (World Bank), Christine Shearer (CoalSwarm), Cyril Cassisa (Enerdata), Daniel Puig (UNEP DTU Partnership), Djaheezah Subratty (UN Environment), Durwood Zaelke (Institute for Governance \& Sustainable Development), Edmundo Barrios (Food and Agriculture Organization), Emma W. Littleton (University of Exeter), Etsushi Kato (The Institute of Applied Energy), Felix Creutzig (Mercator Research Institute on Global Commons and Climate Change/Technical University Berlin), Frank Dentener (European Commission, Joint Research Centre), Gerd Leipold (Humboldt-Viadrina Governance Platform), Glen Peters (CICERO Center for International Climate Research), Greet Maenhout Janssens (European Commission, Joint Research Centre), Henri Waisman (Institute for Sustainable Development and International Relations), Henry Neufeldt (UNEP DTU Partnership), Jan S. Fuglestvedt (CICERO Center for International Climate Research), Jérôme Hilaire (Mercator Research Institute on Global Commons and Climate Change), Joeri Rogelj (International Institute for Applied Systems Analysis), Johannes Gütschow (Potsdam Institute for Climate Impact Research), Johannes Trueby (International Energy Agency), Juan Carlos Altamirano (WRI/ New Climate Economy), Karan Mangotra (The Energy and Resources Institute), Lars J. Nilsson (Lund University), Lera Miles (UN Environment World Conservation Monitoring Centre), Luke Kemp (Australian National University), Maria Belenky (Climate Advisers), Mark Roelfsema (Radboud University), Matt Phillips (European Climate Foundation), Michael Lazarus (Stockholm Environment Institute), Michael Obersteiner (International Institute for Applied Systems Analysis), Miles Perry (European Commission Directorate-General for Climate Action), Oscar Widerberg (Vrije Universiteit Amsterdam - Institute for Environmental Studies), Paul Ekins (University College London), Piers Forster (University of Leeds), Rachel Chi Kiu Mok (World Bank), Ravi Prabhu (World Agroforestry Centre), Rob Dellink (Organisation for Economic Co-operation and Development), Roman Mendelevitch (Humboldt-Universität zu Berlin), Rong Wang (Carnegie Institution for Science), Stefan Kinne (Max Planck Institute for Meteorology), Steffen Dockweiler, (Danish Energy Agency), Sylvain Cail (Enerdata), Thomas Hale (Oxford University), Tim Christophersen (UN Environment), Tom van lerland (European Commission Directorate-General for Climate Action), Toon Vandyck (European Commission,
Joint Research Centre), Valentin Foltescu (UN Environment - Climate and Clean Air Coalition), Wolfgang K. Heidug (King Abdullah Petroleum Studies and Research Center), Zhao Xiusheng (Tsinghua University)

\section{Chief scientific editors}

Anne Olhoff (UNEP DTU Partnership), John Christensen (UNEP DTU Partnership)

\section{Editorial team}

Daniel Puig (UNEP DTU Partnership), Lars Christiansen (UNEP DTU Partnership), Natacha Chater Cure (UNEP DTU Partnership), Henry Neufeldt (UNEP DTU Partnership)

\section{Project coordination}

Lars Christiansen (UNEP DTU Partnership), Natacha Chater Cure (UNEP DTU Partnership), Anne Olhoff (UNEP DTU Partnership), John Christensen (UNEP DTU Partnership), Edoardo Zandri (UN Environment), Philip Drost (UN Environment), Volodymyr Demkine (UN Environment)

\section{External global and national modelling data contributors}

Climate Analytics, Climate Action Tracker (Bill Hare, Marcia Rocha and Michiel Schaeffer), Climate Interactive (Andrew Jones, Lori Siegel), Danish Energy Agency (Steffen Dockweiler), Ecofys (Kornelis Blok), Energy Research Institute, China (Chenmin He), International Energy Agency (Laura Cozzi and Fabian Kesicke), International Institute for Applied Systems Analysis (Nicklas Forsell), Joint Research Centre, European Commission (Alban Kitous, Kimon Keramidas, Bert Saveyn and Giacomo Grassi), National Center for Climate Change Strategy and International Cooperation, China (Fu Sha), PBL Netherlands Environmental Assessment Agency (Kendall Esmeijer and Heleen van Soest), Pacific Northwest National Laboratory (Gokul Iyer), Potsdam Institute for Climate Impact Research (Louise Jeffery), University of Melbourne (Malte Meinshausen)

\section{Media and launch support}

David Cole (UN Environment), Roxanna Samii (UN Environment), Myriam Castanié (European Climate Foundation), Shuzhi Hou (UN Environment), Mette Annelie Rasmussen (UNEP DTU Partnership), Shereen Zorba (UN Environment), Jan Dusik (UN Environment), Rehana Velji (UN Environment), Alessandra Vellucci (UN Information Service) and Diana D. Rizzolio (Geneva Environment Network)

\section{Design, layout and printing}

Caren Weeks (independent consultant), Kailow A/S

\section{Translation of Executive Summary}

\section{Strategic Agenda}

\section{Thanks also to}

German Federal Ministry for the Environment, Nature Conservation, Building and Nuclear Safety (BMUB), Climate Works Foundation, The Finnish Innovation Fund SITRA, the Netherlands Ministry of Infrastructure and Environment, Jacqueline McGlade (UN Environment), Harsha Dave (UN Environment), Brigitte Ohanga (UN Environment), Lucy Ellen Gregersen (UNEP DTU Partnership), Thomas Hebo Larsen (UNEP DTU Partnership), Susanne Konrad (UNEP DTU Partnership), Saran Sohi (University of Edinburgh), Thomas Kragh Laursen (UNEP DTU Partnership, and Pia Riis KofoedHansen (UNEP DTU Partnership) 


\section{Contents}

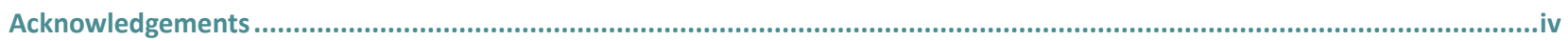

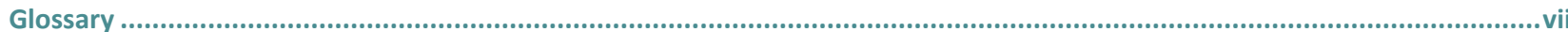

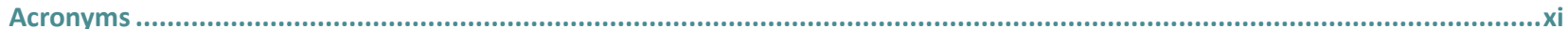

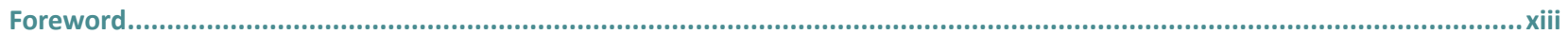

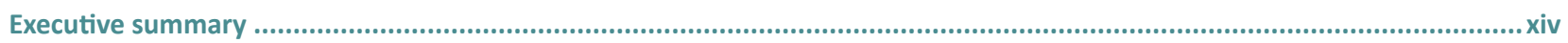

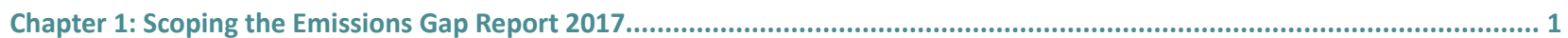

1.1 Moving towards implementation of the Paris Agreement: 2018 as a critical juncture .............................................

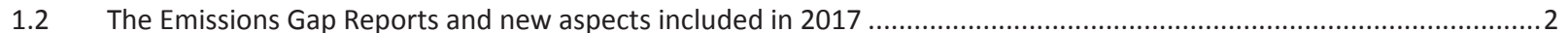



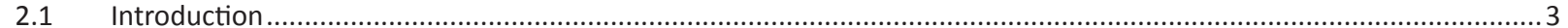

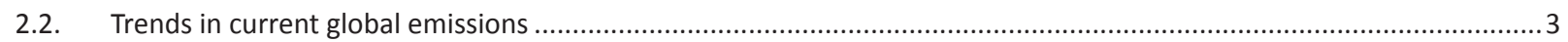

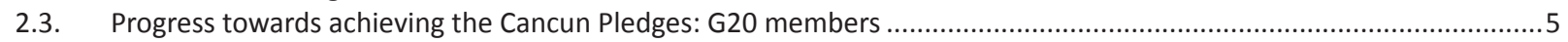

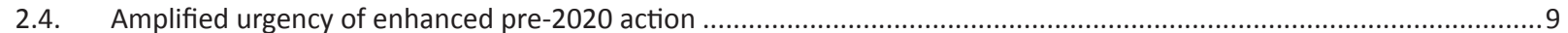

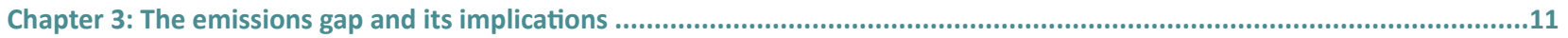

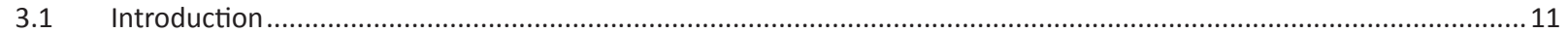

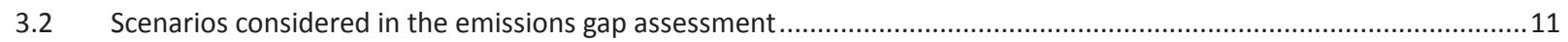

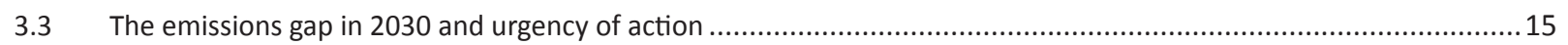

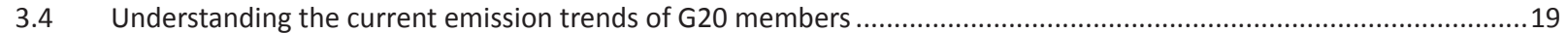

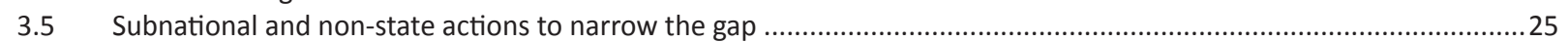

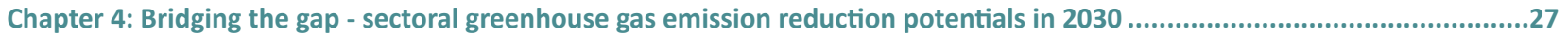

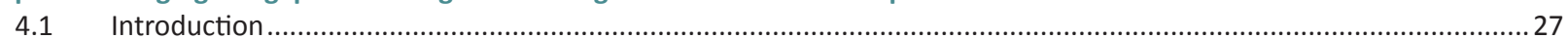

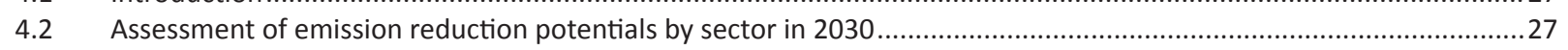

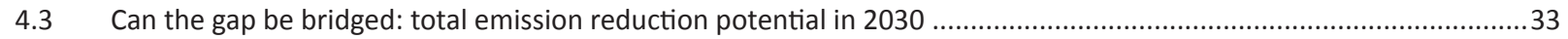

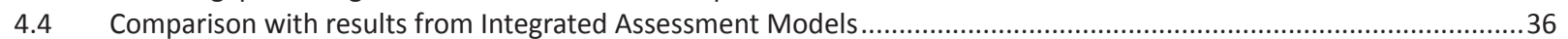

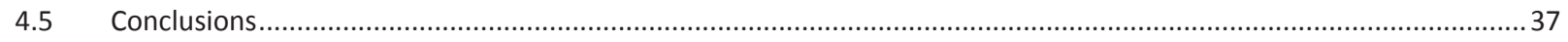

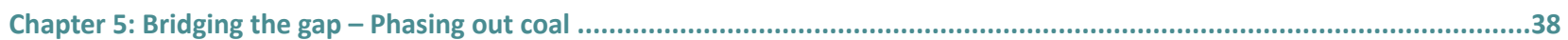

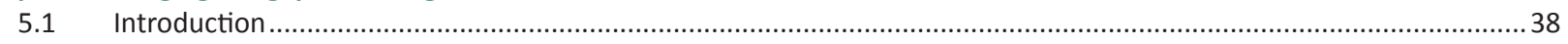

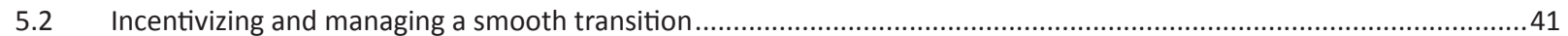

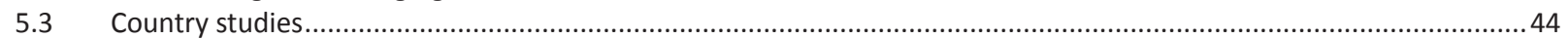

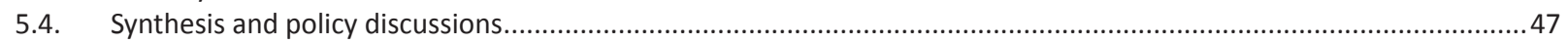

Chapter 6: Bridging the gap - The role of short-lived climate pollutants....................................................................48

6.1 The contribution of SLCPs to climate change - Introduction and framing .............................................................48



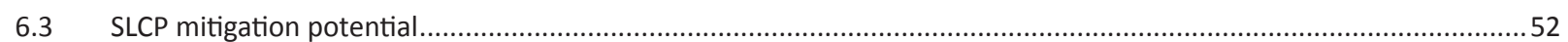

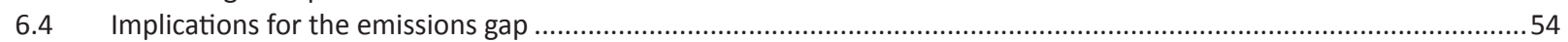

6.5 Implications for the Sustainable Development Goals and other policy goals.........................................................56

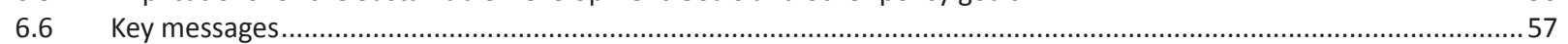

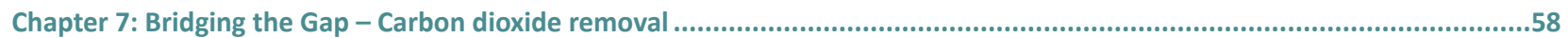

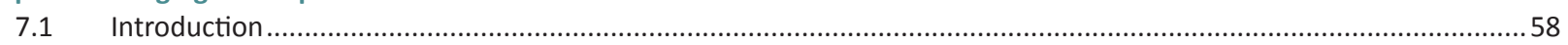

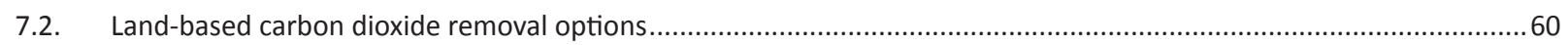

7.3 Combined land/technology-based option: bioenergy with carbon dioxide capture and storage ...............................62



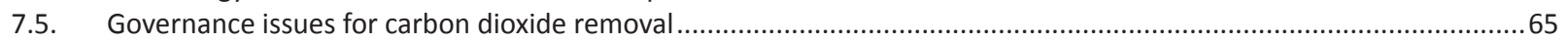

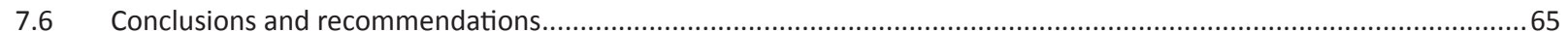

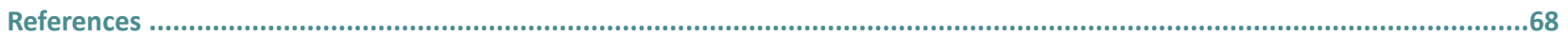




\section{Glossary}

This glossary is compiled by the lead authors of the report, drawing on glossaries and other resources available on the websites of the following organizations, networks and projects: Intergovernmental Panel on Climate Change, Non-State Actor Zone for Climate Action, United Nations Environment, United Nations Framework Convention on Climate Change and World Resources Institute.

Afforestation: Planting of new forests on lands that historically have not contained forests.

Agroforestry: Farming management practice characterized by the deliberate inclusion of woody perennials on farms, which usually leads to significant economic and/or ecological benefits between woody and non-woody system components. In most documented cases of successful agroforestry, tree-based systems are more productive, more sustainable and more attuned to people's cultural or material needs than treeless alternatives. Agroforestry also provides significant mitigation benefits by sequestering carbon from the atmosphere in the tree biomass.

Baseline/reference: The state against which change is measured. In the context of transformation pathways, the term 'baseline scenarios' refers to scenarios that are based on the assumption that no mitigation policies or measures will be implemented beyond those that are already in force and/or are legislated or planned to be adopted. Baseline scenarios are not intended to be predictions of the future, but rather counterfactual constructions that can serve to highlight the level of emissions that would occur without further policy effort. Typically, baseline scenarios are then compared to mitigation scenarios that are constructed to meet different goals for greenhouse gas emissions, atmospheric concentrations or temperature change. The term 'baseline scenario' is used interchangeably with 'reference scenario' and 'no policy scenario'. In much of the literature the term is also synonymous with the term 'business as usual (BAU) scenario', although the term has fallen out of favour because the idea of 'business as usual' in century-long socioeconomic projections is hard to fathom.

Biochar: A solid material obtained from thermochemical conversion of biomass in an oxygen-limited environment.
Bioenergy: Energy derived from any form of biomass such as recently living organisms or their metabolic by-products.

Bioenergy and Carbon Dioxide Capture and Storage (BECCS): The application of Carbon Dioxide Capture and Storage (CCS) technology to bioenergy conversion processes.

Black carbon: The substance formed through the incomplete combustion of fossil fuels, biofuels, and biomass, which is emitted in both anthropogenic and naturally occurring soot. It consists of pure carbon in several linked forms. Black carbon warms the Earth by absorbing heat in the atmosphere and by reducing albedo - the ability to reflect sunlight - when deposited on snow and ice.

Bottom-up model: In the context of this assessment, a model that represents a system by looking at its detailed underlying parts. Compared to so-called top-down models, which focus on economic interlinkages, bottom-up models of energy use and emissions can provide greater resolution with regards to sectors or mitigation technologies.

Cancun Pledge: During 2010, many countries submitted their existing plans for controlling greenhouse gas emissions to the Climate Change Secretariat and these proposals were formally acknowledged under the United Nations Framework Convention on Climate Change (UNFCCC). Developed countries presented their plans in the shape of economy-wide targets to reduce emissions, mainly up to 2020, while developing countries proposed ways to limit their growth of emissions in the shape of plans of action.

Carbon Dioxide Capture and Storage (CCS): A process in which a relatively pure stream of carbon dioxide from industrial, energy-related sources or captured from the air is separated (captured), conditioned, compressed, and transported to a storage location for long-term isolation from the atmosphere.

Carbon dioxide emission budget (or carbon budget): For a given temperature rise limit, for example a $1.5^{\circ} \mathrm{C}$ or $2^{\circ} \mathrm{C}$ long-term limit, the corresponding carbon budget reflects the total amount of carbon emissions that can be emitted for temperatures to stay below that limit. Stated differently, a carbon budget is the area under a carbon dioxide $\left(\mathrm{CO}_{2}\right)$ 
emission trajectory that satisfies assumptions about limits on cumulative emissions estimated to avoid a certain level of global mean surface temperature rise.

Carbon dioxide equivalent $\left(\mathrm{CO}_{2} \mathrm{e}\right)$ : $\mathrm{A}$ way to place emissions of various radiative forcing agents on a common footing by accounting for their effect on climate. It describes, for a given mixture and amount of greenhouse gases, the amount of $\mathrm{CO}_{2}$ that would have the same global warming ability, when measured over a specified time period. For the purpose of this report, greenhouse gas emissions (unless otherwise specified) are the sum of the basket of greenhouse gases listed in Annex A to the Kyoto Protocol, expressed as $\mathrm{CO}_{2} \mathrm{e}$ assuming a 100 -year global warming potential.

Carbon intensity: The amount of emissions of $\mathrm{CO}_{2}$ released per unit of another variable such as gross domestic product, output energy use, transport or agricultural/ forestry products.

\section{Carbon offset: See Offset.}

Carbon price: The price for avoided or released $\mathrm{CO}_{2}$ or $\mathrm{CO}_{2}$ e emissions. This may refer to the rate of a carbon tax or the price of emission permits. In many models that are used to assess the economic costs of mitigation, carbon prices are used as a proxy to represent the level of effort in mitigation policies.

Carbon sequestration: The process of removing carbon from the atmosphere and depositing it in a reservoir.

Carbon stock: The quantity of carbon contained in a carbon pool or reservoir.

Carbon tax: A levy on the carbon content of fossil fuels. Because virtually all of the carbon in fossil fuels is ultimately emitted as $\mathrm{CO}_{2}$, a carbon tax is equivalent to an emission tax on $\mathrm{CO}_{2}$ emissions.

Circular carbon economy: An economy or portion of an economy in which waste, by-product, or ambient $\mathrm{CO}_{2}$ serves as feedstock and is recycled into products (e.g., fuels, chemicals, plastics, carbon composites)

Co-benefits: The positive effects that a policy or measure aimed at one objective might have on other objectives, without yet evaluating the net effect on overall social welfare. Co-benefits are often subject to uncertainty and depend on, among others, local circumstances and implementation practices. Co-benefits are often referred to as ancillary benefits.

Conditional INDC: INDC proposed by some countries that are contingent on a range of possible conditions, such as the ability of national legislatures to enact the necessary laws, ambitious action from other countries, realization of finance and technical support, or other factors.

Conference of the Parties (COP): The supreme body of the Convention. It currently meets once a year to review the Convention's progress.
Current policy trajectory: This trajectory is based on estimates of 2020 emissions considering projected economic trends and current policy approaches including policies at least through 2012. Estimates may be based on either official data or independent analysis.

Deforestation: Conversion of forest to non-forest.

Double counting: In the context of this assessment, double counting refers to a situation in which the same emission reductions are counted towards meeting two countries' pledges.

Economic mitigation potential: The mitigation potential, which takes into account social costs and benefits and social discount rates, assuming that market efficiency is improved by policies and measures and barriers are removed.

Emissions gap: The difference between the greenhouse gas emission levels consistent with having a likely chance (>66 percent) of limiting the mean global temperature rise to below $2^{\circ} \mathrm{C} / 1.5^{\circ} \mathrm{C}$ in 2100 above pre-industrial levels and the GHG emission levels consistent with the global effect of the INDCs, assuming full implementation from 2020.

Emission pathway: The trajectory of annual greenhouse gas emissions over time.

Global warming potential: An index representing the combined effect of the differing times greenhouse gases remain in the atmosphere and their relative effectiveness in absorbing outgoing infrared radiation.

Greenhouse gases: The atmospheric gases responsible for causing global warming and climatic change. The major greenhouse gases are carbon dioxide $\left(\mathrm{CO}_{2}\right)$, methane $\left(\mathrm{CH}_{4}\right)$ and nitrous oxide $\left(\mathrm{N}_{2} \mathrm{O}\right)$. Less prevalent, but very powerful, greenhouse gases are hydrofluorocarbons (HFCs), perfluorocarbons (PFCs) and sulphur hexafluoride $\left(\mathrm{SF}_{6}\right)$.

Hydrofluorocarbons (HFC) bank: Quantities of hydrofluorocarbons already produced or in use of which a portion is likely to eventually be emitted to the atmosphere.

Integrated assessment models: Models that seek to combine knowledge from multiple disciplines in the form of equations and/or algorithms in order to explore complex environmental problems. As such, they describe the full chain of climate change, from production of greenhouse gases to atmospheric responses. This necessarily includes relevant links and feedbacks between socio-economic and biophysical processes.

Intended Nationally Determined Contribution (INDC): Submissions by Parties which identify actions each national government intends to take under the future UNFCCC climate agreement, negotiated in Paris in December 2015. INDCs are, in effect, the basis of post-2020 global emission reduction commitments that will be included in the future climate agreement.

International cooperative initiatives (ICls): Initiatives outside the UNFCCC aimed at reducing emissions of 
climate forcers by, for example, promoting actions that are less greenhouse gas intensive, compared to prevailing alternatives. Cooperative initiatives also involve national and sub-national partners (they are often referred to as, simply, 'cooperative initiatives').

Kigali Agreement: The Kigali Amendment to the Montreal Protocol on Substances that Deplete the Ozone Layer aims for the phase-down of hydrofluorocarbons (HFCs) by cutting their production and consumption.

Kyoto Protocol: An international agreement, standing on its own, and requiring separate ratification by governments, but linked to the UNFCCC. The Kyoto Protocol, among other things, sets binding targets for the reduction of greenhouse gas emissions by industrialized countries.

Land use, land-use change and forestry (LULUCF): A greenhouse gas inventory sector that covers emissions and removals of greenhouse gases resulting from direct humaninduced land use, land use change and forestry activities.

Likely chance: A likelihood greater than 66 percent chance. Used in this assessment to convey the probabilities of meeting temperature limits.

Lock-in: Lock-in occurs when a market is stuck with a standard even though participants would be better off with an alternative.

Medium chance: A likelihood of 50-66 percent chance. Used in this report to convey the probabilities of meeting temperature limits.

Mitigation: In the context of climate change, a human intervention to reduce the sources, or enhance the sinks of greenhouse gases. Examples include using fossil fuels more efficiently for industrial processes or electricity generation, switching to solar energy or wind power, improving the insulation of buildings and expanding forests and other 'sinks' to remove greater amounts of $\mathrm{CO}_{2}$ from the atmosphere.

Monitoring, reporting and verification: A process/concept that potentially supports greater transparency in the climate change regime.

Montreal Protocol: The Montreal Protocol on Substances that Deplete the Ozone Layer is an international treaty that was designed to reduce the production and consumption of ozone-depleting substances in order to reduce their abundance in the atmosphere, and thereby protect the Earth's ozone layer.

Nationally determined Contribution: Actions that, by ratifying the Paris Agreement, each party to the UNFCCC binds itself to pursuing.

Non-state actor: In the context of climate action, 'non-state actor' includes companies, cities, subnational regions and investors. More broadly, non-state actors have been defined as entities that participate or act in international relations. They are organizations with sufficient power to influence and cause a change even though they do not belong to any state institution.
Offset (in climate policy): $\mathrm{A}$ unit of $\mathrm{CO}_{2} \mathrm{e}$ emissions that is reduced, avoided, or sequestered to compensate for emissions occurring elsewhere.

Party: A state (or regional economic integration organization such as the European Union) that agrees to be bound by a treaty and for which the treaty has entered into force.

Pigouvian tax: A tax levied on any market activity that generates negative externalities (costs not internalized in the market price).

Pledge case: This case identifies the maximum level of greenhouse gas emissions that each country or Party could emit in 2020 and still meet its pledge - without considering the use of offsets.

Reforestation: Replanting of forests on lands that have previously contained forests but that have been converted to some other use.

Scenario: A description of how the future may unfold based on 'if-then' propositions. Scenarios typically include an initial socio-economic situation and a description of the key driving forces and future changes in emissions, temperature or other climate change-related variables.

Short-lived climate pollutants (SLCPs): Compounds in the atmosphere that cause warming and have lifetimes roughly below 20 years, including black carbon, ozone, methane, and many hydrofluorocarbons.

Source: Any process, activity or mechanism that releases a greenhouse gas, an aerosol or a precursor of a greenhouse gas or aerosol into the atmosphere.

Shared Socio-Economic Pathways (SSPs): Narratives of possible societal futures that include quantitative projections of socio-economic factors such as population, GDP, urbanization, technologies and regional heterogeneity.

SSP3 (Shared Socio-Economic Pathway - narrative 3): This SSP narrative is characterized by high challenges to mitigation and adaptation. It assumes a focus on national and regional policies, slow economic growth, lack of collaboration, large population remaining in poverty, and low priority for environmental policies, leading to strong environmental degradation in some regions.

Subcritical coal plant: A subcritical coal fired plant uses coal to heat water into high-pressure steam to drive an electrical generator, whereas the steam in the boiler does not pass the supercritical point of water (as compared to supercritical power plants). The resulting efficiency rates are comparably low, i.e. below 37 percent.

Sustainable development: Development that meets the needs of the present without compromising the ability of future generations to meet their own needs.

Technical mitigation potential: Such potential is estimated for given scenarios assuming full implementation of best available pollutant reduction technology, as it exists today, by 2030 independent of their costs but considering technical 
lifetime of technologies and other key constraints (e.g., Uncertainty: A cognitive state of incomplete knowledge that cultural acceptance) that could limit applicability of certain can result from a lack of information or from disagreement measures in specific regions.

Top-down model: A model that applies macroeconomic theory, econometric and/or optimization techniques to aggregate economic variables. Using historical data on consumption, prices, incomes, and factor costs, topdown models assess demand and emissions for goods and services from main sectors, such as energy conversion, transportation, buildings, agriculture and industry.

Tropospheric ozone: Ozone in the lowest portion of the atmosphere extending from the surface to the edge of the stratosphere. Ozone in this region is a powerful greenhouse gas, especially in the mid to upper troposphere, whereas the portion at the surface is damaging to humans and plants. about what is known or even knowable. It may have many types of sources, from imprecision in the data to ambiguously defined concepts or terminology, or uncertain projections of human behaviour. Uncertainty can therefore be represented by quantitative measures (for example a probability density function) or by qualitative statements (for example reflecting the judgement of a team of experts).

Unconditional INDCs: INDCs proposed by countries without conditions attached.

2020 pledge: See Cancun Pledge. 


\section{Acronyms}

$\begin{array}{ll}{ }^{\circ} \mathbf{C} & \text { Degree Celsius } \\ \text { BAU } & \text { Business as usual } \\ \text { CCS } & \text { Carbon capture and storage } \\ \mathrm{CO}_{2} & \text { Carbon dioxide } \\ \mathrm{CO}_{\mathbf{2}} \mathbf{e} & \text { Carbon dioxide equivalent } \\ \mathbf{C O P} & \text { Conference of the Parties to the United Nations Framework Convention on Climate Change } \\ \text { EJ } & \text { Exajoule } \\ \text { G20 } & \text { Group of } 20 \\ \text { Gt } & \text { Gigatonne } \\ \text { GW } & \text { Gigawatt } \\ \text { INDC } & \text { Intended Nationally Determined Contribution } \\ \text { IPCC } & \text { Intergovernmental Panel on Climate Change } \\ \text { LULUCF } & \text { Land use, land-use change and forestry } \\ \mathbf{m}^{2} & \text { Square metre } \\ \text { Mt } & \text { Million tonnes } \\ \text { NDC } & \text { Nationally Determined Contribution } \\ \text { OECD } & \text { Organisation for Economic Cooperation and Development } \\ \text { SLCP } & \text { Short Lived Climate Pollutant } \\ \text { UNFCCC } & \text { United Nations Framework Convention on Climate Change }\end{array}$




\section{Emissions Gap Report 2017}

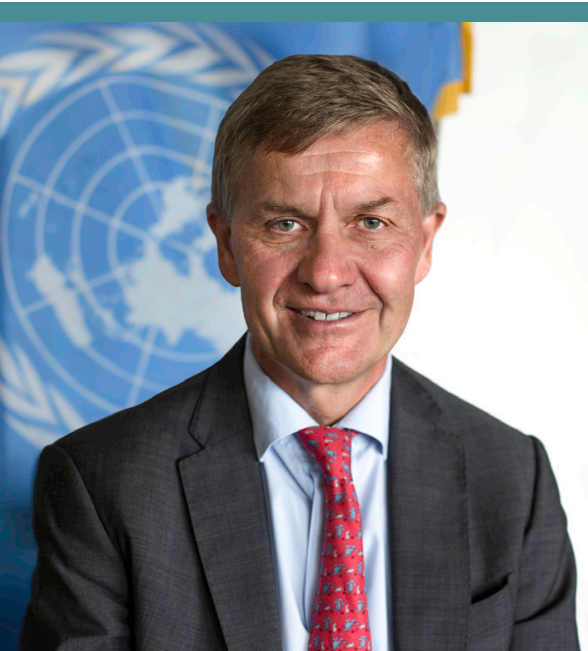

Political, industrial and civil leaders are strengthening and implementing the Paris Agreement on Climate Change. Yet current state pledges cover no more than a third of the emission reductions needed, creating a dangerous gap, which even growing momentum from non-state actors cannot close. This report highlights the dangers of that gap, the issues behind it and the means at our disposal to close it.

Fossil fuels and cement production still account for about 70 percent of greenhouses gases. The report shows how a shift in technology and investment can reduce emissions, while creating huge social, economic and environmental opportunities. Even as greenhouse gas emissions continue to increase, carbon dioxide emissions from energy and industry have remained largely stable since 2014 . This is mainly thanks to, more renewable energy and energy efficiency, and better infrastructure, notably in China and India. For example, record levels of renewable energy were added in 2016, but for 23 percent less investment than in 2015. So, it's little wonder the sector now employs eight million people, including more new jobs in China and the United States than oil and gas.

It proves that using policies and financial frameworks to grow green technology markets can combat climate change, reduce pollution and creates a more sustainable society. And it demonstrates why governments, industry and the financial community can and must collaborate to provide the conditions that foster and fast-track innovative solutions. This is the only way to keep the global temperature rise below 1.5 degrees and reduce the human and economic cost of pollution. Many solutions are already available at a reasonable cost and with sound profits. Encouraging a faster transition will generate widely-shared benefits and momentum for climate action.

To understand the alternative, just look at how Hurricane Harvey flooded 50,000 homes in Texas with nearly 20 trillion gallons of rain in just five days. Listen to Annie Smith explain what it's like going into labour as the floodwaters rise. Even in a such a wealthy nation, her survival was down to a human chain of neighbours and firefighters. Or what about the 1,200 people in India, Nepal and Bangladesh who were less fortunate when the floods hit there? Over 600 Nepalese were rescued by elephants, while Red Cross and Red Crescent workers struggled to find a scrap of dry land and saw farmers left without even drinking water. Such stories are a frightening reminder that we simply cannot save every victim, one at a time, with nothing but compassion.

That is why governments, private sector and civil society must bridge this catastrophic climate gap. Talking less about 'fixing environmental problems' and more about 'grasping economic and social opportunities' is crucial. I hope this report will nurture that change in mind set, to build a more prosperous future for this planet and its people.



Erik Solheim

Head of UN Environment 


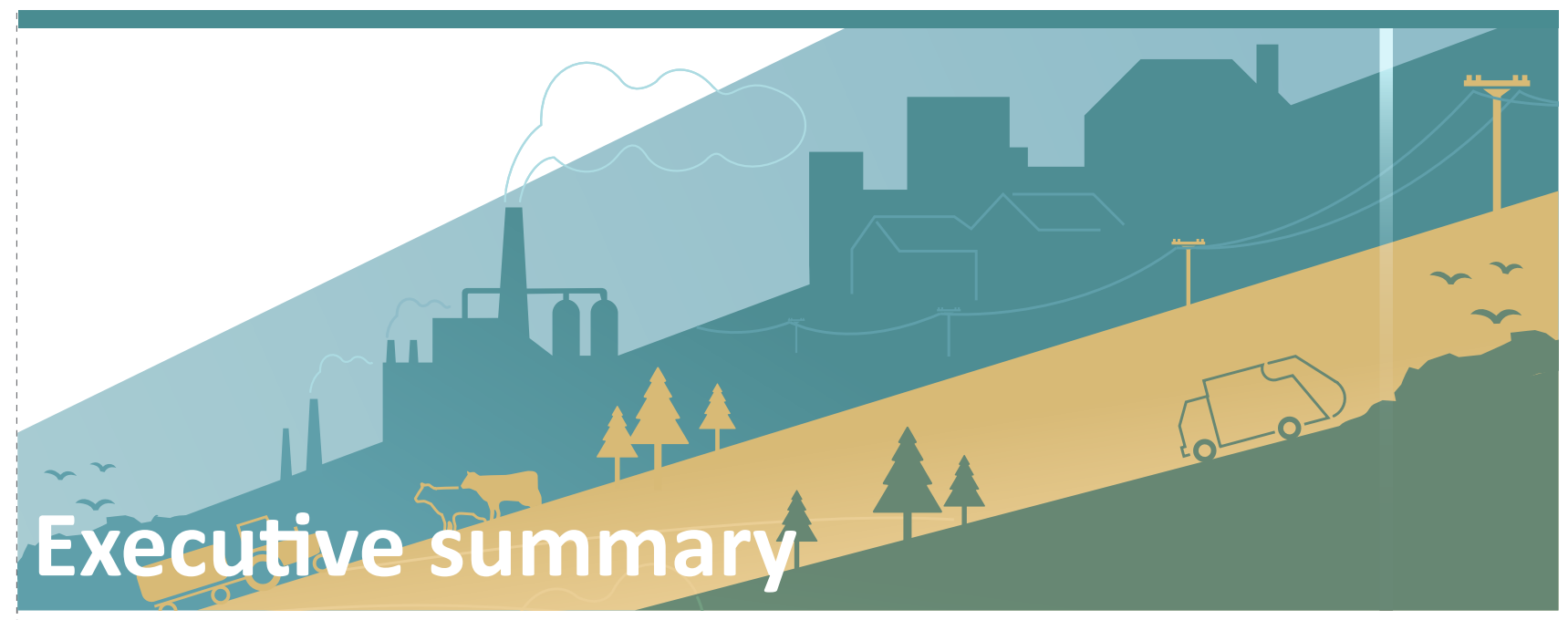

The Paris Agreement adopted in 2015 set the specific goal of holding global warming to well below 2 degrees Celsius $\left({ }^{\circ} \mathrm{C}\right)$ compared to pre-industrial levels, and of pursuing efforts to limit warming to $1.5^{\circ} \mathrm{C}$. This report, which is the eighth Emissions Gap Report produced by UN Environment, focuses on the "gap" between the emissions reductions necessary to achieve these agreed targets at lowest cost and the likely emissions reductions from full implementation of the Nationally Determined Contributions (NDCs) forming the foundation of the Paris Agreement. It also explores potential for enhanced mitigation efforts in a number of key sectors, presenting cost-effective options for enhanced action to close the emissions gap.

The report has been prepared by an international team of leading scientists, assessing all available information, including that reviewed by the Intergovernmental Panel on Climate Change (IPCC) in its Fifth Assessment Report (AR5), as well as more recent scientific studies. The assessment production process has been transparent and participatory. The assessment methodology and preliminary findings were made available to the governments and stakeholders concerned during relevant international forums, as well as on the UNEP Live website. The governments of the countries with specific mention in the report have, throughout the process, been invited to comment on the specific assessment findings.

1. The overarching conclusions of the report are that there is an urgent need for accelerated short-term action and enhanced longer-term national ambition, if the goals of the Paris Agreement are to remain achievable - and that practical and cost-effective options are available to make this possible.

- The successful Paris Agreement has generated and incentivized action at scale by both governments and the private sector. Nevertheless, it marks only a beginning. The NDCs that form the foundation of the Paris Agreement cover only approximately one third of the emissions reductions needed to be on a leastcost pathway for the goal of staying well below $2^{\circ} \mathrm{C}$. The gap between the reductions needed and the national pledges made in Paris is alarmingly high.

- Looking beyond 2030, it is clear that if the emissions gap is not closed by 2030 , it is extremely unlikely that the goal of holding global warming to well below $2^{\circ} \mathrm{C}$ can still be reached. Even if the current NDCs are fully implemented, the carbon budget for limiting global warming to below $2^{\circ} \mathrm{C}$ will be about 80 percent depleted by 2030 . Given currently available carbon budget estimates, the available global carbon budget for $1.5^{\circ} \mathrm{C}$ will already be well depleted by 2030 .

- Action by subnational and non-state actors, including regional and local governments and businesses, is key to enhancing future ambition. There is still limited evidence that non-state action will fill a significant part of the emissions gap, although there is significant potential for it to do so. Enhanced monitoring and reporting of non-state actions and the resulting emissions reductions be will be essential to making pledged actions transparent and credible.

- More ambitious NDCs will be necessary by 2020 and should build on the existing, extensive knowledge about the cost-effective policies and measures that can be taken. A systematic assessment of sectoral mitigation options presented in the report shows that the gap can be closed before 2030 by adopting already known and cost-effective technologies, often by simply adopting or adapting best practice examples already deployed in the most innovative country contexts. The assessment in Chapter 4 shows that emissions could be reduced by up to 30 to $40 \mathrm{GtCO}_{2}$ e per annum, with costs below US\$100/ $\mathrm{tCO}_{2} \mathrm{e}$. It is remarkable that a large part of this potential comes from just six relatively standardized categories: solar and wind energy, efficient appliances, efficient passenger cars, afforestation and stopping deforestation. These six present a combined potential of up to $22 \mathrm{GtCO}_{2}$ e per annum. 
- This eighth Emissions Gap Report assesses in more detail some specific options that may contribute to closing the gap. These include addressing the possibilities and risks associated with technologies and practices to remove carbon dioxide from the atmosphere via enhanced land-use sinks and advanced storage technologies. The land-use related options offer an annual reduction potential in 2030 of the order of between 4 and $12 \mathrm{GtCO}_{2} \mathrm{e}$, forming part of the sectoral potential mentioned above. It is still too early to judge the potential for the emerging technology options.

- The report also covers an assessment of the potential contribution from reductions in short-lived climate pollutants (SLCPS), although they are not directly comparable with reductions in long-lived greenhouse gases. Reductions of SLCPs limit the rate of short-term warming, and when sustained and combined with $\mathrm{CO}_{2}$ reductions, these reductions also help to limit long-term warming, which is the ultimate aim of closing the emissions gap.

- Finally, the report presents an assessment of recent developments in the coal sector, and discusses how a transition away from coal could be incentivized. The assessment shows that a transition could take place remarkably quickly, if political will and market signals provide adequate incentives, but it also shows that a just transition requires careful consideration of the social and energy system impacts and additional policies to cope with such impacts. If these effects are not addressed from the beginning of a transition process, they very often prevent or hamper the process significantly. Government policy is essential not only to incentivize innovation, but also to mitigate adverse effects and to ensure social and political acceptability. It is essential to do everything possible to ensure that the benefits stemming from a transition are shared.

\section{The Facilitative Dialogue and the 2020 revision of the NDCs are the last opportunity to close the $\mathbf{2 0 3 0}$ emissions gap.}

These key messages send a set of strong signals to the Facilitative Dialogue process scheduled to take place under the aegis of the United Nations Framework Convention on Climate Change (UNFCCC) during 2018, and suggest that ambition should be significantly enhanced in the new and updated NDCs that will be submitted in 2020 .

If the climate targets in the Paris Agreement are to remain credible and achievable, all countries will need to contribute to significantly enhancing their national ambitions, augmenting their national policy efforts in accordance with respective capabilities and different circumstances, and ensuring full accounting of subnational action. Furthermore, a strong commitment to facilitating and stimulating widespread, equitable and accountable innovation will be needed, to ensure that the best the world can offer in terms of cost-effective technology, policy and business models is available wherever needed. Non-state actors need to adhere to high standards of accountability in this respect.

Missing the 2020 option of revising the NDCs would make closing the 2030 emissions gap practically impossible.

\section{Global $\mathrm{CO}_{2}$ emissions from energy and industry have remained stable since 2014, but overall greenhouse gas emissions continue to rise slowly.}

Global carbon dioxide $\left(\mathrm{CO}_{2}\right)$ emissions from fossil fuel combustion, cement production and other industrial processes account for about 70 percent of total global greenhouse gas emissions, and were estimated at a total of $35.8 \mathrm{GtCO}_{2}$ for 2016, as shown in figure ES.1. There is increasing evidence that these emissions have remained more or less stable for the past three years, reversing the previous tendency of increases each year. This may indicate a decoupling of energy- and industry-related $\mathrm{CO}_{2}$ emissions from economic growth during these years, in which global Gross Domestic Product increased by between 2 and 3 percent annually. The main drivers have been reduced growth in coal use since 2011, primarily in China and secondarily in the United States, growing renewable power capacity and generation, especially in China and India, combined with enhanced energy efficiency and structural changes in the global economy.

However, the trend is still over a relatively short period, and could potentially be reversed if growth in the world economy accelerates. Furthermore, continued investment in more traditional technologies, especially coal-fired power stations, implies significant technological lock-in and long-term commitment to continued emissions. The assessment shows that between 80 and 90 percent of coal reserves worldwide will need to remain in the ground, if climate targets are to be reached. This compares with approximately 35 percent for oil reserves and 50 percent for gas reserves.

Total global greenhouse gas emissions, including emissions from land use, land-use change and forestry (LULUCF), are estimated at about $51.9 \mathrm{GtCO}_{2} \mathrm{e} /$ year in 2016. The time series data for global total $\mathrm{CO}_{2}$ and greenhouse gas emissions used for the Emissions Gap Reports have been updated since the 2016 report, with the estimate for global total greenhouse gas emissions in 2014 now updated to $51.7 \mathrm{GtCO}_{2} \mathrm{e}$, and the estimate for global total $\mathrm{CO}_{2}$ emissions in 2015 updated to $35.6 \mathrm{GtCO}_{2}$. Emissions still show a slowdown in growth in the past two years, with calculated increases of 0.9 percent, 0.2 percent and 0.5 percent in 2014, 2015 and 2016 respectively, as shown in figure ES.1. 
Figure ES.1.a: Global greenhouse gas emissions for top six emitting countries and regions (excluding land use, land-use change and forestry), international transport emissions, and land use, land-use change and forestry emissions.
Figure ES.1.b: Global carbon dioxide emissions per region from fossil fuel use, cement production and other processes, and from international transport.

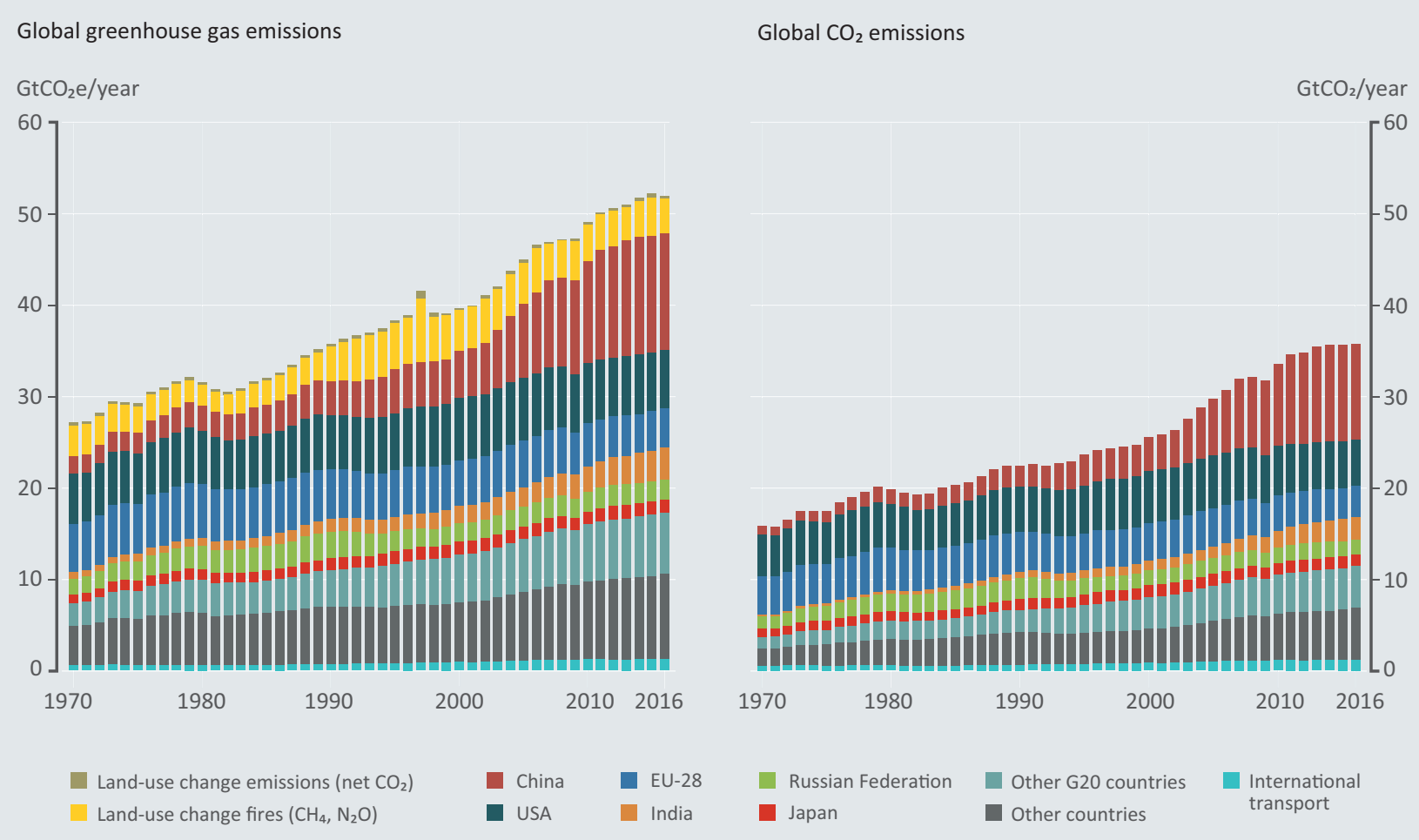

Note: Other G20 countries include Argentina, Australia, Brazil, Canada, Indonesia, Mexico, Republic of Korea, Saudi Arabia, South Africa and Turkey. The greenhouse gas total are expressed in terms of billions of tonnes of global annual $\mathrm{CO}_{2}$ equivalent emissions ( $\mathrm{GtCO}_{2}$ e/year). $\mathrm{CO}_{2}$ equivalent is calculated using the $\mathrm{Global}$ Warming Potentials (GWP-100) metric of UNFCCC as reported in the IPCC Second Assessment Report, similar as has been done in the IPCC Fifth Assessment Report. Source: EDGAR v4.3.2 FT2016 (Olivier et al., 2017).

4. Global greenhouse gas emissions in 2020 are likely to be at the high end of the range of the scenarios consistent with the $2^{\circ} \mathrm{C}$ and $1.5^{\circ} \mathrm{C}$ goals respectively, making it increasingly difficult to be on track to meet the 2030 emission goals.

G20 countries are collectively on track to meet the middle range of their Cancun Pledges for 2020, but for some countries further action is needed and there are still many opportunities to further reduce emissions in the short term, as documented in Chapter 4. While praise for meeting a target is merited, it should be remembered that it does not give any indication of how ambitious the target was.

The assessment shows that according to all available estimates, four of the G20 members - China, the EU28, India and Japan - are on track to meet their 2020 pledges without purchasing offsets. A further three - Australia, Brazil and Russia - are on track according to most estimates.

According to both government and independent estimates, Canada, Mexico, the Republic of Korea, South Africa and the United States are likely to require further action, possibly supplemented by purchased offsets, in order to meet their 2020 pledges. Mexico's 2020 pledge is conditional on the provision of adequate financial and technological support from developed countries as part of a global agreement, and the fulfilment of this condition has not been assessed.
Independent estimates of the Republic of Korea's 2020 emissions are well above the level implied by its pledge. The country's amended Green Growth Basic Act, however, replaced the 2020 pledge with the NDC target for 2030, implying there no longer is a 2020 target.

Insufficient information is currently available to determine whether Indonesia is on track to meet its pledge. Independent projections span a wide range, and official projections reflecting current policies are unavailable.

Finally, Argentina, Saudi Arabia and Turkey have not made greenhouse gas reduction pledges for 2020. All three countries submitted post-2020 pledges to the UNFCCC as part of their Intended Nationally Determined Contributions (INDCS).

The limited collective ambition of the Cancun Pledges means, however, that the global greenhouse gas emissions in 2020 are likely to be at the high end of the range of the scenarios consistent with the $2^{\circ} \mathrm{C}$ and $1.5^{\circ} \mathrm{C}$ targets respectively. This increases the challenge of meeting the necessary 2030 emission goals. With the limited time to 2020, it will be difficult to realize any significant additional emission reductions, but many actions can still be initiated that both lead to short-term reductions and facilitate pathway changes for the next decade. 
5. A large gap exists between $\mathbf{2 0 3 0}$ emission levels and those consistent with leastcost pathways to the $2^{\circ} \mathrm{C}$ and $1.5^{\circ} \mathrm{C}$ goals respectively. The $2^{\circ} \mathrm{C}$ emissions gap for the full implementation of both the conditional and unconditional NDCs for 2030 is 11 to $13.5 \mathrm{GtCO}_{2} \mathrm{e}$. The gap in the case of the $1.5^{\circ} \mathrm{C}$ target is 16 to $19 \mathrm{GtCO}_{2} \mathrm{e}$.

The assessed global scenarios show that if least-cost trajectories are followed, then emissions of all greenhouse gases should not exceed $42 \mathrm{GtCO}_{2} \mathrm{e}$ in 2030 , if the $2^{\circ} \mathrm{C}$ target is to be attained with higher than 66 percent chance. The level for $1.5^{\circ} \mathrm{C}$ has in earlier reports been reported with higher than 50 percent probability and is about $5 \mathrm{GtCO}_{2} \mathrm{e}$ lower than the central estimate for the $2^{\circ} \mathrm{C}$ pathways. New studies are, however, becoming available that present leastcost pathways starting from 2020 that could return global warming to below $1.5^{\circ} \mathrm{C}$ by 2100 with higher than 66 percent probability. These studies indicate a much lower required level of around $24 \mathrm{GtCO}_{2} \mathrm{e}$, which would imply a need for significantly faster and deeper reductions than previously anticipated. The number of published studies on this topic is considered too low to allow for inclusion in the gap assessment with a high level of confidence in 2017, but it is expected that further analysis of these $1.5^{\circ} \mathrm{C}$ pathways with higher than 66 percent probability will be included in the 2018 report.

Figure ES.2: Global greenhouse gas emissions under different scenarios and the emissions gap in 2030 (median estimate and $10^{\text {th }}$ to $90^{\text {th }}$ percentile range).

Annual Global Total Greenhouse Gas Emissions $\left(\mathrm{GtCO}_{2} \mathrm{e}\right)$

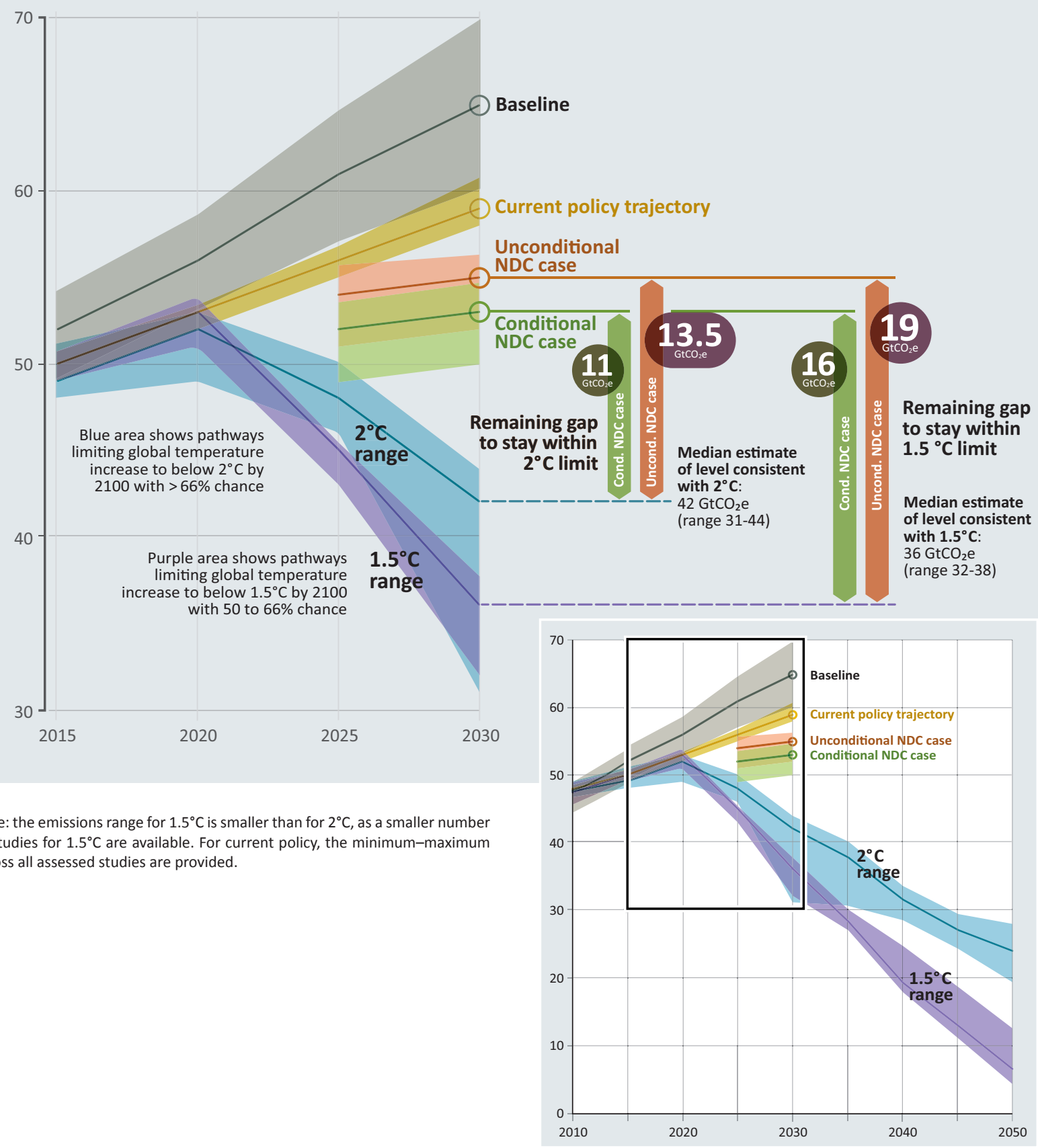


The emissions gap related to the $2^{\circ} \mathrm{C}$ goal for the full implementation of NDCs for 2030 is 11 to $13.5 \mathrm{GtCO}_{2} \mathrm{e}$, for conditional and unconditional pledges respectively. These estimates are slightly lower than the 12 to $14 \mathrm{GtCO}_{2} \mathrm{e}$ estimates in the 2016 report, due to updated information from five global studies with lower emission projections resulting from the NDCs. The emissions gap in the case of $1.5^{\circ} \mathrm{C}$ with higher than 50 percent probability is found to be 16 to $19 \mathrm{GtCO}_{2} \mathrm{e}$ for conditional and unconditional NDCs respectively, which is higher than the 15 to $17 \mathrm{GtCO}_{2} \mathrm{e}$ estimates in the 2016 report, due to new studies on $1.5^{\circ} \mathrm{C}$ pathways and the harmonization of 2010 emission levels across scenarios. As indicated above, there are not enough studies available to give a reliable estimate for a gap in the case of higher than 66 percent probability, but it is clear the gap will be larger.

The alarming number and intensity of extreme weather events in 2017, such as hurricanes, droughts and floods, adds to the urgency of early action. These events underline the importance of the Paris Agreement, which seeks to limit warming to "well below $2^{\circ} \mathrm{C}$ above pre-industrial levels and pursue efforts to limit the temperature increase to $1.5^{\circ} \mathrm{C}$ above pre-industrial levels". The particular class of models referred to in this Emissions Gap Report looks at meeting the Paris Agreement goals at the lowest possible costs, and therefore results do not change even when the risks of climate change become more apparent.

Implications for the carbon budget: If the current NDCs are fully implemented, the carbon budget for limiting global warming to below $2^{\circ} \mathrm{C}$ with higher than 66 percent probability will be about 80 percent depleted by 2030 . Given currently available carbon budget estimates, the available global carbon budget for $1.5^{\circ} \mathrm{C}$ with at least 50 percent probability will already be well depleted by 2030 .

Implications for temperature levels in 2100: Full implementation of the unconditional NDCs and comparable action afterwards is consistent with a temperature increase of about $3.2^{\circ} \mathrm{C}$ by 2100 relative to pre-industrial levels. Full implementation of the conditional NDCs would lower the projection by about $0.2^{\circ} \mathrm{C}$.

\section{Most $\mathrm{G} 20$ countries require new policies} and actions to achieve their NDC pledges.

This 2017 report includes an updated assessment of the emissions associated with the NDC pledges and current policies of each of the G20 countries, including the EU. As these countries collectively generate around three quarters of global greenhouse gas emissions, their success in implementing (or exceeding) their NDC pledges will have a major impact on the achievement of the global temperature goals.

The assessment shows that for many countries, implementing their NDC would lead to lower emissions than the current policies scenario, or in other words that additional policies will have to be implemented to meet the NDC target. The level of ambition embedded in NDCs varies considerably: for some countries the NDC target is actually above current projected policy case emissions.

With this caveat, recent studies assessed suggest that Brazil, China, India and Russia are likely to - or are roughly on track to - achieve their 2030 NDC targets with currently implemented policies. Conversely, Argentina, Australia, Canada, the European Union, Indonesia, Japan, Mexico, South Africa, the Republic of Korea and the United States are likely to require further action in order to meet their NDCs, according to government and independent estimates.

\section{Subnational and non-state action has the potential to reduce the emissions gap by a few gigatonnes $\mathrm{CO}_{2}$ e/year by 2030 . Improved information about the impact of subnational and non-state action is urgently required.}

Subnational and other non-state actors, such as private companies, make a considerable contribution to global greenhouse gas emissions. For example, the world's 100 largest emitting publicly traded companies account for around a quarter of global greenhouse gas emissions. State and non-state actions can both overlap and mutually reinforce each other, but it is currently unclear how many of the actions by non-state actors are included in the national pledges. The assessment provided here suggests that the aggregated additional impact of the various non-state initiatives is of the order of a few $\mathrm{GtCO}_{2} \mathrm{e}$ in 2030, over and above current NDCs. This is potentially a significant contribution to closing the gap, if the initiatives reach their stated goals, and if these reductions do not displace actions elsewhere. Coordinated, comparable and transparent reporting and verification of actions by all actors is essential to clarify effects and possible overlaps. This would also help in gaining recognition of ambitious action and would facilitate replication.

\section{The Kigali Amendment and the ICAO Offsetting Scheme provide some welcome additional momentum and may contribute just under $1 \mathrm{GtCO}_{2} \mathrm{e}$ to closing the gap in 2030.}

The Kigali Amendment, signed in December 2016, aims to phase out the use and production of hydrofluorocarbons, and the agreement is expected to accelerate this process, which some countries have already included in their NDCs. The impact compared to a no-action baseline would globally be of the order of $0.7 \mathrm{GtCO}_{2} \mathrm{e} /$ year in 2030. Since some countries already include hydrofluorocarbons phase-down in their NDCs, the additional impact compared to the NDCs will be smaller. UN Environment will in 2018 undertake a new specific assessment to shed more light on the impacts of implementing the Kigali Amendment.

International aviation emissions are expected to grow from $0.5 \mathrm{GtCO}_{2} \mathrm{e}$ in 2017 to around $1.1 \mathrm{GtCO}_{2} \mathrm{e}$ in 2030, 
with increasing traffic demand over the coming decades. Domestic aviation is included in many countries' NDCs and related national actions, but international aviation is not. The ICAO's Carbon Offsetting and Reduction Scheme for International Aviation (CORSIA) established to reduce emissions from international aviation is estimated to have an impact of 0 to $0.3 \mathrm{GtCO}_{2}$ per year on global emissions in 2030. The wide range implies that the result will depend on the way the offsetting rules will be set. The long-term impact will likely be larger.

9. The assessment of the emissions gap and the mixed progress on implementation of both the Cancun Pledges and the NDCs show that there is a significant distance between the current collective ambitions and commitments and what is required to meet the temperature goals of the Paris Agreement. It is therefore absolutely crucial that the Facilitative Dialogue in 2018 addresses the need and the opportunities for significantly enhanced action pre-2030, including by assisting and informing countries in urgently strengthening their NDCs.

In order to inspire the process of strengthening NDCs, this 2017 Emissions Gap Report addresses a number of key opportunities for closing the 2030 emissions gap, including:

- A systematic review of the mitigation potential of a large number of sector actions. The results here are unambiguous: technologies and institutional innovations are available to bridge the emissions gap, and at reasonable cost.

- A detailed assessment of global developments in the coal sector that also examines the options and barriers for a gradual coal phase-out.

- Opportunities offered by limiting emissions of SLCPS. Reducing these pollutants will limit the rate of shortterm warming, and when sustained and combined with $\mathrm{CO}_{2}$ reductions, help limit long-term warming, which is the ultimate aim of closing the emissions gap.

- Options for both biological and technological carbon dioxide removal: some of the former come with decades of experience, while many of the latter are still in their infancy.

10. The emissions reduction potential by 2030 at costs $<\mathrm{US} \$ 100 / \mathrm{tCO}_{2} \mathrm{e}$, compared to the current policy trajectory, is sufficient to close the emissions gap in 2030 under all cases assessed. It could in addition provide many benefits for other important environmental, social and economic goals.

The systematic review presents estimates of the global emission reduction potentials that could be achieved in 2030 in six key sectors: agriculture, forestry, buildings, energy, industry and transport. For all sectors, the main categories of emissions reduction for 2030 are identified.

The focus is on the socio-economic potential, meaning that the numbers presented refer to the total emissions reductions that can be achieved using all technologies available in a given future year. The potential is defined by all reductions that can be achieved at a cost of no more than US\$100/ $/ \mathrm{CO}_{2} \mathrm{e}$, using social, not private, payback times. Most of the potential, however, can be achieved at a cost significantly below US\$100/tCO 2 e.

There are important uncertainties related to technology development assumptions and implementation rates, such as how rapidly solar photovoltaic energy production can be scaled up, or the rate at which buildings can be retrofitted. Most of the underlying analysis introduces some degree of 'realism' to the assessment and its respective assumptions. In general, the potentials can be achieved if countries around the globe are willing to establish necessary policies that enable the available solutions to be implemented and barriers to be addressed.

The total of all emission reduction potentials in the assessment amounts to 35-41 $\mathrm{GtCO}_{2} \mathrm{e} /$ year in 2030, with details shown in table ES.1. However, there are some areas where estimates of potentials are fairly new, and it is uncertain whether it is indeed feasible to realize them by 2030 . Leaving out these areas will reduce the emission reduction potential to $30-36 \mathrm{GtCO}_{2} \mathrm{e}$, which is still more than double the 2030 emissions gap for the $2^{\circ} \mathrm{C}$ goal.

An important question is of course what are the policies, measures and costs required to implement a substantial part of these emission reduction options? Although answering in full is beyond the scope of the current assessment, some first comments are made in Chapter 4. It is remarkable that a large part of the potential consists of just six relatively standardized categories: solar and wind energy, efficient appliances, efficient passenger cars, afforestation and stopping deforestation. These six measures sum up a potential of $15-22 \mathrm{GtCO}_{2} \mathrm{e}$, making up over 40 percent of the total potential. All these measures can be realized at modest or even net-negative incremental costs, and in most of the cases there are proven policies that can be replicated.

For both current and evolving technologies, the assessment reported here are at the global level. Further work will be needed to disaggregate by region and design appropriate mitigation plans for each country. Countries will need to undertake more specific assessment of the key options relevant to their own circumstances as part of the collective effort to boost the global mitigation ambitions. It will be important to ensure that international technical and financial support is available to facilitate action in developing countries. 
Table ES.1: Overview of emission reduction potentials in 2030 ( $\mathrm{GtCO}_{2}$ e per year).

\begin{tabular}{|c|c|c|c|c|}
\hline Sector & Category & $\begin{array}{l}\text { Emission reduction potential } \\
\text { in } 2030\left(\mathrm{GtCO}_{2} \mathrm{e}\right)\end{array}$ & Category & $\begin{array}{l}\text { Sectoral aggregate potential } \\
\left(\mathrm{GtCO}_{2} \mathrm{e}\right)\end{array}$ \\
\hline \multirow{9}{*}{ Agriculture } & Cropland management & 0.74 & \multirow{5}{*}{ Basic } & \multirow{5}{*}{$3(2.3-3.7)$} \\
\hline & Rice management & 0.18 & & \\
\hline & Livestock management & 0.23 & & \\
\hline & Grazing land management & 0.75 & & \\
\hline & $\begin{array}{l}\text { Restoration of degraded } \\
\text { agricultural land }\end{array}$ & $0.5-1.7$ & & \\
\hline & $\begin{array}{l}\text { Peatland degradation and } \\
\text { peat fires }\end{array}$ & 1.6 & \multirow{4}{*}{ Additional } & \multirow{4}{*}{$3.7(2.6-4.8)$} \\
\hline & Biochar & 0.2 & & \\
\hline & Shifting dietary patterns & $0.37-1.37$ & & \\
\hline & $\begin{array}{l}\text { Decreasing food loss and } \\
\text { waste }\end{array}$ & $0.97-2$ & & \\
\hline \multirow{6}{*}{ Buildings } & New buildings & $0.68-0.85$ & \multirow{4}{*}{ Basic } & \multirow[t]{4}{*}{$1.9(1.6-2.1)$} \\
\hline & Existing buildings & $0.52-0.93$ & & \\
\hline & Renewable heat - bio & 0.39 & & \\
\hline & Renewable heat - solar & 0.21 & & \\
\hline & Lighting & 0.67 & Basic (indirect emissions) & See energy sector \\
\hline & Appliances & 3.3 & & potential \\
\hline \multirow{10}{*}{ Energy sector } & Solar energy & $3-6$ & \multirow{7}{*}{ Basic } & \multirow{7}{*}{$10(9.3-10.6)$} \\
\hline & Wind energy & $2.6-4.1$ & & \\
\hline & Hydropower & 0.32 & & \\
\hline & Nuclear energy & 0.87 & & \\
\hline & Bioenergy & 0.85 & & \\
\hline & Geothermal & 0.73 & & \\
\hline & CCS & 0.53 & & \\
\hline & Bioenergy with CCS & 0.31 & Additional & $0.3(0.2-0.4)$ \\
\hline & Methane from coal & 0.41 & Rocir & 291726 \\
\hline & Methane from oil and gas & 1.78 & Dasic & $2.2(1.7-2.0)$ \\
\hline \multirow{2}{*}{ Forestry } & Restoration of degraded forest & $1.6-3.4$ & \multirow[t]{2}{*}{ Basic } & \multirow[t]{2}{*}{$5.3(4.1-6.5)$} \\
\hline & Reducing deforestation & 3 & & \\
\hline \multirow{5}{*}{ Industry } & Energy efficiency - indirect & 1.9 & Basic (indirect emissions) & $\begin{array}{r}\text { See energy sector } \\
\text { potential }\end{array}$ \\
\hline & Energy efficiency - direct & 2.2 & \multirow{4}{*}{ Basic } & \multirow{4}{*}{$5.4(4.2-6.6)$} \\
\hline & Renewable heat & 0.5 & & \\
\hline & Non- $\mathrm{CO}_{2}$ greenhouse gases & 1.5 & & \\
\hline & CCS & 1.22 & & \\
\hline \multirow{5}{*}{ Transport } & $\begin{array}{l}\text { Heavy Duty Vehicles potential } \\
\text { (efficiency, mode shift) }\end{array}$ & 0.88 & \multirow{5}{*}{ Basic } & \multirow{5}{*}{$4.7(4.1-5.3)$} \\
\hline & $\begin{array}{l}\text { Light Duty Vehicles potential } \\
\text { (efficiency, mode shift, electric } \\
\text { vehicles) }\end{array}$ & 2.0 & & \\
\hline & Shipping efficiency & 0.7 & & \\
\hline & Aviation efficiency & $0.32-0.42$ & & \\
\hline & Biofuels & $0.63-0.81$ & & \\
\hline \multirow[b]{2}{*}{ Other } & Landfill gas recovery & 0.4 & Basic & $0.4(0.3-0.5)$ \\
\hline & $\begin{array}{l}\text { Enhanced weathering } \\
\text { measures }\end{array}$ & $0.73-1.22$ & Additional & $1(0.7-1.2)$ \\
\hline \multicolumn{2}{|c|}{ Total basic emission reduction potential } & & & $33(30-36)$ \\
\hline \multicolumn{2}{|c|}{$\begin{array}{l}\text { Total emissions reduction potential including additional } \\
\text { measures }\end{array}$} & & & $38(35-41)$ \\
\hline
\end{tabular}


11. Avoiding building new coal-fired power plants and phasing out existing ones is crucial to closing the emissions gap. This will require careful handling of issues such as employment impacts, investor interests, grid stability and energy access to achieve a just transition.

Many of the sectoral mitigation options presented above will, if implemented at scale, bring significant changes to the global energy sector, especially in growing but quickly decarbonizing electricity capacity. For this to happen, it will be important to also reduce the fossil-based electricity capacity already in place and under construction and avoid planning new coal plants. A gradual phase-out of coal is needed, recognizing that coal-based power generation will remain significant for a number of both developing and industrialized countries until at least 2030.

Today, there are an estimated 6,683 operating coal-fired power plants in the world, with a combined installed capacity of 1,964 GW. If these plants were operated until the end of their lifetime and not retrofitted with carbon capture and storage (CCS), the stock of operating power plants would emit an accumulated amount of around $190 \mathrm{GtCO}_{2}$.

Without additional policy interventions, the number of coalfired power plants will continue to increase. As of early 2017, across the globe there were additional $273 \mathrm{GW}$ of coalfired capacity in construction and $570 \mathrm{GW}$ at the planning stage. Ten countries make up approximately 85 percent of the entire coal pipeline, with $700 \mathrm{GW}$ being built or planned in China, India, Turkey, Indonesia, Vietnam, Japan, Egypt, Bangladesh, Pakistan and the Republic of Korea alone. As shown in table ES.2, these new plants, if operated until the end of their assumed lifetime of 40 years, would lead to additional accumulated emissions of approximately $150 \mathrm{GtCO}_{2}$. In comparison, the total remaining carbon budget is approximately $1,000 \mathrm{GtCO}_{2}$ for staying below $2^{\circ} \mathrm{C}$ and less than $600 \mathrm{GtCO}_{2}$ for staying below $1.5^{\circ} \mathrm{C}$. On a positive note, in 2016 a large number of planned coal-fired power plants - particularly in China and India - were shelved or cancelled, and globally there was a slower rate of coal expansion generally.

Large-scale phase-out of coal will pose very different challenges and solutions for individual countries, and with respect to existing plants, recently built plants and those in the pipeline.

Chapter 5 discusses experiences with possible market and non-market-based policy instruments and how these could be used to incentivize a transition away from coal. A set of country assessments presents the challenges a transition would have for the largest coal-using and exporting countries. One example, from India, illustrates some of these challenges by showing that coal production, transport, usage and ash disposal employ almost one million people. Coal mining is the second largest employer in India - the largest being the railroads, which again has coal transporting as its number one product and revenue source.

The country examples show that if a transition is to succeed, it will need to be carefully managed, ensuring that impacts on workers, coal owners, industry and energy users are, as far as possible, addressed up front and that compensation measures are developed in consultation with these key stakeholders. Failing to address the interests of the potential "losers" in any transition process has made many societal or industrial transitions fail or created political and social unrest.

Table ES.2: Committed carbon dioxide emissions for coal-fired power plants, in $\mathrm{GtCO}_{2}$, by status and region.

\begin{tabular}{|c|c|c|c|c|c|c|}
\hline Region & Announced & Pre-permitted & Permitted & Construction & Operating & Total \\
\hline East Asia & 12.19 & 12.34 & 6.30 & 30.41 & 126.41 & 187.66 \\
\hline South Asia & 6.21 & 9.87 & 5.89 & 8.28 & 27.42 & 57.67 \\
\hline South-East Asia & 7.00 & 5.78 & 2.63 & 5.21 & 8.95 & 29.60 \\
\hline European Union & 0.60 & 0.66 & 0.17 & 1.14 & 7.22 & 9.79 \\
\hline Non-EU Europe & 4.86 & 5.30 & 1.70 & 0.44 & 3.56 & 15.87 \\
\hline Middle East and Africa & 5.83 & 1.16 & 1.94 & 2.14 & 2.46 & 13.52 \\
\hline Latin America & 0.61 & 0.17 & 0.28 & 0.37 & 1.74 & 3.18 \\
\hline Eurasia & 1.65 & 0.00 & 0.00 & 0.20 & 2.69 & 4.54 \\
\hline North America & 0.00 & 0.00 & 0.15 & 0.00 & 8.85 & 9.01 \\
\hline $\begin{array}{l}\text { Australia and New } \\
\text { Zealand }\end{array}$ & 0.00 & 0.00 & 0.00 & 0.00 & 1.14 & 1.14 \\
\hline Total & 38.97 & 35.28 & 19.08 & 48.20 & 190.44 & 331.97 \\
\hline
\end{tabular}

Note:

- The figures take into account the remaining lifetimes of existing plants.

- A lifetime of 40 years is assumed for newly constructed power plants.

- European Union data refers to the current 28 Member States. North America refers to both Canada and the United States.

- It is assumed that not all permitted, pre-permitted and announced power plants come online.

Source: Edenhofer et al. (2017) and Shearer et al. (2017) 
12. Reductions in SLCP emissions can be an important part of global mitigation efforts and contribute to the achievement of a number of Sustainable Development Goals. Significant potential, beyond existing commitments, is achievable with proven technologies, but dedicated policy action to establish legal frameworks and institutional capacity is required to unlock it.

SLCPs are agents that have a relatively short lifetime in the atmosphere - from a few days to a few decades and a warming influence on climate. The main SLCPs are black carbon, methane and tropospheric ozone, and some hydrofluorocarbons are also included. Although some SLCPs, particularly black carbon, are not greenhouse gases and not included under the UNFCCC and its Paris Agreement, most SLCPs are considered in evaluations of pathways towards the temperature targets. Reducing these pollutants will limit the rate of short-term warming and, when sustained and combined with $\mathrm{CO}_{2}$ reductions, will help limit long-term warming, which is the ultimate aim of closing the emissions gap.

A complete separation between these pollutants and $\mathrm{CO}_{2}$ reductions is also not possible, as decarbonization strategies will lead to reductions in some SLCPs, including black carbon, about a third of which originates from fossil fuel sources, and energy efficiency improvements can reduce all types of emissions. SLCP reductions have the potential to decrease the rate and degree of warming in the next few decades, due to the rapid effect of their mitigation on temperature.

Studies have estimated that mitigation of SLCPs has the potential to avoid up to $0.6^{\circ} \mathrm{C}$ of warming by mid-century and in this way, to reduce impacts that are related to cumulative heat uptake, helping ensure a steady and lower temperature trajectory towards the temperature goals of the Paris Agreement. In addition, there will be a number of other benefits associated with a reduced emissions pathway, notably improved air quality.

Successful cooperation on the individual building blocks of the international climate regime, such as the Climate and Clean Air Coalition or the Montreal Protocol, will build the trust and confidence required to help accelerate progress on some of the bigger elements of the Paris Agreement.

In many NDCs it is usually difficult or impossible to identify particular compounds, as targets are given in $\mathrm{CO}_{2} \mathrm{e}$ often without specific targets for methane, hydrofluorocarbons or black carbon. Instead the NDCs provide a broad list of sectors and actions where mitigation action is planned. Four countries specifically address black carbon in their NDCsMexico, Chile, Nigeria and Canada-with Mexico specifying a target.
13. Carbon dioxide removal from the atmosphere can provide an additional mitigation element to conventional emission abatement strategies. Biological $\mathrm{CO}_{2}$ removal through afforestation, reforestation, forest management, restoration of degraded lands, soil carbon enhancement and biochar application in agriculture can play an immediate role, and can also significantly contribute to achieving several other Sustainable Development Goals.

Carbon dioxide removal refers to a cluster of technologies, practices and approaches that remove and sequester carbon dioxide from the atmosphere. Despite the common feature of removing $\mathrm{CO}_{2}$, these technologies and approaches are very different. In generic terms, they can be distinguished as biological or engineered options. For biological options such as afforestation, reforestation or soil carbon management, experience has been accumulated over decades. On the other hand, engineered options such as bioenergy combined with carbon capture and storage, or certainly direct air capture, have large potential but are still in the early stages of development.

As indicated in the sectoral mitigation options presented in table ES.1, the potential for significant contributions to close the gap exists in the agricultural and forestry sectors. Chapter 7 presents a more detailed assessment of some of these options, along with some of the more recent technological approaches to capturing and storing $\mathrm{CO}_{2}$.

Land-based carbon removal options, including forests, wetlands and soils have been managed by humans for many years and as such, there is a wealth of knowledge that can be readily applied today with confidence. In addition, these approaches present opportunities to meet other global sustainability goals, such as improved water quality, ecosystem restoration, biodiversity preservation and improved crop yields. The total annual reduction potential is in the order of 4 to $12 \mathrm{GtCO}_{2} \mathrm{e}$, with relatively wide ranges for the various options; some studies indicate a significantly higher potential.

For these land-based options to contribute to carbon removal at the gigatonne scale, large land areas and ecosystems may need to be engaged in new ways. There are substantial uncertainties regarding effective carbon removal rates, possible volumes and duration of effective sequestration, and implications for ecosystem services and food production currently associated with these land areas.

The chapter presents a detailed assessment of one specific set of options that has briefly been addressed in previous Emissions Gap Reports-bioenergy with carbon capture and storage. This option warrants a specific focus, because it forms an integral part of the solutions considered within many integrated assessment models, and its components are already applied at a large scale. Most scenarios that aim to 


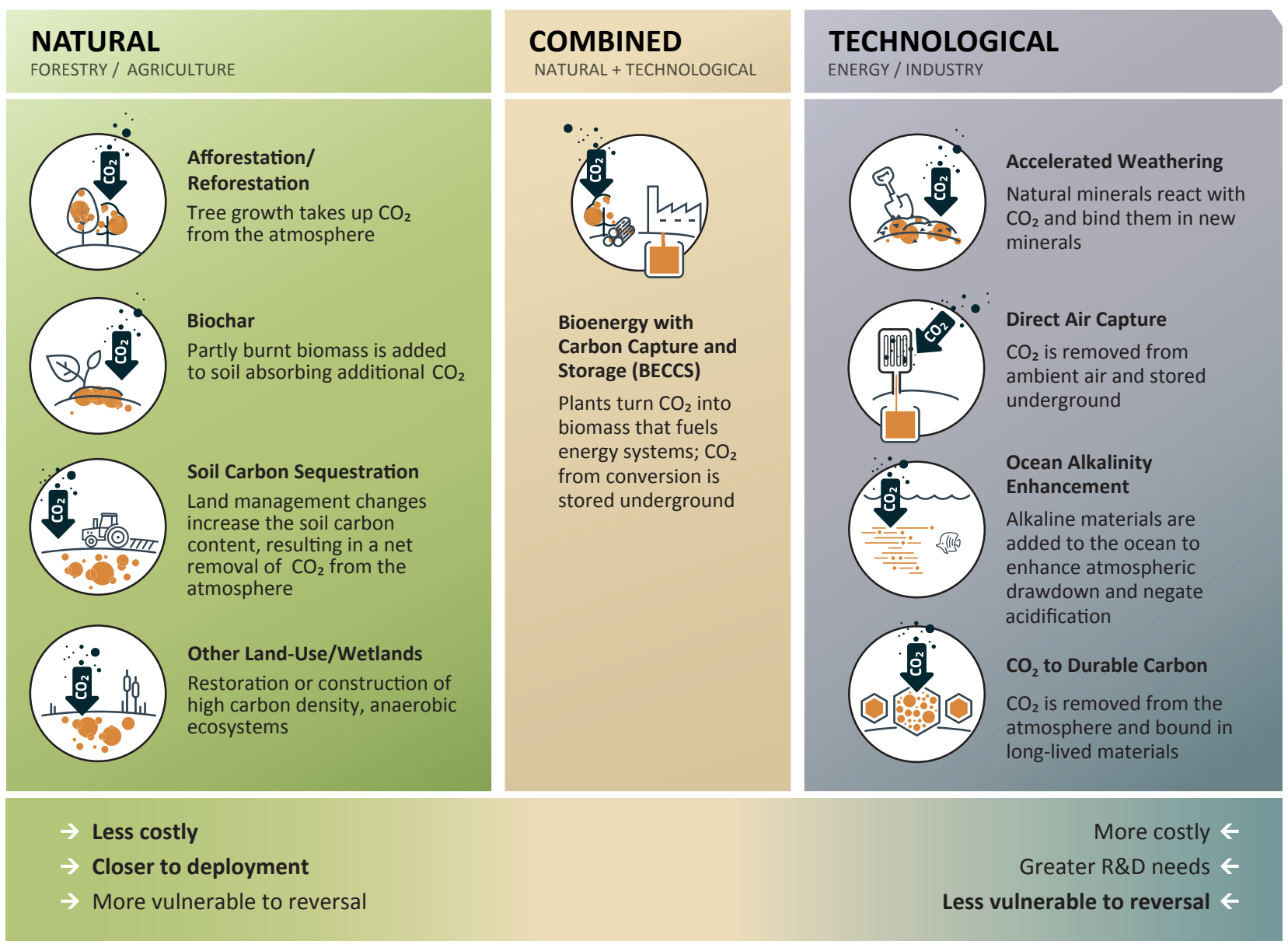

Note: This figure includes the major strategies that have been discussed in the literature so far (Minx et al., 2017).

keep global warming below $2^{\circ} \mathrm{C}$, and especially those aiming for below $1.5^{\circ} \mathrm{C}$, include contributions from this option at the gigatonne scale. Achieving these reductions, however, would entail significant land-use and water-resource requirements and substantial investment; the question of whether the model assumptions are realistic is therefore a relevant one. In addition, while bioenergy and carbon capture and storage are relatively mature technologies individually, there is very little deployment of them in combination, especially at a large scale. Whether the combined option can thus be scaled up promptly to help achieve the ambitious climate targets remains uncertain. Mitigation action in other sectors should therefore not be delayed.
As for engineering options, the chapter provides an assessment of emerging options, such as direct air capture combined with carbon storage, accelerated weathering of materials, ocean alkalinity enhancement and conversion of $\mathrm{CO}_{2}$ into long-lived products. Most of these options are at early piloting stage, so it is hard to judge the technical and economic potential in the short term, and the chance of these technologies making a real contribution to closing the 2030 gap seems unrealistic. Beyond 2030, these technologies may show additional important reduction potential. When global emissions need to move towards net zero by around 2050, $\mathrm{CO}_{2}$ removal may offer some welcome flexibility and, as with other technologies, cost and performance will likely improve with increased deployment. 



\title{
Chapter 1
}

\section{Scoping the Emissions Gap Report 2017}

\author{
Lead authors: Anne Olhoff and John Christensen, UNEP DTU Partnership
}

\subsection{Moving towards implementation of the Paris Agreement: 2018 as a critical juncture}

The adoption of the Paris Agreement at the 2015 Conference of the Parties to the United Nations Framework Convention on Climate Change (UNFCCC) marks a milestone in international efforts to establish a universal foundation for ambitious climate change action. The Agreement builds on national plans and contributions submitted by almost all Parties to the Convention during 2015: the Intended Nationally Determined Contributions (INDCs). The Agreement entered into force on November 4, 2016, following a very rapid ratification process. As of 15 October 2017, 168 of the 197 Parties to the Convention have ratified the Agreement, thereby turning their Intended Nationally Determined Contributions into Nationally Determined Contributions (NDCs). This report consequently refers to NDCs, unless specifically mentioning a country that has not yet ratified the Agreement.

The Paris Agreement's long-term goal of "holding the increase in the global average temperature to well below $2^{\circ} \mathrm{C}$ above pre-industrial levels and to pursue efforts to limit the temperature increase to $1.5^{\circ} \mathrm{C}$ above pre-industrial levels" (UNFCCC, 2015:22) accentuates the urgency of enhanced and immediate mitigation action. In 2015 and 2016, the UN Environment Emissions Gap Reports undertook thorough assessments of the aggregate effects of the NDCs on global greenhouse gas emissions in 2025 and 2030 - the years referred to in the NDCs (UNEP, 2015; 2016). The overall conclusion of these assessments was that although NDCs represent an increase in ambition compared with global greenhouse gas emission levels resulting from a projection of the impacts from the current policies, these contributions are far from the level of ambition required for an emissions pathway consistent with staying below a $2^{\circ} \mathrm{C}$, let alone a $1.5^{\circ} \mathrm{C}$, temperature increase. Currently, the NDCs cover only around one third of the emission reductions needed by 2030 .
Recognizing this significant gap and the urgent need to bridge it, Article 4 of the Paris Agreement specifies that "Each Party shall communicate a nationally determined contribution every five years" and furthermore that "Each Party's successive nationally determined contribution will represent a progression beyond the Party's then current nationally determined contribution and reflect its highest possible ambition" (UNFCCC, 2015a:22). The successive NDCs are to be informed by the global stocktakes, which are specified in Article 14 of the Paris Agreement (UNFCCC, 2015). These stocktakes will take place every five years, starting from 2023, to assess the collective progress towards achieving the objective of the Agreement and its longterm goal.

However, as an important precursor to the global stocktakes, a Facilitative Dialogue will take place during 2018. In line with the subsequent global stocktakes, the purpose of the Facilitative Dialogue is "to take stock of the collective efforts of Parties in relation to progress towards the long-term goal and to inform the preparation of nationally determined contributions" (UNFCCC 2015:4).

During 2017, there have been extensive consultations with Parties on the organization of the Facilitative Dialogue, with a view to reporting their findings to the 23rd Conference of the Parties (COP23) taking place in November 2017. Initial feedback indicates that the dialogue is likely to consist of a preparatory and political phase, with the preparatory phase starting officially at the intersessionals in Bonn in May 2018 and continuing until the $24^{\text {th }}$ Conference of the Parties (COP24) in December 2018. The preparatory phase will include absorbing the information from the 2018 special report on the impacts of global warming of $1.5^{\circ} \mathrm{C}$ above preindustrial levels and related global greenhouse gas emission pathways that the Intergovernmental Panel on Climate Change (IPCC) was invited to produce in the decision to adopt the Paris Agreement (UNFCCC, 2015). The political phase, which is expected to take place at the $24^{\text {th }}$ Conference 
of the Parties, will focus in particular on how to strengthen the next NDCs (UNFCCC, 2017).

The year 2018 and the Facilitative Dialogue will be a critical juncture for countries to identify and pursue opportunities to strengthen their mitigation action and raise the ambition of their NDCs by 2020. Indeed, the outcome of the Facilitative Dialogue and the 2020 submission of new or updated NDCs are likely to determine whether it will be feasible to bridge the emissions gap by 2030.

Time lags between implementing policies and actions and the resulting mitigation benefits imply that by delaying the strengthening of NDCs until after the global stocktake in 2023, the opportunity to bridge the emissions gap by 2030 will be lost.

\subsection{The Emissions Gap Reports and new aspects included in 2017}

The 2017 Emissions Gap Report is the eighth assessment undertaken by UN Environment to provide countries with an independent scientific assessment of how actions and pledges by countries affect the global greenhouse gas emissions trend, and how this compares to emissions trajectories consistent with the long-term goal of the Paris Agreement. The difference has become known as the 'emissions gap'. The reports additionally provide information on options to achieve the emissions reductions necessary to bridge the gap. Based on requests by countries, UN Environment has prepared this eighth Emissions Gap Report to inform the political process, as we move towards full implementation of the Paris Agreement.

In line with previous years, the report provides an update on the progress of G20 members in achieving their Cancun Pledges for 2020 and an overview of global emission trends (Chapter 2). This is followed by an update of the estimated gap between countries' mitigation actions and NDCs for 2030 and the emission levels consistent with pathways that are aligned with the long-term temperature goal of the Paris Agreement (Chapter 3). New for 2017 are brief assessments of the potential implications on the gap of the Kigali Amendment to the Montreal Protocol, and the new global market-based Carbon Offsetting and Reduction Scheme for International Aviation (CORSIA) under the auspices of the International Civil Aviation Organization (ICAO).

In addition, and to inspire the process of strengthening the NDCs, this 2017 Emissions Gap Report assesses a number of the issues that will be central to bridging the 2030 emissions gap. Firstly, the report provides a systematic review of the sectoral mitigation potential by 2030 . The results are positive and unambiguous: technologies and institutional innovations are available to bridge the emissions gap by 2030 at reasonable cost (Chapter 4). Secondly, the report includes a detailed assessment of global developments in the coal sector that also examines the options and barriers for a gradual coal phase-out (Chapter 5). Thirdly, the report looks into the opportunities offered by limiting emissions of short-lived climate pollutants (SLCPS). Reducing these pollutants will limit the rate of short-term warming and, when sustained and combined with $\mathrm{CO}_{2}$ reductions, will help limit long-term warming, which is the ultimate aim of closing the emissions gap (Chapter 6). Finally, options for land-based and technological carbon dioxide removal that will become increasingly critical over this century to stay within the Paris goals are assessed (Chapter 7).

As in previous years, the 2017 report is based on an assessment approach and has been prepared by a wide range of scientists from around the world. This year, 63 scientists from 49 institutions in 23 countries have contributed to the report.

The assessment builds on all available information, including that reviewed by the IPCC in its fifth assessment report, as well as more recent scientific studies. The assessment production process has been transparent and participatory, involving two rounds of external reviews and overseen by a steering committee. The governments of the countries with specific mention in the report have been invited to comment on the specific assessment findings during the production process. 


\section{Chapter 2}

\section{Pre-2020 action: trends and progress}

Lead authors: Michel den Elzen (PBL Netherlands Environmental Assessment Agency), Taryn Fransen (World Resources Institute), Takeshi Kuramochi (NewClimate Institute)

Contributing authors: Jasmin Cantzler (Climate Analytics), Hanna Fekete (NewClimate Institute), Jos Olivier (PBL Netherlands Environmental Assessment Agency), Paola Yanguas Parra (Climate Analytics)

\subsection{Introduction}

This chapter provides an update, based on the latest available scientific literature, on trends in global emissions and progress towards the $\mathrm{G} 20$ members meeting their Cancun Pledges. These trends give key indications of pre2020 mitigation progress and action.

In light of the Paris Agreement, enhanced pre-2020 mitigation action is more urgent than ever: studies indicate that holding the increase in global average temperature well below $2^{\circ} \mathrm{C}$ above pre-industrial levels, and pursuing efforts to limit the temperature increase to $1.5^{\circ} \mathrm{C}$ above pre-industrial levels, requires that global greenhouse gas emissions peak before 2020. Moreover, enhancing pre-2020 action would facilitate the implementation and strengthening of the Nationally Determined Contributions (NDCs), as well as the transition to the stringent long-term emissions reductions that are required to reach the temperature target of the Paris Agreement.

To assess whether emissions show signs of peaking, section 2.2 provides an overview of current trends in total global emissions of greenhouse gases, and of energy- and industryrelated carbon dioxide $\left(\mathrm{CO}_{2}\right)$ emissions as a major driver of total global greenhouse gas emissions. This is followed by an update on the extent to which G20 members are on track to meet their Cancun Pledges (section 2.3). This update is based on an assessment of current policy portfolios of the G20 members and plausible assumptions regarding macroeconomic trends and offsets. The chapter ends by reiterating the urgency of immediately enhancing mitigation action to facilitate the transition towards least-cost emission reduction trajectories after 2020 that are aligned with the $2^{\circ} \mathrm{C}$ and $1.5^{\circ} \mathrm{C}$ temperature goals.

\subsection{Trends in current global emissions}

Total global greenhouse gas emissions continue to increase, although the rate of growth has decreased over the past few years. Total global greenhouse gas emissions, including emissions from land use, land-use change and forestry (LULUCF), were estimated at about $51.9 \mathrm{GtCO}_{2} \mathrm{e} /$ year in 2016 (Olivier et al., 2017)1․ Often, greenhouse gas emissions from LULUCF are accounted for separately, because they show large inter-annual variation and are very uncertain (see Grassi et al., 2017). Considering total global greenhouse gas emissions excluding LULUCF (thus also excluding forest fires), reveals a slowdown in growth in the past three years. They reached 47.8 billion tonnes of $\mathrm{CO}_{2}$-equivalent in 2016 following increases of 0.9 percent in 2014, 0.2 percent in 2015, and 0.5 percent in 2016 (Olivier et al., 2017)2. Taking into consideration that 2016 was a leap year, and thus 0.3 percent longer than other years, the growth in total global emissions in 2015 and 2016 is the slowest since the early 1990s, except for years of global economic recession.

1 The greenhouse gas emissions estimates in EDGAR 4.3.2 (Olivier et al., 2017) for recent years have decreased compared to the earlier greenhouse gas emission estimates presented in UNEP $(2016 ; 2015)$. Apart from revisions due to revised statistics (for example, for China), also the use of more detailed emission factors (for example, for cement clinker) and sometimes a change in data source for other sources than fuel combustion (for example, gas flaring and LULUCF emissions including biomass burning emissions), led to a lower level of $\mathrm{CO}_{2}$ emissions. Likewise, replacing so-called Fast Track estimates for $\mathrm{CH}_{4}$ and $\mathrm{N}_{2} \mathrm{O}$ emissions by more detailed and recent statistics and improved information on emission factors and abatement (for example, $\mathrm{CH}_{4}$ in fossil fuel production) led to lower calculated emissions. Combined, this leads to total greenhouse gas emissions that are about $1 \mathrm{GtCO}_{2} \mathrm{e}$ lower for recent years than presented in recent Emissions Gap Reports.

2 The data presented here have been calculated using the new EDGAR 4.3.2 dataset (Olivier et al., 2017), which provides emissions per source and country for the period 1970-2012 (Janssens-Maenhout et al., 2017). This was extended for $\mathrm{CO}_{2}$ using international statistics through 2016, and for other greenhouse gases using statistics through 2014 (FAO), 2017, 2016 (IEA 2017, BP 2017), and other data sources such as CDM projects through 2016 (for example, reductions of $\mathrm{CH}_{4}, \mathrm{~N}_{2} \mathrm{O}$ and $\mathrm{HFC}-23$ ). 
Figure 2.1.a: Global greenhouse gas emissions for top six emitting countries and regions (excluding land use, land-use change and forestry), international transport emissions, and land use, landuse change and forestry emissions.
Figure 2.1.b: Global carbon dioxide emissions per region from fossil fuel use, cement production and other processes, and from international transport.

Global $\mathrm{CO}_{2}$ emissions
Global greenhouse gas emissions

$\mathrm{GtCO}_{2} \mathrm{e} /$ year

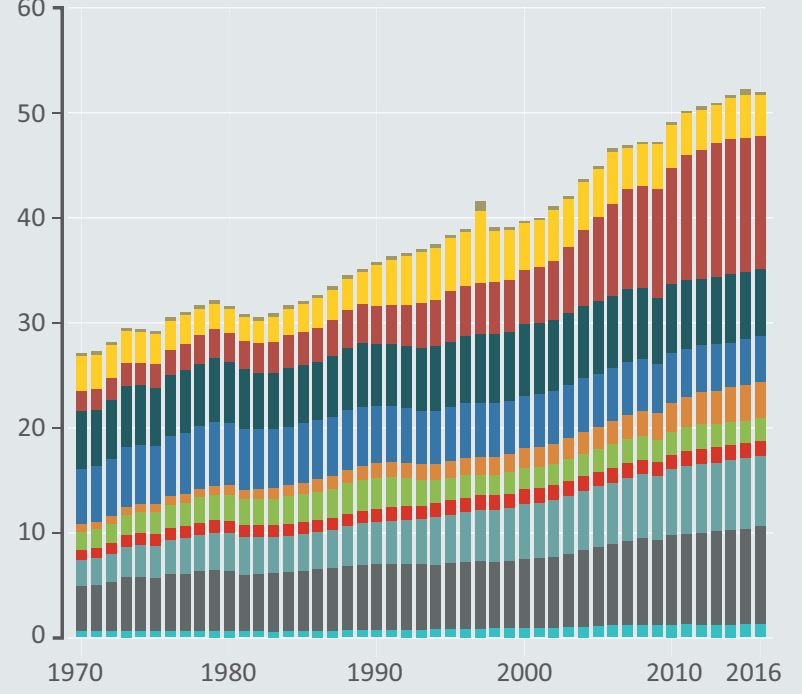

$\mathrm{GtCO}_{2} /$ year



Note: Other G20 countries include Argentina, Australia, Brazil, Canada, Indonesia, Mexico, Republic of Korea, Saudi Arabia, South Africa and Turkey. The greenhouse gas total are expressed in terms of billions of tonnes of global annual $\mathrm{CO}_{2}$ equivalent emissions $\left(\mathrm{GtCO}_{2} \mathrm{e} / \mathrm{year}\right)$. $\mathrm{CO}_{2}$ equivalent is calculated using the $\mathrm{Global}$ Warming Potentials (GWP-100) metric of UNFCCC as reported in the IPCC Second Assessment Report, similar as has been done in the IPCC Fifth Assessment Report.

Source: EDGAR v4.3.2 FT2016 (Olivier et al., 2017).

Figure 2.1 shows the trends in total global emissions for the period 1970-2016. Trends in global greenhouse gas emissions are illustrated in Figure 2.1a, while Figure 2.1b shows the development in global carbon dioxide $\left(\mathrm{CO}_{2}\right)$ emissions from fossil fuel combustion, cement production and other processes. It should be noted that the time series data for total global greenhouse gas and $\mathrm{CO}_{2}$ emissions used for the Emissions Gap Reports have been updated since the 2016 report. This affects the numbers presented in the 2016 report, where the updated estimate for total global greenhouse gas emissions in 2014 is $51.7 \mathrm{GtCO}_{2} \mathrm{e}$, and the estimate for global total $\mathrm{CO}_{2}$ emissions in 2015 is $35.6 \mathrm{GtCO}_{2}$.

Carbon dioxide emissions from fossil fuel combustion, cement production and other processes ${ }^{3}$ are the major source of total global greenhouse gas emissions. Currently they account for about 70 percent of total global greenhouse gas emissions and were estimated at a total of $35.8 \mathrm{GtCO}_{2}$ for 2016 (Olivier et al., 2017) ${ }^{4}$. Given their share of total greenhouse gas emissions, it is relevant to look more closely at their trend. As Figure 2.1b indicates, global $\mathrm{CO}_{2}$ emissions from fossil fuel use and cement production remained stable for the second year in a row in 2016, against a backdrop of

3 Including flaring of waste gas during gas and oil production, feedstock and other non-energy uses of fuels, and several other small sources.

4 This is slightly lower than the 2015 emissions estimate of $36.2 \mathrm{GtCO}_{2}$, as presented last year, due to regular annual statistical revisions of fuel consumption in International Energy Agency and British Petroleum statistics as well as revisions and some full updates, including emission factors, for several other sources (gas flaring, cement production, solvent use, ammonia production, urea and lime application) (Olivier et al., 2017). relatively stable economic growth. Reduced growth in coal use since 2011, primarily in China and secondarily in the United States, plays a key role in the recent slowdown in growth in global $\mathrm{CO}_{2}$ emissions (Olivier et al., 2017; Peters et al., 2017). Growing renewable power generation has also contributed, but has had a less significant impact than economic factors and energy efficiency (Peters et al., 2017). These findings are in line with other studies on trends in global energy-related $\mathrm{CO}_{2}$ emissions until 2016 (BP, 2017; IEA, 2017; Jackson et al., 2016).

A number of studies provide detailed analysis of key drivers for the development in $\mathrm{CO}_{2}$ emissions from fossil fuel use and cement production at the country level (Olivier et al., 2017; Peters et al., 2017). In China, $\mathrm{CO}_{2}$ emissions have decreased since 2015, following a slowdown in annual growth of China's $\mathrm{CO}_{2}$ emissions since 2012. The decrease since 2015 is mainly caused by reduced coal use, but is also due to structural changes in the country's economy and energy mix. The European Union has consistently reduced $\mathrm{CO}_{2}$ emissions since 1979, mainly driven by continual improvements in energy intensity and carbon intensity combined with lower economic growth since the global financial crisis. In the United States of America, energy-related $\mathrm{CO}_{2}$ emissions have decreased over the last 10 years. This decrease has mainly occurred in the power sector, due to a shift from coal to natural gas use in electricity generation, but also from increased use of renewables and a somewhat slower economic growth. In contrast, India's emissions have grown steadily over the past decade. 


\section{Box 2.1: Greenhouse gas emissions development: how have G20 members performed collectively?}

G20 members have made more efficient use of energy resources: total greenhouse gas emissions from G20 countries grew by 34 percent between 1990 and 2014, while GDP grew by nearly 117 percent during the same period. Per capita energy-related $\mathrm{CO}_{2}$ emissions seem to have peaked and there are signs of an absolute decoupling of economic growth and greenhouse gas emissions.

Current levels of effort are, however, not enough. Climate Transparency (2017) concludes that current efforts are sufficient neither in speed nor in depth to keep global warming to the limit set in the Paris Agreement. One area that requires major effort is the power sector, given that the carbon intensity of electricity has not improved for the last 25 years, because the electricity mix has continued to be dominated by coal and other fossil fuels.

Figure 2.2 Key indicators on the G20 transition to a low-carbon economy: trends between 1990 and 2014.

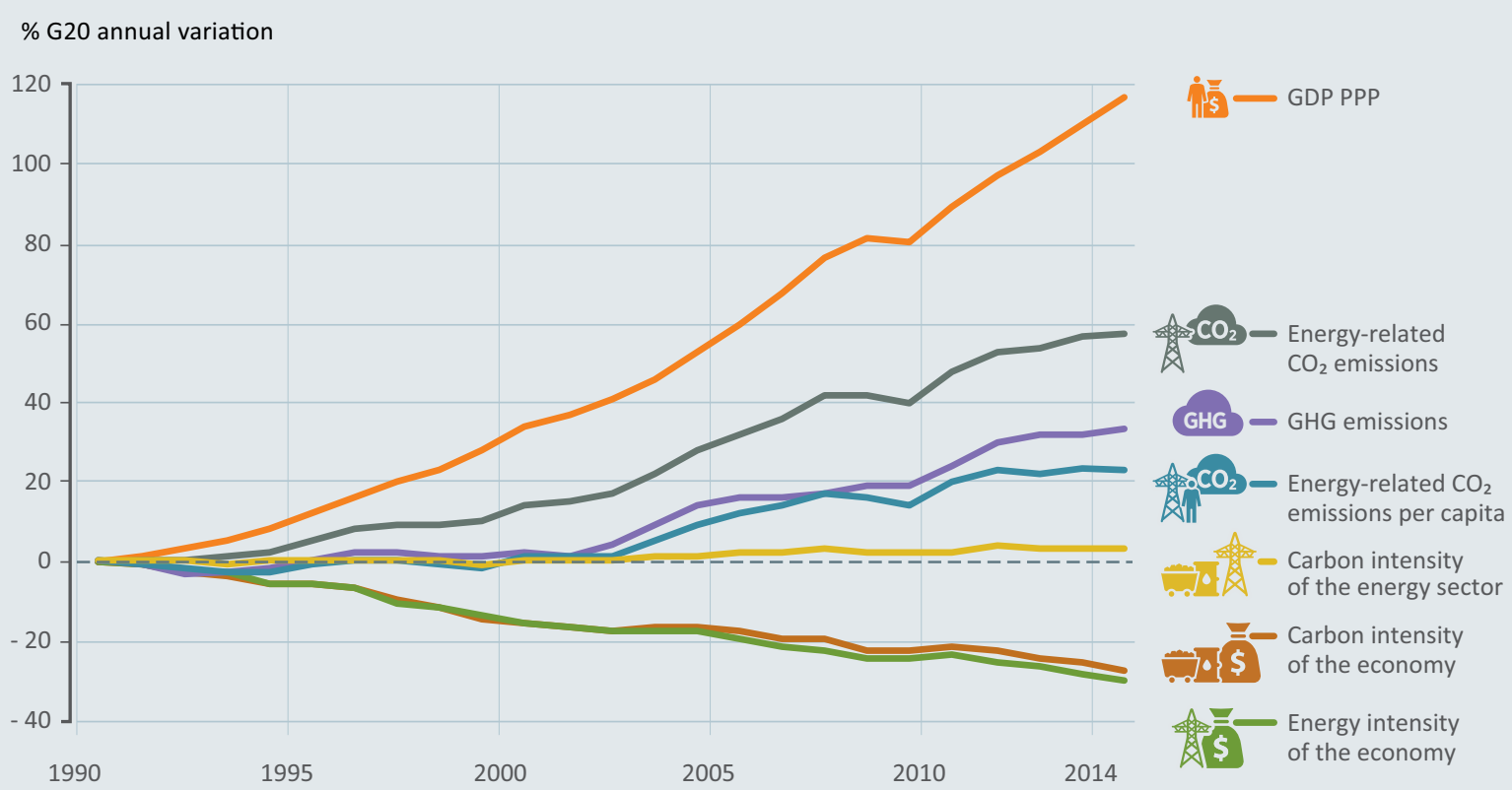

Source: Climate Transparency (2017)

Focusing on emissions and energy and carbon intensities of the G20 members, box 2.1 describes the trends of key indicators on the transition to a low-carbon economy observed between 1990 and 2014 for G20 members (Climate Transparency, 2017).

In summary, global greenhouse gas emissions continue to grow, although the slowdown in growth of global greenhouse gas emissions and the apparent stabilization of global levels of $\mathrm{CO}_{2}$ emissions from fossil fuels and industry over the past two to three years is very encouraging. However, it is still too early to say whether it is likely to be permanent, and both the speed and depth of mitigation efforts require significant scaling up to enable a transition towards mitigation pathways consistent with the long-term temperature goal of the Paris Agreement.

\subsection{Progress towards achieving the Cancun Pledges: G20 members}

In line with last year's Emissions Gap Report, this section provides an update on the progress towards achieving the Cancun Pledges, focusing on the G20 members $^{5}$. Thirteen of the members have pledges for 2020 (counting the EU members France, Germany, Italy and UK as one member) and three do not have pledges. These economies collectively generate around three quarters of total global greenhouse gas emissions ${ }^{6}$. Although it is critical that all countries advance as far as possible towards achieving their Cancun Pledges, the role of the highest-emitting economies is particularly critical to achieving the Paris Agreement mitigation goals.

5 The members of the G20 are Argentina, Australia, Brazil, Canada, China, France, Germany, India, Indonesia, Italy, Japan, Mexico, Republic of Korea, Russia, Saudi Arabia, South Africa, Turkey, the UK, the USA, and the EU. In our analysis, the EU including all its Member States (regardless of G20 status) is considered as a single Party, and EU Member States are not considered individually. In general, evaluating the pledges of other countries is limited by a lack of data. Aggregate measures for the G20 do not double count EU members that are also $\mathrm{G} 20$ members as individual countries.

In 2012, these parties accounted for 77 percent of global emissions excluding LULUCF and 75 percent of global greenhouse gas emissions including LULUCF (WRI CAIT, 2017). 


\section{Box 2.1: Assumptions of the assessment of progress towards the Cancun Pledges}

For each G20 member, estimates of 2020 emissions are compared under three cases:

1. Pledge case (official data): Identifies the maximum level of greenhouse gas emissions that each member could emit in 2020 and still meet its pledge - without considering the use of offsets. Where available, the 2020 emission level described by the member as the pledge level is used; alternatively, these levels are calculated working from official base-year or baseline data. The sources of official country data are provided in Table 2.1.

2. Current policy trajectory case (official data): Identifies most recent, publicly available official estimates of 2020 emissions, considering projected economic trends and current policy approaches. The sources of official country data are provided in Table 2.1.

3. Current policy trajectory case (independent analysis): Identifies estimates of 2020 emissions, considering the best current estimates of projected economic trends and current policy approaches, including policies at least through 2015, based on independent analysis rather than official data. Estimates are drawn from the Climate Action Tracker (CAT) (2017g) and PBL (den Elzen et al., 2016a; Kuramochi et al., 2016b; PBL, 2017) for all countries, as well as other, country-specific sources where noted. The independent analysis of current policy trajectories supplements the official sources described in point two by providing data that targets consistency across countries and political independence.

Source: Adapted from UNEP (2015)

To assess the progress of G20 members towards their Cancun : based on official data; a current policy trajectory case, Pledges, this section compares current emissions trajectories based on official data; and a current policy trajectory case, with the trajectories associated with the achievement of the based on independent analysis. These three cases are briefly pledges of these members. In line with previous Emissions described in box 2.1.

Gap Reports, three cases are considered: a pledge case, :

Table 2.1: Studies used to estimate the emissions in 2020 under the pledge case and current policy trajectory case for G20 members

\begin{tabular}{|c|c|c|c|}
\hline \multirow[t]{2}{*}{ Country } & \multirow{2}{*}{$\begin{array}{l}2020 \text { pledge case } \\
\text { Official data }\end{array}$} & \multicolumn{2}{|c|}{ Current policy trajectory } \\
\hline & & Official data & Independent estimates \\
\hline Argentina & No pledge $^{a}$ & $\begin{array}{l}\text { Ministry of the Environment and } \\
\text { Sustainable Development, Argentina } \\
\text { (2015) }\end{array}$ & CAT \\
\hline Australia & Government of Australia (2016) & Government of Australia (2016) & CAT, PBL, RepuTex (2016) \\
\hline Brazil & Government of Brazil (2010) & N/A & CAT, PBL \\
\hline Canada & Government of Canada (2016) & Government of Canada (2016) & CAT, PBL \\
\hline China & $N / A^{b}$ & N/A & CAT, PBL, Sha et al. (2017) \\
\hline EU28 & EEA (2014) & EEA (2016b) & CAT, PBL \\
\hline India & $\begin{array}{l}\text { Planning Commission Government of } \\
\text { India }(2011,2014)\end{array}$ & & CAT, PBL, Mitra et al. (2017) \\
\hline Indonesia & BAPPENAS (2015) & N/A & CAT, PBL \\
\hline Japan & Government of Japan (2016) & N/A & CAT, PBL \\
\hline Mexico & NCCS (2013) & $\begin{array}{l}\text { (Government of Mexico, 2012b; NCCS, } \\
\text { 2013) }\end{array}$ & CAT, PBL \\
\hline Russia & Government of Russia (2014) & Government of Russia (2015) & CAT, PBL \\
\hline Saudi Arabia & No pledge ${ }^{a}$ & N/A & CAT \\
\hline South Africa & $\begin{array}{l}\text { Department of Environmental } \\
\text { Affairs, Republic of South Africa (2011a, } \\
\text { 2011b) }\end{array}$ & N/A & CAT, PBL \\
\hline $\begin{array}{l}\text { Republic of } \\
\text { Korea }\end{array}$ & Republic of Korea (2016) & N/A & CAT, PBL \\
\hline Turkey & No pledge $^{a}$ & $\begin{array}{l}\text { Republic of Turkey, Ministry of } \\
\text { Environment and Urbanization (2016) }\end{array}$ & CAT, PBL \\
\hline USA & US Department of State (2016) & US Department of State (2016) & CAT, PBL \\
\hline
\end{tabular}

Note:

${ }^{a}$ Argentina, Saudi Arabia and Turkey have not proposed greenhouse gas reduction pledges, and here we assume current policies.

${ }^{b}$ China has no official estimate for the 2020 pledge, and here we assume the 2020 emissions estimate for China's 2020 pledge based on the average outcome of four global studies (PBL, Climate Action Tracker, LSE and University of Melbourne (see Chapter 3). 
Figure 2.3: Greenhouse gas emissions of G20 members and the group of non-G20 countries (also includes the international bunker emissions) for the 2020 pledges and current policies scenario.

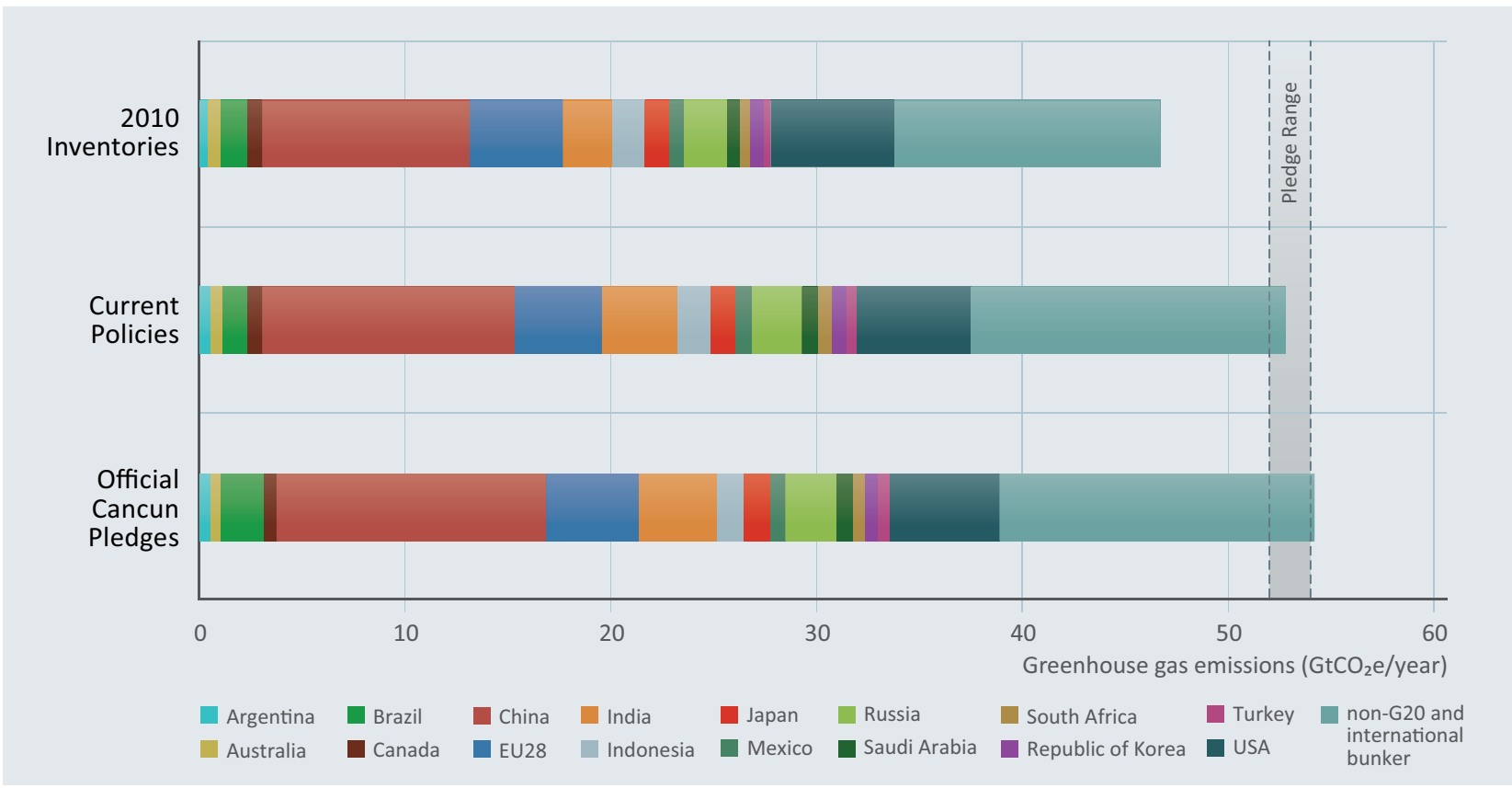

Source: Table 2.1.

Collectively, G20 countries are on track to achieving the mid- : but has amended the Green Growth Basic Act to replace the range of the Cancun Pledges, but several countries will need to accelerate action to meet their Cancun Pledge by 2020 (see Figure 2.4). Seven G20 members (Australia, Brazil, China, the EU, India, Japan, and Russia) are on track to meet their Cancun Pledges according to most or all available analyses. Five members (Canada, Mexico, the Republic of Korea, South Africa and the United States) are likely to require further action or to have to purchase offsets - or a combination of the two - to meet their pledges. (The Republic of Korea has not rescinded its pledge communicated to the UNFCCC, 2020 pledge with the NDC target for 2030.) Better data are necessary to adequately track progress in some countries, including Indonesia, where there is currently insufficient information to assess whether the country is on track to meet its pledges. The three remaining G20 members (Argentina, Saudi Arabia and Turkey) have no Cancun Pledges. Further details are provided in Box 2.2, which highlights the three important caveats that should be kept in mind when assessing country progress towards the Cancun Pledges.

\section{Box 2.2: Assessing progress towards achieving the Cancun pledges: three caveats}

1. Pledges do not necessarily demand the same level of effort to achieve. In other words, a country currently on track to achieve its pledge has not necessarily made a greater effort to mitigate emissions than a country not yet on track.

2. Projections are subject to uncertainty associated with macroeconomic trends, such as changes in gross domestic product (GDP) and population trends, as well as the impact of each country's climate policy action.

3. The potential impact of using offsets to achieve pledges is not quantified for the emission trajectories considered. If offsets are traded internationally, and are stemming from actions that are not really additional or if offsets are counted twice (towards the pledges of both buying and selling parties), the global impact of the pledges will be weakened. Most countries have not clarified their intentions concerning their use of offsets to meet their 2020 pledges. Australia, Brazil, Canada, the European Union, and the United States have explicitly not excluded the possibility; other members have not formally commented (WRI, 2015).

Source: UNEP (2015) 


\section{Cancun Pledges}

According to all available analyses, four G20 members China, the EU, India, and Japan - are on track to meet their pledges with currently implemented policies without purchasing offsets. Australia is on track based on the carbon budget approach. Two more countries - Brazil and Russia are also on track according to most estimates.

China, which pledged a reduction of 40-45 percent in $\mathrm{CO}_{2}$ emissions intensity, is projected by several studies to be on track to achieve a reduction of at least 42 percent (IEA, 2015; Sha et al., 2015; den Elzen et al., 2016b; Climate Action Tracker, 2017c; Sha et al 2017). China also pledges to increase the share of non-fossil fuels in primary energy consumption to around 15 percent by 2020 and to increase forest coverage and forest stock volume. The Climate Action Tracker update of May 2017 (Climate Action Tracker, 2017c) has made a downward revision of economy-wide greenhouse gas emissions (excluding LULUCF) under current policies for China. Projections are now 11.9-12.2 $\mathrm{GtCO}_{2} \mathrm{e} /$ year instead of the 12.2-12.5 $\mathrm{GtCO}_{2} \mathrm{e} /$ year projected in the 2016 update. This compares to the pledged emission level of 13.2$13.5 \mathrm{GtCO}_{2} \mathrm{e} /$ year excluding LULUCF, taking into account both $\mathrm{CO}_{2}$ intensity and non-fossil fuel targets (Climate Action Tracker, 2017c). Some analysts have argued that structural shifts in the economy in recent years make much steeper reductions in the $\mathrm{CO}_{2}$ intensity of GDP likely; Green and Stern (2017) include an illustrative pathway where $\mathrm{CO}_{2}$ intensity is halved from 2005 to 2020.

Regarding the EU pledge to reduce its greenhouse gas emissions by 20 percent from 1990 levels, official data for 2014 shows that this pledge has already been met and, in fact, exceeded (EEA, 2016a).

India pledged to reduce its emissions intensity of GDP, excluding the agriculture sector, by 20-25 percent below 2005 levels by 2020. Independent studies project that India will meet its pledge by a narrow margin through the policies that are currently implemented (Climate Action Tracker, 2017d; Mitra et al., 2017; PBL, 2017). The Climate Action Tracker update of May 2017 has made a small downward revision of current policies projections for India for economywide greenhouse gas emissions (excluding LULUCF) from 3.6 to $3.5 \mathrm{GtCO}_{2} \mathrm{e} /$ year in 2020. Meanwhile Mitra et al. (2017) project $2.9 \mathrm{GtCO}_{2} \mathrm{e} /$ year, considering the impacts of five key policies and excluding the agriculture and land-use sectors.

Japan pledges to reduce its greenhouse gas emissions by 3.8 percent from 2005 levels by 2020 . This pledge assumes the same electricity mix as 2012, which was fossil fueldominant following the Fukushima nuclear accident. Recent studies (Climate Action Tracker, 2017e; Kuramochi et al., 2016b) project that Japan will overachieve its 2020 pledge due to lower-than-expected end-use energy demand and considerable increase of renewable electricity generation following the introduction of a feed-in-tariff scheme in 2012. Official projections reflecting current policies are unavailable.

In accordance with the Kyoto Protocol accounting rules, Australia uses a carbon budget approach that accounts for cumulative emissions over the 2013-2020 period in order to assess progress towards its pledge. Australia's latest official projections find that for the budget period (2013-2020), Australia is now on track to overachieve its 2020 pledge by $97 \mathrm{MtCO}_{2}$ e (cumulative), excluding a $128 \mathrm{MtCO}_{2}$ e carry-over from its first commitment period under the Kyoto Protocol (Government of Australia, 2016). Independent studies consider the year 2020 in isolation, and find a difference of about $63 \mathrm{MtCO}_{2}$ e between Australia's projected 2020 emissions and its pledge level for that year (Kuramochi et al., 2016b; PBL, 2017; Reputex, 2016), which is higher than the $37 \mathrm{MtCO}_{2}$ e difference of Australia's latest official projections (Government of Australia, 2016). The former do not factor in the most recent official projections.

Brazil pledged to reduce its emissions including LULUCF by between 36.1 percent and 38.9 percent by 2020, compared to a business as usual (BAU) scenario. Independent analysis estimates emission projections under current policies at well below the 2020 Cancun Pledge (Climate Action Tracker, 2017b; Kuramochi et al., 2016b; PBL, 2017).

Russia pledged a 25 percent reduction from 1990 levels, excluding LULUCF. According to official data, Russian emissions are projected at about $2.4 \mathrm{GtCO}_{2}$ e/year for 2020 (Government of Russia, 2014), which is below the pledge level of $2.5 \mathrm{GtCO}_{2}$ e/year (Government of Russia, 2015). Independent estimates show a similar emission projection.

\section{G20 members that are likely to require further action or purchased offsets}

Five countries - Canada, Mexico, the Republic of Korea, South Africa and the United States - are likely to require further action and/or to have to purchase offsets in order to meet their pledges, according to government and independent estimates.

Canada's Cancun Pledge aims to reduce emissions by 17 percent below 2005 levels by 2020. However, according to official projections, Canada's emissions are expected to reach $731 \mathrm{MtCO}_{2}$ e/year in 2020 (Environment and Climate Change Canada, 2017), well above the pledged level of $620 \mathrm{MtCO}_{2} \mathrm{e} /$ year (Government of Canada, 2016). Independent analysis also suggests that Canada is set to miss its 2020 pledge by a wide margin (Climate Action Tracker, 2017g; PBL, 2017).

Mexico's Cancun Pledge to reduce its greenhouse gas emissions by 30 percent below BAU levels including LULUCF is conditional on the provision of adequate financial and technological support from developed countries as part of a global agreement (UNFCCC, 2011). Under its current policies, Mexico is not on track to meet its pledge. This conclusion is based on official estimates by the Government of Mexico (2012a), adjusted per the National Climate Change Strategy (NCCS, 2013), and independent estimates (Climate Action Tracker, 2017g; PBL, 2017).

Independent estimates of the Republic of Korea's 2020 emissions are well above the level implied by its pledge. Although the country has not rescinded its pledge communicated to the UNFCCC, it amended the Green 
Growth Basic Act to replace the 2020 pledge with the NDC target for 2030 (The Law National Information Center, 2016).

South Africa's Cancun Pledge includes a reduction in greenhouse gas emissions, including LULUCF, of 34 percent below BAU by 2020 . Independent studies translate this pledge to a range of $400-600 \mathrm{MtCO}_{2} \mathrm{e} /$ year in 2020 (Climate Action Tracker, 2017f; Kuramochi et al., 2016b). An independent current policy scenario projection that covers LULUCF (Kuramochi et al., 2016b) indicates that South Africa is slightly short of reaching the upper end of this range.

The United States submitted a pledge to reduce greenhouse gas emissions levels to 17 percent below 2005 levels by 2020. The most recent official projections, produced before the current Administration took office, indicated that the United States was on track to achieve its 2020 pledge, assuming full implementation of planned measures as of mid-2015 (US Department of State, 2016). However, more recent independent analysis that takes a range of possible policy changes into account raises questions as to whether the United States will meet its 2020 pledge (Climate Action Tracker, 2017a; Climate Advisers, 2017; Climate Interactive, 2017; Hafstead, 2017; Rhodium Group, 2017).

\section{Other $\mathbf{G 2 0}$ members}

Insufficient information is currently available to determine whether Indonesia is on track to meet its pledge. Indonesia's Cancun Pledge includes an unconditional 26 percent below BAU and a conditional 41 percent reduction below BAU by 2020 , both including LULUCF. There is considerable uncertainty regarding the pledge emission level; the unconditional pledge is translated as 2.2 $\mathrm{GtCO}_{2} \mathrm{e} /$ year when using the BAU projection from the First Biennial Update Report, and $1.3 \mathrm{GtCO}_{2} \mathrm{e} /$ year when using the BAU projection consistent with the one reported in Indonesia's NDC (BAPPENAS, 2015). Recent assessments (Kuramochi et al., 2016b; WRI, 2016) project greenhouse gas emissions, including LULUCF, ranging between 1.65 and $1.81 \mathrm{GtCO}_{2} \mathrm{e} /$ year in 2020.
Three G20 member states - Argentina, Saudi Arabia and Turkey - have not proposed greenhouse gas reduction pledges for 2020. However, all three countries have submitted post-2020 pledges to the UNFCCC as part of their Nationally Determined Contributions. In addition, Turkey has submitted a Biennial Report which includes its projected emissions for 2020 (Republic of Turkey, Ministry of Environment and Urbanization, 2016). In all four countries, the emissions are projected to increase towards 2020 and beyond under current policies (Kuramochi et al., 2016b).

\subsection{Amplified urgency of enhanced pre-2020 action}

As the previous sections have demonstrated, mitigation action shows several encouraging signs. However, the progress of $\mathrm{G} 20$ countries towards decarbonization has been slow, as illustrated in Box 2.1. The projected emissions under current policies for 2020 are still far from what is required to improve the starting point for reaching the emission levels in 2030 consistent with pathways aligned with the long-term temperature goal of the Paris Agreement (see Chapter 3). The 2020 emissions under current policies are estimated to be in the mid-range of the Cancun Pledge scenario (see section 2.3), and any further delay in strengthened shortterm action will decrease the chance of keeping global warming well below $2^{\circ} \mathrm{C}$ and will make the $1.5^{\circ} \mathrm{C}$ target increasingly unattainable.

The UNFCCC and its Parties need to seriously consider the growing number of science-based policy targets and roadmaps that have recently been proposed to strengthen shortterm action to meet the Paris Agreement's long-term goals (Figueres et al., 2017; Kuramochi et al., 2016a; Rockström et al., 2017). Box 2.3 presents an action proposal by Figueres et al. (2017), which focuses on pre-2020 ambition. As Figueres et al. suggest, concerted global effort is required to scale up existing solutions rapidly and to encourage optimism. 


\section{Box 2.3: Mission 2020’s six-point plan}

In collaboration with knowledge leaders and several think tanks, the Mission 2020 initiative convened by Christiana Figueres, the former Executive Secretary of the UNFCCC, developed a six-point plan to enhance pre-2020 action to achieve the Paris Agreement's long-term goals (Figueres et al., 2017):

1. Energy

- renewable electricity: increase renewable energy from 23.7 percent of the world's electricity supply in 2015 to at least 30 percent in 2020;

- coal-fired power plants: do not approve any new plants beyond 2020 and retire all existing ones;

2. Infrastructure

- fully decarbonize buildings and infrastructure by 2050 with US\$300 billion in annual funding. Cities are already upgrading their building stock to zero- or near-zero emission structures at a rate of 3 percent per year;

3. Transport

- electric vehicles: at least 15 percent share in new car sales globally, up from the current less than 1 percent share;

- doubling of mass-transit use in cities;

- heavy duty vehicles: 20 percent increase in fuel efficiency;

- aviation: 20 percent reduction in greenhouse gas emissions per kilometre travelled;

4. Land use

- deforestation and land use change: net zero emissions within the 2020s;

- enhanced afforestation and reforestation;

5. Industry

- heavy industry: strengthen action in line with halving emissions well before 2050;

6. Finance

- mobilize US\$1 trillion per year for climate action, mostly from the private sector through, for example, a tenfold increase in green bonds compared with their current level (US\$\$1 billion in 2016).

Figueres et al. also proposes three necessary steps to enable the achievement of the aforementioned sectorspecific goals: (1) use science to guide decisions and set targets, (2) scale up existing solutions rapidly, and (3) encourage optimism. 


\section{Chapter 3}

\section{The emissions gap and its implications}

Lead authors: Michel den Elzen (PBL Netherlands Environmental Assessment Agency), Niklas Höhne (NewClimate Institute), Kejun Jiang (Energy Research Institute, China)

Contributing authors: Jasmin Cantzler (Climate Analytics), Philip Drost (UN Environment), Taryn Fransen (World Resources Institute), Hanna Fekete (NewClimate Institute), Takeshi Kuramochi (NewClimate Institute), David Lee (Manchester Metropolitan University), Kelly Levin (World Resources Institute), Joeri Rogelj (International Institute for Applied Systems Analysis), Fu Sha (National Center for Climate Strategy and International Cooperation), Michiel Schaeffer (Climate Analytics) and Zoi Vrontisi (E3M-Lab)

\subsection{Introduction}

The Paris Agreement aims to limit global average temperature increase to well below $2^{\circ} \mathrm{C}$ relative to pre-industrial levels and to pursue efforts to further limit it to $1.5^{\circ} \mathrm{C}$. In 2015 , almost all countries submitted national climate action plans and commitments for 2025 or 2030: their Intended Nationally Determined Contributions (INDCs). These form the foundation of the Paris Agreement, which entered into force on 4 November 2016. For the 168 countries that have to date (24 October 2017) ratified this Agreement, the INDCs have become Nationally Determined Contributions (NDCs).

This chapter provides an update on the mitigation challenge associated with the global temperature goal of the Paris Agreement, and the estimated global emission levels under various assumptions regarding the implementation of current policies and NDCs or INDCs (hereafter referred to as NDCs, unless specifically mentioned in relation to a country that has not ratified the Paris Agreement) (section 3.2 and 3.3). It also assesses the additional impact of the Kigali Amendment and the International Civil Aviation Organization (ICAO) Agreement (section 3.3), before further exploring the projected impact up to 2030 of the current policies and NDCs on emissions for each G20 member and considering how the ambition of NDCs can be compared across countries (section 3.4). Finally, the chapter provides an update on recent estimates of emission reduction potentials by subnational and non-state actor action (section 3.5).

\subsection{Scenarios considered in the emissions gap assessment}

\subsubsection{Overview of scenarios}

In line with the 2016 Emissions Gap Report, the assessment of the emissions gap draws on six scenarios (Rogelj et al., 2016). These comprise:

- Two reference scenarios:

- No-policy baseline scenario, which projects global greenhouse gas emissions based on the assumption that no new climate policies are put into place from 2005 onwards.

- Current policy scenario, which provides best estimates of future global emissions taking all currently adopted and implemented policies ${ }^{1}$ into account, but assuming that no additional mitigation action is taken beyond these policies.

- Two NDC scenarios²:

- Unconditional NDC scenario, where Parties with NDCs are assumed to implement only the portions of their targets that are without conditions, while Parties that solely have a conditional target are assumed to follow a current policy scenario.

- Conditional NDC scenario, where all Parties with NDCs in addition to their unconditional targets are assumed to implement their conditional targets, and Parties that only have an unconditional target are assumed to implement that target.

- Two scenarios that limit global warming to below $2^{\circ} \mathrm{C}$ and $1.5^{\circ} \mathrm{C}$, respectively:

- $2^{\circ} \mathrm{C}$ scenario, which is based on global emission scenarios that assume limited action until 2020 and least-cost emission reduction pathways from 2020, and are consistent with a greater than 66 percent

1 These are defined as legislative decisions, executive orders, or their equivalent.

2 In both the unconditional and conditional NDC cases, it is assumed that for any traded international offsets, each unit is counted towards the NDC of a single country only - either the buyer or the seller - to avoid issues of double counting. 
chance of limiting global warming in 2100 to below $2^{\circ} \mathrm{C}$ above pre-industrial levels.

- $1.5^{\circ} \mathrm{C}$ scenario, which is based on global emission scenarios that assume limited action until 2020 and least-cost emission reduction pathways from 2020, and are consistent with a 50-66 percent chance of limiting global warming in 2100 to below $1.5^{\circ} \mathrm{C}$ above pre-industrial levels.

The assessment draws on multiple individual scenarios from the published literature. Each scenario is global in scope, reflecting possible actions by all countries (for further details, see Appendix A, available online). It should be noted that the two NDC scenarios assume full implementation of the conditional and unconditional NDCs for all countries, including the United States of America, as the NDC of the United States of America has not yet been officially repealed. Section 3.3 discusses the impact of a possible withdrawal of the United States of America from the Paris Agreement.

In line with the 2016 Emissions Gap Report (UNEP, 2016) and as indicated above, the 2017 assessment mainly draws on $1.5^{\circ} \mathrm{C}$ scenarios that assume least-cost pathways starting from 2020 and return global warming to below $1.5^{\circ} \mathrm{C}$ in 2100 with a lower (50-66 percent) probability than for the $2^{\circ} \mathrm{C}$ scenarios (greater than 66 percent probability) (see box 3.1 for additional information about these scenarios). New studies are emerging that provide leastcost pathways from 2020 consistent with a greater than 66 percent chance of limiting global warming in 2100 to below $1.5^{\circ} \mathrm{C}$. The preliminary findings of these new studies and their implications for the 2030 global emission levels are summarized in section 3.2.3. More studies are under way and will be fully integrated into the gap assessment next year, as current estimates may still change during the review process of the studies. Box 3.1 provides a discussion of the extent to which the $1.5^{\circ} \mathrm{C}$ and $2^{\circ} \mathrm{C}$ least-cost pathways are informed by the growing damages that increasingly are being attributed to early impacts of climate change.

Table 3.1 provides an overview of the projected global emission estimates under the six scenarios considered for the assessment in this report, showing the median global emission levels for 2025 and 2030 - the years countries use in their NDCs.

\section{Box $3.1 \mathrm{How}$ are recent extreme events reflected in the $1.5^{\circ} \mathrm{C}$ and $2^{\circ} \mathrm{C}$ pathways used in the Emissions Gap Report?}

With drought in Africa, floods in South Asia and repeated hurricanes in the Caribbean, 2017 will probably prove to have been a record year for the human, social and economic cost of extreme weather events. Although it would be a mistake to attribute all extreme weather events to the impact of climate change, there is growing evidence that climate change may be contributing to the their increasing frequency and severity.

It would be logical to think that the damage caused by climate change should affect the least-cost pathways that are at the core of the analysis in this report: the earlier and more severe the damage, the stronger the case for early action to reduce emissions.

Some models, such as the Dynamic Integrated Climate-Economy (DICE) model, do indeed incorporate damage functions (Nordhaus, 2017). These are a subset of Integrated Assessment Models that combine physical and economic elements and are termed 'cost-benefit Integrated Assessment Models'. These cost-benefit studies monetize the impacts of climate change and then balance the economic implications of mitigation and climate damages to identify the optimal trajectory of emissions reductions that will maximize total welfare (see box 6.1 in Clarke et al., 2014). However, since by design such scenarios do not achieve a specific climate goal, they are less directly useful as a benchmark to assess pathways towards achieving the long-term temperature goal set in Paris.

For this reason, the Emissions Gap Report makes use of a different class of Integrated Assessment Models, termed 'costeffectiveness' models (see Weyant (2017) for a discussion of all types of Integrated Assessment Models). These models distribute the emission reductions across regions, sectors and gases in such a way that the global discounted reduction costs are minimized over time, and the climate target is achieved ( Rogelj et al., 2016; Clarke et al., 2014). In practice, the Emissions Gap Report selects pathways that aim to limit global mean temperature increase to either $1.5^{\circ} \mathrm{C}$ or $2^{\circ} \mathrm{C}$ relative to pre-industrial levels, with varying levels of probability. This means that, unless decision makers decide to make the global climate target even more ambitious, the benchmark pathways used in the Emissions Gap Report will not change in response to the impact of extreme weather events.

It does not follow that decision makers can ignore the impact of extreme weather. The events of 2017 reinforce the case for early and sustained action to reduce emissions. 
Table 3.1: Global total greenhouse gas emissions in 2025 and 2030 under different scenarios (median and $10^{\text {th }}$ to $90^{\text {th }}$ percentile range).

\begin{tabular}{|c|c|c|c|}
\hline \multicolumn{4}{|c|}{ Emissions estimates ( $\mathrm{GtCO}_{2} \mathrm{e} /$ year) (rounded to the nearest gigatonne) } \\
\hline Scenario & Global total emissions in 2025 & Global total emissions in 2030 & Number of scenarios in set \\
\hline No-policy baseline & $61.0(56.7-64.3)$ & $64.7(59.5-69.5)$ & 179 \\
\hline Current policy trajectory & $55.4(53.5-56.8)$ & $58.9(57.6-60.7)$ & 4 \\
\hline Unconditional NDCs & $53.8(50.6-55.3)$ & $55.2(51.9-56.2)$ & 10 \\
\hline Conditional NDCsa & $52.2(49.3-54.0)$ & $52.8(49.5-54.2)$ & $10(6+4)$ \\
\hline $\begin{array}{l}2^{\circ} \mathrm{C} \text { pathways (more than } 66 \% \text { chance } 2^{\circ} \mathrm{C} \text {, } \\
\text { least-cost from 2020) }\end{array}$ & $47.7(46.2-50.2)$ & $41.8(30.6-43.5)$ & 10 \\
\hline $\begin{array}{l}1.5^{\circ} \mathrm{C} \text { pathways } \\
\left(50-66 \% \text { chance } 1.5^{\circ} \mathrm{C} \text {, least-cost from }\right. \\
2020)^{\mathrm{c}}\end{array}$ & $44.5(43.1-45.5)^{d}$ & $36.5(32-37.7)^{\mathrm{d}, \mathrm{e}}$ & 6 \\
\hline
\end{tabular}

Note:

Ranges are computed as described in Rogelj et al. (2016). In cases where estimates are based on less than 10 scenarios, the minimum-maximum range is provided. The row of "Conditional NDCs" is only provided for information, as a direct comparison with the "Unconditional NDCs" ranges is not possible, due to arbitrary model sampling differences. The emissions range for $1.5^{\circ} \mathrm{C}$ is smaller than for $2^{\circ} \mathrm{C}$, as fewer studies for $1.5^{\circ} \mathrm{C}$ are available. Source: adjusted from Rogelj et al. (2016).

${ }^{a}$ Assuming full implementation of both unconditional and conditional NDCs. Six studies provided an estimate for the conditional NDC case. The median estimate of influence derived from these six studies is used to adjust the unconditional NDC estimate of the four remaining studies that did not include conditional NDC estimates. The estimated improvement of moving from the unconditional to the conditional case is in the range of $2.4(1.2-3.0 \mathrm{GtCO} e / \mathrm{year}$, full range).

${ }^{b}$ As in UNEP (2015): greater than 66 percent probability of limiting global average temperature increase to below $2^{\circ} \mathrm{C}$ in 2100 (probabilities never drop below 60 percent during the entire century).

As in UNEP (2016): 50 percent to 66 percent probability of limiting global average temperature increase to below $1.5^{\circ} \mathrm{C}$ in 2100 (allowing median global average temperature to temporarily exceed the $1.5^{\circ} \mathrm{C}$ limit before 2100 )

${ }^{\mathrm{T}}$ These numbers have been harmonized to the same 2010 emissions levels as the $2^{\circ} \mathrm{C}$ pathways.

e Forthcoming peer-reviewed research indicates that this median value is broadly consistent with results for scenarios that assume a middle-of-the-road future socioeconomic development (cf. SSP2 Fricko et al., 2017). At the same time, recent research suggests that the ranges, however, could be extended further at the lower end (Rogelj et al., 2017a), that is 32-34 $\mathrm{GtCO}_{2} \mathrm{e} /$ year.

\section{Box 3.2 The impact of uncertainties}

Additional research is necessary, as the uncertainty ranges overlap for many countries and since the number of studies available for the current policy trajectory case and the NDC cases vary significantly. A recent study (Rogelj et al., 2017a) explores six dimensions that contribute to uncertainties in the assessment of emissions outcomes of NDCs. These comprise (i) variations in overall socioeconomic conditions, such as Gross Domestic Product and population growth, (ii) uncertainties in historical emission inventories, (iii) the conditionality of certain NDCs, (iv) the definition of NDC targets as ranges instead of single values, ( $v$ ) the way in which renewable energy targets are expressed, and (vi) the way in which traditional biomass use is accounted for, as renewable energy or otherwise. They find that depending on assumptions in these six dimensions, NDC estimates can range from 47 to $63 \mathrm{GtCO}_{2} \mathrm{e} /$ year in 2030, which is a wider range than the 50 to $56 \mathrm{GtCO}_{2} \mathrm{e} /$ year combined unconditional and conditional NDC scenario range of this report (table 3.1). Uncertainties in socioeconomic developments are the dominant driver, accounting for more than half of the uncertainty, followed by uncertainties in the way renewable energy targets are expressed. These uncertainties are not fully accounted for in the range of this study, as this is based on the central estimates of all studies that individually make implicit or explicit assumptions on the above-mentioned uncertainties.

Another issue is the accounting of land-use-related mitigation, which has been identified as an important source of uncertainty (Forsell et al., 2016; Grassi et al., 2017; Rogelj et al., 2016), but is not explored explicitly in Rogelj et al. (2017a). Grassi et al. (2017) find a current $\pm 3 \mathrm{GtCO}_{2}$ e/year difference in global LULUCF net emissions between country reports (data submitted to UNFCCC, such as greenhouse gas inventories and national communications) and scientific studies (as reflected in Intergovernmental Panel on Climate Change (IPCC) reports). Among the many possible reasons for these differences, Grassi et al. suggest that a key factor, which deserves further analysis, relates to what is considered 'anthropogenic sink'.

Finally, there is some additional uncertainty around the impact of Global Warming Potentials. There is no consistency in the historical data and the future projections across the studies in the use of Global Warming Potentials. Some studies use the Global Warming Potentials from the IPCC Second Assessment Report (AR2) consistently for all countries, whereas others use the Global Warming Potentials from the IPCC Fourth and Fifth Assessment Reports (AR4 and AR5), depending on the NDC information. With regard to the magnitude of uncertainty related to the choice of Global Warming Potentials, global total greenhouse gas emissions for 2014 are reported to be 3 percent higher when the IPCC Fourth Assessment Report (AR4) Global Warming Potentials are used, compared to when the IPCC Second Assessment Report (AR2) Global Warming Potentials are used (Gütschow et al., 2017). The difference can be larger at a country level when, for example, the share of Methane $\left(\mathrm{CH}_{4}\right)$ emissions in total greenhouse gas emissions of a country is larger than the global average. 
The studies from which the current policy trajectory scenario and the NDC scenario are drawn differ in a number of respects, such as their treatment of conditional versus unconditional NDCs; assumptions regarding non-covered sectors and gases; treatment of land use, land-use change and forestry (LULUCF) and surplus emission units; different bases for calculating Global Warming Potentials. These differences are further described in the 2016 Emissions Gap Report, which also provides a fuller discussion of the six scenarios. The methodological differences between the studies cannot be fully harmonized, which leads to some uncertainty as indicated in the results presented in section 3.3, where the implications of the differences between studies are also further explored (see also box 3.2).

\subsubsection{Updates to the assessment}

The emissions estimates presented in table 3.1 are based on the 2016 Emissions Gap Report (UNEP, 2016), but updates have been made in a number of cases.

There are no updates to the no-policy baseline scenario compared to the 2016 report. However, the current policies projections at the global level have been updated, drawing on data from the Climate Action Tracker (CAT, 2017), the Joint Research Centre (Kitous et al., 2017), PBL Netherlands Environmental Assessment Agency (den Elzen et al., 2016a; Kuramochi et al., 2016; PBL, 2017), and the International Energy Agency (IEA, 2016).

The global emissions projections of the two NDC scenarios have also been updated with data from the four abovementioned modelling studies, and with updated data from Climate Interactive (2017).

The estimates for the $2^{\circ} \mathrm{C}$ pathways with higher than 66 percent probability in 2100 remain unchanged since the 2016 Emissions Gap Report.

The estimates for the $1.5^{\circ} \mathrm{C}$ pathways with $50-66$ percent probability in 2100 have been updated, resulting in 2030 global emission estimates that are around $3 \mathrm{GtCO}_{2} \mathrm{e}$ lower than those in the 2016 Emissions Gap Report. The update is based on: (a) the inclusion of new data that have become available from scenarios generated with updated or other modelling frameworks, and (b) the harmonization of the $1.5^{\circ} \mathrm{C}$ pathways with the same global 2010 emissions as for the $2^{\circ} \mathrm{C}$ pathways. The new data considered lower the 2030 emission estimates by around $1 \mathrm{GtCO}_{2} \mathrm{e}$ and have also expanded the emissions range. Under the assumption of continuedhistoricalsocioeconomictrends, Rogeljetal. (2017a) find emissions in 2030 in the range of 35-37 $\mathrm{GtCO}_{2} \mathrm{e} /$ year, whereas when assuming enhanced efforts to limit energy demand and a shift towards sustainable consumption patterns, cost-optimal emission levels in 2030 are estimated at 32-34 $\mathrm{GtCO}_{2}$ e/year.

The harmonization has been undertaken to resolve a discrepancy between the global emissions in 2010 of the $1.5^{\circ} \mathrm{C}$ pathways and the $2^{\circ} \mathrm{C}$ pathways ${ }^{3}$. More specifically, the global emissions in 2010 of the $1.5^{\circ} \mathrm{C}$ pathways included in the 2016 Emissions Gap Report were about $3 \mathrm{GtCO}_{2} \mathrm{e}$ higher than the median 2010 levels of the $2^{\circ} \mathrm{C}$ pathways. This resulted in higher global emissions by 2020 for the $1.5^{\circ} \mathrm{C}$ pathways compared to the $2^{\circ} \mathrm{C}$ pathways. The harmonization brings the 2010 global emission estimates to the same level for the assessed $1.5^{\circ} \mathrm{C}$ pathways and $2^{\circ} \mathrm{C}$ pathways, and leads to comparable 2020 emission levels for the two pathways. This harmonization further affects the projected global emission levels in 2030, lowering them by around a further $2 \mathrm{GtCO}_{2} \mathrm{e}$. The estimated global emission level is about $5 \mathrm{GtCO}_{2} \mathrm{e}$ lower than the central estimate for the $2^{\circ} \mathrm{C}$ pathways, as shown in table 3.1.

\subsubsection{Emerging studies on pathways with a greater than 66 percent chance of limiting global warming to below $1.5^{\circ} \mathrm{C}$}

The strengthened temperature targets of the Paris Agreement and the forthcoming 2018 Special Report on the impacts of global warming of $1.5^{\circ} \mathrm{C}$ above pre-industrial levels and related global greenhouse gas emissions pathways by the IPCC have generated substantial interest in scenarios that assume least-cost pathways starting from 2020 and that have a higher than 66 percent probability of returning global warming to $1.5^{\circ} \mathrm{C}$ in 2100 .

For the 2016 Emissions Gap Report, no such scenarios were available. Therefore the report focused on the least-cost pathways starting from 2020 that had a lower probability (50 percent) of returning global warming to below $1.5^{\circ} \mathrm{C}$ in 2100, based on a review by Rogelj et al. (2015) of earlier published scenarios (Luderer et al., 2013; Rogelj et al., 2013a; Rogelj et al., 2013b).

However, new scenarios are now emerging that assume least-cost pathways starting from 2020 that can return global warming to below $1.5^{\circ} \mathrm{C}$ in 2100 with at least 66 percent probability. These are reported in the ADVANCE project's policy briefs (Luderer et al., 2016; Vrontisi et al., 2016) and its forthcoming paper (Vrontisi et al., 2017). At the ninth meeting of the research dialogue at the Subsidiary Body for Scientific and Technological Advice (SBSTA) in Bonn, May 2017, Rogelj et al. (2017b) also presented the first draft of least-cost $1.5^{\circ} \mathrm{C}$ pathways starting from 2020 based on a multi-model comparison study and the framework of the Shared Socioeconomic Pathways (Riahi et al., 2017) .

These higher probability $1.5^{\circ} \mathrm{C}$ scenarios have extensive implications for 2030 global emission levels. Vrontisi et al. (2016) reported scenarios from various models that assume least-cost pathways starting from 2020 that can return global warming to below $1.5^{\circ} \mathrm{C}$ in 2100 with at least 66 percent probability. Emission levels in 2030 for $1.5^{\circ} \mathrm{C}$ scenarios are estimated at 24 (range: 19-34) $\mathrm{GtCO}_{2} \mathrm{e}$, which is about

3 The harmonization is based on the average outcome of adopting the three harmonization methods from the literature (Rogelj et al., 2011).

4 These scenarios represent an extension of the set of 'Representative Concentration Pathways' (RCPs) towards scenarios that limit end-of-century forcing to $1.9 \mathrm{~W} / \mathrm{m}^{2}$. 
$18 \mathrm{GtCO}_{2} \mathrm{e}$ lower than the central estimate for the $2^{\circ} \mathrm{C}$ pathways (table 3.1).

\subsection{The emissions gap in 2030 and urgency of action}

This section updates the 2030 emissions gap from previous reports (section 3.3.1) and examines the implications of the estimated emission levels associated with the NDC scenarios for peaking of emissions, depletion of the carbon budget and global average temperature increase by the end of the century (section 3.3.2). It then assesses the potential positive effects on the 2030 emissions gap of two important agreements outside the UNFCCC: the Kigali Amendment and the International Civil Aviation Organization Agreement.

\subsubsection{The effect of NDCs on global greenhouse gas emissions and the resulting emissions gap}

This section presents the emissions gap for 2030, drawing on the estimated global total greenhouse gas emission levels in 2030 under the six scenarios described in section 3.2 and provided in table 3.1. As in previous reports, the emissions gap in 2030 is defined as the difference between global total greenhouse gas emissions from least-cost scenarios that are consistent with the below $2^{\circ} \mathrm{C}$ and $1.5^{\circ} \mathrm{C}$ temperature target

Figure 3.1: Global greenhouse gas emissions under different scenarios and the emissions gap in 2030 (median estimate and $10^{\text {th }}$ to $90^{\text {th }}$ percentile range).

Annual Global Total Greenhouse Gas Emissions $\left(\mathrm{GtCO}_{2} \mathrm{e}\right)$

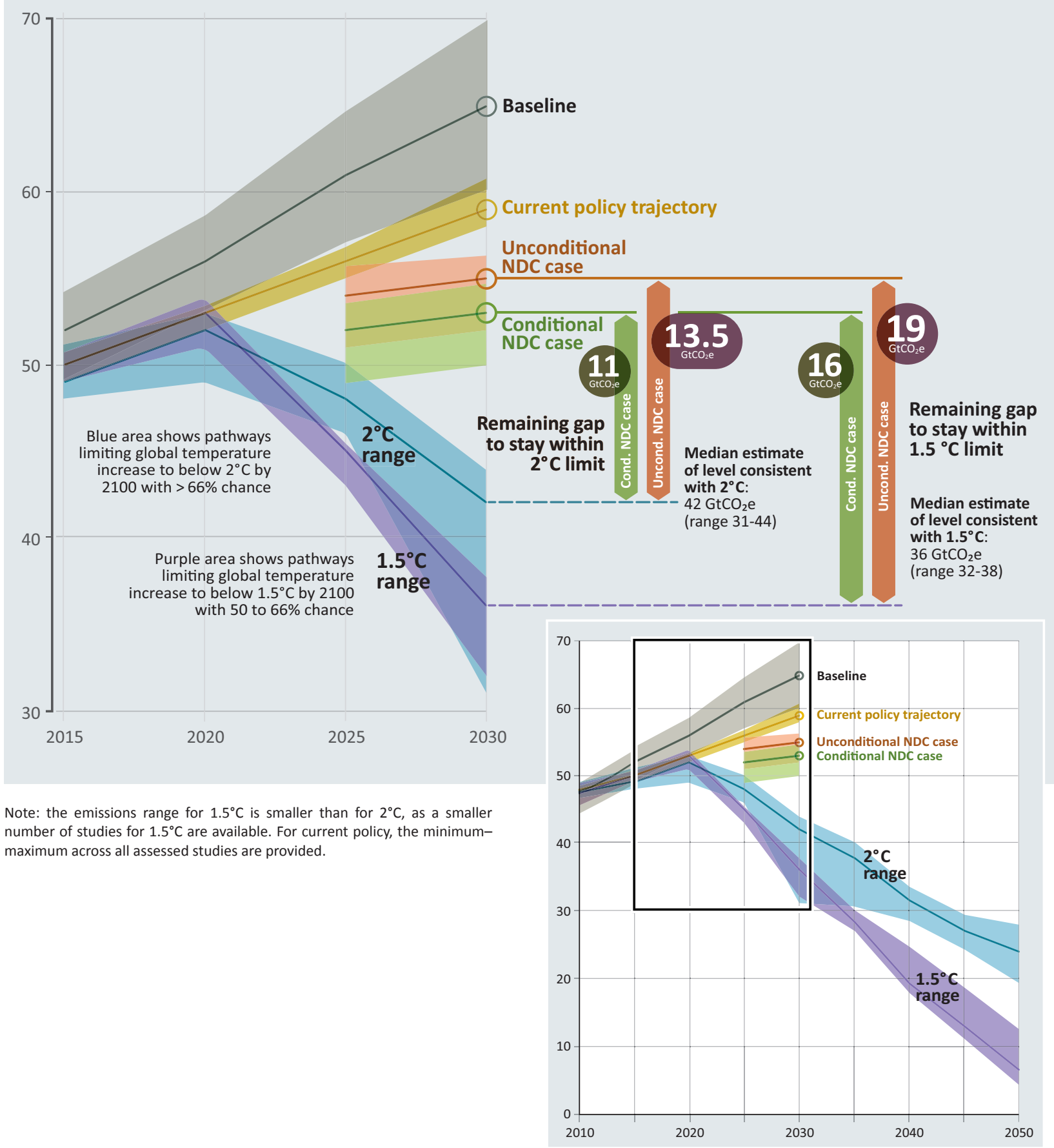


and the expected global total greenhouse gas emissions implied if NDCs are fully implemented. Findings regarding the aggregate effect of full implementation of the NDCs on global total greenhouse gas emissions in 2025 and 2030 are also compared to the emissions implied by the no-policy baseline scenario and the current policy scenario.

The results are illustrated in figure 3.1, which shows that the emissions gap in 2030, compared with least-cost pathways limiting global warming to below $2^{\circ} \mathrm{C}$ with a greater than 66 percent chance, ranges from $11-13.5 \mathrm{GtCO}_{2}$ e for the full implementation of the conditional and the unconditional NDCs respectively. These estimates are slightly lower than those made in 2016 (12-14 $\left.\mathrm{GtCO}_{2} \mathrm{e}\right)$, due to updated information from five global studies resulting in lower emission projections for the NDCs. The emissions gap in the case of least-cost pathways limiting global warming to below $1.5^{\circ} \mathrm{C}$ with $50-66$ percent chance is $16-19 \mathrm{GtCO}_{2} \mathrm{e}$ for conditional and unconditional NDCs respectively. This is higher than the estimates made in 2016 (15-17 $\left.\mathrm{GtCO}_{2} \mathrm{e}\right)$ due to the updated $1.5^{\circ} \mathrm{C}$ pathways (see section 3.2). As indicated by the emerging new studies, the gap would be significantly larger if a higher probability ( $>66$ percent) of limiting global temperature increase to $1.5^{\circ} \mathrm{C}$ in 2100 was considered.

It is apparent from figure 3.1 that current policies lead to emissions that are markedly lower than the baseline, which assumes that no additional climate policies are put in place from 2005. This indicates that the baseline will become increasingly less useful as a reference case. The current policies projections have lowered by about $1 \mathrm{GtCO}_{2} \mathrm{e}$ compared with the estimate made in 2016, mainly due to lower current policy projections from China.

Figure 3.1 shows that full implementation of the unconditional NDCs will reduce annual global greenhouse gas emissions in 2030 by $9 \mathrm{GtCO}_{2} \mathrm{e}^{5}$ (range: $8-13$ ) relative to the median no-policy baseline, and by $4 \mathrm{GtCO}_{2}$ e (range: $2-7$ ) relative to the median current policy trajectory. Comparing these cost-optimal $2^{\circ} \mathrm{C}$ and $1.5^{\circ} \mathrm{C}$ scenarios with the unconditional NDC projections shows a large discrepancy. More specifically, there is a gap in 2030 of $13.5 \mathrm{GtCO}_{2} \mathrm{e}$ (range: 10-15) between the unconditional NDC scenario and the median $2^{\circ} \mathrm{C}$ scenario. Comparing the unconditional NDC scenario with the median global emissions pathway consistent with meeting $1.5^{\circ} \mathrm{C}$ with a 50-66 percent chance leads to a gap of $19 \mathrm{GtCO}_{2} \mathrm{e}$ (range: $15-21$ ), which is $2 \mathrm{GtCO}_{2} \mathrm{e}$ higher than the gap in the 2016 report, due to the lower $1.5^{\circ} \mathrm{C}$ emissions pathways.

In comparison, if countries were to also fully implement the conditional NDCs, estimated global greenhouse gas emissions would be about $2.4 \mathrm{GtCO}_{2} \mathrm{e}$ (range: $1.2-3.0$ ) lower in 2030 compared with the unconditional NDC scenario case. This leaves a gap in 2030 of 11 (range 8-12) $\mathrm{GtCO}_{2} \mathrm{e}$

5 The gap numbers and ranges in the text are rounded to the nearest $\mathrm{Gt}$ between the conditional NDC scenario and the median cost-optimal $2^{\circ} \mathrm{C}$ scenario. Comparing the conditional NDC scenario with the median $1.5^{\circ} \mathrm{C}$ scenarios (50-66 percent chance) increases the gap to $16 \mathrm{GtCO}_{2}$ e (range: $13-18$ ).

It should be noted that the two NDC scenarios assume full implementation of the conditional and unconditional NDCs submitted by all countries. Considering the announcement of the United States of America regarding its withdrawal from the Paris Agreement and policy changes in the United States of America, section 3.4 also discusses recent studies estimating possible effects on the United States of America's emissions.

The gap calculations assume that there is no double counting of reductions. In other words, transferred reductions are only counted towards the achievement of one country's NDC, not towards both the country buying and selling. The Paris Agreement provides for voluntary use of "international transferred mitigation outcomes", such as trading of offset credits, on the basis that parties shall avoid double counting. If, in a theoretical scenario, all Parties were to freely double count (contrary to the provisions of the Paris Agreement), this could increase the global emissions by 2030 by $0.8 \mathrm{GtCO}_{2} \mathrm{e}$ in the case of both unconditional and conditional NDCs ${ }^{6}$.

\subsubsection{The implications on peaking, carbon budget and temperature}

Global total greenhouse gas emissions (covering all sectors and gases) are expected to increase and not peak before 2030 under both the NDC scenarios and the current policy scenario. New actions would be necessary to change this. In contrast, the $2^{\circ} \mathrm{C}$ and $1.5^{\circ} \mathrm{C}$ least-cost pathways assume that global total greenhouse gas emissions peak no later than in 2020. This stresses the urgency of strengthening mitigation action as well as NDCs before 2020, as Chapter 2 also concludes.

Another indication of the urgency of action concerns the implications of projected global total $\mathrm{CO}_{2}$ emissions for the carbon dioxide $\left(\mathrm{CO}_{2}\right)$ budget. The $\mathrm{CO}_{2}$ budget indicates the total cumulative $\mathrm{CO}_{2}$ emissions that can be emitted for temperatures to stay below $2^{\circ} \mathrm{C}$ and $1.5^{\circ} \mathrm{C}^{7}$. If the NDCs are fully implemented, they will result in cumulative emissions of 750-800 $\mathrm{GtCO}_{2}$ during the 2011-2030 period, which is about 80 percent of the remaining $\mathrm{CO}_{2}$ budget of $1,000 \mathrm{GtCO}_{2}$ (range: 750-1,400) for limiting global warming to below $2^{\circ} \mathrm{C}$ with more than 66 percent probability. The available global carbon budget for $1.5^{\circ} \mathrm{C}$ with $50-66$ percent probability will already be well depleted by 2030 . A recently published paper (Millar etal., 2017) suggests that the available budget for $1.5^{\circ} \mathrm{C}$

6 Consistent with the earlier analysis of double counting in the UN Environment 2014 Emissions Gap Report, for the NDC cases it is assumed that international emission offsets could account for 33 percent of the difference between current policies trajectory and emission levels for the NDC cases by 2030 for the OECD countries. This is an arbitrary, conservative estimate, as many parties have yet to specify any limits on the use of transferable units.

7 Box 2-1 (UNEP, 2014) explains how cumulative $\mathrm{CO}_{2}$ emissions are influenced by various factors, such as the transient climate response to cumulative carbon emissions and non- $\mathrm{CO}_{2}$ greenhouse gases. 
Figure 3.2: Comparison of projected emissions by 2030 and all-time $1.5^{\circ} \mathrm{C}$ and $2^{\circ} \mathrm{C}$ carbon budgets.

\section{Cumulative $\mathrm{CO}_{2}$ emissions $2011-2030\left[\mathrm{GtCO}_{2}\right]$}


Note: The figure shows cumulative global total $\mathrm{CO}_{2}$ emissions for the conditional NDC case, the unconditional NDC case and the current policies scenario, and carbon budgets from the Fifth Assessment Report of the IPCC (IPCC AR5) (IPCC, 2014a). The carbon budget ranges show the values based on the range of scenarios assessed by Working Group III (IPCC, 2014b). The solid horizontal line at 1,000 $\mathrm{GtCO}_{2}$ shows the estimate based on complex Earth-System Models, assessed by Working Group I (IPCC, 2014a). Historical emissions until 2015 are based on Le Quéré et al. (2015). 
might be bigger. However, criticism on the study points to the fact that using different global average temperature data sets in the calculations would not lead to higher budgets ${ }^{8}$.

Finally, the urgency of action and enhanced ambition becomes unquestionable when the global average temperature implications of the NDCs are taken into consideration. Estimates of the level of global average temperature increase associated with the implementation of the NDCs depend on the assumptions made about what will happen after 2030, and the probability assigned to the global average temperature increase. Previous Emissions Gap Reports adopt the approach of Rogelj et al. (2016), which assumes that, as a minimum, the level of climate mitigation effort implied by the NDCs is continued after 2030, until the end of the century. As reported in the 2016 Emissions Gap Report, full implementation of unconditional NDCs and comparable action afterwards is consistent with a global average temperature increase of about $3.2^{\circ} \mathrm{C}$ (median, range: $2.9-3.4^{\circ} \mathrm{C}$ ) relative to pre-industrial levels with greater than 66 percent probability by 2100 . Full implementation of the conditional NDCs would lower the projection by about $0.2^{\circ} \mathrm{C}$ by 2100 .

\subsubsection{Impact of the Kigali Amendment}

The Kigali Amendment to the Montreal Protocol aims to phase down production and imports of hydrofluorocarbons (HFCs), thereby reducing hydrofluorocarbon emissions, which is in the spirit of the Paris Agreement to reduce greenhouse gas emissions to net zero. It solidifies the international efforts and provides more certainty that national measures to reduce these emissions will be implemented. Against a no-action baseline, the reductions could be in the order of $0.7 \mathrm{GtCO}_{2}$ e/year in 2030 (Höglund-Isaksson et al., 2017).

The Kigali Amendment may have a lower additional impact against the NDCs, but one that is uncertain as countries are not clear about the extent to which such reductions are already covered by the NDCs. Most countries set targets for all greenhouse gases including the hydrofluorocarbons. For them, implementing the commitments of the Kigali Amendment will not necessarily lead to lower hydrofluorocarbon emissions than implementing the NDC. Some, most notably China, have not included these emissions in their NDC. For them, the implementation of the Kigali Amendment would lead to lower emissions than implementing the NDC and would, therefore, narrow the emissions gap.

The long-term impact of the Kigali Amendment is assessed in Chapter 6, which shows that it can be substantial.

8 https://www.carbonbrief.org/factcheck-climate-models-have-not-exaggerated-global-warming; http://www.realclimate.org/index.php/archives/2017/ 09/is-there-really-still-a-chance-for-staying-below-1-5-c-global-warming/

\subsubsection{Impact of the International Civil Aviation Organization Agreement}

The International Civil Aviation Organization is the United Nations body responsible for international civil aviation emissions of $\mathrm{CO}_{2}$ under Article 2.2 of the Kyoto Protocol. Although international aviation is not explicitly identified under the Paris Agreement, it is assumed that the International Civil Aviation Organization will continue to take responsibility for international emissions.

The International Civil Aviation Organization adopted a target of 'Carbon Neutral Growth from 2020', that is no increase of international aviation emissions of $\mathrm{CO}_{2}$ from 2020 onwards. In order to achieve this, the International Civil Aviation Organization agreed a global market-based measure, the 'Carbon Offsetting and Reduction Scheme for International Aviation' (CORSIA) at the 39th International Civil Aviation Organization Assembly (Resolution A39-3) in 2016. The Carbon Offsetting and Reduction Scheme for International Aviation relies on emissions offsetting and work is currently ongoing on agreeing a monitoring, reporting and verification system and defining the emissions units and registries to be used. In addition, the International Civil Aviation Organization is working on implementing technical measures to increase efficiency or the use of sustainably sourced low-carbon fuels to also contribute to the target of 'Carbon Neutral Growth from 2020'.

As of 2015, total emissions of aviation $\mathrm{CO}_{2}$ are estimated to be of the order of $0.9 \mathrm{GtCO}_{2} \mathrm{e}$ (International Energy Agency data) ${ }^{9}$, around 62 percent of which are international. Domestic emissions fall under the reporting and reduction plans of States. International aviation emissions are expected to grow from $0.5 \mathrm{GtCO}_{2} \mathrm{e}$ in 2017 to around $1.1 \mathrm{GtCO}_{2} \mathrm{e}$ in 2030 with increasing traffic demand over the coming decades, despite emission reductions from operational improvements, aircraft technology and utilization of sustainable alternative fuels. If growth after 2020 is compensated by offsets, emissions of the order of $0.3 \mathrm{GtCO}_{2} \mathrm{e} /$ year in 2030 could be saved over the reference development. This is consistent with the International Civil Aviation Organization's own estimate ${ }^{10}$.

Given that participation in the first phases of the Carbon Offsetting and Reduction Scheme for International Aviation is voluntary, that certain developing countries are permanently exempt, and that its actual effectiveness depends on its implementation by States, the impact of the Carbon Offsetting and Reduction Scheme for International Aviation is still uncertain. So far, around 70 States have declared their commitment to join the Carbon Offsetting and Reduction Scheme for International Aviation.

9 Here, aviation $\mathrm{CO}_{2}$ e emissions are effectively $\mathrm{CO}_{2}$ emissions alone, the sector having no significant emissions of methane, Nitrous Oxide $\left(\mathrm{N}_{2} \mathrm{O}\right)$ etc. Aviation does have non- $\mathrm{CO}_{2}$ impacts, however, from emissions of particles, nitrogen oxides $\left(\mathrm{NO}_{\mathrm{x}}\right)$ and water vapour that impact on ozone $\left(\mathrm{O}_{3}\right)$, reduce methane, and affect cloudiness but these are not estimated in $\mathrm{CO}_{2} \mathrm{e}$ since the scientific uncertainty of doing so in terms of Global Warming Potential 100 is still rather large (Fuglestvedt et al., 2010; Lee et al., 2009; Lee et al., 2010).

10 https://www.icao.int/environmental-protection/Pages/A39_CORSIA_FAQ3. aspx estimates range from $0.288-0.376 \mathrm{GtCO}_{2}$ per year in 2030 . 
Whether the offsetting under the Carbon Offsetting and Reduction Scheme for International Aviation reduces the emissions gap (between the NDCs and what is needed for the Paris Agreement long-term goals) also depends on the quality of the offsets that are allowed under the Carbon Offsetting and Reduction Scheme for International Aviation regime. The gap (as defined in this report) would be narrowed if only offsets that reduce emissions beyond the NDC of the country that was selling the offsets were allowed. The gap would not be narrowed if credits were allowed that were already counted towards meeting the countries' NDCs. This would be the case, for example, for Clean Development Mechanism (CDM) projects initiated several years ago that keep operating regardless of whether or not the Clean Development Mechanism credits are sold, and whose reductions are included in the current emission trajectory of the country selling the offsets (Schneider et al., 2017). Whether the offsetting under the Carbon Offsetting and Reduction Scheme for International Aviation reduces the emissions gap also depends on the level of participation.

Hence, the International Civil Aviation Organization Agreement to reduce greenhouse gas emissions from aviation may have an impact of between 0 and $0.3 \mathrm{GtCO}_{2} \mathrm{e}$ on closing the emissions gap in 2030.

\subsection{Understanding the current emission trends of $\mathbf{G} 20$ members}

\subsubsection{A comparison of current emission trends of G20 members}

This section presents a comparison of country-specific findings for the $\mathrm{G} 20$ members. To assess these, figure 3.3 shows the projected impact up to 2030 of the NDCs and current policies on greenhouse gas emissions for each G20 member. As mentioned in Chapter 2, these economies collectively generate around three quarters of global greenhouse gas emissions. Therefore their success in implementing (or exceeding) their NDCs will have a major impact on the achievement of global climate goals.

NDCs are not static or one-off commitments; countries have the obligation to strengthen them regularly. The assessment conducted in this section is on current NDCs, acknowledging that they can be revised in the future.

For each of the $\mathrm{G} 20$ members, median emission projections resulting from the current policies and full implementation of the NDCs is calculated. As described in box 2.2 in Chapter 2, current policies projections from independent analyses presented in Chapter 2 cover the main energy and climate policies implemented as of a recent cut-off date and do not consider prospective policies that are being debated or planned.
The calculation is based on the same data as the 2016 Emissions Gap Report was (UNEP, 2016), but updates have been used for: the current policies and the NDC projections from the Climate Action Tracker (CAT, 2017); the International Energy Agency (IEA, 2016); the Joint Research Centre (Kitous et al., 2017); PBL Netherlands Environmental Assessment Agency (den Elzen et al., 2016a; Kuramochi et al., 2016; PBL, 2017); updated NDC projections from Climate Interactive (2017); and some updated national and official studies (Reputex, 2016; Sha et al., 2017) (see Appendix A available online). More specifically, the data is sourced from: (i) the official estimates included in the NDCs (UNFCCC, 2015a); (ii) calculations based on the NDCs and on other documents submitted by countries to the UNFCCC (such as national greenhouse gas inventories, national communications, biennial reports, and biennial update reports); (iii) estimates published in country-specific studies; and (iv) eight independent global analyses ${ }^{11}$. These are described in further detail in Appendix A, which is available online.

The results of this assessment are presented for all G20 members in figure 3.3 (with the 28 European Union members represented collectively instead of by the four Member States, who are individual G20 members), noting that data are not available for all countries for all studies. By comparing the current policy scenarios and the NDC scenarios, the figure provides an indication of whether or not a country needs to implement policies additional to the current policy trajectory to meet its NDC target. The figure does not indicate the level of ambition of the NDC targets. Box 3.3 considers possible principles for assessing and comparing the ambition of NDCs across countries. It is also important to note that the current policy trajectory scenarios, which attempt to reflect the most recent mitigation policies, differ from the baseline or 'business as usual' (BAU) scenarios employed by some countries, which typically assume that no new policies are adopted or implemented after a given cut-off year.

11 The UNFCCC synthesis report and the Danish Energy Agency (DEA) study are excluded here, as these studies do not provide national estimates. 
Figure 3.3 a

Emissions $\left(\mathrm{GtCO}_{2} \mathrm{e} /\right.$ year)

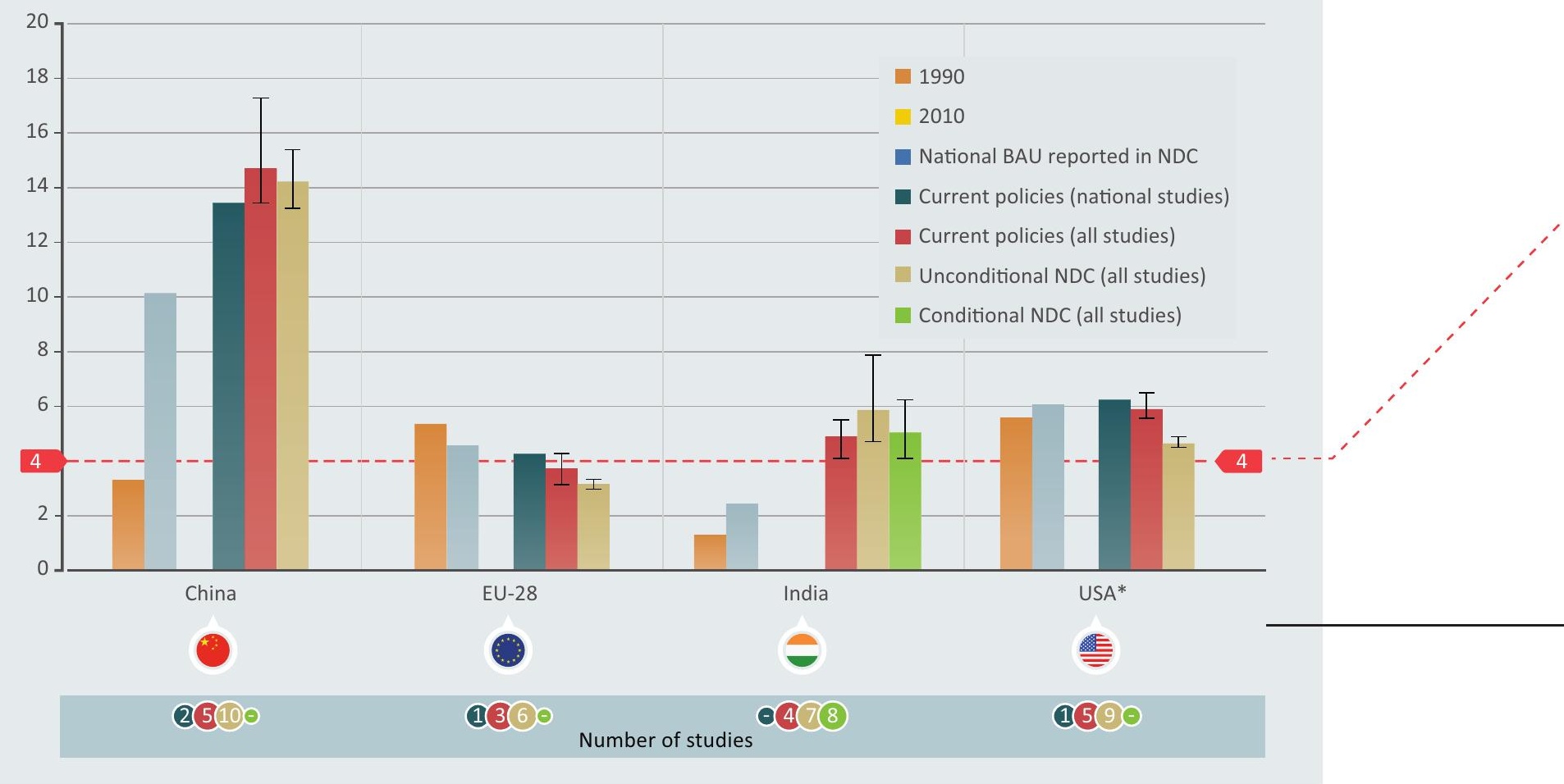

* For the US, the unconditional NDC is for 2025

Note: Greenhouse gas emissions (all gases and sectors) of the G20 members by 2030 for the BAU emissions projection from the NDC submission (third bar), for the current policies scenario from official and national studies (fourth bar), from all studies, including official, national and global model studies (fifth bar), for the unconditional NDC scenario (sixth bar), and for the conditional NDC scenario (seventh bar). For current-policy and NDC scenarios respectively, the minimum-maximum and 10th-90th-percentile range across all assessed studies are provided. The uncertainty ranges are explained in the main text. For reporting reasons, the emissions projections for China, European Union, India and United States of America are shown in panel (a), and the other countries in panel (b), with different vertical axis. The figure also shows the number of studies underlying the estimate (if available) for the last four bars: current policies (national studies), current policies (all studies) and the unconditional NDC and conditional NDC (all studies).

Figure 3.3 shows that for many countries the implementation of their NDC would lead to lower emissions than the current policies scenario, or in other words that additional policies would have to be implemented to meet the NDC target. For some countries the NDC is above the current policies scenario, indicating that it should be possible to enhance ambition quite easily. For eight G20 members, the NDC is above 2010 emission levels.

Recent studies suggest that Brazil, China, India and Russia are likely to - or are roughly on track to - (over)achieve their (unconditional) 2030 targets through their currently implemented policies.

Argentina, Australia, Canada, the European Union, Indonesia, Japan, Mexico, South Africa, Republic of Korea and the United States of America are likely to require further action in order to meet their NDCs, according to government and independent estimates.

From the existing studies, it is not possible to determine whether Saudi Arabia and Turkey are on track to meet their NDCs.

Figure 3.3 furthermore illustrates that the progress on cutting down greenhouse gas emissions varies across the G20 countries. For 11 of the 16 G20 members (counting the 28 European Union members as one), emission projections based on current policies are higher than their 2010 emission levels. More specifically, for some non-OECD Member States (Argentina, China, India and Saudi Arabia) as well as for some OECD Member States (Australia, Mexico, Republic of Korea and Turkey), currently implemented policies do not stop annual emissions from increasing until 2030. Annual emissions in other countries are projected to remain stable at about 2010 levels (including in Canada, Russia and the United States of America), or to decrease further (such as in the European Union with a 7-32 percent reduction compared to 2010 levels), under current policies. The following section provides more detail on each of the $\mathrm{G} 20$ members. 
Figure 3.3 b

Emissions $\left(\mathrm{GtCO}_{2} \mathrm{e} /\right.$ year)

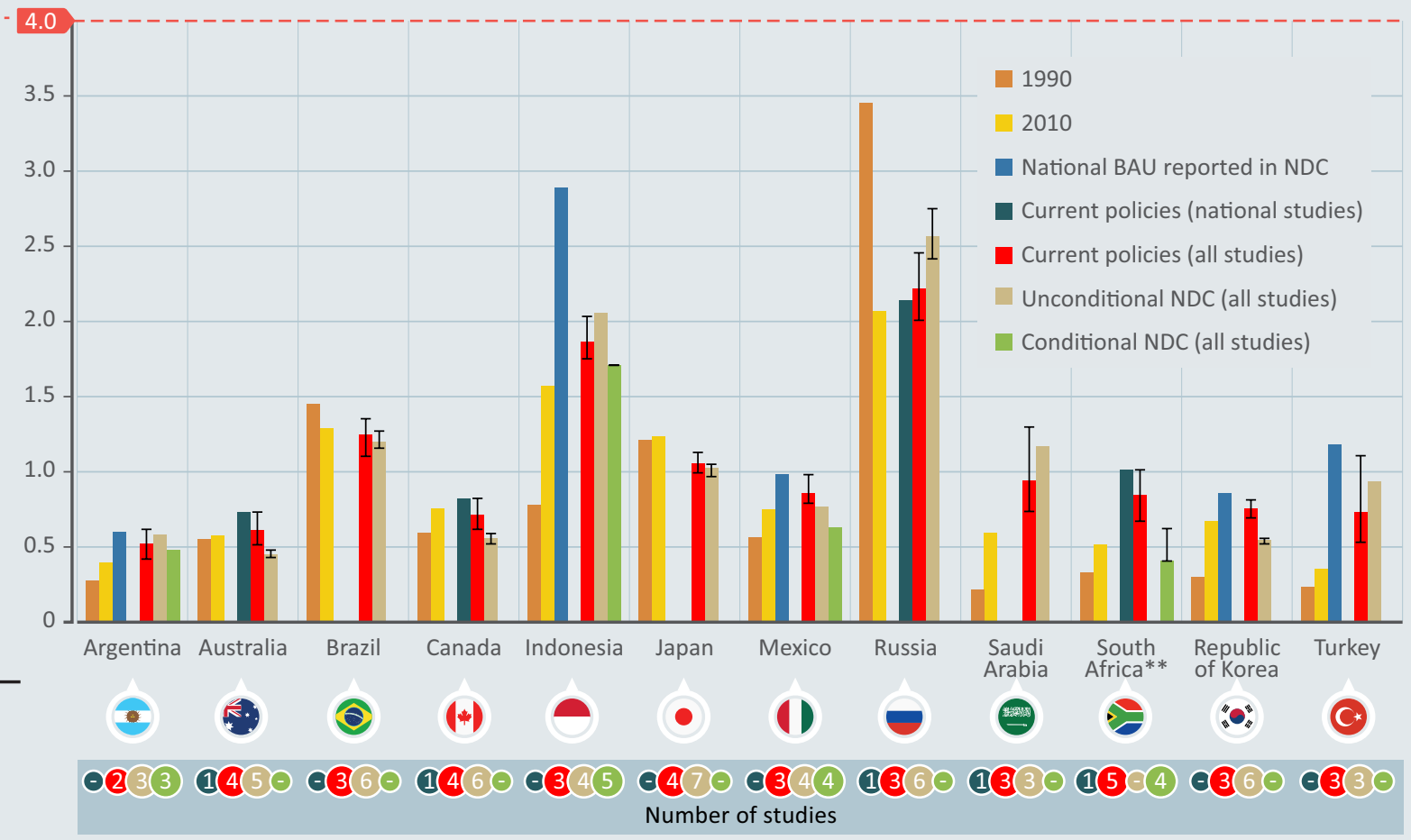

** South Africa's NDC is based on an emissions trajectory with an emissions range of 398-614 $\mathrm{MtCO}_{2} \mathrm{e}$ including LULUCF over the period $2025-2030$. 


\section{Box 3.3 Comparing the ambition of countries' NDCs}

When countries put forward their NDCs for the Paris Agreement, they were asked to explain why these are ambitious. These explanations can be used to derive metrics to compare countries' actions.

The literature on assessing the ambition of NDCs is growing. It compares different energy and climate indicators between countries and analyses what would be necessary in terms of national ambition to be compatible with the Paris Agreement (Aldy et al., 2016; Climate Transparency, 2017; Höhne et al., 2017). Höhne et al. (2017) argue that only a comprehensive approach that covers all perspectives can be used to assess the ambition of national climate policy. Many principles could be used by countries to assess ambition, including (based on Höhne et al. 2017):

- A country's reduction of emissions since 1990 (or any other base-year): the standard perspective for developed countries used since 1992, also used in the Kyoto Protocol - the metric used by the European Union, for example.

- Change in recent trend in emissions: a country would do more than before - the main argument in the proposal by the United States of America. This can also be measured as a deviation from a BAU scenario.

- Time and level of peaking emissions per capita: countries go through different levels of development with first rising, then peaking and then declining emissions - the metric chosen by China.

- Comparison with equity-based effort-sharing calculations: There is a long history of scientific studies that use 'effortsharing' principles to calculate 'fair' emission targets for countries. The principles include responsibility (for example those who emitted more in the past now have to reduce more) or capability (for example those with higher per capita income levels should do more), equality (that is equal emission rights per capita), cost-effectiveness (total abatement cost per Gross Domestic Product), as well as combinations.

- Comparison with benchmarks of decarbonization indicators: A number of indicators can be used to describe countries' circumstances and developments, for example at the national level, emissions per Gross Domestic Product, emissions per capita, energy use per capita or the energy mix. At the sectoral level it could be emissions per kilometre travelled or per tonne of cement or steel produced. Indicators can measure activity (for example vehicle kilometres travelled) or intensity (emissions per vehicle kilometre) (see also the data portal of the Climate Action Tracker).

- In line with globally cost-effective model pathways: Modelling exercises can identify the country reductions required to minimize the aggregated global costs of emission reductions. As a result, reductions are required in those sectors and countries where they are least-cost from a global perspective.

- Comparison with best practice policy package or policy menu: A comparison can be made on the extent to which a country has implemented supporting policies, addresses barriers, or has counterproductive policies in place. A contribution can be regarded as ambitious if it includes many policies that are considered good practice, while it would be less ambitious if the country were not to implement the policies that most of its peers had already successfully implemented (see also climate policy database ${ }^{12}$, Climate Transparency 2017).

Comprehensive studies that evaluate diverse metrics are not yet available. However, their inclusion would be very useful in future Emissions Gap Reports, as well as for the further processes under the UNFCCC, including the Facilitative Dialogue in 2018 and the global stocktake in 2023.

\subsubsection{NDCs and emission trends of individual G20 members}

China's NDC includes four major targets: (1) an intention to peak $\mathrm{CO}_{2}$ emissions around 2030, making best efforts to peak earlier, (2) to reduce the carbon intensity of Gross Domestic Product by 60-65 percent from 2005 levels by 2030 , (3) to increase the share of non-fossil fuels in primary energy consumption to around 20 percent by 2030 , and (4) to increase the forest stock volume by around 4.5 billion $\mathrm{m}^{3}$ from 2005 levels by 2030. For the first two targets, the NDC does not clarify which sectors are covered (Damassa et al., 2015). Recent independent studies (Climate Action Tracker, 2017a; den Elzen et al., 2016b; IEA, 2016; Sha et al., 2015)

12 www.climatepolicydatabase.org, https://newclimate.org/2015/12/01/goodpractice-policies/ suggest that China's emissions under currently implemented policies would roughly be in line with what the NDC targets would mean for overall emissions, but do not provide strong indication that $\mathrm{CO}_{2}$ emissions would peak before $2030^{13}$. Total greenhouse gas emissions are projected to keep on growing up to 2030 , albeit at a much lower rate than previously observed, which is also concluded in the analysis of Jiang et al. (2017). Several studies have revised their projection for 2030 downward compared to last year's projection.

Driven by air pollution control action policies (State Council, 2013), China started to control coal use and promote clean energy use in 2012. Together with economic structural

13 Some analysts have argued that structural shifts in the economy in recent years make likely much steeper reductions in the $\mathrm{CO}_{2}$ intensity of Gross Domestic Product. Fergus and Stern (2017) include an illustrative pathway wherein intensity is halved from 2005 to 2020 , and the result is a peak in $\mathrm{CO}_{2}$ emissions between 2020 and 2025 . 
changes, this resulted in a slowdown of most energyintensive production, a peak in coal consumption in 2013 in physical unit and in 2014 in standard coal equivalents, and continued decline from 2014. Coal consumption reduced by 4.7 percent in 2015, and 3.7 percent in 2016 (China Statistic Year Book, 2017). Due to the increase in natural gas and petroleum production, the total $\mathrm{CO}_{2}$ emissions have started to decline after 2014. Based on the energy use data, energy related $\mathrm{CO}_{2}$ emissions are around $450 \mathrm{MtCO}_{2}$ lower in 2016 than in 2014, which amounts to 5 percent of total $\mathrm{CO}_{2}$ emissions from energy activities. Despite a small increase in emissions from clinker manufacture, $\mathrm{CO}_{2}$ emissions in 2016 are still $430 \mathrm{MtCO}_{2} /$ year lower than in 2015 (China Statistic Year Book, 2017).

In the last two years, newly installed capacity on wind power, solar power, and hydropower has increased to more than $120 \mathrm{GW}$, which together with $11 \mathrm{GW}$ newly installed capacity for nuclear has dominated the global newly installed capacity for low-carbon power. Low-carbon power accounts for more than 40 percent of global newly installed capacity in the last two years (CEC, 2017; REN21, 2017).

Due to structural change in the industry sector, energy demand increase is projected to be quite low, with energy demand by 2020 much lower than that projected in government planning. Based on scenario analysis, the increase in energy demand in the near future could be provided by renewable energy, nuclear and natural gas. Given the recent trends, coal use decline could continue. Taking into account these recent developments, $\mathrm{CO}_{2}$ emissions may already have peaked, or may not increase in the future (Green and Stern, 2017), a development that is not yet included in the studies cited above and may be visible in future Emissions Gap Reports.

Meanwhile, the European Union's NDC contains a commitment of a 40 percent reduction in domestic emissions by 2030 compared to 1990 . Recent independent studies (CAT, 2017; Kitous et al., 2016) and the European Environment Agency (EEA) Trends report (EEA, 2016) suggest that the European Union will fall slightly short of its NDC target under existing policies.

India's NDC commits to, by 2030, reduce its emissions intensity of Gross Domestic Product by 33-35 percent below 2005 levels, increase the share of non-fossil energy in total power generation capacity to 40 percent, and create an additional cumulative carbon sink of $2.5-3 \mathrm{GtCO}_{2} \mathrm{e}$ through additional forest and tree cover. In figure 3.3, unconditional NDCs assume either current policies or only the intensity target, while conditional NDCs assume full implementation of the NDC, including the non-fossil fuel target. Independent studies project that the emission level under the intensity target would be overachieved, but it is uncertain what emission level would be reached under all three targets combined (Climate Action Tracker, 2017a; Mitra et al., 2017; PBL, 2017). Recent policy developments include the Draft Electricity Plan published in December 2016 (Central Electricity Authority, 2016). Although this is currently not an official policy and is in a draft stage, the analysis in the document forecasts that no new coal-fired power capacity would be required during the period 2022-2027, in contrast to around $50 \mathrm{GW}$ of additional capacity expected for the period 2017-2022 (Central Electricity Authority, 2016). As a result, the share of renewables in total installed capacity in this scenario is projected to increase to around 43 percent in 2027 (Central Electricity Authority, 2016). Overall, the assessment suggests that the positive development provides ample room for India to strengthen its NDC.

The INDC communicated by the United States of America in 2015 indicated an intent to reduce greenhouse gas emissions by between 26 and 28 percent below 2005 levels in 2025, which translates to 4.6-4.8 $\mathrm{GtCO}_{2} \mathrm{e} /$ year (national estimate, in the IPCC Fourth Assessment Report (AR4) Global Warming Potential terms). In June 2017, President Donald Trump announced that the United States of America intended to withdraw from the Paris Agreement and would cease implementation of the NDC. The United States of America subsequently communicated its intent to the United Nations Secretary-General (The Representative of the United States of America to the United Nations, 2017). The earliest that United States of America withdrawal can take effect is in 2020, four years after the Paris Agreement entered into force. Seven studies to date estimate that 2025 emissions under the new Administration's policies will range from 5.7-6.8 $\mathrm{GtCO}_{2} \mathrm{e} /$ year, in contrast to 5.0-6.6 $\mathrm{GtCO}_{2} \mathrm{e} /$ year under the previous Administration's policies (Chai et al., 2017; Climate Action Tracker, 2017a; Climate Advisers, 2017; Climatelnteractive, 2017; Hafstead, 2017; Rhodium Group, 2017a, b). The impact of current and upcoming action by subnational and non-state actors may also be significant (Kuramochi et al., 2017).

Argentina presented a revised NDC at the COP 22 in November 2016 (Government of Argentina, 2016). This new NDC includes an unconditional absolute emissions target of $483 \mathrm{MtCO}_{2} \mathrm{e} /$ year by 2030 and a conditional target of $369 \mathrm{MtCO}_{2}$ e by 2030 , both including LULUCF. The revised NDC is significantly more ambitious than the previous one in terms of absolute emissions (about $190 \mathrm{MtCO}_{2} \mathrm{e} /$ year lower for the unconditional target), which is partially attributable to the revised methodology for quantifying the historical emissions data. The Climate Action Tracker concludes in its latest analysis (Climate Action Tracker, 2017b) that the 2030 emissions projections, previously assessed to be on track to meet the unconditional target (Kuramochi et al., 2016), would not reach the revised NDC targets.

Australia committed to a 26-28 percent reduction of greenhouse gas emissions by 2030 below 2005 levels, including LULUCF. Government projections indicate that emissions are expected to reach $592 \mathrm{MtCO}_{2}$ e/year in 2030 (Government of Australia, 2016), in contrast to the targeted range of $429-440 \mathrm{MtCO}_{2} \mathrm{e} /$ year. Independent analyses (Kuramochi et al., 2016; Reputex, 2016) confirm that the emissions are set to far exceed its Paris Agreement NDC target for 2030. The Emissions Reduction Fund, which the Government of Australia considers to be a key policy 
measure to reduce emissions alongside other measures such as the National Energy Productivity Plan and targets for the reduction of hydrofluorocarbons ( 85 percent by 2036), does not set Australia on a path to meeting its targets.

Brazil has put forward an absolute emissions reduction target, committing to reduce emissions to $1.3 \mathrm{GtCO}_{2} \mathrm{e} /$ year by 2025 and $1.2 \mathrm{GtCO}_{2} \mathrm{e} /$ year by 2030 , which is equivalent to 37 percent and 43 percent below 2005 emissions levels including LULUCF. Recent independent studies suggest current policy projections to be in line with the NDC targets (CAT, 2017; Kuramochi et al., 2016; PBL, 2017). Uncertainty nevertheless remains about the future of emissions growth; for example, the LULUCF emissions reduced by 86 percent between 2005 and 2012 (Ministry of Science and Technology of Brazil, 2016), but recent data and analyses suggest that the decreasing trend on deforestation and the resulting emissions reductions have slowed down or even stopped (SEEG, 2017).

Canada's NDC commits to emissions reductions of 30 percent from the 2005 level by 2030. Government projections indicate that emissions are expected to reach $742 \mathrm{MtCO}_{2} \mathrm{e} /$ year in 2030, in contrast to the targeted level of $523 \mathrm{MtCO}_{2} \mathrm{e} /$ year (excluding LULUCF) (Environment and Climate Change Canada, 2017). Independent studies (Climate Action Tracker, 2017h; PBL, 2017) also agree that Canada will miss its NDC target under current policies by a large margin (610-820 $\mathrm{MtCO}_{2} \mathrm{e} /$ year compared to the NDC target of 510-580 $\mathrm{MtCO}_{2} \mathrm{e} /$ year in 2030).

Indonesia's NDC includes an unconditional target of 29 percent below BAU and a conditional 41 percent reduction below BAU with sufficient international support by 2030 , both including LULUCF. The NDC includes emissions due to deforestation and peat land destruction, which are the country's largest sources of greenhouse gas emissions. Studies covered in figure 3.3 show that Indonesia is close to being on track to achieving its unconditional NDC, which is based on new independent analyses (CAT, 2017; Kuramochi et al., 2016; PBL, 2017) that show a range of emission projections under current policies for 2030, although the upper end of the projection range is not expected to achieve the unconditional NDC target.

Japan aims to reduce its greenhouse gas emissions by 26 percent below 2013 levels by 2030 under its NDC. Recent analyses (CAT, 2017; PBL, 2017) show that the target could possibly be reached with currently implemented policies, although there is still a great deal of uncertainty regarding the future role of nuclear and coal power. It is worth noting that the government has started the process to formulate a new Basic Energy Plan, in which a revised future electricity mix target for 2030 and subsequent years would be laid out.

Mexico aims, in its NDC, to reduce its greenhouse gas emissions by between 22 percent (unconditional) and 36 percent (conditional) from BAU by 2030 . Under its current policies, Mexico is not on track to meet its NDC target. Independent studies (Climate Action Tracker, 2017c; PBL,
2017) agree that Mexico will fall short of its unconditional NDC target (759 $\mathrm{MtCO}_{2} \mathrm{e} /$ year) by $20-160 \mathrm{MtCO}_{2} /$ year under its current policies.

The Republic of Korea committed under its NDC to reduce its greenhouse gas emissions by 37 percent below BAU by 2030. Recent independent analyses (CAT, 2017; PBL, 2017) indicated that the emissions projections under current policies would fall short of the NDC emission level. However, it should be noted that the new President Moon Jae-in recently announced that the Republic of Korea will reduce its dependency on coal-fired and nuclear power generation (Cheong Wa Dae, 2017; MOTIE-MOE-MOLIT, 2017), while increasing renewable electricity. No official government document has been published.

Russia's INDC aims to limit its greenhouse gas emissions to 70-75 percent of 1990 levels by 2030. Independent estimates on the INDC emission level vary significantly (2.4-2.7 $\mathrm{GtCO}_{2} \mathrm{e} /$ year including LULUCF), mainly due to different interpretations on the accounting of LULUCF emissions (Government of Russia, 2014). The emission levels under current policies projected by independent analyses are approximately 2.0-2.4 $\mathrm{GtCO}_{2} \mathrm{e} /$ year (including LULUCF) in 2030 and reach the lower end of Russia's INDC range (Kuramochi et al., 2016). The latest current policies projections for 2030 excluding LULUCF by the Climate Action Tracker (Climate Action Tracker, 2017d) have been revised downward by $0.2-0.3 \mathrm{GtCO}_{2} \mathrm{e} /$ year compared to the 2016 assessment. Our assessment suggests that there is ample room for Russia to strengthen its NDC.

Saudi Arabia's NDC aims to achieve mitigation co-benefits of up to $130 \mathrm{MtCO}_{2}$ e avoided annually by 2030 through actions and plans outlined to contribute to economic diversification and adaptation. The country has not yet defined a baseline, which the NDC states will be determined based on differently weighted combinations of two scenarios, which differ in terms of their assumptions on the allocation of oil: produced for either domestic consumption or export. Among independent studies, PBL Netherlands Environmental Assessment Agency and the European Commission's Joint Research Centre project that Saudi Arabia will achieve its NDC (Kitous et al., 2017), whereas Climate Action Tracker projects it to miss the NDC target (Climate Action Tracker, 2017e).

South Africa's NDC consists of a peak, plateau and decline in the greenhouse gas emissions trajectory range, which gives a range of 398-614 $\mathrm{MtCO}_{2} \mathrm{e} /$ year between 2025 and 2030, reaching a peak between 2020 and 2025 and a plateau for the following decade, before starting to fall. All studies (Climate Action Tracker, 2017f; Kitous et al., 2017; PBL, 2017) agree that South Africa will not achieve its NDC range under current policies by a margin of $50 \mathrm{MtCO}_{2} \mathrm{e} /$ year to nearly $400 \mathrm{MtCO}_{2} \mathrm{e} /$ year in 2030.

Turkey's NDC sets an economy-wide greenhouse gas emission reduction target of up to 21 percent below BAU in 2030. Among independent studies, PBL Netherlands 
Environmental Assessment Agency and the European Commission's Joint Research Centre project that Turkey will overachieve its NDC considerably by 370-410 $\mathrm{MtCO}_{2} \mathrm{e} /$ year (Kitous et al., 2017; PBL, 2017; van Vuuren et al., 2017; Vandyck et al., 2016) while Climate Action Tracker projects it to miss the NDC target, based on the government projection (Climate Action Tracker, 2017g).

\subsection{Subnational and non-state actions to narrow the gap}

In line with previous Emissions Gap Reports, this report finds that subnational and non-state actions could possibly make a significant contribution to narrowing the gap (figure 3.4). The aggregate impact of the initiatives could be in the order of a few $\mathrm{GtCO}_{2} \mathrm{e}$ in 2030 beyond the current NDCs, if the initiatives reach their stated goals and if these reductions do not displace actions elsewhere. Since the 2016 report, only updates on earlier studies (Compact of Mayors 2015; CDP and We Mean Business, 2016; The Climate Group, 2016; Graichen et al., 2017), but no significantly new aggregation reports, have become available.
Analysis of the extent to which individual subnational and non-state actors or initiatives meet their stated objectives is still scarce. Chan et al. (2016) find that not all initiatives deliver on their promises. Graichen et al. (2017) provide a preliminary assessment of the actual emission reductions of an initiative compared to its potential. Based on such analysis, several studies (Graichen et al., 2016; Michaelowa and Michaelowa, 2017) have identified criteria for initiatives to be effective:

- Permanent funding and secretarial support

- Inclusion of Non-Govermental Organizations in the design and implementation of the initiative

- Definition of mitigation targets including baseline

- Regular monitoring, reporting and verification

The process around and following the COP 21 in Paris in 2015 has brought about much higher recognition and institutionalization of the role of non-state actors in the intergovernmental climate change process. This process continued at COP 22 in Marrakech in 2016, where the Marrakech Partnership for Global Climate Action was

Figure 3.4: Illustration of the potential impact of international cooperative initiatives in 2030.

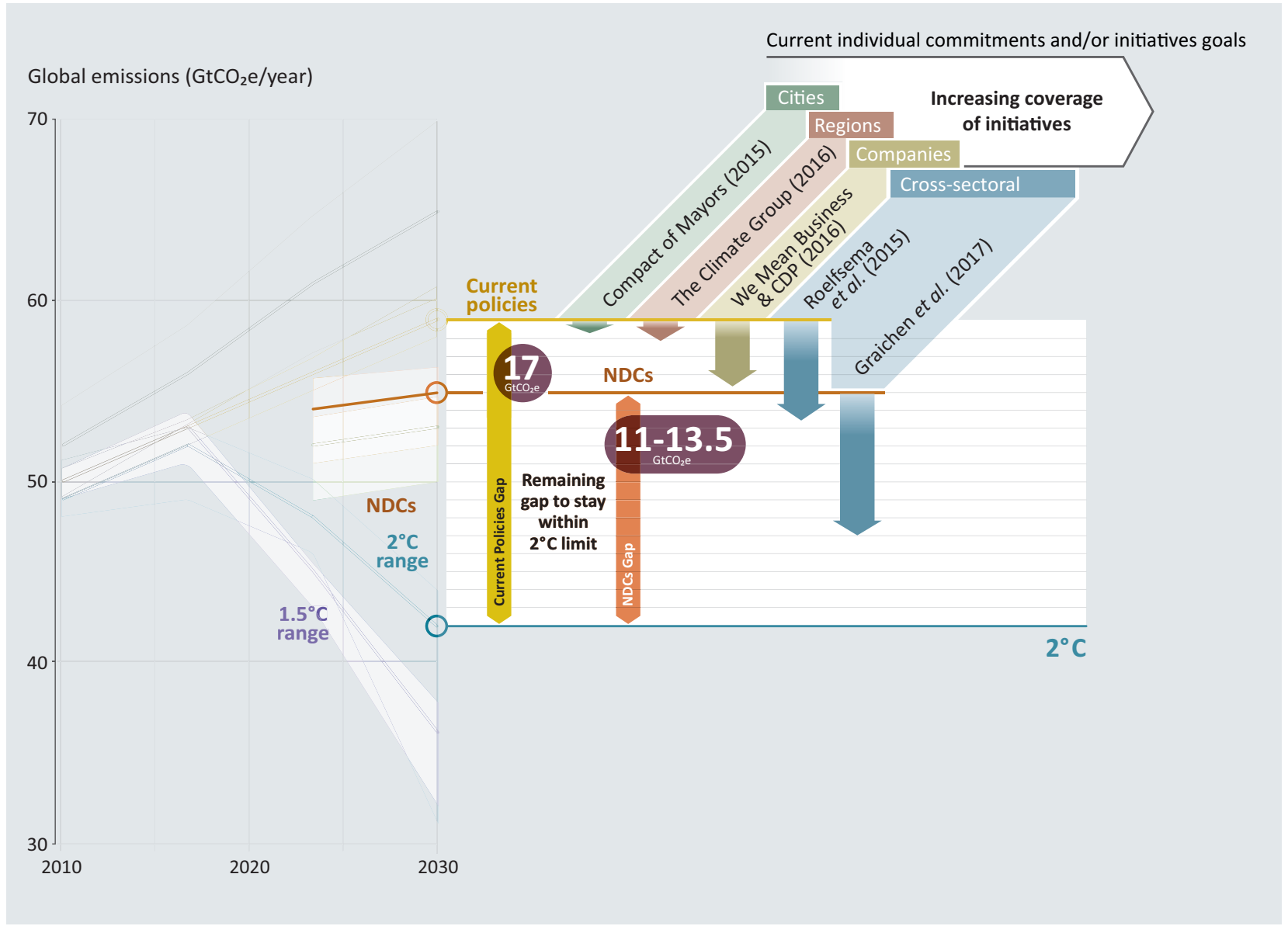

Note: The arrows showing the emission reductions potential start at different levels because the individual studies use different baselines (the last study explicitly estimated the impact additional to NDCs). 
launched ${ }^{14}$. It provides guidance on how the UNFCCC process will catalyse and support climate action by Parties and non-Party stakeholders in the period up to 2020 , in line with the arrangements of the Paris Agreement. It also promotes an assessment of the compatibility of commitments with regard to the long-term objectives of the Paris Agreement, and seeks to increase the coherence with the Sustainable Development Goals.

A number of new cooperative initiatives involving non-state actors were launched at COP 22 in Marrakech. The '2050 Pathways' platform intends to build a bridge to long-term decarbonization scenarios and strategies and brings together both state and non-state actors ${ }^{15}$. The Global South was well represented in new initiatives such as the Marrakech Investment Committee for Adaptation Fund, the Initiative for Renewable Island Energy and the Marrakech Pledge for Fostering Green Capital Markets in Africa. A host of other initiatives were launched in various areas, including forests, water, energy, human settlements, oceans, transport and agriculture ${ }^{16}$. However, there was little information on the progress regarding the non-state initiatives launched in Paris.

The number of non-state commitments and actions included in the Non-State Actor Zone for Climate Action ${ }^{17}$ platform, where the UNFCCC captures and recognizes climate commitments from non-state actors, continued to grow to over 12,000 (mostly individual) commitments in 2016, compared to 10,000 in 2015 . The Non-State Actor Zone for Climate Action also aims to assess the progress in these commitments, but so far there is little data available. UN Environment's Climate Initiatives Platform ${ }^{18}$, which provides the Non-State Actor Zone for Climate Action with data on important cooperative non-state climate initiatives, has also started collecting this information.
Actions by subnational and non-state actors have the potential to reinforce each other (Andonova et al., 2017) and could make the Paris Agreement more robust. Even if Parties announce the withdrawal of their support from implementing the Paris Agreement, other actors in the same country could step in to reaffirm their commitment. For example, following the announcement of the Trump Administration to withdraw from the Paris Agreement, the United States of America has seen a number of new initiatives driven by subnational and non-state actors, such as America's Pledge on Climate ${ }^{19}$, We Are Still In $^{20}$, Climate Mayors ${ }^{21}$ and the US Climate Alliance ${ }^{22}$. If backed by action, these initiatives have the potential to make up for the withdrawal (Kuramochi et al., 2017).

Jerry Brown, governor of California, announced ${ }^{23}$ in July 2017 that the State of California will convene representatives from subnational governments, businesses, investors and civil society in San Francisco, California, in September 2018 for a Global Climate Action Summit ${ }^{24}$. The meeting aims to demonstrate the groundswell of innovative, ambitious climate action, highlight the economic and environmental transition already under way and spur deeper commitment from all parties, including national governments.
14 http://unfccc.int/files/paris_agreement/application/pdf/marrakech_ partnership_for_global_climate_action.pdf

15 http://newsroom.unfccc.int/unfccc-newsroom/high-level-climatechampions-launch-2050-pathways-platform/

$16 \mathrm{http}: / /$ newsroom.unfccc.int/climate-action/non-state-actors-partner-withgovernments-to-boost-climate-action/

$17 \mathrm{http}: / /$ climateaction.unfccc.int/

18 http://climateinitiativesplatform.org/

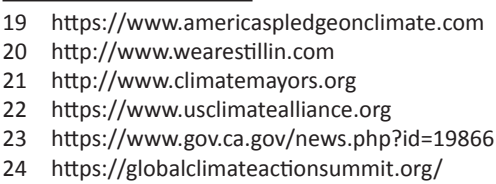




\section{Chapter 4}

\section{Bridging the gap - sectoral greenhouse gas emission reduction potentials in $\mathbf{2 0 3 0}$}

Lead authors: Kornelis Blok (Ecofys), Angélica Afanador (Ecofys), Detlef van Vuuren (PBL Netherlands Environmental Assessment Agency)

Contributing authors: Tom Berg (Ecofys), Christian Breyer (Lappeenranta University of Technology), Oreane Edelenbosch (PBL Netherlands Environmental Assessment Agency), Ann Gardiner (SQ Consult), Danny Harvey (University of Toronto), Atul Kumar (TERI University), Roberto Schaeffer (Universidade Federal do Rio de Janeiro), Pete Smith (University of Aberdeen), Lynn Price (Lawrence Berkeley National Laboratory), Irina van der Hoorn (Ecofys), Paul Waide (Waide Strategic Efficiency), Hans Joosten (Greifswald University)

\subsection{Introduction}

This chapter explores two central questions: Can the emissions gap in 2030 be bridged, and what are the most promising options to do so? As presented in Chapter 3, the estimated emissions gap in 2030 is 11 to $13.5 \mathrm{GtCO}_{2} \mathrm{e}$ for the below $2^{\circ} \mathrm{C}$ target ( $>66$ percent 'likely' chance), and 16 to $19 \mathrm{GtCO}_{2}$ e for the $1.5^{\circ} \mathrm{C}$ target (50-66 percent 'medium' chance). Chapter 3 furthermore assessed the difference in 2030 between emissions under the current policy scenario and the emission levels consistent with a likely chance of staying below $2^{\circ} \mathrm{C}$ and a medium chance of staying below $1.5^{\circ} \mathrm{C}$ of about 17 and $22.5 \mathrm{GtCO}_{2}$ e respectively (table 3.1 ). To be sufficient to bridge the gap, emission reduction potentials in 2030 need to be of a comparable magnitude.

The chapter provides a detailed review of greenhouse gas emission reduction potentials in 2030 for key economic sectors (section 4.2). Sectoral emission reduction potentials, also called bottom-up potentials, provide detailed estimates of the level of emission reductions that is feasible within a certain sector or for a specific emissions category up to a certain marginal cost level. When added up, and adjusting for any overlaps, these estimates give an indication of the total potential for reducing global greenhouse gas emissions in 2030. The total potential can then be compared to the gap, to determine whether it can be bridged (section 4.3). In addition, the estimates provide policy makers with a clear and granular view of where important emission reduction options exist, that is, how the gap can be bridged. The sectoral estimates are then compared to emission reduction options provided by integrated assessment models (section 4.4).

Previous Emissions Gap Reports have provided both sectoral emission reduction potential estimates and estimates based on integrated assessment models (see UNEP, 2014; 2013; 2012; 2011). However, most of the previous assessments provide estimates of emission reduction potentials for 2020, and the most recent assessments of sectoral emission reduction potentials date from more than six years ago. These include UNEP (2011) for 2020, IPCC (2007) for 2020 and 2030, and McKinsey (2010) for 2030. Assessments that are more recent include IPCC (2014) and IEA (2017), but these do not include a sector-by-sector assessment of the full emission reduction potential in 2030 .

\subsection{Assessment of emission reduction potentials by sector in 2030}

Drawing on a detailed review of recent studies, this section presents estimates of the global emission reduction potentials that are technically and economically feasible in 2030. The focus is on six main sectors: agriculture, buildings, energy, forestry, industry, and transport (sections 4.2.1 to 4.2.6). However, some promising options for emission reductions are difficult to allocate under one sector. These are considered in section 4.2.7. For all sectors, the main categories of emission reductions for 2030 are identified.

The focus of the analysis is on the socio-economic potential. This means that the potentials presented here refer to the total of emission reductions that can be achieved using all technologies available in a given future year, which are economically attractive from a social cost perspective (IPCC, 2001). This potential is defined as all reductions that can be achieved at a marginal cost of no more than US\$100/tCO $\mathrm{e}$, at current prices, which is the cost level often assumed to be necessary by 2030 for achieving ambitious reduction pathways (IPCC, 2014; IEA, 2016). There are important uncertainties related to assumptions regarding technology deployment and implementation rates, including, for 
example, how rapidly solar photovoltaic energy production can be scaled up, and the rate at which buildings can be retrofitted. The underlying analysis introduces some degree of 'realism' in the assessment and its respective assumptions. In general, it is assumed that the potentials can be achieved, if countries around the globe are willing to set policies that enable the implementation of the available solutions.

The potentials are assessed against a current policy scenario, which provides a reference level in 2030 against which the greenhouse gas emission reductions could be achieved. The current policy scenario emissions projected for 2030 amount to $61.1 \mathrm{GtCO}_{2} \mathrm{e}$. If emissions from peat degradation and peat fires are excluded, projected emissions are $59.2 \mathrm{GtCO}_{2} \mathrm{e}$ which corresponds well with the $58.9 \mathrm{GtCO}_{2}$ e current policy projection listed in Chapter 3, where peat-related emissions are excluded in 3 out of the 4 underlying scenarios. Details on the current policy scenario are included in Appendix B, available online. The following gases are included in the analysis: carbon dioxide $\left(\mathrm{CO}_{2}\right)$, methane $\left(\mathrm{CH}_{4}\right)$, nitrous oxide $\left(\mathrm{N}_{2} \mathrm{O}\right)$, perfluorocarbons (PFCs), hydrofluorocarbons (HFCs) and sulfurhexafluoride $\left(\mathrm{SF}_{6}\right)$. Black carbon is not included in the assessment (for impacts on global warming of short-lived climate pollutants, including black carbon, see Chapter 6). The potentials are adjusted to be in line with the current policy scenario used for this chapter. Emission factors are based on the average global emission intensities for 2030 from the World Energy Outlook 2016 (IEA, 2016). For the electricity sector the average emission intensity of fossil-fuel based power plants is used. Finally, interactions between mitigation measures (for example, efficient appliances versus power sector decarbonisation) are taken into account and handled on a case-by-case basis.

\subsubsection{Emission reduction options and potential in the agriculture sector}

Studies of emission reduction potentials for the agriculture sector vary widely. Since IPCC AR5, studies that report mitigation potentials in the agriculture sector with carbon prices up to US\$100/tCO provide annual reductions of between 0.26 to $4.6 \mathrm{GtCO}_{2} \mathrm{e}$ (Smith et al., 2014) $)^{1}$. These estimates exclude demand-side options. However, demand side mitigation options are included in the assessment below. While net carbon emissions from soils are negligible in current policy trajectories, Smith et al. (2007) argue that around 90 percent of the mitigation potential can be attributed to carbon sequestration in soils, like cropland, grazing land and the restoration of degraded land. In addition, non- $\mathrm{CO}_{2}$ greenhouse gases from enteric fermentation and rice cultivation can be avoided. Finally, a large share of peatrelated emissions can be avoided.

Regarding cropland management, Smith et al. (2008) cite a mitigation potential of $0.74 \mathrm{GtCO}_{2}$ e in 2030 , with 90 percent of the potential coming from $\mathrm{CO}_{2}$, while long-term biophysical potentials of $2.6 \mathrm{GtCO}_{2} \mathrm{e} /$ year are reported (Smith, 2016). The non- $\mathrm{CO}_{2}$ component is more or less in line with the

1 Lower range figure only concerns non- $\mathrm{CO}_{2} \mathrm{GHGs}$ and thus excludes soil Carbon sequestration where the largest share of the potential lies.
$0.04 \mathrm{GtCO}_{2} \mathrm{e}$ from USEPA (2013), presenting a range of options to reduce the emissions originating from crop farming. The estimate is established through a combination of no-tillage and residue management, agronomy and nutrient management, which are all three applied on one-third of global croplands. Recently, there has been discussion on no-tillage measures, for example in Dimassi et al. (2014), who argue that an increase in the soil-carbon stock may be the result of a redistribution of carbon between soil layers. However, this would not affect the potential from Smith et al. (2008), since the area to which no-tillage measures are applied can be substituted with measures that have a more or less similar potential from the other cropland management categories, like agronomy and nutrient management (Smith et al., 2008). We therefore maintain the estimate potential of $0.74 \mathrm{GtCO}_{2} \mathrm{e}$ in 2030 for cropland management.

Grazing lands are typically managed less intensively than croplands, leaving significant potential for enhanced removals and emission reduction. Grazing land measures suggested by Smith et al. (2008) include: adjusting grazing intensity and allowing for more biomass growth, increasing land productivity by reducing nutrient deficiencies, using more precise nutrient additions resulting in savings in fertilizer, fire management (reducing frequency and fire intensity in fireprone areas), and species introduction, for example of grass species with higher productivity from associated nitrogen inputs (Smith et al., 2008). Together, these measures have the potential to sequester an additional $0.75 \mathrm{GtCO}_{2}$ in 2030 , if measures under US\$100/tCO 2 are adopted.

Degraded wetlands, drained for agricultural use, contribute disproportionally to global greenhouse gas emissions from the land-use sectors, with approximately 25 percent of all land-use emissions originating from degraded peatlands (Bonn et al., 2014). When peatlands are drained, organic matter in soils starts oxidizing and releases significant volumes of carbon dioxide emissions, until drainage is reversed or all peat is lost (Bonn et al., 2014). Currently, global greenhouse gas emissions from peatland degradation and peat fires are in the order of $2.2 \mathrm{GtCO}_{2} \mathrm{e} /$ year and are expected to decrease to $1.9 \mathrm{GtCO}_{2} \mathrm{e} / \mathrm{year}$ in 2030. Smith et al. (2008) provides 2030 mitigation potentials for the restoration of cultivated organic (peaty) soils of $1.3 \mathrm{GtCO}_{2} \mathrm{e}$, but excludes mitigation from fires. In practice, peat fires can only be prevented when an economic value is attributed to the peatlands, or when they are rewetted effectively (Joosten et al., 2012). Taking the substantial cost of peat fires into account and considering measures of up to US\$100/tCO is assumed that emissions from peat fires can be reduced to zero for the majority of the peat sites in the world (World Bank, 2016; Wichtmann et al., 2016). Remaining emissions from peat fires in the current policy scenario are $0.3 \mathrm{GtCO}_{2}$. Emission reductions from peatland degradation and peat fires combined would therefore amount to $1.6 \mathrm{GtCO}_{2}$ in 2030 .

Based on a simulation of alternative rice management scenarios using varying management techniques, USEPA (2013) estimates an emissions reduction potential of 
$0.18 \mathrm{GtCO}_{2} \mathrm{e}$ in 2030, a reduction of nearly 25 percent compared to emissions under the current policy scenario. The scenarios include measures such as adjusting the flooding regime, applying no-tillage, and using various fertilizer alternatives.

Recently, biochar has gained attention as a potential carbon removal option in agricultural lands, mainly cropland. Biochar is produced by heating biomass under anaerobic conditions, and can under the right conditions enhance soil fertility and improve soil's water retention properties while enhancing the soil organic carbon content. Woolf et al. estimate that after 15 years, a reduction of about $0.2 \mathrm{GtCO}_{2} \mathrm{e}$ can be realized (Woolf, et al., 2010).

Although current-policy emissions from enteric fermentation and manure management make up a significant part of total emissions in agriculture, the mitigation potential from livestock management is limited. Based on country-level livestock populations from USEPA (2012), and livestock production and market price projections from Nelson et al. (2010), a global mitigation potential at costs below US $\$ 100 / \mathrm{tCO}_{2}$ in 2030 of $0.23 \mathrm{GtCO}_{2} \mathrm{e}$ is estimated (8 percent of current policy scenario emissions). The mitigation options with the highest cost-effective potentials are waste and manure digesters, anti-methanogens (vaccines that suppress methane production in the rumen), intensive grazing, and improved feed conversion and propionate precursors (animal feed addition that converts more of the produced hydrogen into propionate instead of methane).

Based on a combination of intensive restoration projects on agricultural lands ( 15 million hectares) and farmer-managed natural regeneration projects ${ }^{2}$ (135 million hectares), the Global Commission on the Economy and Climate estimates that an emission reduction of $1.1 \mathrm{GtCO}_{2} \mathrm{e} /$ year can be achieved by 2030 (GCEM, 2015). These estimates are scaled up from case-study results in China and Niger respectively, and an uncertainty range of 0.5 to $1.7 \mathrm{GtCO}_{2} \mathrm{e}$ is applied.

Turning to demand-side mitigation options, efforts can be made to lower the carbon footprint of the average diet. Stehfest et al. (2013) model the impact of shifting food patterns to a diet recommended by the World Health Organization, which sets recommendations on the consumption of animal products and fat, and compare this impact using two different economic models: the International Food Policy Research Institute's (IFPRI) International Model for Policy Analysis of Agricultural Commodities and Trade (IMPACT) and the so-called LEITAP model from the Global Trade Analysis Project (GTAP). Both models were coupled to the integrated assessment model IMAGE. As a result of less agricultural demand from less land- and resource-intensive diets, total greenhouse gas emissions decrease by 0.37 to $1.37 \mathrm{GtCO}_{2} \mathrm{e} /$ year in 2030 (Stehfest et al., 2013).

2 A land restoration method using living tree stumps or roots in crop fields, grazing pastures, woodlands or forests that have proven to have co-benefits in combating poverty and hunger (Haglund et al., 2011).
Stehfest et al. (2013) also studied the effect of reducing food waste, utilising the same methods as described in the previous paragraph. Within the agricultural supply chain, significant losses can be identified when factors such as harvesting inefficiency, bad harvesting conditions, deterioration during storage, and consumer behaviour are considered. Estimates of total losses vary considerably, between 30 to 50 percent (Nelleman et al., 2009; Lundqvist, 2009), and the effect of waste reduction is modelled at a 15 percent reduction in the amount of food needed to meet similar nutrition levels, which requires a 45-75 percent reduction in the amount of wasted food. Modelled impacts on greenhouse gas emissions are somewhat higher than shifting dietary patterns, with IMPACT reporting 2030 potentials of $0.79 \mathrm{GtCO}_{2} \mathrm{e} /$ year and LEITAP of $2 \mathrm{GtCO}_{2} \mathrm{e} /$ year.

Combining the potentials of all the measures discussed leads to an emission reduction potential of $3 \mathrm{GtCO}_{2} \mathrm{e} /$ year in 2030 (uncertainty range $2.3-3.7 \mathrm{GtCO}_{2} \mathrm{e}$ ), if uncertain measures like biochar, peat-related emission reductions, and demandside measures are excluded. These three measures add up to an additional potential of $3.7 \mathrm{GtCO}_{2} \mathrm{e}$ (uncertainty range $2.6-4.8 \mathrm{GtCO}_{2} \mathrm{e}$ ) in 2030, after correction for overlap with other measures.

\subsubsection{Emission reduction options and potential in the buildings sector}

Under the current policy scenario, buildings account for annual energy-related greenhouse gas emissions of $12.6 \mathrm{GtCO}_{2}$ in 2030 . Of these emissions, 29 percent are direct, mainly from space heating and hot water production, and 71 percent are indirect, mainly from electric appliances and lighting. Improvements in energy efficiency is an important emission reduction option for all energy uses. In addition, renewable energy can play a role.

In many countries, policy measures and legislation are already addressing the energy efficiency potential of new buildings. Concepts like net-zero buildings, insulation, smart glazing, and building automation are of increasing interest. While developing new buildings with energy-efficient technologies is an important step in reducing emissions from the sector, retrofitting of existing buildings is also essential.

Based on the method used by the Climate Action Tracker it is estimated that for new buildings between 0.68 and $0.85 \mathrm{GtCO}_{2}$ /year could be avoided in 2030 (Climate Action Tracker, 2016). This would require that all new buildings in OECD countries are near-zero energy from 2020 onwards, and from 2020 to 2025 onwards also in non-OECD countries. It is assumed that near-zero energy buildings have 90 percent lower emissions than the current standard. This figure is consistent with Blok et al. (2015) who based on an analysis of several studies estimated a potential from ambitious energy efficiency standards for new buildings of 0.7 to $1.3 \mathrm{GtCO}_{2} /$ year in 2030. This is also consistent with C40 (2014), which reports a reduction potential of $0.9 \mathrm{GtCO}_{2} /$ year in 2030 for heating efficiency in new buildings. 
For the thermal retrofit of existing buildings, the estimated emission reduction potential is 0.52 to $0.93 \mathrm{GtCO}_{2} /$ year in 2030 using the same method as in the Climate Action Tracker (2016). The lower range requires annual renovation rates of 3 percent in OECD and non-OECD countries from 2020 onwards, with 75 percent direct emissions reduction per retrofit (GBPN, 2013). The higher range requires annual renovation rates from 2020 onwards of 5 percent in OECD countries and of 3 percent in non-OECD countries, with 90 percent direct emissions reduction per retrofit (GBPN, 2013). This emission reduction potential is consistent with C40 (2014), which forecasts a reduction potential of $0.8 \mathrm{GtCO}_{2}$ /year for existing buildings in 2030 .

According to IRENA (2016) and Wagner (2017) heat from renewable sources can grow by 5.4 EJ for solid, liquid and gaseous biofuels and by 2.9 EJ for solar energy compared to the current policy scenario. This equals an emission reduction potential of $0.39 \mathrm{GtCO}_{2} /$ year in 2030 from biomass and $0.21 \mathrm{GtCO}_{2} /$ year for solar heat.

For electric appliances (excluding lighting) in households and the service sector, an assessment of the emission reduction potential is calculated based on Molenbroek et al. (2015), leading to an estimate of $3.3 \mathrm{GtCO}_{2} /$ year in 2030 . This is in line with the estimation of adopting the world's best end-use equipment technology by CLASP (2011). For energy efficient lighting, a report by UN Environment (UNEP, 2014) estimates energy savings of $4.4 \mathrm{EJ}$, equivalent to $0.92 \mathrm{GtCO}_{2} /$ year in 2030. Molenbroek et al. (2015) reports emission reductions from lighting of $0.67 \mathrm{GtCO}_{2}$ /year in 2030 . We will use this figure, which is slightly lower than the older estimate in CLASP (2011).

The total emission reduction potential for direct emissions from buildings is $1.9 \mathrm{GtCO}_{2} /$ year (uncertainty range $1.6-2.1 \mathrm{GtCO}_{2}$ ) in 2030 after correction for overlap between energy efficiency and renewable energy measures. The reduction potential for indirect emissions is included in the energy sector potential.

\subsubsection{Emission reduction options and potential in the energy sector}

In the current policy scenario, energy sector emissions amount to $21.3 \mathrm{GtCO}_{2}$ in 2030 , of which $16.3 \mathrm{GtCO}_{2}$ comes from power generation (IEA, 2016, USEPA, 2012). Main options for reducing emissions in the energy sector are wind and solar energy. In addition, hydro, nuclear, carbon capture and storage and bioenergy combined with carbon capture and storage can contribute. Emission reductions from the oil and gas sector and coal mining are also discussed.

The installed global wind capacity was $487 \mathrm{GW}$ by the end of 2016 (REN21, 2017). Wind energy capacity can grow to between 2,110 and 3,064 GW in 2030 (GWEC, 2016; Teske et al., 2015), compared to $940 \mathrm{GW}$ in the current policy scenario. This represents an emission reduction of between 2.6 and $4.1 \mathrm{GtCO}_{2}$ in 2030. Reaching these potentials would require an annual growth of installed capacity of
11 to 15 percent per year. For comparison, the growth in the past decade amounted to 21 percent per year.

Solar power capacity can reach 3,725 GW in 2030 (Teske et al., 2015), compared to $708 \mathrm{GW}$ in the current policy scenario, which represents an emissions reduction of $3.0 \mathrm{GtCO}_{2} /$ year in 2030 . The installed global solar capacity by the end of 2016 amounted to 303 GW (REN21, 2016). Reaching these potentials would require an annual growth of installed capacity of 14 to 20 percent per year (Teske et al., 2015). For comparison, the growth in the past decade amounted to 48 percent per year. Creutzig et al. (2017) find that many models have consistently underestimated deployment of solar photovoltaics. However, some newer studies provide higher potentials. A recent analysis by Breyer et al. (2017) estimate a potential of 7,100-9,100 GW. This potential would require a growth of the installed solar photovoltaics capacity of 26 to 29 percent per year and would lead to avoided emissions of 5.5 to $7.2 \mathrm{GtCO}_{2} / \mathrm{year}^{3}$. For a more electrified energy system, Breyer et al. report a potential of $12,000 \mathrm{GW}$. An Ecofys study done for Sitra, showed that, by scaling up the solar photovoltaics energy strategy of Germany to the whole world, the potential global increase in solar photovoltaics could be in the range of 3,885 to $8,722 \mathrm{GW}$ in 2030 . This is equivalent to a potential emission reduction of 2.49 to $6.17 \mathrm{GtCO}_{2} \mathrm{e} /$ year in 2030 (SITRA, 2015; Afanador et al., 2015) 4 . Based on the large variation of numbers presented here, and leaving out the highest ones, we come to a potential of 3 to $6 \mathrm{GtCO}_{2} /$ year avoided through solar photovoltaics.

Other electricity production options also have potential to reduce emissions in the energy sector in 2030. Compared to emission levels under the current policy scenario, biomass has a potential of $0.85 \mathrm{GtCO}_{2} /$ year and geothermal has a potential of $0.73 \mathrm{GtCO}_{2} /$ year (Teske et al., 2015). For hydro power and nuclear energy, the IEA (2016) in its 450 scenario indicates a potential increase of $147 \mathrm{GW}$ and $154 \mathrm{GW}$ compared to the current policy scenario. The emission reduction potentials are estimated at 0.32 and $0.87 \mathrm{GtCO}_{2}$ /year in 2030, respectively.

The total emission reduction potential for carbon capture and storage (CCS) is estimated by IEA (2017) at $2.03 \mathrm{GtCO}_{2} /$ year in 2030, which is slightly lower than the estimation of Mac Dowell and Fajardy (2017) of $2.5 \mathrm{GtCO}_{2}$, based on an earlier IEA study. This includes a reduction of $0.8 \mathrm{GtCO}_{2} /$ year in 2030 for $\mathrm{CO}_{2}$ for enhanced oil recovery and $0.1 \mathrm{GtCO}_{2} /$ year in 2030 for carbon capture and utilisation in 2030 . This reduction potential can be allocated either to the energy sector or to the industry sector. Based on the allocation in IEA (2016), 67 percent is allocated to the industry sector and 33 percent to the energy sector. The amount of carbon dioxide avoided is smaller than the amount of carbon dioxide captured,

Given the high penetration of solar photovoltaics, we use average emission factors here instead of marginal emission factors.

4 According to the study, the level of uncertainty of the estimation is about 20 percent, due to data limitations at the country level. The study scales up the solar photovoltaics case of Germany in each individual country and then aggregates them to a global potential. In cases where country data was not available, the authors used regional data. 
because it consumes energy to operate CCS. This ratio is 70 to 90 percent (Herzog et al., 2005). Therefore, a 20 percent discount is applied to correct for the stored $\mathrm{CO}_{2}$ that is reported. In the industrial sector, a correction of 10 percent is applied since the $\mathrm{CO}_{2}$ in these sectors is often emitted at higher purity. The above leads to a reduction potential of $0.53 \mathrm{GtCO}_{2} /$ year in 2030 for the energy sector and $1.22 \mathrm{GtCO}_{2}$ /year in 2030 for the industry sector ${ }^{5}$.

Bioenergy with CCS has a reduction potential of $0.31 \mathrm{GtCO}_{2}$ /year in 2030 (IEA, 2017). There is uncertainty about whether bioenergy with CCS exceeds the costs of US $\$ 100 / \mathrm{tCO}_{2}$. Several studies provide cost estimations ranging from above to under the US\$100/tCO . Arasto et al. (2014) estimate costs at US\$100-200/tCO, while McGlashan et al. (2012) estimate the average costs for bioenergy with CCS to be US\$80-90/tCO , and Johnsen et al. (2014) estimates that bioenergy with CCS applied on biofuels production in 2030 will cost $€ 25-175 / \mathrm{tCO}_{2}$. Since there are studies with estimations under and above US\$100/tCO ${ }_{2}$, the potential for bioenergy with CCS is allocated to the energy sector category as an additional option.

This chapter does not include the shift from coal to gas, since natural gas declines in the World Energy Outlook 450 scenario compared to the current policy scenario (IEA, 2016). However, within certain regions the shift from coal to gas can play a role in the reduction of emissions from the energy sector. In the World Energy Outlook 450 scenario, only a small increase is visible in India (0.3 EJ) and South Africa (0.04 EJ) (IEA, 2016). Given the small size, this is not included in the potentials.

The total emission reduction potential in the power sector is large. It makes up about 70 percent of the power sector emissions in the current policy scenario, without considering overlaps. Adding electricity savings from the buildings and industry sector implies that power sector emissions in 2030 could be reduced by more than 100 percent compared with the current policy scenario, which is obviously not possible unless bioenergy with CCS is applied on a large scale. However, there will be increasing interaction between the different emission reduction options long before the 100 percent is reached, making the total potential smaller than the sum of the individual options. In the assessment, it is assumed that total emissions in the power sector are reduced by a maximum of 57 to 65 percent, which are the largest percentages found in the literature (Deng et al., 2012; Teske et al., 2015) $)^{6}$. This will lead to total emission reductions of 9.3 to $10.6 \mathrm{GtCO}_{2}$ /year in 2030, which indicates the 'basic' potential. However, given the large potentials for the individual categories, power sector decarbonization may develop faster (see, for example, Breyer et al., 2017). Implementing large shares of intermittent renewable sources would require the use of flexibility options such as

5 Compared with Chapter 7, this chapter considers different groupings of emission reduction options, timeframes and cost levels. For this reason, estimates are not directly comparable across chapters.

6 For comparison, the recent Energy Technology Perspective reports (IEA, 2016; IEA, 2017), give reductions of 35 percent and 48 percent compared to the current policy scenario. demand response, flexibility of supply, network optimization and expansion, and storage to match supply and demand. For an overview of flexibility options, see Papaefthymiou et al. (2014).

Outside the power sector, methane emissions from the distribution of gas and the production and transmission of oil and gas can be reduced by $1.78 \mathrm{GtCO}_{2}$ /year in 2030 (Klimont and Höglund-Isaksson, 2017). This is 75 percent of the current policy scenario emissions from the oil and gas industry. These reductions can mainly be achieved by implementing measures for the recovery and utilization of vented gas and the reduction of leakages.

Methane emissions from coal mining can be reduced by $0.41 \mathrm{GtCO}_{2} \mathrm{e} /$ year in 2030, which is a reduction of 56 percent compared to the current policy scenario (Klimont and Höglund-Isaksson, 2017). Measures implemented in this scenario include pre-mining degasification measures and the installation of ventilation air oxidizers.

Combining the potentials of all the electricityrelated measures discussed, also in buildings and industry, leads to a potential of $10.0 \mathrm{GtCO}_{2} \mathrm{e}$ (uncertainty range 9.3$10.6 \mathrm{GtCO}_{2} \mathrm{e} /$ year) in 2030. Bioenergy with CCS could provide an additional potential of $0.3 \mathrm{GtCO}_{2}$ e in 2030 (uncertainty range $0.2-0.4 \mathrm{GtCO}_{2} \mathrm{e}$ ). Emission reductions from the oil and gas sector and coal mining are $2.2 \mathrm{GtCO}_{2} \mathrm{e}$ /year (uncertainty range $\left.1.7-2.6 \mathrm{GtCO}_{2} \mathrm{e}\right)$.

\subsubsection{Emission reduction options and potential in the forestry sector}

Since IPCC AR5, studies of mitigation potentials in the forestry sector with carbon prices up to US\$100/tCO 2 report values between $0.2-13.8 \mathrm{GtCO}_{2} \mathrm{e} /$ year, largely depending on the types of models used (Smith et al., 2014). There are two main options for reducing emissions in this sector: halting deforestation, and restoration of degraded forest land.

Emission reduction potentials from halting deforestation come with great uncertainty. These uncertainties relate, for example, to the degree to which decreased deforestation leads to lowered degradation and associated carbon emissions, but also depend on the baseline used (GCEM, 2015). We assume a global potential in 2030 of $3 \mathrm{GtCO}_{2} \mathrm{e}$ (based on Clarke et al., 2014). This central estimate assumes that the current policy scenario emissions remain stable from current levels.

Global commitments on restoration of degraded forests, such as commitments to the Bonn Challenge and the New York Declaration on Forests, aim to bring a total of 350 million hectares of degraded and deforested land under restoration (Messinger and DeWitt, 2015). Reaching this target by 2030 would yield emission reductions in the order of 1.6$3.4 \mathrm{GtCO}_{2} /$ year, with a central estimate of $2.3 \mathrm{GtCO}_{2} /$ year in 2030 (Verdone et al., 2015). 
Combining the potentials of the measures discussed leads to a total contribution from the forestry sector of $5.3 \mathrm{GtCO}_{2} \mathrm{e} /$ year (with an uncertainty range of $4.1-6.5 \mathrm{GtCO}_{2} \mathrm{e}$ ).

\subsubsection{Emission reduction options and potential in the industry sector}

Industry sector greenhouse gas emissions are $19.3 \mathrm{GtCO}_{2} \mathrm{e}$ in 2030 under the current policy scenario. The two main sources of industrial greenhouse gas emissions are direct and indirect (via electricity consumption) use of fossil fuels. There are also smaller sources of greenhouse gas emissions, including 'non-energy' use of fossil fuels (for example, fossil fuels as feedstock for chemical processes) and emissions from industrial processes (for example, carbonization in the cement process and several sources of non- $\mathrm{CO}_{2}$ greenhouse gases). By applying a broad set of mitigation options (Fischedick, 2014), the industry sector can achieve substantial emission reductions by 2030, mainly from energy efficiency, non- $\mathrm{CO}_{2}$ measures and $\mathrm{CCS}$, with a smaller contribution from renewable heat.

For energy efficiency, the emission reduction potential for 2030 is estimated at $4.1 \mathrm{GtCO}_{2} /$ year compared to the current policy scenario. This estimate is based on data from ClimateWorks Foundation and the World Bank (Akbar et al., 2014), scaled up from six major regions to the entire world and correcting for measures other than energy efficiency. The emission reduction implies a nearly 30 percent reduction compared to the current policy scenario. This is compatible with the estimate by Worrell and Carreon (2017) (see also Saygin et al. (2011), who estimated a static potential of $27 \pm 9$ percent). It should be noted that the potentials vary by sector and by region. For example, it is estimated at 9 - 30 percent for iron and steel, 4-7 percent for primary aluminium, for cement the estimate is $20-25$ percent, for petrochemicals 23-7 percent, and for ammonia production 11-25 percent (Worrell and Carreon, 2017). Based on the share in current policy emissions, a $2.2 \mathrm{GtCO}_{2}$ /year emission reduction is allocated to direct emissions and a $1.9 \mathrm{GtCO}_{2} /$ year is allocated to indirect emissions.

Renewable energy use in the form of solid, liquid and gaseous biofuels, solar thermal energy and geothermal can generate 9.7 EJ (IRENA 2016), which is an additional 7.8 EJ compared to the current policy scenario. This will reduce emissions by $0.5 \mathrm{GtCO}_{2}$ /year in 2030.

Carbon capture and storage in the manufacturing industry is associated with an emission reduction potential of $1.22 \mathrm{GtCO}_{2}$ /year in 2030 (see the discussion of the option in the section on the energy sector).

For non- $\mathrm{CO}_{2}$ greenhouse gases, the largest reduction is from HFCs, which can be reduced by $1.5 \mathrm{GtCO}_{2} \mathrm{e} /$ year in 2030 (Purohit and Höglund-Isaksson, 2017)7. USEPA (2013) estimates an additional reduction potential for non- $\mathrm{CO}_{2}$

7 Note that these estimates do not consider the emission reduction impacts associated with implementing the Kigali Amendment to the Montreal Protocol. Taking these impacts into account would lower the estimate (see Chapters 3 and 6 . greenhouse gas emissions of $0.2 \mathrm{GtCO}_{2} \mathrm{e} /$ year in 2030, where $0.12 \mathrm{GtCO}_{2} \mathrm{e}$ comes from nitric and adipic acid production and the rest from perfluorocarbons from primary aluminium production and sulphur hexafluoride from electric power systems and magnesium production.

Based on the above, the emission reduction potential for industry for direct emissions is $5.4 \mathrm{GtCO}_{2}$ e/year in 2030 (uncertainty range $4.2-6.6 \mathrm{GtCO}_{2} \mathrm{e}$ ). No correction for overlap is needed, as many industrial plants are so large that energy efficiency measures can be combined with CCS or renewable energy. The reduction potential of indirect emissions is already accounted for in the potential for the energy supply sector.

\subsubsection{Emission reduction options and potential in the transport sector}

In the current policy scenario, total emissions for transport are $9.7 \mathrm{GtCO}_{2}$ in 2030, of which $9.42 \mathrm{GtCO}_{2}$ are direct emissions and $0.28 \mathrm{GtCO}_{2}$ indirect emissions for electricity use. The emission reduction potential differs per mode of transport, but is most significant for light-duty vehicles and heavy-duty vehicles, with other contributions coming from shipping, aviation and biofuels.

In the automobile sector, fuel efficiency measures could potentially reduce emissions by $0.88 \mathrm{GtCO}_{2}$ /year (heavy duty vehicles) and by $2.0 \mathrm{GtCO}_{2} /$ year (light duty vehicles) by 2030 (ICCT, 2012). These numbers include modal shifts. A shift to more electric vehicles is also included. ICCT (2012) assumes that electric-drive vehicles will form a small, but not insignificant, share (up to 9 percent) of new-vehicle sales by 2030 . This is in line with the estimations of IRENA (2016) (10 percent) and Bloomberg New Energy Finance (2017) (7 percent). Note that substantial emission reductions due to fuel economy standards for passenger cars are already included in the current policy scenario.

Aviation can reduce emissions with up to 0.32 (ICCT 2012) or up to 0.42 (ICAO 2013) $\mathrm{GtCO}_{2} /$ year in 2030 by using alternative fuels, improved infrastructure use and technical improvements.

Several studies indicate an emission reduction for shipping (Alvik et al., 2010; Faber et al., 2011; Eide et al., 2011; Hoffmann et al., 2012) ranging from 0.39 to $0.99 \mathrm{GtCO}_{2}$. The studies contain several measures focused on fuel efficiency. The most recent study, from Bouman et al. (2017), reports an emission reduction potential of $0.70 \mathrm{GtCO}_{2} /$ year in 2030 . The numbers for aviation and shipping are in the same order as those in the study from New Climate Economy (GCEM, 2015), which shows a reduction potential between 0.60 and $0.90 \mathrm{GtCO}_{2}$ per year.

Biofuels is another measure that is relevant for the transport sector. ICCT (2012) provides no potential for biofuels in 2030 due to the high uncertainty. IRENA (2016) does provide an estimate for biofuels to cover 10 percent of the sector's total fuel use in 2030. Taking into account that greenhouse gas 
emissions from biofuels are 70 percent to 90 percent lower than those of conventional fuels (BLE, 2016; Ecofys, 2017 forthcoming) an emission reduction potential of 0.63 to $0.81 \mathrm{GtCO}_{2} \mathrm{e} /$ year in 2030 can be calculated.

Based on the above, the total emission reduction potential for the transport sector is $4.7 \mathrm{GtCO}_{2}$ /year in 2030 (with an uncertainty of $4.1-5.3 \mathrm{GtCO}_{2}$ ). No overlap correction is needed, as biofuels can be used as drop-in fuels.

\subsubsection{Other promising emission reduction options and potential}

Some options for emission reduction are difficult to allocate to one of the sectors assessed in the previous sections. This may be because it is still unknown in which sector it can best be implemented, or because the option can be applied to multiple sectors. Some promising mitigation measures are described below.

Methane constitutes some 90 percent of greenhouse gas emissions from the waste sector. Landfill gas recovery and utilization is one option for reducing methane emissions. USEPA (2013) estimates that landfill gas recovery can reduce emissions by $0.4 \mathrm{GtCO}_{2} \mathrm{e} /$ year in 2030 , which represents 42 percent of the emissions in the current policy scenario.

Enhanced weathering measures aim to draw carbon from the atmosphere via, among others, the natural chemical weathering process of silicates (other processes elaborated in Chapter 7). Preliminary global estimates using waste material only, for example from cement and iron and steel manufacturing, arrive at $0.73-1.22 \mathrm{GtCO}_{2} /$ year in 2030, excluding stockpiled waste (Renforth et al., 2012).
There are other measures that are not included in this chapter. In April 2017 the book, Drawdown, was published containing the 100 most substantive solutions to reverse global warming (Hawken, 2017). Comparing the top 20 of Drawdown with this analysis, two high-ranked measures are missing in this chapter: educating girls and family planning. It is expected that the quantitative impact of such measures is mostly beyond 2030 .

\subsection{Can the gap be bridged: total emission reduction potential in 2030}

An overview of the estimated total emission reduction potentials in 2030 assessed in the previous sections is provided in table 4.1. The table shows that estimates based on proven technologies and relatively precautionary assumptions regarding potentials in 2030 (the 'basic' potential in table 4.1), leads to a total emission reduction potential in 2030 of $33 \mathrm{GtCO}_{2} \mathrm{e} /$ year (uncertainty 30 $36 \mathrm{GtCO}_{2} \mathrm{e}$ ). The basic emission reduction potential in 2030 is also shown in figure 4.1. If, in addition, areas where estimates of potentials are relatively new, and the feasibility of realizing these in 2030 is more uncertain, are considered (the 'additional' potential in table 4.1), the potential is $38 \mathrm{GtCO}_{2} \mathrm{e} /$ year (uncertainty range $35-41 \mathrm{GtCO}_{2} \mathrm{e}$ ).

Importantly, even if only the basic emission reduction potential for 2030 is considered, the estimated total potential listed here is sufficient to bridge the emissions gap in 2030 for $2^{\circ} \mathrm{C}$ ( $>66$ percent chance) and $1.5^{\circ} \mathrm{C}$ (50 to 66 percent chance). It exceeds the estimated difference in 2030 between emissions under the current policy scenario and the emission levels consistent with a likely chance of staying below $2^{\circ} \mathrm{C}$ and a medium chance of staying below

Figure 4.1: Total emission reduction basic potentials compared to the current policy scenario in 2030.

Annual Global Total Greenhouse Gas Emissions $\left(\mathrm{GtCO}_{2} \mathrm{e}\right)$

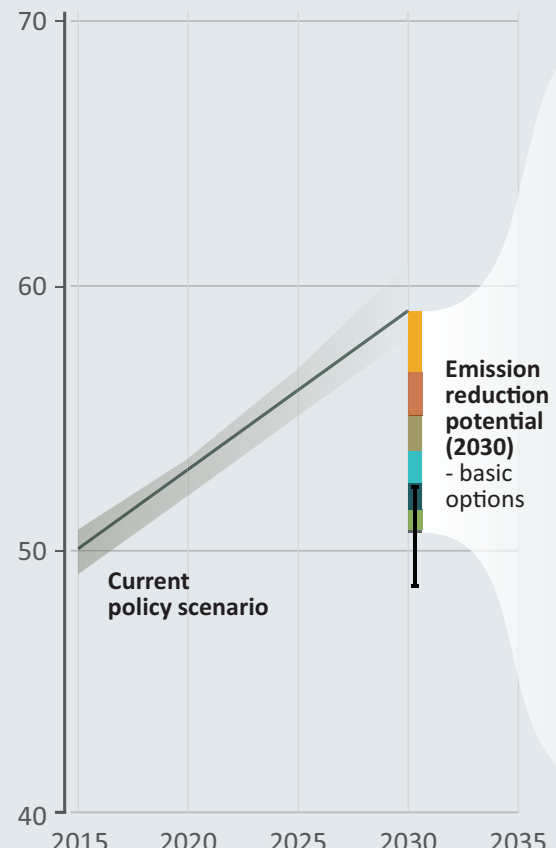

Sectoral emission reduction potentials in 2030

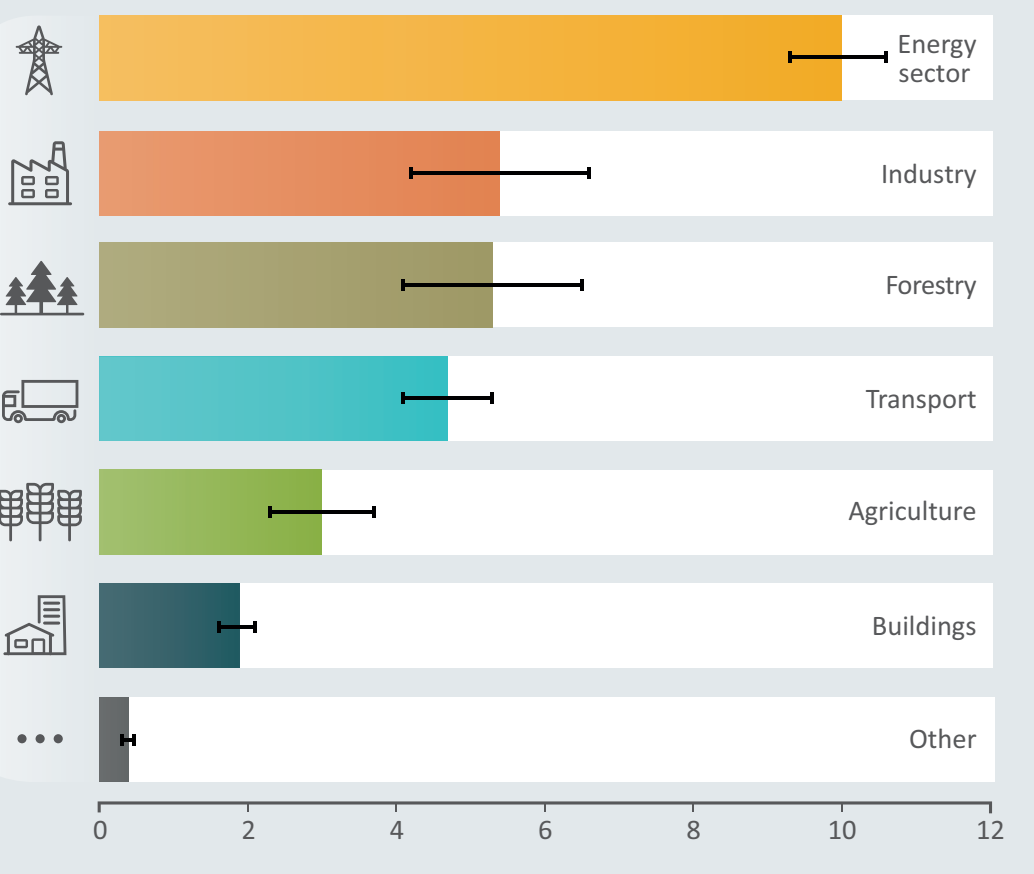


$1.5^{\circ} \mathrm{C}$ of about 17 and $22.5 \mathrm{GtCO}_{2}$ e respectively, as indicated in the introduction to this chapter.

An important question is what the efforts and costs of realizing these emission reductions are. Although it is beyond the scope of the current chapter to answer this question in full, a number of observations can be made. It is remarkable that a large part of the potential consists of just six categories, that is, solar and wind energy, efficient appliances, efficient passenger cars, afforestation and stopping deforestation. These six categories sum up a potential of $18.5 \mathrm{GtCO}_{2} \mathrm{e}$ in 2030 (range: $15-22 \mathrm{GtCO}_{2} \mathrm{e}$ ), making up more than half of the basic potential. Equally important, all these measures can be realized at modest cost, and are predominantly achievable through proven policies:

- Solar photovoltaics and wind energy. Many countries around the world have targets for renewable energy and have policies in place to stimulate its adoption. The most dominant policy instruments are feed-in tariffs or feed-in premiums, which have been implemented in 75 countries and 29 states or provinces in the world, providing long-term power purchase agreements with a specified price or premium price per $\mathrm{kWh}$ for a renewable energy technology (REN21, 2017). An instrument with increasing popularity is competitive bidding or auctioning, especially for large scale developments, where the renewable energy market is mature and governments have already achieved a degree of success with renewable installation through feed-in-tariffs (REN21, 2017). Costs of electricity from solar and wind electricity have already declined to levels comparable with fossil-fuel based electricity (Lazard, 2016), and auctions have accelerated this trend (IRENA, 2017). Continuation of feed-in policies and/ or a shift to auctions are a straightforward and cheap approach to rapid decarbonization of the power sector.

- Energy efficient appliances and cars. A combination of labelling and minimum energy performance standards are the dominant policies to stimulate the uptake of efficient appliances. Over 60 countries have adopted or pledged to adopt policies to shift to more energy-efficient lighting (UNEP, 2014). Under the United for Efficiency (U4E) public-private-partnership, UN Environment is supporting developing countries and emerging economies to move their markets to energy-efficient appliances and equipment (UNEP, 2017). In terms of performance standards for cars, several countries have opted to implement fuel economy standards in miles per gallon or $\mathrm{CO}_{2}$ emission standards in $\mathrm{gCO}_{2}$ per $\mathrm{km}$; these standards exist in Brazil, the EU, India, Japan, Mexico and the USA (ICCT, 2017). Typically, energy efficiency standards are implemented in such a way that life-cycle costs are minimized, hence leading to net negative costs for the consumer. Similar policies are in place in many countries for new building construction (UNEP, 2016). Further continuation of these policies, scaling them up to more countries while raising ambitions is a way forward to limit the growth of energy use and hence reducing emissions.

- Stopping deforestation and restoration of degraded forests. There are several examples of policies successfully stopping deforestation, the most largescale being the Brazilian 'Action Plan for Prevention and Control of Deforestation in the Amazon', consisting of (1) territorial and land-use planning, (2) environmental control and monitoring, and (3) fostering sustainable production activities. The programme led to a reduction of the rate of deforestation by more than 80 percent. Costs are found to be US\$13/tCO e on average (Afanador et al., 2015; Sitra, 2015). For reforestation of degraded forests, the scale of operations is not of that size, but promising examples are available for China (Chen et al., 2016), Costa Rica (Afanador et. al 2015), and the Republic of Korea (Kim and Zsuffa, 1994). Costs are comparable with the costs of stopping deforestation.

These are examples of a few of the options that can be implemented at relatively low cost and based on significant existing experience. Together they represent more than half of the basic potential identified. Previous Emissions Gap Reports provide many more examples of scaling up of existing policies and programmes, as do other studies, including the study Green to Scale (Sitra, 2015).

Although the available studies prevent an explicit, economic assessment of all emission reduction options, there is a relatively high degree of confidence that all options included in table 4.1 have costs below US\$100/ $\mathrm{tCO}_{2} \mathrm{e}$ avoided. In many cases, this is explicit in the source documents. For some, however, it is not clear whether the costs will be below US\$100/ $/ \mathrm{CO}_{2}$ e. For example, some electricity sources may show costs above US\$100/ $\mathrm{CCO}_{2} \mathrm{e}$, as there are large variations in costs (Lazard, 2016). However, given that there are abundant options in the electricity sector, leaving out these options will not affect the total potential. 
Table 4.1: Overview of emission reduction potentials.

\begin{tabular}{|c|c|c|c|c|}
\hline Sector & Category & $\begin{array}{l}\text { Emission reduction potential } \\
\text { in } 2030\left(\mathrm{GtCO}_{2} \mathrm{e}\right)\end{array}$ & Category & $\begin{array}{l}\text { Sectoral aggregate potential } \\
\left(\mathrm{GtCO}_{2} \mathrm{e}\right)\end{array}$ \\
\hline \multirow{9}{*}{ Agriculture } & Cropland management & 0.74 & \multirow{5}{*}{ Basic } & \multirow{5}{*}{$3(2.3-3.7)$} \\
\hline & Rice management & 0.18 & & \\
\hline & Livestock management & 0.23 & & \\
\hline & Grazing land management & 0.75 & & \\
\hline & $\begin{array}{l}\text { Restoration of degraded } \\
\text { agricultural land } \\
\end{array}$ & $0.5-1.7$ & & \\
\hline & $\begin{array}{l}\text { Peatland degradation and } \\
\text { peat fires }\end{array}$ & 1.6 & \multirow{4}{*}{ Additional } & \multirow{4}{*}{$3.7(2.6-4.8)$} \\
\hline & Biochar & 0.2 & & \\
\hline & Shifting dietary patterns & $0.37-1.37$ & & \\
\hline & $\begin{array}{l}\text { Decreasing food loss and } \\
\text { waste }\end{array}$ & $0.97-2$ & & \\
\hline \multirow{6}{*}{ Buildings } & New buildings & $0.68-0.85$ & \multirow{4}{*}{ Basic } & \multirow{4}{*}{$1.9(1.6-2.1)$} \\
\hline & Existing buildings & $0.52-0.93$ & & \\
\hline & Renewable heat - bio & 0.39 & & \\
\hline & Renewable heat - solar & 0.21 & & \\
\hline & Lighting & 0.67 & \multirow[t]{2}{*}{ Basic (indirect emissions) } & \multirow{2}{*}{$\begin{array}{r}\text { See energy sector } \\
\text { potential }\end{array}$} \\
\hline & Appliances & 3.3 & & \\
\hline \multirow{10}{*}{ Energy sector } & Solar energy & $3-6$ & \multirow{7}{*}{ Basic } & \multirow{7}{*}{$10.0(9.3-10.6)$} \\
\hline & Wind energy & $2.6-4.1$ & & \\
\hline & Hydropower & 0.32 & & \\
\hline & Nuclear energy & 0.87 & & \\
\hline & Bioenergy & 0.85 & & \\
\hline & Geothermal & 0.73 & & \\
\hline & CCS & 0.53 & & \\
\hline & Bioenergy with CCS & 0.31 & Additional & $0.3(0.2-0.4)$ \\
\hline & Methane from coal & 0.41 & & \\
\hline & Methane from oil and gas & 1.78 & Dasti & $2.2(1.7-2.0)$ \\
\hline \multirow{2}{*}{ Forestry } & Restoration of degraded forest & $1.6-3.4$ & Basic & \multirow{2}{*}{$5.3(4.1-6.5)$} \\
\hline & Reducing deforestation & 3 & & \\
\hline \multirow{5}{*}{ Industry } & Energy efficiency - indirect & 1.9 & Basic (indirect emissions) & $\begin{array}{r}\text { See energy sector } \\
\text { potential }\end{array}$ \\
\hline & Energy efficiency - direct & 2.2 & \multirow{4}{*}{ Basic } & \multirow{4}{*}{$5.4(4.2-6.6)$} \\
\hline & Renewable heat & 0.5 & & \\
\hline & Non- $\mathrm{CO}_{2}$ greenhouse gases & 1.5 & & \\
\hline & $\operatorname{CCS}$ & 1.22 & & \\
\hline \multirow{5}{*}{ Transport } & $\begin{array}{l}\text { Heavy Duty Vehicles potential } \\
\text { (efficiency, mode shift) }\end{array}$ & 0.88 & \multirow{5}{*}{ Basic } & \multirow{5}{*}{$4.7(4.1-5.3)$} \\
\hline & $\begin{array}{l}\text { Light Duty Vehicles potential } \\
\text { (efficiency, mode shift, electric } \\
\text { vehicles) }\end{array}$ & 2.0 & & \\
\hline & \begin{tabular}{|l} 
Shipping efficiency \\
\end{tabular} & 0.7 & & \\
\hline & Aviation efficiency & $0.32-0.42$ & & \\
\hline & Biofuels & $0.63-0.81$ & & \\
\hline \multirow[b]{2}{*}{ Other } & Landfill gas recovery & 0.4 & Basic & $0.4(0.3-0.5)$ \\
\hline & $\begin{array}{l}\text { Enhanced weathering } \\
\text { measures }\end{array}$ & $0.73-1.22$ & Additional & $1(0.7-1.2)$ \\
\hline \multicolumn{2}{|c|}{ Total basic emission reduction potential } & & & $33(30$ - 36) \\
\hline \multicolumn{2}{|c|}{$\begin{array}{l}\text { Total emissions reduction potential including } \\
\text { additional measures }\end{array}$} & & & $38(35-41)$ \\
\hline
\end{tabular}

Note: Although for many emission reduction categories a single point estimate is given, there are always uncertainties, assumed to be \pm 25 percent. For the categories peatland degradation and peat fires, biochar and energy efficiency, the potential in 2030 is more uncertain. Therefore, a higher uncertainty range of 50 percent is applied to these categories. In the final column, the categories are aggregated to the sectoral level. The numbers in the third column are not corrected for overlap between measures. The numbers in the final column are corrected for overlap, and this is also reflected in the total potential. Therefore, the total is smaller than the sum of the individual potentials in the third column. The aggregate potentials for indirect emission reductions in buildings and industry are reflected in the electricity sector potential. 


\subsection{Comparison with results from Integrated Assessment Models}

In this section, the results of the bottom-up sector-by-sector assessment is compared with the sectoral emissions as reported by a range of state-of-the-art integrated assessment models. This is relevant because integrated assessment models provide information on how a given climate target can be achieved in a "least-cost" way through a full costcomparison across all sectors, and by taking account of the interactions between the different reduction options and the interactions with the wider economy. Since the scenarios by definition stay within the $2^{\circ} \mathrm{C}$ or $1.5^{\circ} \mathrm{C}$ target, they bridge the emissions gap in 2030 and the difference between emissions levels associated with the current policy scenario and the emissions in line with the $2^{\circ} \mathrm{C}$ and $1.5^{\circ} \mathrm{C}$ target. Hence, the package of mitigation measures identified in the scenarios can be viewed as successful examples of how to close the gap. Moreover, the scenarios of the integrated assessment models also provide the foundation for the gap analysis in other chapters of the Emissions Gap Report. Details regarding the baseline scenarios for the integrated assessment models used are provided in Appendix B, available online.

Figure 4.2 compares the emission reduction potentials of the sector-by-sector technology-based analysis with the mitigation activities in the integrated assessment model set for the $2^{\circ} \mathrm{C}$ scenario, noting that the integrated assessment models assume a slightly higher total 2030 emission level as described in Appendix B, available online. The average total mitigation in 2030 in the integrated assessment model scenarios is $23 \mathrm{GtCO}_{2} \mathrm{e}$, with a full range of $5-42 \mathrm{GtCO}_{2} \mathrm{e}$. The wide range across the integrated assessment models is caused by different reduction strategies over time and different baseline assumptions. Overall, the integrated assessment model range of reductions are lower than the total emission reduction potential found in the sector-by-sector analysis, which supports the technical feasibility of the integrated assessment model scenarios. The sectoral breakdown shows that in the electricity sector, emission reductions are

Figure 4.2: Comparison of mitigation in the integrated assessment models under a $2^{\circ} \mathrm{C}$ pathway with the emission reduction potentials found in the sector-by-sector analysis.

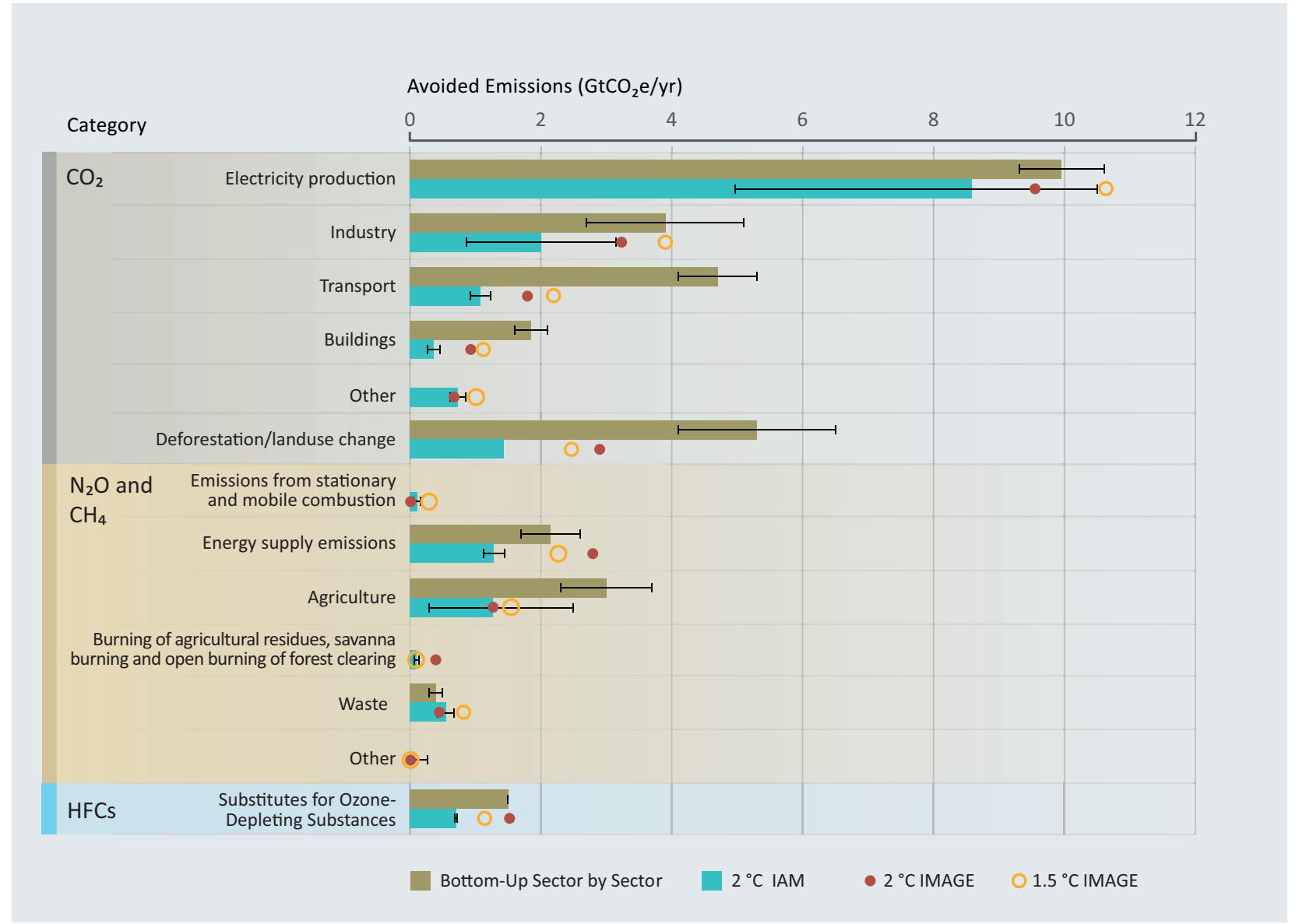

Note: The integrated assessment model results show the results of six models, in terms of the mean and the range (15-85th range, thus each time exlcuding the two most extreme models). The red dots indicate the reduction in the integrated assessment model IMAGE for both $2^{\circ} \mathrm{C}$ and $1.5^{\circ} \mathrm{C}$ (in some cases the IMAGE numbers are outside the indicated range of IAM model results.) 
comparable, although the integrated assessment models show a very wide range for this sector. This is also true for the underlying contribution of increased use of renewable and nuclear power, fossil fuel and CCS, fuel switch and bioenergy and CCS. Typically, however, integrated assessment models show a relatively high contribution of bio-energy and fossil fuel CCS technology, certainly also for the long-term. This highlights the importance of research and development with respect to negative emission options, even though their role might still be limited in the short-term. Chapter 7 further discusses this. For the various end-use sectors, the integrated assessment models show considerably lower emission reductions than the sector-by-sector estimates. In the literature, this is explained by 1 ) the relatively large implementation barriers complicating emission reductions in these sectors, and 2) the possible predominant focus of integrated assessment models on energy supply. While the sectoral, bottom up assessment finds energy efficiency improvements much more important than fuel switching in the end-use sections, integrated assessment models results show both measures to be equally important. The emission reduction potential of biological carbon removal by means of reforestation and increasing carbon in agricultural soil is also less in integrated assessment models than in the sectorby-sector assessment. It should be noted, however, that in general integrated assessment models do not consider the option of increasing carbon in agricultural soils. Finally, for non- $\mathrm{CO}_{2}$ greenhouse gases, a similar picture emerges: the emission reduction in the integrated assessment model $2^{\circ} \mathrm{C}$ scenarios is smaller than the total potential of the sector-bysector analysis.

It is not possible to compare the sector-by-sector analysis with the integrated assessment models for $1.5^{\circ} \mathrm{C}$, because most of these integrated assessment model scenarios are yet to be published (see Chapter 3). However, focusing on the results of one integrated assessment model, the IMAGE model, figure 4.2 shows the IMAGE results for both $2^{\circ} \mathrm{C}$ and $1.5^{\circ} \mathrm{C}$. The figure shows that moving to the more ambitious target requires scaling up emission reductions in several sectors, including the electricity sector and most enduse sectors.

In conclusion, the emission reductions of the integrated assessment model $2^{\circ} \mathrm{C}$ scenarios as well as the IMAGE $1.5^{\circ} \mathrm{C}$ are typically within the overall sector specific potential of the bottom up assessment. The electricity sector is an exception - but here it should be noted that the current policy emissions in the bottom up assessment were lower than for the integrated assessment models. The analysis also suggests that predominantly further emission reductions in the integrated assessment model scenarios could be achieved via energy efficiency and biological carbon removal options.

\subsection{Conclusions}

The assessment presented confirms that the total emission reduction potential is more than sufficient to bridge the emissions gap in 2030, with measures that are technically and economically feasible, and at a marginal cost of no more than US\$100/tCO $\mathrm{e}$. The total potential exceeds the difference between the current policy trajectory in 2030 and the emission levels consistent with a $2^{\circ} \mathrm{C}$ (>66 percent chance) and a $1.5^{\circ} \mathrm{C}$ (50 to 66 percent chance) temperature target.

All sectors present substantial emission reduction potentials that add up to a total of $33 \mathrm{GtCO}_{2} \mathrm{e} /$ year in 2030 (range: $30-36)$. This does not include emission reduction potentials of fairly new measures (such as direct capture of atmospheric $\mathrm{CO}_{2}$, decreasing food loss and waste, and biochar) because it is uncertain whether these emission reductions potentials could be realized by 2030 .

Notably, six specific categories of measures have the potential to reduce emissions between 15 to $22 \mathrm{GtCO}_{2} \mathrm{e} /$ year in 2030, which is more than half of the total emission reduction potential. This is comparable to the estimated difference in 2030 between the current policy trajectory and the emissions consistent with the $2^{\circ} \mathrm{C}$ and $1.5^{\circ} \mathrm{C}$ target. These six categories include solar and wind energy, efficient appliances, efficient passenger cars, afforestation and stopping deforestation. All these measures can be realized at modest costs, and countries around the world have already established policies to implement many of them. By scaling up these measures that are relatively cheap and easy to implement, the world could collectively get on track to bridge the emissions gap by 2030 .

To realize the full emission reduction potential, countries need to implement ambitious policies immediately, to enable and accelerate the implementation of the full socio-economic potential of available measures and technologies. Most of the studies used for the bottom-up assessment of sectoral emission reduction potentials assume that implementation of measures start immediately, underscoring the urgency of pre-2020 mitigation action (see also Chapter 2). 


\section{Chapter 5}

\section{Bridging the gap - Phasing out coal}

Lead authors: Amit Garg (Indian Institute of Management Ahmedabad), Jan Christoph Steckel (Mercator Research Institute on Global Commons and Climate Change)

Contributing authors: Jesse Burton (University of Cape Town), Julio Friedmann (Energy Futures Initiative), Frank Jotzo (Australian National University), Gunnar Luderer (Potsdam Institute for Climate Impact Research), Pao-Yu Oei (German Institute for Economic Research / Berlin Technical University), Michiel Schaeffer (Climate Analytics), Sàmantha Smith (Just Transition Centre), Fabby Tumiwa (Institute for Essential Services Reform), Adrien Vogt-Schilb (Inter-American Development Bank), Paola Yanguas-Parra (Climate Analytics), Xianli Zhu (UNEP DTU Partnership)

\subsection{Introduction}

If the temperature increase is to be kept well below $2^{\circ} \mathrm{C}$ by 2100 , the global economy must undergo rapid decarbonization. The power sector holds a critical role, given the widely available and relatively cheap decarbonization options in the sector (Kriegler et al. 2014; Luderer et al. 2017; Sachs et al. 2014; Williams et al. 2012). In most of the scenarios consistent with limiting warming to below $2^{\circ} \mathrm{C}$ in the Intergovernmental Panel on Climate Change's (IPPC) Fifth Assessment Report (Clarke et al. 2014), unabated coalfired power not equipped with carbon dioxide capture and storage $(\mathrm{CCS})^{1}$ declines rapidly, and is almost completely phased out by mid-century ${ }^{2}$ (Audoly, Vogt-Schilb, and Guivarch 2014; Kriegler et al. 2014; Luderer et al. 2017; Rogelj et al. 2015; Williams et al. 2012) (Chapter 3). In the scenarios consistent with a $1.5^{\circ} \mathrm{C}$ increase in global mean temperature by 2100 , the decline of the power sector's carbon emissions has to be even faster (Rogelj et al. 2015), leading to a faster phase-out of power production from

1 Carbon capture, (transport) and storage (CCS) consists of three stages, beginning with capturing $\mathrm{CO}_{2}$ from large stationary emitters, such as coal i 5 power plants or industrial facilities, then transporting it to an underground storage site, before compressing it in suitable geological formations. Scenarios by the IPCC (2014) projected large-scale CCS utilization, particularly given its potential to provide negative emissions when used in combination with biomass plants (see also Chapter 6).

2 Coal is the most carbon-intensive fossil fuel, responsible for about 46 percent of global carbon emissions from fossil fuels (Olivier et al. 2016). It is commonly categorized as steam coal $(5,811 \mathrm{Mt}$; 75 percent market share), metallurgical or coking coal (1,090 Mt; 15 percent market share) and lignite ( $807 \mathrm{Mt} ; 10$ percent market share), based on its material properties and end " use (IEA/OECD 2016). This chapter and most policies focus on steam coal and lignite, which are primarily used for generating electricity.

$\mathrm{coal}^{3}$. The longer the world continues to use coal, the greater the need for negative emissions technologies in the second half of the century (Luderer et al. 2013; Riahi et al. 2015) ${ }^{4}$.

There are currently an estimated 6,683 coal-fired power plants in operation worldwide, with a combined installed capacity of 1,964 GW. Emissions from coal alone were responsible for a major share of past emissions. If run until the end of their lifetime, and not retrofitted with $\mathrm{CCS}^{5}$, the stock of operating power plants would emit around $190 \mathrm{GtCO}_{2}$. Furthermore, they would use a large share of the available carbon budget for internationally agreed climate targets figure 5.1 and table 5.1).

Coal-based power generation is the single most important cause of carbon lock-in (Bertram, Johnson, et al. 2015; Davis, Caldeira, and Matthews 2010) ${ }^{6}$. Without additional policy interventions, the number of coal-fired power plants would likely continue to increase. In early 2017, across

3 Without large-scale deployment of CCS, achieving climate targets would also involve a large transformation of the upstream coal sector (Meinshausen et al. 2009; Bauer et al. 2016). Between 82 percent and 88 percent of current coal reserves are considered 'unburnable', compared with 33 percent-35 percent of oil and 49 percent-52 percent of gas reserves (McGlade and Ekins 2015, see also box 5.1).

See also Chapter 7 of this report for a detailed discussion.

Today, there are 17 large-scale CCS projects operating worldwide, mostly in combination with enhanced-oil recovery (EOR), which inject a total of $22 \mathrm{MtCO}_{2} / \mathrm{y}$. Two of the 17 large-scale CCS projects operating worldwide are coal power retrofits: Boundary Dam in Saskatchewan and Petra Nova in Texas. Each of these projects captures and stores $>1 \mathrm{M}$ tonnes/year, and effectively decarbonizes a unit by 90 percent. The Petra Nova project costs ('all in') are roughly US\$100/tonne, with analysts anticipating second and fourth project costs for the same technology at US\$80/tonne and US\$60/tonne respectively. Although some countries have very little $\mathrm{CO}_{2}$ storage resources, overall there does not appear to be a shortage of such resources (GCCSI 2017).

Coal power plants have a long economic lifetime, often over forty years, meaning that every new coal-fired power commits a large amount of $\mathrm{CO}_{2}$ emissions if run over its economic lifetime (Davis and Socolow 2014). 
the globe there were an additional $273 \mathrm{GW}$ of coal-fired capacity in construction, and $570 \mathrm{GW}$ in pre-construction (Shearer et al. 2017). Ten countries make up approximately 85 percent of the entire coal pipeline, with $700 \mathrm{GW}$ being built or planned in China, India, Turkey, Indonesia, Vietnam, Japan, Egypt, Bangladesh, Pakistan and the Republic of Korea alone (Shearer et al. 2017). While a large amount of planned power plants were shelved or cancelled in 2016 particularly in China and India (with reductions of 54 percent and 52 percent, respectively, compared to $2015^{7}$ ) - other countries, such as Indonesia, Japan, Egypt, Bangladesh and Pakistan, announced new investments in 2016 (with increases of 40,60, 784, 40 and 100 percent, respectively, compared to 2015) (Edenhofer et al. 2017). If run until the end of their assumed lifetime of 40 years, the plants currently under construction (273 GW) and those planned (570 GW) would lead to emissions of approximately $150 \mathrm{GtCO}_{2}$, of which $50 \mathrm{GtCO}_{2}$ can be attributed to those currently under construction (figure 5.1 and table 5.1).
To meet international emissions targets, further lock-ins should be avoided (box 5.1). Nonetheless, this would not suffice, as existing stocks and plants currently under construction would still commit approximately $240 \mathrm{GtCO}_{2}$ over their lifetime. Closing the emissions gap requires that these plants run with lower capacity rates, and are phased out before the end of their lifetime, and/or retrofitted with CCS facilities.

Figure 5.1: Committed emissions to the atmosphere from coal-fired power plants (existing, under construction and planned) and other economic sectors, by region.

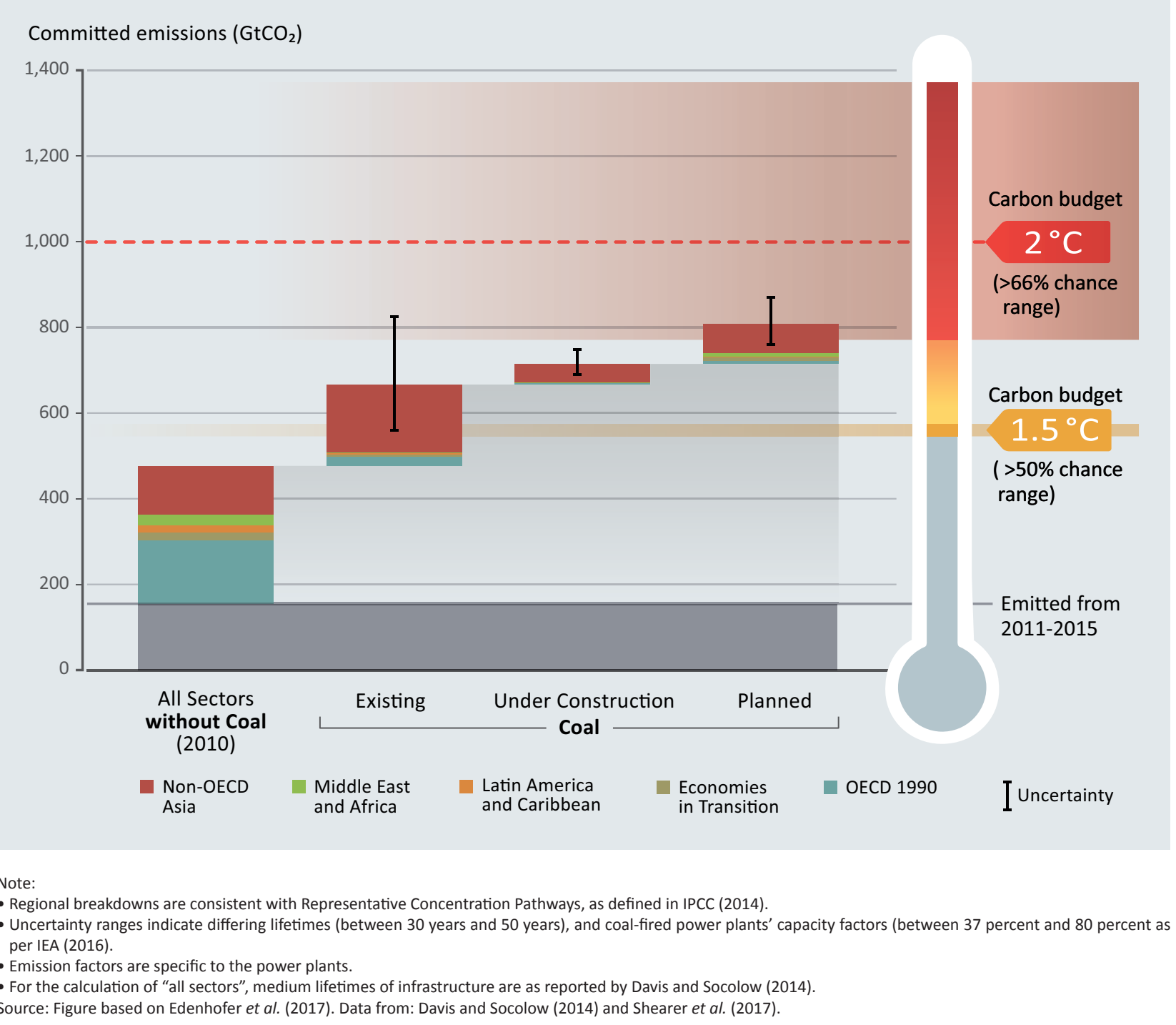

7 The slowdown of China and India is significant because together the two countries accounted for 86 percent of all new capacity between 2006 and 2016. Both countries face a marked slowdown in the anticipated domestic demand for new coal power, due to overcapacity in China and a downturn in solar prices in India (Shearer et al. 2017, see also section 5.3). 
Table 5.1: Committed carbon dioxide emissions for coal-fired power plants, in $\mathrm{GtCO}_{2}$, by status and region

\begin{tabular}{|c|c|c|c|c|c|c|}
\hline Scenario & Announced & Pre-permitted & Permitted & Construction & Operating & Total \\
\hline East Asia & 12.19 & 12.34 & 6.30 & 30.41 & 126.41 & 187.66 \\
\hline South Asia & 6.21 & 9.87 & 5.89 & 8.28 & 27.42 & 57.67 \\
\hline South-East Asia & 7.00 & 5.78 & 2.63 & 5.21 & 8.95 & 29.60 \\
\hline European Union & 0.60 & 0.66 & 0.17 & 1.14 & 7.22 & 9.79 \\
\hline Non-EU Europe & 4.86 & 5.30 & 1.70 & 0.44 & 3.56 & 15.87 \\
\hline Middle East and Africa & 5.83 & 1.16 & 1.94 & 2.14 & 2.46 & 13.52 \\
\hline Latin America & 0.61 & 0.17 & 0.28 & 0.37 & 1.74 & 3.18 \\
\hline Eurasia & 1.65 & 0.00 & 0.00 & 0.20 & 2.69 & 4.54 \\
\hline North America & 0.00 & 0.00 & 0.15 & 0.00 & 8.85 & 9.01 \\
\hline Australia and New Zealand & 0.00 & 0.00 & 0.00 & 0.00 & 1.14 & 1.14 \\
\hline Total & 38.97 & 35.28 & 19.08 & 48.20 & 190.44 & 331.97 \\
\hline
\end{tabular}

Note:

- The figures take into account the remaining lifetimes of existing plants.

- A lifetime of 40 years is assumed for newly constructed power plants.

- European Union data refers to the current 28 Member States. North America refers to both Canada and the United States.

- It is assumed that not all permitted, pre-permitted and announced power plants come online.

Source: Edenhofer et al. (2017) and Shearer et al. (2017).

Phasing out coal can have important societal benefits, going beyond climate change mitigation. Key among these are improved air quality, especially reduced particulate matter and reduced emissions of sulphur dioxide and nitrogen oxides (IEA/OECD 2016 and West et al. 2013) (Chapter 6), and increased water availability (Zhou et al. 2016). However, a transition away from coal can be expected to be politically difficult (Vogt-Schilb and Hallegatte 2017). Meanwhile, cobenefits and rapidly decreasing costs of alternatives ${ }^{8}$ might not suffice to achieve a transformation of the scale, and at the speed, that is required to meet international climate targets. Investment into coal can also be attractive, as it can support other societal goals, such as cheap energy supply, energy security or energy access (Jakob and Steckel 2016). There is also limited evidence that long-term climate targets alone are impacting current investment decisions. Climate policy may not be viewed as credible by fossil fuel investors, for whom returns on continued investment may be assured by (i) lobbying (Dolphin, Pollitt, and Newbery 2016; Kim, Urpelainen, and Yang 2016), (ii) market design, or (iii) limited implementation of domestic policies to meet emission reduction targets (Nemet et al. 2017). Without credible additional policies, coal will likely remain attractive in many countries, due to its technological maturity, wide availability and relatively low price (ignoring externalities) (Edenhofer et al. 2017; Steckel, Edenhofer, and Jakob 2015).

If climate policies are to be implemented, they will need to be supported to ease the social and economic burden of adjustment (Trebilcock 2014). For example, distributional effects that might result from such policies, be it by increasing energy prices (Sterner 2012) or potential job losses in the industry (Arent et al. 2017), can be a major stumbling block for a transition away from coal. 


\section{Box 5.1: Stranded assets}

The term 'stranded assets' is used to describe various situations (Caldecott 2017):

- Assets that are lost because of the impact of climate change itself.

- Man-made capital that has to be retired prematurely or is underutilized, because of direct or indirect climate policies (such as coal power plants that become unprofitable after a carbon price is implemented) (Guivarch and Hood 2011; Wynn 2016), or which can simply no longer compete against the falling costs of alternative technologies (BNEF 2017; IEA-RETD 2016).

- Fossil fuel resources that cannot be burned if a given climate target is to be reached, also called 'unburnable carbon' (McGlade and Ekins 2015).

A number of studies have shown that the $2^{\circ} \mathrm{C}$ target requires early retirement of coal power plants (Guivarch and Hood 2011; Pfeiffer et al. 2016; Rogelj et al. 2013), and that the longer ambitious mitigation action is delayed, the more the rate of retirement increases (Bertram, Johnson, et al. 2015; Johnson et al. 2015; Luderer et al. 2017). Iyer et al. (2015) estimate that catching up with $2^{\circ} \mathrm{C}$-consistent pathways would involve stranding about $1,500 \mathrm{GW}$ of coal and gas power plants worldwide after 2030, while Johnson et al. (2015) estimate that a carbon price consistent with the $2^{\circ} \mathrm{C}$ target would strand at least US\$165 billion worth of coal plants worldwide.

Furthermore, stringent emission reductions translate into substantial upstream unburnable carbon assets, where the emissions embodied in fossil fuel reserves already exceed extraction budgets consistent with $1.5^{\circ} \mathrm{C}$ or $2^{\circ} \mathrm{C}$ (McGlade and Ekins 2015), while $\mathrm{OCl}$ (2016) have calculated that developed coal reserves (that is, current mining areas) already exceed the budget for the $1.5^{\circ} \mathrm{C}$ target. The lower capital intensity of coal (compared to oil and gas) means lower costs of stranding, but does point to both loss of value invested in coal producers (about US\$800 billion according to IRENA (2017b), and potential wasted capex in mining (worth US\$177 billion) if climate policies are later implemented successfully (Carbon Tracker Initiative 2015). Investor-owned firms hold lower reserves than state-owned companies and nation states, thus state-owned companies and nations may pose a greater risk to exceeding the carbon budget (Heede 2014; Heede and Oreskes 2016), equity considerations notwithstanding (see also section 2.2).

\subsection{Incentivizing and managing a smooth transition}

Policy instruments will be needed to incentivize the transition, both with respect to avoiding lock-ins, and facilitating the phase-out of existing stocks, including retrofitting them with CCS where feasible?

\subsubsection{Policy instruments}

Global climate policies in general can be organized along different metrics: market-based economic instruments (notably taxes and subsidies, tradable allowances or credits, and border tax adjustments) (Kolstad et al. 2014), regulatory non-market-based approaches (such as standards, and non-compliance penalties), and complementary policy instruments (notably government provision of goods and services) (Oei and Mendelevitch 2016). It is increasingly acknowledged that a transition to a low-carbon economy will require adjustment to a variety of fiscal and normative rules that have an impact on investment decisions (OECD 2017). This section assesses possible policy interventions, and how their introduction can be managed in a socially balanced way. Coal phase-out would have different requirements in different geographies for existing coal plants, recently built coal plants, and those in the pipeline. Therefore, a different combination of these instruments might be necessary.

\section{Market-based instruments}

The economically efficient approach to cutting global coal use (without CCS), as part of an overall drive to reduce carbon emissions, would have governments remove coal subsidies, enforce Pigouvian taxes on local air pollution, and use a carbon price to internalize the global warming impacts of burning coal. A carbon price creates incentives for markets to use all available levers to reduce emissions, and should theoretically result in a broadly cost-effective overall emissions reductions outcome (Cramton et al. 2017; Nordhaus 1991; Pearce 1991; Pigou 1920). Pricing carbon strongly disincentivizes the use of coal, as it is the most emissions-intensive fossil fuel.

Many countries have emissions trading and other forms of carbon pricing schemes in place that, in 2016, covered 13 percent of global greenhouse gas emissions (World Bank and Ecofys 2016). However, the resulting carbon prices are typically much lower than the social cost of carbon (the estimated monetized negative impact of climate change caused by greenhouse gas emissions) and lower than the rates required to achieve significant reductions in coal use.

Instead of being taxed, in many countries fossil fuel consumption and production are subsidized, with fiscal subsidies to fossil fuel production and use being estimated to be over US\$300 billion, or around 0.4 percent of global

$9 \quad$ Note that application of CCS in the coal sector might result in a prolonged usage of coal and therefore allow for a longer transition period. 
gross domestic product in 2015 (Coady et al. 2016) ${ }^{10}$. Most of these fiscal subsidies were for oil and gas, with only a relatively small amount for coal. The picture changes dramatically once the lack of taxation of negative externalities of fossil fuel use is accounted for. Comparing actual taxes on coal with the estimated damage to society from air pollution reveals an implicit global subsidy to coal of US\$2,400 billion in 2015, or US\$3,100 billion (half of total implicit to all fossil fuels) if the damage to climate is accounted for (Coady et al. 2016).

In the absence of full implementation of carbon prices, coal taxes could potentially reduce carbon leakage (Collier and Venables 2014), provide credible long-term price signals, and reduce (or even avoid) carbon lock-ins (Lazarus, Erickson, and Tempest 2015). When coordinated among major coalproducing countries, they could raise global coal prices and lower global coal consumption, and hence reduce emissions (Mendelevitch, Richter, and Jotzo 2015).

\section{Non-market-based instruments}

Implementing carbon prices that are sufficiently high might not be politically feasible (section 2.2). Hence, complementing a carbon price - or even temporarily substituting it with alternative policy instruments such as performance standards, feebates, or targeted financial instruments (such as subsidized loans) that apply only to new, clean power plants can avoid early retirement of existing plants, thus preserving vested interests, and ease the phase-out (Bertram, Johnson, et al. 2015; Rozenberg, Vogt-Schilb, and Hallegatte 2017). Preventing the construction of new assets is especially vital in countries that currently invest in coal (figure 5.1 and table 5.1). In contrast to a high carbon price, standards, mandates or feebates on new power plants do not prompt current producers to underutilize existing coal plants. While they would avoid stranded assets (box 5.1), they would likely redirect new investments towards greener options. Stated differently, the stock of coal power plants would stop increasing, and instead decrease progressively as plants aged and were retired (Rozenberg, Vogt-Schilb, and Hallegatte 2017).

Another policy option in this direction is to enact a moratorium (a ban) on new coal power plants or coal mines beyond a specific timeline (Bertram et al. 2015; Pfeiffer et al. 2016; Rozenberg, Vogt-Schilb, and Hallegatte 2017). Those approaches can have advantages in political economy terms, in that they impact owners of existing coal power plants and mines less, and hence reduce resistance to change (Rozenberg, Vogt-Schilb, and Hallegatte 2017). When a high carbon price is not feasible, typically due to political economy considerations, a low price coupled with a moratorium and other complementary policy instruments, such as support for low-carbon electricity generation capacities, could indeed help make progress towards the $2^{\circ} \mathrm{C}$ target, while drastically limiting stranded assets (Bertram et al. 2015).

10 We added together 'pre-tax subsidies' and 'foregone consumption tax revenue' from IMF figures to calculate this total, which we call 'fiscal subsidy'. The IMF adds the failure to internalize externalities related to fuel usage to arrive at its headline 'fossil fuel subsidy' figure.

\section{Complementary instruments}

Even if complemented with non-market-based instruments, carbon prices alone would fail to overcome other market failures, notably network externalities or imperfections in the capital market. While usually assumed to play a key role in future electricity supply, renewable energy technologies, such as wind or solar power, require additional infrastructure to provide a reliable electricity supply (IPCC 2014) ${ }^{11}$. To support their increased deployment, governments can invest in improved grid infrastructure and storage facilities to address variable availability (Hirth, Ueckerdt, and Edenhofer, 2015). Smart grids, including bidirectional power flows and metering at the individual level, could further enhance system efficiency, in turn increasing the market share of clean technologies (Iqtiyanillham, Hasanuzzaman, and Hosenuzzaman 2017; Meadowcroft et al. 2017; Rifkin 2011).

Being more capital-intensive than coal, low-carbon technologies are sensitive to perceived investor risks, both political and financial, and to other capital market constraints. For example, regional differences in the weighted average costs of capital play a more important role in evaluating investments in renewable energy technologies than differing natural conditions, such as differences in solar irradiation or wind potentials (Ondraczek, Komendantova, and Patt 2015, for photovoltaic technologies). These differences can lead to carbon prices alone being unable to trigger a transition away from coal (Hirth and Steckel 2016).

To address the existing investor risks, and improve the attractiveness of alternatives to new coal investments, instruments for de-risking clean investment are suggested for all financial institutions and governments across the world. These include, for example, support for policy design, identification and removal of regulatory hurdles, improvement of institutional capacity, and provision of bridging investment subsidies. Such financial de-risking instruments can transfer risk from private investors to public actors. A range of 'private sector instruments', such as guarantees, subordinated debt or equity, is already available (Torvanger et al. 2016). National or multilateral development banks could employ public financing to mobilize private investments, which contribute to a declared development target. Concessionary climate finance can also be used to de-risk low-carbon investments (Steckel et al. 2017), while coal investment could also be made less attractive. In 2016, public finance by G20 countries for coal projects outstripped financing for renewable projects by four to one internationally (Chen 2017).

11 Additional infrastructure investments would also be necessary for increasing the deployment and use of CCS. Recent trends suggest that a large-scale utilization of CCS as decarbonization technology for the electricity sector is unlikely, as the combination of renewables with storage and demand-side technologies provides the cheaper alternative (Breyer et al. 2017; Löffler et al. 2017). Nevertheless, large-scale power storage technologies to match demand-supply mismatches is still a technological challenge and requires additional research (Annaluru and Garg 2017; Park and Lappas 2017). Critically, the ministers of 26 countries agree that without overt policy support (as has been provided in the past to renewable, nuclear, and power storage technology), CCS will encounter challenges entering the market and achieving emissions reductions. 


\subsubsection{Managing the transition}

Some of the stakeholders negatively impacted by the transition away from coal, including workers, coal owners, and energy users relying on low prices, may have the power to veto proposed reforms (Arent et al. 2017; Kern and Rogge 2016; Sovacool et al. 2016; Trebilcock 2014). As one example, governments that have tried to pass fossil fuel subsidy reforms on the grounds of technical soundness and administrative feasibility, without taking into account the political economy of reforms, have often failed (Bazilian and Onyeji 2012; Rentschler and Bazilian 2016; Sdralevich, Sab, and Zouhar 2014).

A review of previous experience with reforms in the energy sector provides guidance on measures to navigate the political economy of phasing out coal (Fay et al. 2015; Louie and Pearce 2016; Sovacool et al. 2016; Vogt-Schilb and Hallegatte 2017) ${ }^{12}$. These include managing the impact on workers, coal owners, industry and energy users, as well as the role of communication.

\section{Managing impacts on workers}

A transition away from coal affects many different groups of workers. Historically, transitions away from coal have often left workers and communities to bear the brunt of job losses and deindustrialization (Caldecott, Sartor, and Spencer 2017; Trebilcock 1981). While macroeconomic analyses of the employment impact of switching to more renewable energy usually find net job creation (Cameron and van der Zwaan 2015; Perrier and Quirion 2016; Ragwitz et al. 2009; Wei, Patadia, and Kammen 2010), they may mask job losses in other locations, and might hence be a poor indicator for a just transition ${ }^{13}$. Indeed, case-by-case analyses are often needed to assess the kinds of jobs created, their wages and conditions, the skills required by these jobs, and whether they can be accessed by roughly the same population group affected by a coal phase-out (Miller, Richter, and O'Leary 2015).

Support, such as wage subsidies (to encourage hiring in expanding sectors) and unemployment insurance for displaced workers, can help effectively mitigate most of the losses at generally modest costs (Louie and Pearce 2016; Porto 2012). More generally, research on past transitions shows that social dialogue, social protection and economic diversification are instrumental in ensuring just transitions (Caldecott, Sartor, and Spencer 2017; Galgóczi 2014; Healy and Barry 2017). This can be expected to be more challenging in developing countries, where resources and institutional capacities are scarcer and the mining workforce is semi- or unskilled.

\section{Managing impacts on coal owners and industry}

A coal phase-out would lead to a devaluation of existing coal assets (section 5.1 and box 5.1). In a situation in which

12 Including energy taxation, energy subsidy removal, and carbon taxes, as well as adjustment packages for, and re-training of, energy sector workers.

13 The International Labour Organization has produced the Guidelines for a Just Transition Towards Environmentally Sustainable Economies and Societies for All (International Labour Organization 2015), which are explicitly recognized in the Paris Agreement (United Nations 2015). the competitiveness of other industries was reduced, for example following a potential increase in energy prices associated with a coal phase-out process (Branger and Quirion 2014), the prospects of successfully completing a coal phase-out process would be compromised ${ }^{14}$. Model analyses find that losses incurred by coal owners could be compensated by governments redistributing a fraction of the carbon rent ${ }^{15}$ (Arent et al. 2017; Bauer et al. 2016; Goulder and Schein 2013; Kalkuhl and Brecha 2013). Several countries or regions, such as Alberta in Canada, have coal phase-out agreements, to ensure an efficient, progressive, and politically acceptable reduction in coal power generation (Jordaan et al. 2017) ${ }^{16}$. In the United Kingdom, compensatory subsidies were given to support the industry in its efforts to compete in the reformed electricity market (Oosterhuis and Brink 2014).

\section{Managing impacts on energy users}

The negative impacts of a coal phase-out on poor and middle-class energy users, notably through increased electricity prices, can also challenge the political feasibility of reforms, regardless of the progressivity or regressivity of increased coal prices on consumers (Lindebjerg, Peng, and Yeboah 2015; Arze del Granado, Coady, and Gillingham 2012). Compensatory redistributive policies can mitigate the distributional impacts to a large extent, especially if a fraction of revenues is recycled into transfers to poor and middle-class households (Brenner, Riddle, and Boyce 2007; Burtraw, Sweeney, and Walls 2009; Callan et al. 2009; Coady, Parry, and Shang 2017; Gonzalez 2012; Liang and Wei 2012; Rausch, Metcalf, and Reilly 2011; Symons, Proops, and Gay 1994). This can be done through different instruments that specifically target the subset of the population that is directly affected. For example, direct cash transfers can be used as compensatory measures, where appropriate systems exist (Rentschler 2015; Robles, Rubio, and Stampini 2015; World Bank 2015). Alternatively, compensation can be offered through in-kind measures, such as electrification in poor and rural areas, distributing efficient light-bulbs, improving public transport, or eliminating fees at government-run schools (Coady, Parry, and Shang 2017; Fay et al. 2015; Garg et al. 2017).

Redirecting resources, from coal use to the provision of public goods, helps governments garner support for coal phase-out plans (Stiglitz and Stern 2017). For instance, governments can use revenues from taxation or savings from avoided fossil fuel subsidies to invest in public infrastructure (Jakob et al. 2016, 2015), energy infrastructure ${ }^{17}$, or social assistance (Hallegatte et al. 2016). Governments can also

14 These kinds of dislocations played a role in the 2016 US elections, where loss of coal jobs over the past 20-30 years affected entire communities and states, leading to massive shifts in voting behaviour.

15 The 'carbon rent' describes the economic value of being allowed to emit, which would be captured by governments implementing a carbon price, that is a tax or an emissions trading scheme.

16 To do so, the government of Alberta committed to "provide transition payments to the companies which were originally slated to operate their coal-fired units beyond 2030". These payments "represent the approximate economic disruption to their capital investments" (Government of Alberta 2015).

17 See, for example, the case study on India, in Section 5.3. 
use those savings to reduce income taxes and payroll taxes, to correct impacts on those consumers who do pay taxes (Metcalf 1999).

Cash transfers (to directly affected communities) and tax reductions (benefiting all citizens) are not necessarily mutually exclusive (Parry and Williams 2010). Indeed, a combination of transfers and a reduction of distortive taxes funded by energy taxes could foster more progressive income distribution patterns, and drive a reduction in low-cost coal usage (Bach et al. 2002).

\section{Communicating policy packages}

Communicating potential benefits and involving stakeholders is an essential precondition for a successful transition away from coal (Healy and Barry 2017). Coady et al. (2017), comparing 32 energy pricing reforms, found that the absence of an effective communication strategy was decisive in unsuccessful past reforms.

\subsection{Country studies}

This section presents policies, measures and instruments being used by major coal users and producers around the world, to highlight the challenges and opportunities associated with coal phase-out. Success rates differ and major gaps need to be bridged for a quicker phase-out. However, the breadth of positive experiences is enough to offer a buoyant outlook on the overall direction.

\subsubsection{Australia: coal exports and policy challenges} In Australia, which has relied heavily on its abundant coal reserves for domestic electricity production, transitioning away from coal is likely to pose significant policy challenges. It is widely anticipated that the number of coal-fired power plants will continue to decline, as plants come towards the end of their planned lifetimes. A number of older coal-fired power plants have been shut down, and new coal-fired capacity is now widely seen as 'uninvestable' by the private sector, due to carbon risks and because renewable energy is rapidly gaining a cost advantage (Morgan 2017).

Being the world's second largest coal exporter ${ }^{18}$, the even bigger question is the future of coal exports. Thermal coal exports, which are directly dependent on other countries' climate change policies, currently stand at around 200 million tonnes per year (Australian Government 2017), almost double the volume from a decade ago. Large-scale expansion of coal mining for export from inland areas of north-eastern Australia is under discussion.

There is currently no policy to accelerate the phase-out of coal in domestic use, and no systematic framework to ease the transition away from coal in regions where large coal-based infrastructure exists, or where coal is mined. Australia's experience with climate policy has been a difficult one, with the issue heavily politicized, and emission reduction policy instruments the subject of political contest.

18 Note that Australia is the largest exporter of coal when also accounting for metallurgical coal.
Australia is the only country that introduced a full-scale carbon pricing scheme (in 2012) and then abolished it (in 2014). Policy uncertainty is deep-seated in the energy sector, stifling investment (Jotzo, Jordan, and Fabian 2012).

\subsubsection{China: slowly turning the wheel}

Being the world's largest consumer of coal (BP, 2017), and relying largely on coal in its energy supply, China has (in its Nationally Determined Contribution) committed to achieve a peak in coal emissions by 2030 , and eventually diversify its energy supply. Since 2013, coal consumption seems to have stalled, with some claiming that the period of major growth in China's coal consumption is already over (IEA 2016) or that China's coal consumption has already peaked (Green and Stern 2017; IEA 2016).

While it is too early to interpret current developments, China is adopting a wide range of cross-sectoral policies and measures to reduce its coal production and consumption, largely motivated by the need to tackle local air pollution (Chong et al. 2015; Hao et al. 2016). Specific policies include phasing out coal in key cities and regions to improve air quality, improving the efficiency of coal-fired power plants and industrial boilers and furnaces, mandatory closure of old and inefficient coal mines, as well as coal-fired power plants, and industrial facilities. For instance, during the 2011-2014 period, $24 \mathrm{GW}$ of coal-fired power plants and 473 million tonnes of coal production capacity were closed (Hart, Bassett, and Johnson 2017; NDRC 2016). The Government also promotes the development of low-carbon energy sources, for example by feed-in tariffs for renewable energy and granted grid access. The newly introduced carbon dioxide emissions trading scheme can also be expected to make coal consumption relatively unattractive (Swartz 2016). In addition, to address the overcapacity of industries and power generation, the Government has also halted the approval of new capacity ${ }^{19}$, although it remains to be seen how many of these projects will be cancelled or just postponed until after 2020. To soften the social side effects of closing insolvent, polluting and inefficient state-owned coal mines, an Industry Adjustment Fund has provided Chinese Yuan100 billion (approximately US\$15 billion) to manage unemployment in the steel and coal sectors (NDRC 2016).

Despite those developments, China still added $14 \mathrm{GW}$ of new coal-fired power generation capacity during the first half of 2017. Even though this increase is 52 percent smaller than that during the same period in 2016 (CEC 2017), at the beginning of 2017 there were still $280 \mathrm{GW}$ in the pipeline, of which $145 \mathrm{GW}$ were under construction (Shearer et al. 2017). Facing a marked slowdown in new coal capacity in the country, the central government has encouraged Chinese coal enterprises to seek opportunities outside the country (Bal Kishan Sharma 2016). In recent years, China has become a major player in developing coal-fired power plants abroad, including providing the funding, equipment and labour. By the end of 2016, China had been involved in the construction of a total capacity of $250 \mathrm{GW}$ of coal-fired

19 In the second half of 2016, $120 \mathrm{GW}$ acronym of power plant capacity under construction and planned were halted (Zhang 2017). 
capacity at different stages (that is, from the planning phase to plants that were operational in 2016) across the globe (Ren, Liu, and Zhang 2017).

\subsubsection{Europe: Learning from past experiences}

In terms of managing a coal phase-out, trends in European countries are diverging, roughly along an east/west divide. Most Western European countries have either already phased out coal (Belgium, Cyprus, Luxembourg, Malta, and the Baltic countries), agreed on a phase-out path within the next 10 years (Portugal, Finland, the United Kingdom, Denmark and Austria), or are currently discussing pathways with declining coal demand in the medium term (Germany, France, Spain, Italy and the Netherlands) (Graichen, Kleiner, and Buck 2016). Lessons from these experiences can be drawn to design future coal phase-out pathways. The closure of most steam coal mines in Western Europe (located mainly in the United Kingdom and Germany) at the end of the 20th century was based on economic reasoning. Public subsidies were granted with the aim of securing supply and easing the social impact of reduced coal production (Fothergill 2017; Galgóczi 2014; Matthes et al. 2015). Local supplies were at first replaced by steam coal imports, and eventually also by natural gas. The latter was supported by European Union policies, in combination with national measures such as the introduction of a carbon dioxide price floor and emission performance standards in the United Kingdom (Fothergill 2017; Matthes et al. 2015).

Public financial support in Western Europe has been shifting from conventional technologies such as coal (or nuclear) towards renewables. Energy transitions, as seen in countries such as Denmark (Danish Energy Agency 2017; Gerdes 2016) and Germany (Matthes 2017; Renn and Marshall 2016), have been facilitated by cooperation between unions, employers, governments and research institutions, in a continuous process spanning several decades (Sovacool 2017).

In Eastern Europe, countries (most notably Poland) continue to support coal-fired electricity with the aim of backing up their domestic coal production. Energy security and energy prices are major political concerns, while European Union climate policy and the German "transition towards sustainable energy" are regarded rather critically across political parties (Bouzarovski and Tirado Herrero 2017; Marcinkiewicz and Tosun 2015; Szulecki et al. 2016). As a consequence, coal mining companies, under economic pressure due to the plummeted global coal prices, are given (indirect) state subsidies or are renationalized (Jonek Kowalska 2015; Widera, Kasztelewicz, and Ptak 2016). Debates on potential coal phase-out scenarios are met with great scepticism, due to previous negative experiences with (coal sector) restructuring programmes having resulted in high unemployment, as they failed to create jobs in other sectors (Suwala 2010; Szpor 2017). However, missing the opportunity to start the necessary structured phase-out process might result in difficulties to transform the industry in a socially balanced way, risking much bigger complications in the future for the regions involved. In turn, in some countries, ongoing lock-ins and related unwillingness to address a transformation might also negatively impact future approaches to European Union climate policy (Marcinkiewicz and Tosun 2015).

\subsubsection{India: balancing multiple objectives}

India's starting point is the urgent need for poverty alleviation and more energy for development: in 2016, 21.9 percent of Indians lived below the national poverty line, while more than 240 million people lacked access to electricity (ADB 2017; IEA 2016). The country, in line with many others, faces a dilemma in addressing its developmental goals: it needs to respond to demands in poverty reduction, energy access and urbanization, while reconstructing its development pathway towards a cleaner energy system that has been coupled historically with fossil fuel use (Arent et al. 2017).

Coal has remained the mainstay of India's electricity generation, contributing 61 percent of total national generation capacity (Central Electricity Authority Government of India 2016). With the goal of providing power more efficiently to more people, India is investing in modernizing its power plant fleet. Since 2006 the country has added $151 \mathrm{GW}$ of new coal power, making a total of $218 \mathrm{GW}$ as of June 2017, with about 75 percent of this capacity being subcritical (Shearer et al. 2017). Coal-based power plants closed or declared non-functional due to their inefficiency and pollution amounted to $18.5 \mathrm{GW}$ in 2013-2014, $23 \mathrm{GW}$ in 2014-2015, 26.8 GW in 2015-2016, and $30.5 \mathrm{GW}$ in 2016-2017) (Ministry of Power, Government of India, n.d.). There are plans to shut down about $37 \mathrm{GW}$ of antiquated, heavily polluting subcritical coal plants in the near future (Singh 2016).

Coal use in India is subject to a form of carbon tax. Total collections of around US\$ 9 billion until June 2017 are mainly used to support renewable energy programmes. India plans to install $175 \mathrm{GW}$ of renewable power by 2030 , which includes $100 \mathrm{GW}$ of solar photovoltaic power (Gol 2015). $4 \mathrm{GW}$ of solar-powered capacity was added to the grid in 2016, that is double the addition of the previous year (IEA 2017).

Energy security concerns are often presented as a major barrier for India to quickly and decisively turn away from domestic coal (Garg and Shukla 2009). In addition, coal production, transport and usage and ash disposal employ almost one million people ${ }^{20}$. Income from coal royalties constitutes almost 50 percent of total earning of states such as Chhatisgarh, Jharkhand and Odisha (Mondal 2017), which are some of the least developed large Indian states. Therefore, and perhaps more so than in other countries, coal use policies have strong socio-economic and sociopolitical linkages. A successful energy transition in India hence requires a broader perspective that includes economic development and measures that balance the associated social transformation, notably protecting displaced workers (Khosla et al. 2015; Reddy 2016).

20 Coal mining is the second largest employer in India (the largest is the railroads, which ship coal as their number one product and revenue source). 


\subsubsection{Indonesia: covering increasing demand with domestic resources}

In 2015, Indonesia was the world's fifth largest coal producer and the largest steam coal exporter in the world, exporting mainly to neighbouring countries, such as China, India, Japan, the Republic of Korea, and the Philippines (IEA/OECD 2016). In the last two decades, coal production has accelerated sharply, but the most recent years have seen a decrease in both production and exports, particularly to China and Japan. Coal contributes to 2.4 percent of Indonesia's gross domestic product (GDP), and in 2014 led to US\$22 billion in exports (PWC Indonesia and ICMA 2016).

With Indonesia increasingly using its coal for domestic purposes, it is now also the world's eighth largest coal consumer. About $27 \mathrm{GW}$ of coal capacity provide more than half of the electricity generated in the country (MEMR 2016). Existing power plants are comparably inefficient and have low environmental standards, leading to high emissions of nitrogen oxides, sulphur dioxide, and particulate matter (Centre for Science and Environment 2017).

Indonesia's electricity demand is expected to increase rapidly, as millions will gain access to electricity (Enerdata 2015). The country aims to provide an increasing share of energy by domestic sources, including coal, although due to lower-than-expected economic growth rates, $7 \mathrm{GW}$ of planned coal-fired power plants were recently deferred in Sumatra and Java. The state-owned utility (PLN) nevertheless estimates that, in the next decade, $77 \mathrm{GW}$ of additional capacity will be needed, of which $32 \mathrm{GW}$ are planned to be covered by coal plants (MEMR 2017). Building those would cause coal use for electricity generation to triple by 2025 . To secure domestic supply, the country has announced in its National Energy Plan that it will regulate exports.

Indonesia is also rich in other energy sources. The country is a large producer and exporter of natural gas, and has large potential for renewable energy, not only in solar, wind and biomass, but also hydropower and geothermal power, the latter of which could, in some cases, produce power at a relatively low cost (IRENA 2017a). There are plans for exploration and possible significant expansion of hydropower and geothermal power, but implementation tends to face significant practical hurdles.

\subsubsection{South Africa: political lock-in}

The lock-in of interests, institutions, and infrastructure may slow down the process of coal phase-out in South Africa, despite economics favouring low-carbon alternatives. South Africa is a good example of how the politics of a country may make incentivizing a transition away from coal substantially more difficult. The country depends on coal for the production of 90 percent of its electricity, in a sector dominated by the state-owned, vertically integrated monopoly Eskom (Eskom 2017).

In scenarios compatible with the $2^{\circ} \mathrm{C}$ target, coal-fired electricity is phased out before 2050 (Burton et al. 2016). Nonetheless, independent power producers are planning, and Eskom is building, new coal-fired capacity at costs that are approximately 40-50 percent higher than the prices achieved for wind and solar photovoltaic in recent renewable energy auctions (CSIR 2016). Independent power producers will receive 30-year power purchase agreements and guaranteed minimum off-take (Baker and Burton, in press). A regulated electricity price, state subsidies, and guarantees on Eskom's debt have offset the large cost and time overruns at plants under construction. Stated differently, although new coal-fired capacity is no longer competitive, as the state-owned monopoly Eskom is not subject to competitive electricity markets, investors in new coal plants are essentially guaranteed returns on their investments through the institutional arrangements in the electricity sector. Furthermore, the grid operator Eskom is able to limit a rapid transition, as it compares long-term prices for new capacity against the fuel costs of depreciated coal plants, without a clear differentiation in the market between overall system efficiency and Eskom's financial interests.

\subsubsection{United States of America: cheap alternatives}

A dramatic reduction in coal use by United States power utilities was facilitated by several factors. First and foremost was the availability of abundant low-cost natural gas, and some expectation that costs would remain low indefinitely. Two major studies (DoE 2017b; Houser, Bordoff, and Marsters 2017) support this view, stating that low-cost gas drove the majority of coal-to-gas fuel changes. Additional factors included conventional pollution controls (such as regulations to reduce mercury emissions), concern over carbon liability (notably through the Clean Power Plan, but also through shareholder votes), and the age of many shuttered plants (some over 60 years old). This suggests that access to sustained low-cost gas can accelerate a coalto-gas transition. Similarly, in regions where gas is scarce or expensive, that transition would be slower (Citi GPS 2015). It should be noted that further closures will continue, but will likely plateau as the oldest, dirtiest, and least efficient plants close.

Recently, a number of policy proposals have emerged to incentivize the deployment of CCS. One of the more promising approaches concerns a production tax credit for CCS, which pays operators for tonnes stored or used (the FUTURE Act (US Senate 2017)). By guaranteeing a fully refundable tax credit for 12 years of US\$50 for saline formation and US\$30 for carbon dioxide use (including Enhanced Oil Recovery), its goal is to create markets for CCS technology and projects such that project financing is possible. Additional proposed policies include a combination of production and investment tax credits (White House 2016, 2015), changing renewable portfolio standards to clean energy portfolio standards (Great Plains Institute 2016), building CCS pipeline infrastructure (DoE 2017a), providing access to master limited partnerships (Coons 2015), and taxexempt debt financing (Portman 2017). 


\subsection{Synthesis and policy discussions}

Phasing out coal consumption in the power sector (without CCS) is an indispensable condition for achieving international climate change targets, but one that is at odds with recent developments. At the global scale, the stock of coal-fired power plants is increasing, as are emissions related to coal. The existing stocks, in combination with what is currently planned and built (assuming standard lifetimes and usage rates), will account for a significant share of the available carbon budget for a $2^{\circ} \mathrm{C}$ target, and would make a $1.5^{\circ} \mathrm{C}$ target probably infeasible. Avoiding further lock-ins is therefore a major and urgent requirement, as is phasing out existing coal use gradually.

Coal is mainly used in the power sector, where cleaner and mature technological alternatives are available at increasingly lower costs. However, the low price (ignoring externalities) of coal, wide domestic availability, and path dependencies under a business-as-usual scenario could make coal an ongoing large investment. Its negative externalities, such as air pollution, land degradation and airborne emissions, are regularly not priced in, leading to economic incentive structures that favour the extraction and use of coal over clean alternatives. Particularly where energy demand is increasing rapidly, investments in coal are still attractive. While case studies suggest that new coal plants are being considered increasingly risky and new investment growth is slowing down, stronger policy interventions are needed to turn the tide.

With regard to a transition away from coal, it is hence pivotal to price in the negative side effects of coal through appropriate mechanisms. Increasing prices would affect the current stock as well as future investments, by making current plants as well as future investments less attractive than other alternatives. Subsidies for coal, where they apply, should be phased out immediately. On the other hand, a carbon price, or pricing coal directly (for example in coal-producing countries) needs to be phased in very soon. This would generate revenues that in turn could help ease the transition, for example by financing public infrastructure, social security systems or investments in clean energy infrastructure.

Even though getting the prices right is highly important, a transformation will likely need to be backed by a set of complementary policy instruments. Their implementation can be expected to be politically challenging. Even though they increase global welfare, policies necessary to phase out coal will negatively affect a society's important interest groups; not only producers and owners of coal, but also workers that are employed in the industry, and households or energy-intensive industry that benefit from current low energy prices. These groups might have the power to veto measures necessary to trigger the transformation. Therefore, for a transformation to be successful, their interests need to be taken into account and addressed by additional measures, be it compensation for higher prices or lost business models, training for workers or the provision of alternative employment options. Examples for successful transformations include introducing phase-out agreements between important stakeholders in a country, phasing out inefficient plants first, reducing coal subsidies and promoting renewable energy.

Scenarios that achieve temperature stabilization well below $2^{\circ} \mathrm{C}$ do not envisage any further room for new investments into coal. Given the difficulty of retiring or phasing out coal once plants are built, it is even more important to ensure that no new coal-fired power plants are constructed, and that carbon lock-in from coal is reduced to a minimum. Financial institutions worldwide should realize that financing coal is quickly becoming riskier, as these investments would become stranded. Energy investments are, however, required to tackle energy poverty in many developing countries, and to upgrade energy infrastructure even in many developed countries, which will need to move towards alternatives. Countries should ensure that alternatives can enter the market easily. This requires investments in the smart grid infrastructure and storage capacities that facilitate the integration of variable, low-carbon alternatives. Additionally, investments in alternatives to coal (such as renewable sources of energy) should be supported, for example by de-risking investments for investors.

Considering the very recent developments of the coal pipeline (that is, power plants that are planned or under construction) gives some reason for hope. The pipeline decreased significantly in 2016 (compared with 2015) and many power plants that were planned have been shelved or even cancelled. Important emerging economies that are largely dependent on coal, such as China and India, have announced policies that address coal consumption from various angles, including price mechanisms and policies that can socially support a transformation.

However, despite the coal pipeline shrinking, there are still large investments in new coal capacities. Some countries have recently announced that they will invest more heavily in coal (often alongside large investments in renewable energy), primarily to cover their increasing energy demands. A transition away from coal will only be successful if poor, fast-growing countries seek low-carbon alternatives to cover their rapidly increasing energy demand. Making those alternatives viable will require strong policies around the globe. Developing and newly industrializing countries will likely need support from the international community to design and implement the policies that are needed to achieve multiple societal objectives, including energy provision and achieving climate change mitigation targets. 


\section{Chapter 6}

\section{Bridging the gap - The role of short-lived climate pollutants}

Lead authors: Zbigniew Klimont (International Institute for Applied Systems Analysis), Drew Shindell (Duke University)

Contributing authors: Nathan Borgford-Parnell (UN Environment), Lena Höglund-Isaksson (International Institute for Applied Systems Analysis), Steffen Kallbekken (CICERO Center for International Climate Research), Johan Kuylenstierna (Stockholm Environment Institute at York), Luisa Molina (Molina Center for Energy and the Environment/ Massachusetts Institute of Technology), Leena Srivastava (TERI University), Shu Tao (Peking University), Chandra Venkataraman (Indian Institute of Technology Bombay)

\subsection{The contribution of SLCPs to climate change - Introduction and framing}

This chapter outlines the opportunities to reduce the emissions gap afforded by limiting emissions of short-lived climate pollutants (SLCPS). This is a topic that has not been included in previous Emissions Gap Reports.

Greenhouse gas (GHG) emission reduction policies contribute to varying degrees to reducing emissions of SLCPs: while methane sources are covered, black carbon sources are only partially covered (for example, through policies to regulate emissions from diesel engines). In light of this, and given that SLCPs have a relatively short residence time in the atmosphere, implementing targeted SLCP reduction measures can provide rapid reductions in global warming. For this reason, this chapter focuses on measures that are specific to SLCPS.

Anthropogenic climate change is largely driven by humaninduced changes in the composition of the atmosphere, including long-lived GHGs (that have lifetimes of approximately eight years or more) and short-lived climate pollutants (that have lifetimes of approximately 20 years or less) (Myhre et al., 2013) ${ }^{1}$. The most recent assessment report by the Intergovernmental Panel on Climate Change (IPCC) found that increases in carbon dioxide $\left(\mathrm{CO}_{2}\right)$ were the largest single contributor to climate change. However, other compounds also play large roles and, for this reason, it is standard practice to include all climate drivers in analyses of historical and projected trends ${ }^{2}$. In sum, although some SLCPs - particularly black carbon - are not explicitly part

1 These groupings of pollutants by lifetime are consistent with the IPCCs Fifth Assessment Report (AR5), and methane is included within both groups.

2 This extends to allowable carbon budgets, for which the IPPC's Fifth Assessment Report presented analyses for both $\mathrm{CO}_{2}$ alone and all climate drivers. of the Paris Agreement, which targets long-lived GHGs only, SLCPs are routinely included in analyses aimed to identify emission trajectories that are consistent with temperature targets.

This report defines the 'emissions gap' as the difference between the emission trajectories resulting from implementation of Nationally Determined Contributions (NDCs), and the trajectories associated with emission scenarios that are consistent with temperature targets, such as the $2^{\circ} \mathrm{C}$ target. For some SLCPs, however, such a definition is problematic. For example, emissions of black carbon can increase relative to current policies under a $2^{\circ} \mathrm{C}$ pathway, due to a greater reliance on biofuels, or growing numbers of diesel vehicles without particulate filters and/or stringent fuel quality standards. In light of this, the definition of 'emissions gap' that applies to this chapter is "the difference between emission levels that are consistent with emission trajectories resulting from NDC implementation, and the lowest emission levels achievable using current mitigation technologies and policies". For methane and hydrofluorocarbons, results are presented in $\mathrm{CO}_{2}$ equivalents $\left(\mathrm{CO}_{2} \mathrm{e}\right)$. Additionally, the temperature response associated with mitigation measures covering all SLCPs is presented ${ }^{3}$.

Strategies to reduce SLCPs will typically target methane, tropospheric ozone, black carbon and hydrofluorocarbons. Other short-lived climate forcers, such as sulphur dioxide and organic carbon, lead to cooling and are therefore not targeted. These SLCP reduction strategies will sometimes affect only a single pollutant, for example intermittent rice irrigation affects methane alone. Nonetheless, most strategies to reduce SLCPs will affect multiple pollutants. It follows that an evaluation of mitigation measures must

3 The analysis presented in this chapter cannot assess the emissions gap in terms of national pledges, as most countries pledged reductions in $\mathrm{CO}_{2} \mathrm{e}$. 
examine emissions of both long-lived GHGs and all SLCPs, to assess the net impact on warming.

Sustained SLCP reduction strategies can help limit long-term warming, especially when combined with $\mathrm{CO}_{2}$ reduction, and therefore contribute to closing the emissions gap. A complete separation between $\mathrm{SLCP}$ and $\mathrm{CO}_{2}$ reductions is not possible for two reasons. Firstly, decarbonization strategies will lead to a reduction of some SLCPs, including black carbon, about one third of which originates from fossil fuel sources (Bond et al., 2013; Klimont et al., 2017). Secondly, efficiency increases can reduce all types of emissions, but many SLCP mitigation strategies are distinct from strategies to reduce $\mathrm{CO}_{2}$, especially in the near term, as many decarbonization measures require lengthy structural changes.

Reductions in SLCPs have the potential to decrease the rate and degree of warming in the next few decades, with SLCP mitigation having a rapid effect on temperature. In contrast, reducing $\mathrm{CO}_{2}$ (and associated emissions, which often include cooling agents such as sulphur dioxide or nitrogen oxides) tends to reduce warming more slowly. Hence, the climate impact of mitigating SLCPs is not equivalent to reducing $\mathrm{CO}_{2}$, which is a much longer-lived GHG, owing to the differing temporal evolution of the radiative forcing response to these emissions (Myhre et al., 2013). It has been estimated that SLCP mitigation has the potential to avoid up to $0.6^{\circ} \mathrm{C}$ of warming by mid-century (for example $\mathrm{Hu}$ et al., 2013; Rogelj et al., 2014; Shindell et al., 2012), while aggressive $\mathrm{CO}_{2}$ mitigation in a comparable scenario leads to less than half as much near-term reduction in warming (Hu et al., 2013). SLCPs will also affect long-term global mean temperatures. In that context, the impact of sustained emissions changes of SLCPs can be usefully compared with pulse emission changes of long-lived GHGs (Allen et al., 2016). Furthermore, existing air quality and $\mathrm{CO}_{2}$ mitigation policies will reduce emissions of sulphate and nitrogen oxides, which will drive up warming in the near term (despite improving air quality). Enhancing SLCP mitigation measures can help counteract this unmasked warming.

When considering opportunities to reduce the emissions gap, it is also important to consider how the measures and strategies adopted to cover the temperature gap will affect societies, human well-being and health, as well as ecosystems. The text of the Paris Agreement commits the world to an ambitious long-term temperature target (Article 2a and 4.1), but places this ambition within the context of "sustainable development and efforts to eradicate poverty." Through the lens of sustainable development, the path that the world choses to reach the long-term climate target is as important as achieving the target itself, particularly for those that are already suffering from the impacts of climate change (Shindell et al., 2017a).

In this context, near-term mitigation of SLCPs is perhaps even more important. In addition to the fast temperature response, reductions of SLCPs would contribute to reducing climate change impacts that are based on cumulative heat uptake (for example, sea-level rise, and glacier and ice sheet melting). They would also help reduce the likelihood of passing irreversible thresholds and triggering large positive feedbacks. In doing so, they would strengthen other climate change mitigation efforts (Shindell et al., 2017a; Xu and Ramanathan, 2017). SLCP reductions also improve air quality, with benefits for human health, agricultural yields, rainfall stability and other environmental and social policy goals (section 6.5).

Finally, cutting levels of black carbon and other SLCPS delivers short-term benefits, which may help governments to increasingly view collective action on climate change as feasible (Victor et al., 2015). Capitalizing on efforts such as the Climate and Clean Air Coalition or the Montreal Protocol on Substances that Deplete the Ozone Layer can increase the momentum for climate change mitigation (Sabel and Victor, 2015).

\subsection{Recent SLCP emissions trends and outlook towards 2030}

Efforts to estimate emissions of SLCPs and their future trends have intensified, following a global assessment of emission trends for black carbon and tropospheric ozone precursors (UNEP/WMO, 2011). Many recent studies have focused on improving the understanding about emissions from poorly quantified sources ${ }^{4}$, with a secondary focus on large emitting regions ${ }^{5}$.

\subsubsection{Historical estimates}

Recent work has led to revised global estimates of SLCP emissions (Crippa et al., 2016; Höglund-Isaksson, 2017; Höglund-Isaksson et al., 2017; Klimont et al., 2017; Purohit and Höglund-Isaksson, 2017; Wang et al., 2014), and to the re-estimation of historical emissions of SLCPs that were used to develop the Representative Concentration Pathways (Lamarque et al., 2010) and Shared Socio-Economic Pathways (Rao et al., 2017) ${ }^{6}$. While estimates of SLCP emissions remain uncertain, the revised historical estimates are higher than previously assumed (Hoesly et al., 2017; Klimont et al., 2017). This is especially important with regard to black carbon, where the inclusion of emissions from kerosene lamps, open burning of waste, gas flaring, and regional data on coal use in China results in emission levels that are over a million tonnes (over 15 percent) higher in 2010 than in the integrated assessment models used in the

4 These include black carbon from kerosene lamps (Jacobson et al., 2013; Lam et al., 2012), gas flaring (Conrad and Johnson, 2017; Stohl et al., 2013; Weyant et al., 2016), brick manufacturing (Cardenas et al., 2012; Maithel et al., 2012; Weyant et al., 2014), open burning of residential waste (Christian et al., 2010; Wiedinmyer et al., 2014), open burning of agricultural residues (Stockwell et al. (2016), and methane from the oil and gas industry (HöglundIsaksson, 2017).

5 Notably China, India, Russia and the Arctic (Evans et al., 2017, 2015; Huang et al., 2015; Kholod et al., 2016; Kondo et al., 2011; Kurokawa et al., 2013; Lu et al., 2011; Shen et al., 2012; Winiger et al., 2017).

6 See Hoesly et al. (2017) for additional details concerning past trends on anthropogenic emissions of reactive gases and aerosols. 
Representative Concentration Pathways and Shared SocioEconomic Pathways scenarios ${ }^{7}$.

Asia's role in emissions of black carbon and methane is ever-increasing, while North America and Europe (including Russia) combined represented nearly one third of global methane emissions in 2010, primarily via emissions from the oil and gas sector. Although sectoral structures of emissions vary greatly across pollutants, a few sectors tend to dominate. For black carbon, residential combustion (cooking and heating in solid fuel stoves) has been a key source of emissions, with transport and industry gaining importance in recent years (Hoesly et al., 2017).

\subsubsection{Projected emissions (including NDCs)}

Within Nationally Determined Contributions (NDCs), identifying particular compounds is usually difficult or impossible. This is because emissions reduction targets are expressed in $\mathrm{CO}_{2} \mathrm{e}$, often without specific targets for methane, hydrofluorocarbons or black carbon, but rather providing a list of target sectors. Only Mexico, Chile, Nigeria and Canada name SLCPs (black carbon) in their NDCs (and only Mexico specifies a target) ${ }^{8}$. It follows that NDCs are unsuited to analyses of SLCP projections. For this reason, the assessment below relies upon air pollutant and GHG emissions modelling that provides pollutantspecific estimates.

Recent projections of black carbon emissions indicate a change in trends (figure 6.1), driven by legislation developed to address primarily the health impacts of particulate matter ${ }^{9}$. Following the introduction of diesel particulate filters, black carbon emissions from diesel engines in OECD countries have continued to decline since about 2005. A similar impact is expected in developing countries, where comparable legislation has been recently introduced (DieselNet, 2015; GOI, 2014; MoRTH, 2016) in addition to measures to reduce smoke exposure among rural populations cooking with biomass and using kerosene for lighting (Venkataraman et al., 2010). Finally, China's policy to reduce coal use in households and small industries is likely to play an important role in near-future emissions of black carbon.

Recent scenarios reflect these policies to curb emissions of black carbon. figure 6.1 shows how projected emissions of black carbon (and methane and hydrofluorocarbons)

$7 \quad$ A recent study by Höglund-Isaksson (2017) reports a considerably higher release of methane and ethane from global oil and gas systems for the period 1980 to 2012, with oil production emerging as a much larger contributor than natural gas production. The results of this study show much closer consistency between bottom-up and top-down estimates of global ethane emissions from fossil sources than existing bottom-up inventories (EC-JRC/ PBL, 2013; US EPA, 2012).

8 By 2030, Mexico aims to achieve a 51 percent reduction in emissions of black carbon, compared to the country's emissions levels in 2013. This is an ambitious goal, requiring significant reductions in transport (over 70 percent), residential combustion (nearly 60 percent), and industry (50 percent), and the enforcement of a ban on open burning of residues (INDC-Mexico, 2015). Beyond developing the strategy, the government issued new legislation regarding the transport sector requiring improved efficiency and emission standards.

9 Reductions in emissions of black carbon is an ancillary benefit of policies aimed to curb particulate matter emissions. compare with Shared Socio Economic Pathways scenarios ${ }^{10}$. In addition to the three Shared Socio-Economic Pathways scenario ranges, an 'updated policy' pathway is shown, reflecting the latest policy assessments ${ }^{11}$. In the period prior to 2030 , this pathway is consistent with all the Shared SocioEconomic Pathways trajectories associated with a radiative forcing of $2.6 \mathrm{Watts} / \mathrm{m}^{2}$ (which corresponds to a $2^{\circ} \mathrm{C}$ increase in global mean temperature at the end of this century). After 2030, the 'updated policy' pathway is consistent with Shared Socio-Economic Pathway - narrative 3 trajectories associated with a radiative forcing of $3.4 \mathrm{Watts} / \mathrm{m}^{2}$. Unlike recent estimates, the Shared Socio-Economic Pathway narrative 3 (reference - no mitigation) scenario does not include the most recent policies in the transport sector. Considering the latest developments with respect to diesel engines (notably stricter standards, bans in cities, and the development of alternative propulsion systems), the projected decline in emissions from diesel engines over the next decades appears plausible. Finally, it is worth noting that the estimated near-term baseline developments do not consider some of the ongoing discussion that could bring further commitments to reduce SLCP emissions ${ }^{12}$.
10 The figure shows projected emission ranges for three Shared Socio-Economic Pathways scenario groups. Shared Socio-Economic Pathway - narrative 3 (reference - no mitigation) assumes a focus on national and regional policies, slow economic growth, lack of collaboration, large population remaining in poverty, and low priority for environmental policies, leading to strong environmental degradation in some regions. Shared Socio-Economic Pathway - narrative $3\left(3.4\right.$ Watts $\left./ \mathrm{m}^{2}\right)$ assumes the same socio-economic pathways, except that they include aggressive policies to curb climate change. Shared Socio-Economic Pathways 1-5 (2.6 Watts $\left./ \mathrm{m}^{2}\right)$ trajectories are consistent with the $2^{\circ} \mathrm{C}$ target that is achieved for all Shared Socio-Economic Pathways except Shared Socio-Economic Pathway - narrative 3 (reference - no mitigation) (Rao et al. 2017; Riahi et al. 2017).

11 Updates include recent emission legislation (as of 2015) and updated energy projections, as described in IEA (2016).

12 Four commitments are especially significant:

- The member states of the Arctic Council have pledged to reduce black carbon emissions by between 25 percent and 33 percent of 2013 levels by 2025 .

- Black carbon is covered by the Gothenburg Protocol to the United Nations Economic Commission for Europe's Convention on Long-Range Transboundary Air Pollution. While no specific target is set, the Convention requires parties to prioritize important sources of black carbon emissions in their strategies to reduce emissions of particulate matter.

- The International Maritime Organization is considering options to reduce emissions of black carbon from the maritime industry.

- Thirty-eight partner countries to the Climate and Clean Air Coalition have pledged to develop or refine inventories of black carbon ( 55 countries are now partners in the coalition, which targets SLCPs, including black carbon). Other non-state actors have also made commitments, with the state of California in the United States adopting specific legal targets for reductions of each of the major SLCPS. 
Figure 6.1: Global annual emissions of methane, black carbon (including forest and savannah fires) and hydrofluorocarbons.

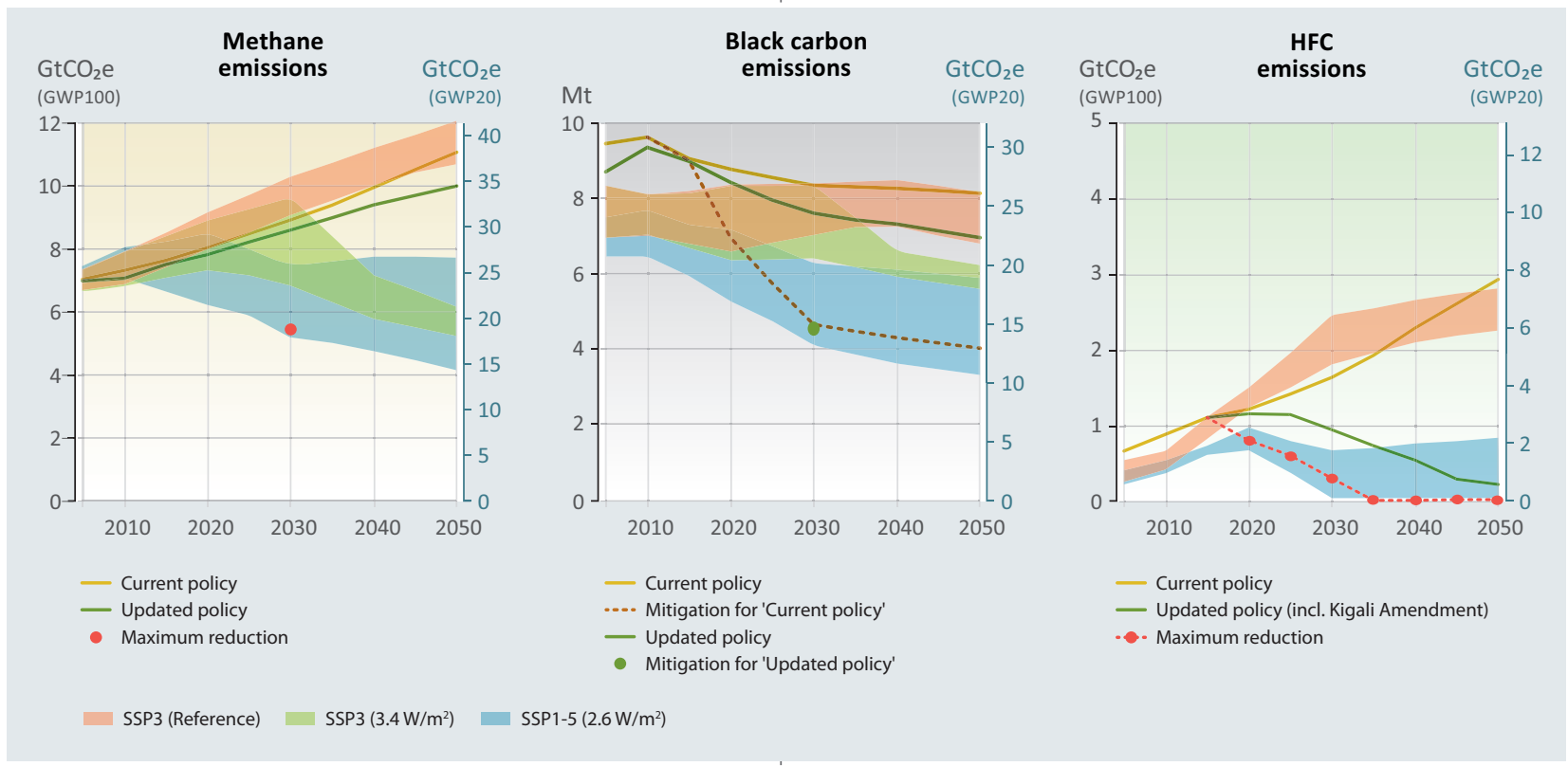

Note: For black carbon, values are shown in million tonnes and also based upon çonversion to $\mathrm{CO}_{2}$ e using 20-year global warming potentials (Bond et al., 2013). For methane and hydrofluorocarbons, the values shown are based upon conversion to $\mathrm{CO}_{2}$ e using both 100-year (left axis) and 20-year (right axis) global warming potentials, to highlight the dependence of comparisons between SLCPs and $\mathrm{CO}_{2}$ on the choice, of metric. Note that a 100-year global warming potential of 21 is used for methane, for consistency with prior issues of the 'emissions gap report', even though current'studies and IPCC assessments use values more than 60 percent higher (Gasser et al., 2017; Myhre et al., 2013).

Source: The figures were developed using data from Shared Socio Economic Pathways database (https://tntcat.iiasa.ac.at/SspDb/dsd), Riahi et al. (2017) and data for policy and mitigation scenarios from the GAINS model (http://gains.iiasa.ac.at)' documented in Klimont et al. (2017); Stohl et al. (2015), and Purohit and HöglundIsaksson (2017).

For methane and hydrofluorocarbons, the baseline trajectories (labelled 'current policy' in figure 6.1) relying on near-term energy projections (IEA, 2016; Purohit and Höglund-Isaksson, 2017) appear similar to the Shared SocioEconomic Pathway - narrative 3 trajectories. Numerous parties to the United Nations Framework Convention on Climate Change (including the top three global consumers of hydrofluorocarbons, China, the United States and European Union) are already taking action to reduce emissions through national policies and legislation. In their Intended Nationally Determined Contributions INDCs/NDCs, 99 countries pledged to reduce emissions of hydrofluorocarbons ${ }^{13}$.

\subsubsection{Impact of the Kigali Amendment}

A 2015 study found that phasing down hydrofluorocarbons could avoid between $4.0 \mathrm{GtCO}_{2} \mathrm{e}$ and $5.3 \mathrm{GtCO}_{2} \mathrm{e}$ per year by 2050, compared to a reference scenario (Velders et al., 2015). A related study from 2017, which uses

13 Three sets of initiatives are worth noting

- In May 2014, as part of an action plan to implement the energy conservation and emission reduction targets of its 12th five-year plan, the State Council of China announced that it would strengthen emission reduction requirements for hydrofluorocarbons, and accelerate their phase-out and replacement. " In its INDC/NDC, China has stated that it will completely phase out hydrofluorocarbon-123.

- The European Union's regulation 842/2006 on fluorinated greenhouse gases, which entered into effect on 1 January 2015, envisages that, by 2030, hydrofluorocarbon levels will have reduced by 79 percent of the levels registered in the period between 2009 and 2012

- The United States considered federal-level measures to reduce the manufacture and use of hydrofluorocarbons. In August 2017, a court struck down part of a 2016 decision by the country's Environmental Protection Agency, which sought to revoke approval for several of the most potent " hydrofluorocarbons. However, it is unclear how much impact this ruling will " have, as it returned the decision to the Agency, for further justification. In " parallel, several state administrations in the United States are regulating " hydrofluorocarbons. For example, California has set a new emissions reductions target for hydrofluorocarbons (a 40 percent reduction to 2013 levels by 2030) more up-to-date assumptions about emission reduction policies and a revised reference scenario, found that full compliance with the Kigali Amendment to the Montreal Protocol could reduce global hydrofluorocarbon emissions by $0.7 \mathrm{Gt} \mathrm{CO}_{2}$ e per year by 2030 , and up to $2.7 \mathrm{Gt} \mathrm{CO}_{2}$ e per year by 2050 (Höglund-Isaksson et al., 2017). This would avoid cumulative emissions of $39 \mathrm{GtCO}_{2}$ e between 2018 and 2050 (figure 6.1) ${ }^{14}$. Strengthening phase-down efforts (that is, pursuing a reduction in emissions that goes beyond that afforded by the implementation of the Kigali Amendment and that seeks to reach the maximum potential) could provide about 30 percent greater cumulative benefits (figure 6.1), while avoiding additional future emissions by precluding a build-up of storage hydrofluorocarbon banks (Velders et al., 2014).

In addition to efforts to avoid direct emissions of hydrofluorocarbons, additional indirect $\mathrm{CO}_{2} \mathrm{e}$ mitigation is likely through parallel improvements in the energy efficiency of refrigeration and air-conditioning appliances and equipment. Past phase-outs under the Montreal Protocol have catalysed significant improvements in the energy efficiency of appliances - up to 30 percent in some subsectors (US EPA, 2002). Höglund-Isaksson et al. (2017) found that full compliance with the Kigali Amendment could reduce global electricity consumption by between 
0.2 percent and 0.7 percent over the period 2018 to 2050 , due to the adoption of more energy-efficient technologies ${ }^{15,16}$.

\subsection{SLCP mitigation potential}

Some of the reduction potential for black carbon identified in early studies (Shindell et al., 2012; UNEP/WMO, 2011) is expected to be realized in the updated baselines (Section 6.2). Nonetheless, significant additional opportunities exist, which could reduce black carbon emissions by about 70 percent by 2030 (and more, in the longer term) (figure 6.1). Provided that strong targeted SLPC policies are introduced, these reductions in emissions could be achieved quickly ${ }^{17}$. While the illustrated potential was estimated for an energy scenario with $\mathrm{CO}_{2}$ emission levels similar to the Shared Socio-Economic Pathway - narrative 3 trajectory, the shown potential appears comparable with, or even larger than, the strict climate mitigation strategies that assume significant structural changes in the energy system. However, these strict climate policy scenarios are not compatible with the socio-economic developments associated with Shared Socio-Economic Pathway - narrative 3. Therefore, the intermediate climate target scenario results (reaching a $3.4 \mathrm{Watts} / \mathrm{m}^{2}$ forcing level, or approximately a concentration of $550 \mathrm{ppm}$ of $\mathrm{CO}_{2}$ ) were added. These results illustrate the co-benefits of climate policies on black carbon emissions. Indeed, under this scenario emissions are reduced by about 30 percent by 2050 , compared to the Shared Socio-Economic Pathway - narrative 3 trajectory.

Any further mitigation of black carbon emissions would require either tightened air quality standards, and/or strengthened development policy. These are included in the SLCP mitigation case, and in the strict climate policies case (as shown in the 2.6 Watts $/ \mathrm{m}^{2}$ scenarios). By 2030 , very limited reduction is demonstrated in this scenario, contrary to the SLCP mitigation case, where effective technological solutions and tested policy approaches afford much larger emission reduction potentials. In general, the new global set of scenarios (Shared Socio Economic Pathways) shows a fairly large span of emissions, even within the same Shared Socio Economic Pathways (Rao et al., 2017). This differs from the Representative Concentration Pathways data set, where assumptions that economic growth automatically leads to decreases in pollution were uniformly used across all the models for projecting changes in emissions of air pollutants, including SLCPs (Amann et al., 2013).

15 This would result in a cumulative reduction of about $5.5 \mathrm{GtCO}_{2} \mathrm{e}$ due to electricity savings when using country-specific emission factors that take into account country-specific transformation and distribution losses (Brander et al., 2011).

16 A 2015 study suggested that, in the air conditioning sector alone, improving the energy efficiency of equipment by 30 percent, while simultaneously transitioning to alternatives with low global warming potential, could provide cumulative mitigation of nearly $100 \mathrm{GtCO}_{2}$ e by 2050 (Shah et al., 2015).

17 Past experience on a regional and local scale exists, demonstrating fast and effective implementation, provided that appropriate enforcement mechanisms are set in place along the regulation; several examples are provided in, for example, Coaen (2012); Klimont et al. (2017); Kodjak (2015); Saikawa (2013); Shindell et al. (2012).
In the Shared Socio-Economic Pathway - narrative 3 scenarios, the global technical mitigation potential for methane is estimated at about 45 percent by 2030, provided that an appropriate policy environment is introduced ${ }^{18}$. Most of the emission reduction opportunities are in the exploration and distribution of coal, oil and gas, and in the waste sector ${ }^{19}$. The reductions available are comparable with those in the deep climate mitigation scenarios (figure 6.1). In general, policies to reduce emissions of $\mathrm{CO}_{2}$ will effectively cover a large portion of methane emissions.

Technical measures could bring about fast and significant reductions in emissions of black carbon and methane (for example Amann et al., 2013; Höglund-Isaksson, 2012; Klimont et al., 2017) ${ }^{20}$. However, introducing such measures has proven problematic in some instances. For example, programmes that focus on substituting cooking stoves with clean alternatives have often had disappointing results, with declining penetration rates over time (Aggarwal and Chandel, 2004; Pine et al., 2011; Ruiz-Mercado et al., 2011; Venkataraman et al., 2010; Wickramasinghe, 2011) ${ }^{21}$. Nevertheless, some other types of programmes have been successful, including emissions reduction strategies for motor vehicles, such as those focused on diesel particulate filters or emissions standards (CAI-Asia, 2011; Chambliss et al., 2013; Coan, 2012; Kodjak, 2015; Saikawa, 2013; US EPA, 2017).

This chapter presents estimates of technical mitigation potentials, since they are more widely used, and therefore more abundant, than estimates of economic mitigation potentials. Notwithstanding, it is acknowledged that economic potentials may be more relevant with regard to understanding the political feasibility of mitigation actions ${ }^{22}$.

18 In figure 6.1 this is coded 'maximum reduction', and represented by the following symbol:

19 The emissions reduction potential associated with rice and anaerobic digestion is only significant in certain regions.

20 Emission reduction rates would be faster than those brought about by transformational changes associated with low $\mathrm{CO}_{2}$ strategies.

21 Nonetheless, locally tailored projects, often embedded in a larger scale policy process, and coupled with awareness-raising efforts, have proven successful (GACC, 2015; Sinton et al., 2004; Thomas et al., 2015). Political feasibility depends strongly on the design of the programme, its local sustainability, the strong involvement of local stakeholders, and on the incentives for national governments to act.

22 The economic potential of SLCP mitigation differs substantially from the technical potential of $\mathrm{CO}_{2}$ mitigation for two main reasons: (i) the total benefits of SLCP mitigation are typically larger, because they include nonclimate benefits; and (ii) with SLCP mitigation, a large share of the benefits is nationally appropriable, in particular for black carbon. Shindell et al. (2017b) estimate that the social cost of methane (that is, the monetized societal damages resulting from a tonne of emissions incorporating climate and air quality related impacts) is $\mathbf{5 0}$ to 100 times greater than the corresponding social cost of $\mathrm{CO}_{2}$. Estimates of the net benefits that are nationally appropriable are not yet available in the literature. Research programmes are ongoing to bridge this research gap. 


\subsubsection{Methane}

The technical mitigation potential identified through the integrated assessment models used to develop Shared SocioEconomic Pathways scenarios draws primarily on the work of United States Environmental Protection Agency (US EPA, 2013). The estimates for methane have been further updated (Höglund-Isaksson, 2012; UNEP/WMO, 2011) to include explicit consideration of unconventional gas production, new regional characteristics for oil and gas production (Höglund-Isaksson, 2017), and waste management. For coal production, a structural update was made, to allow for the separate estimation of emissions and mitigation potentials from pre-mining operations (de-gasification), mining operations (ventilation air methane oxidation), and postmining activities. Finally, current model implementation includes impacts of animal feed and manure management options as described in FAO (2013), but does not include changes in consumer preferences or behaviour, which could add mitigation potentials in the agricultural sector through reduced consumption of meat (especially beef) and reduced food waste generation (Stehfest et al. (2009) (Chapter 4). Figure 6.2 shows regional estimates of 'Current policy' emission trajectories and reduction potentials in the coming decades. These estimates are consistent with International Energy Agency projections of energy use (IEA, 2012), and integrate the refinements highlighted above ${ }^{23}$.

Mitigation potentials vary across regions, and are often characterized by a dominating source sector ${ }^{24}$. Nonetheless, solid waste separation and treatment offers opportunities across all regions. In Europe and Brazil, reduction potentials are smaller, as agriculture is the dominating methane source, and there are relatively limited technical mitigation opportunities. The comparison with the 'Climate policy' scenario (based on the IEA (2012) 450 ppm CO mitigation strategy) shows that most of the near-term emissions reduction potential appears to require dedicated SLCP measures.

23 In terms of $\mathrm{CO}_{2}$ emission levels, the International Energy Agency's scenario is comparable to Shared Socio-Economic Pathway - narrative 3 (reference - no mitigation) and 'Current policy', shown in figure 6.1

24 For example, capturing ventilation air methane from coal mines represents the key mitigation opportunity in China.

Figure 6.2: Regional baseline methane and black carbon [shaded background] emissions and mitigation potential by 2030 [Mt per year].


Source: The figures were developed using data from the GAINS model (http://gains.iiasa.ac.at) and scenarios documented in Höglund-Isaksson (2012, 2017); Klimont et al. (2017); Stohl et al. (2015), with underlying energy scenarios from IEA (2012). 


\subsubsection{Black carbon}

Figure 6.2 gives estimates of mitigation potentials for black carbon in a number of world regions. The estimates reflect updates referred to above (Klimont et al., 2017; Stohl et al., 2015). With regard to black carbon, key updates include improved characterisations of the gas flaring sector, kerosene lighting, diesel generators, and the brickmanufacturing sector.

The 'Current policy' trajectory varies greatly between regions, depending on the structure of emissions and current policies. Consequently, the mitigation potential varies too. For the European Union and the United States, a strong decline is observed (owing to strict transport legislation), which explains the limited mitigation potential that remains. In China, the transformation in the coke sector, ever-more stringent policies in transport, and reductions of coal use in the residential sector lead to significant reductions relative to the reference scenario emission levels. Therefore, mitigation potential is larger in China than in the European Union and the United States. In some of the other regions with a large share of emissions from biomass cooking (notably India), significant opportunities exist.

While the overall global potential by 2030 was estimated at over 70 percent (figure 6.1), the regional potentials vary from about 40 percent to over 80 percent. In regions where solid fuel cooking and heating dominates emissions of black carbon, the emissions reduction potential increases significantly beyond 2030 (not shown) ${ }^{25}$.

\subsubsection{Hydrofluorocarbons (HFCs)}

Full compliance with the Kigali Amendment would achieve a 61 percent decrease in hydrofluorocarbon emissions in the period between 2018 and 2050, compared to the emission levels in a reference scenario (Höglund-Isaksson et al., 2017). Transitioning to available low global warming potential alternatives faster and more thoroughly than contemplated by the Kigali Amendment represents a major opportunity to reduce emissions of hydrofluorocarbons. Such accelerated transition is feasible. In countries with high ambient air temperatures, almost 70 percent of sectors currently using hydrochlorofluorocarbons can leapfrog past high global warming potential hydrofluorocarbon refrigerants, directly to low global warming potential alternatives with equal or better energy efficiency (Zeiger et al., 2014). The same study notes that other low global warming potential alternatives are in development, and expected to be ready to replace the remaining uses by 2025 . Höglund-Isaksson and colleagues (2017) report that the maximum technical abatement potential, relying on existing technologies, is 85 percent below the reference scenario emission levels (in the period between 2018 and 2050) (figure 6.1). They further note that, towards the end of the period, the mitigation potential could represent as much as 98 percent of the annual reference scenario emission levels. Interestingly, most of the model realizations of the Shared Socio-Economic Pathways scenarios consistent with the $2.6 \mathrm{~W} / \mathrm{m}^{2}$ trajectories assume even faster and steeper reductions than the Kigali Amendment (figure 6.1).

\subsection{Implications for the emissions gap}

Compared to the Shared Socio-Economic Pathway narrative 3 trajectories, assessments of the impact of updated policies show weaker growth or, depending on the pollutant, greater decreases in emissions of methane, black carbon, organic carbon, and sulphur dioxide (and $\mathrm{CO}_{2}$ ). These trends can be translated into likely changes in temperature ${ }^{26}$. Recent policies lead to roughly $0.09 \pm 0.04^{\circ} \mathrm{C}$ less warming due to methane, $0.04 \pm 0.02^{\circ} \mathrm{C}$ less warming due to $\mathrm{CO}_{2}$, and $0.17 \pm 0.11^{\circ} \mathrm{C}$ less cooling due to sulphate in $2030^{27}$. These results evidence that, in the near term, the net warming due to reductions in $\mathrm{CO}_{2}$ and co-emissions (primarily sulphur dioxide) is roughly offset by reductions in SLCP, primarily methane. Modelling results highlight that SLCP holds a substantial additional emission reductions potential, as described in section 6.3 .

Table 6.1: Warming mitigation resulting from SLCP emission reductions

\begin{tabular}{|l|l|l|}
\hline Additional SLCP mitigation & 2030 & 2050 \\
\hline & $0.22 \pm 0.11$ & \multicolumn{2}{c|}{ Change in temperature $\left({ }^{\circ} \mathrm{C}\right)$} \\
\hline All SLCPs (HFCs following the Kigali Amendment) & $0.09 \pm 0.03$ & $0.59 \pm 0.27$ \\
\hline Methane & $0.005 \pm 0.002$ & $0.30 \pm 0.12$ \\
\hline HFCs following Kigali Amendment & $0.02 \pm 0.01$ & $0.07 \pm 0.02$ \\
\hline HFCs Maximum Feasible Reduction & $0.1 \pm 0.1$ & $0.10 \pm 0.03$ \\
\hline Black carbon-rich sources & $0.2 \pm 0.2$ \\
\hline
\end{tabular}

Note: The estimates in the table represent departures from the estimates associated with the International Energy Agency's 'current policies' scenario (see the main text for details). HFCs stands for hydrofluorocarbons. HFCs Maximum Feasible Reduction includes Kigali Amendment. Source: Own elaboration.

25 This is due to the assumptions made about the effectiveness of cooking stove programmes, and the large increases in diesel vehicle emissions in some regions.

26 To do so, we used the complementary analyses described in Shindell et al. (2017b) that included:

- a simple energy-balance calculation, incorporating climate response functions based on the CMIP5 models (Geoffroy et al., 2013);

- $\quad$ estimate of the impact of emissions on the carbon cycle (Gasser et al., 2017); - updated radiative forcing for methane, including shortwave absorption (Etminan et al., 2016).

27 Smaller changes due to other pollutants are not reported here. 
Global mean surface temperature change $\left({ }^{\circ} \mathrm{C}\right)$

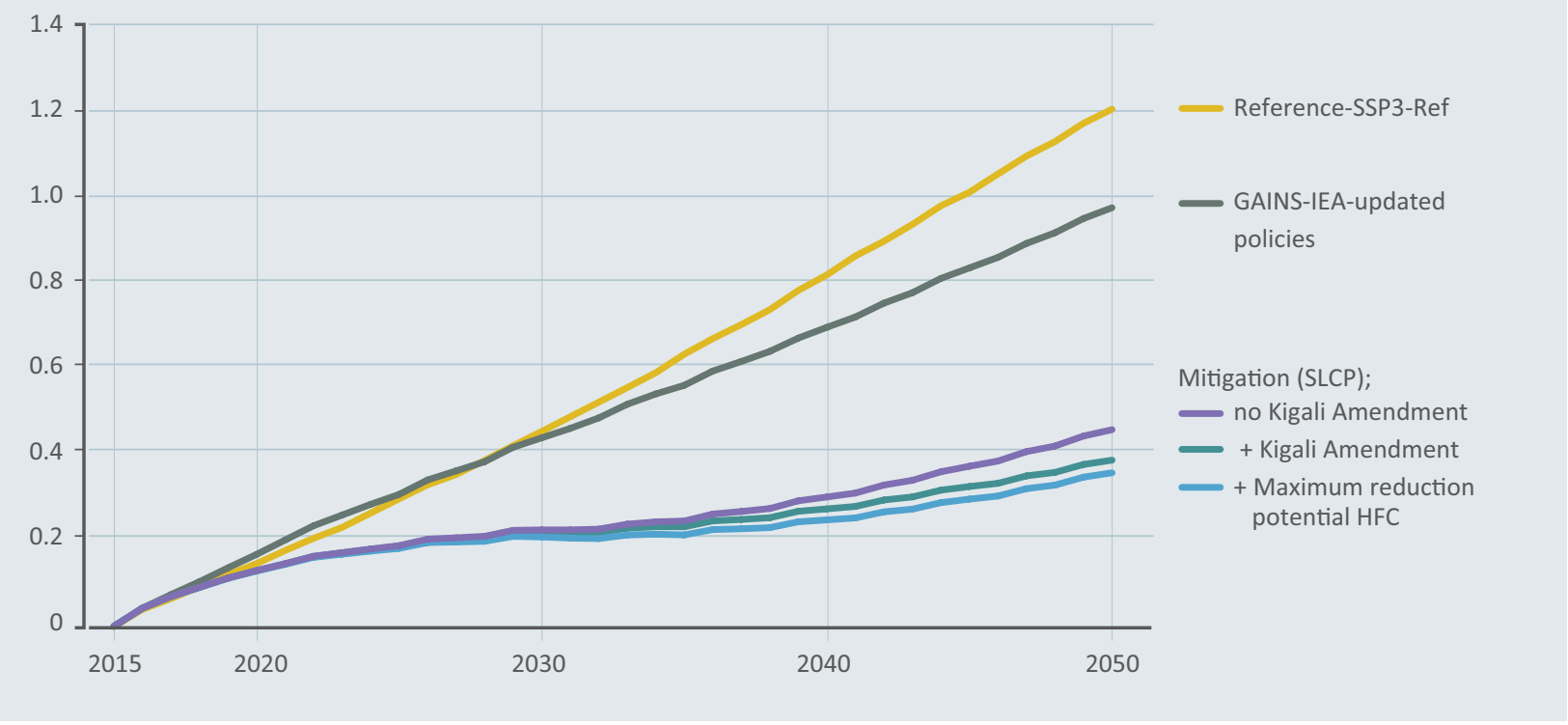

Source: Own elaboration.

Additional SLCP mitigation could avert a large fraction of projected warming over the near term (figure 6.3 and table 6.1). By 2050, methane reductions contribute the largest share (table 6.1). Realizing the maximum emission reduction potentials for emissions of hydrofluorocarbons, thus going beyond what is envisaged in the Kigali Amendment to the Montreal Protocol, would lead to fourfold additional savings by 2030 (figure 6.1 ) $^{28}$. The remaining half to one third of the benefits stem from the net impact of the measures targeting black carbon-rich sources.

Figure 6.1 illustrates the near-term mitigation potential for black carbon using 20-year global warming potentials. By 2030, such near-term mitigation potential is roughly three quarters that of methane. As noted, however, understanding the full impact of measures to mitigate black carbon requires an assessment of the impact of all pollutants affected. Compared to methane, changes in emissions of black carbon lead to faster changes in concentrations of black carbon. When the effects of organic carbon and carbon monoxide from black carbon-rich sectors are taken into account, the net impact on 2030 temperatures is also about three quarters that of methane. This fraction decreases over time, as methane concentrations adjust more fully to emissions changes. By 2050, the black carbon mitigation potential is approximately two thirds that of methane, but the temperature response is just over 50 percent (again, including co-emissions of black carbon). This shows that mitigation potentials using 20-year global warming potentials can be a useful, but only rough, guide to near-term temperature impacts. For the longer term, the 2030 additional mitigation potential for methane is about $3 \mathrm{GtCO}_{2} \mathrm{e}$ per year (using a 100-year global warming

28 With hydrofluorocarbons, emissions reductions are phased in early: in 2050 additional gains would reach about 30 percent, which represents a much more moderate rate in reductions, compared to those achievable by 2030. potentials of 21), and roughly $5 \mathrm{GtCO}_{2} \mathrm{e}$ per year (using updated 100 -year global warming potentials of 34$)^{29}$.

The relatively large near-term warming mitigation potentials presented above are similar to those in several prior studies. Excluding hydrofluorocarbons, they are similar to the results presented in (UNEP/WMO, 2011) and Shindell et al. (2012). Warming mitigation values are slightly larger in 2050 , consistent with the inclusion of additional mitigation measures in this analysis, along with the extension of SLCP mitigation through 2050, which offset the decrease in benefits associated with the later start in mitigation. Including hydrofluorocarbons, values for 2050 are similar to those reported elsewhere (Xu et al., 2013) (30. $^{30}$

29 A reduction of that magnitude, sustained for 100 years, would be equivalent to reducing $\mathrm{CO}_{2}$ emissions by $170 \mathrm{GtCO}_{2}$ in one year (Allen et al., 2016).

30 Other research found smaller warming mitigation from SLCPs, although compared to reference cases with reduced SLCP emissions. For example, Smith and Mizrahi (2013) used a model that assumed that (i) all control measures with a negative cost automatically happen based on 'rational economic behaviour', and (ii) projected increases in wealth worldwide lead to automatic adoption of strict emission control standards. Therefore, in essence this study calculated benefits of additional efforts to remove SLCPS after many of the available emissions control had already happened. Another study explored many possible reference cases, unsurprisingly reporting smaller SLCP-related benefits in comparison to reference cases with relatively low SLCP emissions, and similar values in comparison with high-SLCP emission reference cases akin to those seen in the detailed modelling presented above (Section 6.2) (Rogelj et al., 2014). In comparison with reference cases incorporating stringent climate mitigation policies focused on $\mathrm{CO}_{2}$, that study found a substantial decrease in the mitigation potential for SLCPS. This reflects the overlap mentioned previously between stringent $\mathrm{CO}_{2}$ controls that transition away from fossil fuel use (covering energy-related methane emissions and diesel-related black carbon emissions). Those results are consistent with the drop in black carbon emissions under the Shared SocioEconomic Pathway - narrative $33.4 \mathrm{~W} / \mathrm{m}^{2}$ scenario relative to the Shared Socio-Economic Pathway - narrative 3 reference scenario shown in figure 6.1, although such scenarios also include structural changes (for example, with regard to renewable sources of energy, energy access or electric vehicles), and increased energy access for the poor, which may be more difficult to realize than technical SLCP control measures, and would likely take longer to materialize. 
Given the potential for enhanced SLCP reductions to reduce warming substantially in the near term, relative to current policies, such reductions could clearly help to close the emissions gap defined by long-term global mean annual average temperature. They could also help offset near-term warming caused by $\mathrm{CO}_{2}$ mitigation strategies. Near-term SLCP mitigation is also a critical lever for slowing the rate of change in the next few decades, which is particularly important for reducing cumulative climate impacts, such as sea-level rise. Hu et al. (2013) found that curbing emissions of SLCPs immediately can reduce the rate of sea-level rise by approximately 18 percent by 2050, while immediate reductions in $\mathrm{CO}_{2}$ would yield minimal benefits with regard to sea-level rise. Delaying SLCP mitigation by 25 years could decrease the impact of both $\mathrm{CO}_{2}$ and SLCP mitigation on sea-level rise by approximately 30 percent. Not least, reducing near-term warming can also decrease risks of lowprobability, high-impact climate change effects ( $\mathrm{Xu}$ and Ramanathan, 2017).

\subsection{Implications for the Sustainable Development Goals and other policy goals}

This chapter assesses the role of SLCPs, including black carbon (a component of particulate matter) and methane, in bridging the emissions gap. In addition to the climate change mitigation benefits associated with curbing emissions of SLCPS, a reduction in emissions of these pollutants would contribute significantly to the achievement of several of the United Nations' Sustainable Development Goals (SDGs) ${ }^{31}$.

The SDGs capture key human and planetary needs and challenges, and achieving them by 2030 requires coordinated actions on diverse fronts. Implementing SLCP mitigation measures can clearly contribute to the achievement of multiple SDGs, because of the impact of SLCPs on climate change and air pollution ${ }^{32}$.

Residential combustion of solid fuels in traditional cooking stoves and the use of kerosene for lighting in the AsiaPacific and African regions results in very high levels of indoor air pollution (Karekezi et al., 2006). The World Health Organization has estimated that indoor and ambient air pollution cause 6.5 million premature deaths, recognizing it as "the single most important environmental health risk factor worldwide", and noting that it is driving a global health emergency (WHO, 2016). The provision of modern and clean energy forms for meeting these basic requirements, particularly those of rural households, would not only help reduce the emissions gap, but would also help achieve SDG 3 on ensuring healthy lives and promoting well-being, SDG 4

31 The majority of black carbon emissions are accounted for by the AsiaPacific region (including China), followed by Africa. Emissions come largely from residential combustion of fuels and diesel burning in the transport sector. Sources of black carbon also emit a large proportion of precursors of tropospheric ozone globally. Methane is another significant precursor of the increasing background levels of ozone.

32 SLCP mitigation is also complementary to $\mathrm{CO}_{2}$ mitigation: many SLCP mitigation strategies can yield $\mathrm{CO}_{2}$ mitigation co-benefits, and vice versa (Haines and et al., under review). on ensuring inclusive education, SDG 5 on empowering women and girls, and SDG 15 on sustainable forests (Griggset al., 2014).

Tropospheric ozone is also harmful to human health. Recent estimates show that the significance of this pollutant as a cause of premature mortality is higher than had previously been estimated (Malley et al., 2017). In addition, tropospheric ozone is the pollutant that causes the most significant crop yield losses. Therefore, early action on sources of SLCPs could lead to a rapid reduction in these adverse impacts.

Another key area of global concern is the increasing levels of pollution in urban areas. Urbanization is a global megatrend, and it is expected that nearly 70 percent of the world's population will be living in urban areas by 2050 (compared with 54 percent in 2014). The major causes of urban air pollution, namely transportation and industrial activity, are also major contributors to SLCP emissions. Improving fuel and technology choices in the transport sector, banning the open burning of biomass and waste in urban areas, and improving energy efficiencies, all contribute to reducing SLCPs. In doing so, these initiatives would also contribute to achieving several SDGs (Cherian, 2015): SDG 2 on sustainable agriculture, SDG 3 on health, SDG 7 on energy, SDG 11 on inclusive and sustainable cities, and SDG 12 on sustainable production and consumption.

Actions to reduce SLCP emissions can be synergistic with efforts to improve energy efficiency. For example, when coupled with energy efficiency policies, measures to phase out hydrofluorocarbon-based refrigerants can save between $340 \mathrm{GW}$ and $790 \mathrm{GW}$ of peak power load globally, while also avoiding about $98 \mathrm{Gt}$ of $\mathrm{CO}_{2}$ emissions by 2050 (Shah et al., 2015).

Despite widespread efforts to reduce emissions of several air pollutants, especially sulphur dioxide, nitrogen oxides, and particulate matter, in several regions air pollution will not improve enough to reduce the burden on human health (IEA, 2016). On the contrary, regional demographics, rising energy use and urbanization may lead to growth in the number of premature deaths due to outdoor air pollution, especially in Asia. However, introducing efficient reduction measures in the power sector, industry, and transport, and accelerating access to clean energy for cooking - measures that are compatible with an SLCP mitigation strategy - could reduce the number of premature deaths significantly (IEA, 2016). These results are consistent with those of Schmale et al. (2014), who estimated that, by halving the concentrations of SLCPs in the atmosphere, more than 40 million deaths from respiratory and cardiovascular diseases could be avoided by 2030 .

Compared to introducing policies to mitigate SLCPS, introducing policies to implement the SDGs is often more feasible politically. For this reason, the latter can be used to exploit the opportunity of reducing emissions of SLCPs. 
Reductions in emissions of SLCPs offer significant potential to slow the rate of near-term warming, contribute to the achievement of the long-term Paris Agreement temperature targets, improve well-being via improved air quality, and facilitate the achievement of several SDGs. Although technical control measures already exist and have been demonstrated, scaling up those measures to their full potential would require dedicated policy efforts beyond those embodied in either current policies or low-carbon policies. Ideally, by aggressively reducing both SLCPs and $\mathrm{CO}_{2}$, policies would optimize the societal welfare associated with efforts to curb climate change, improve air quality and achieve sustainable development.

\subsection{Key messages}

Large reductions in emissions of short-lived climate pollutants (SLCPS) are an important part of mitigation efforts in virtually all scenarios that meet the $2^{\circ} \mathrm{C}$ target, and especially those that meet the $1.5^{\circ} \mathrm{C}$ target.

Reductions in SLCP emissions cannot be considered equivalent to reductions in long-lived greenhouse gases, as many impacts are not directly proportional to global mean temperature change at a given point in time. For this reason, climate change mitigation policies need to consider these two classes of emissions separately.

Early reductions in SLCP emissions would provide substantial health benefits, limit the short-term rate of climate change, slow self-amplifying feedbacks, and facilitate the achievement of the Paris Agreement's long-term temperature target.
Significant SLCP mitigation potential, beyond existing commitments, is available via proven technologies. However, to unlock that potential requires dedicated policy action to strengthen legal frameworks and institutional capacities. This is because many SLCP mitigation strategies are distinct from strategies to reduce $\mathrm{CO}_{2}$ emissions.

Over the period 2018-2050, stringent SLCP reductions based on existing, demonstrated technical measures could reduce warming by between $0.3^{\circ} \mathrm{C}$ and $0.9^{\circ} \mathrm{C}$ relative to current emissions projections. Roughly half of the mitigation potential is associated with methane, one third with black carbon, and the remainder with hydrofluorocarbons. As some policies that reduce $\mathrm{CO}_{2}$ emissions also reduce SLCP emissions, a substantial portion of SLCP reductions could be achieved through $\mathrm{CO}_{2}$ mitigation efforts. However, compared with policies specifically targeting SLCP controls, the reductions in $S L C P$ emission resulting from $\mathrm{CO}_{2}$ mitigation efforts would be slower.

Reduction of SLCP emissions, specifically black carbon, might play an important role in mitigating the regional impacts of climate change. 


\section{Chapter 7}

\section{Bridging the Gap - Carbon dioxide removal}

Lead authors: Pete Smith (University of Aberdeen), Julio Friedmann (Carbon Wrangler, LLC)

Contributing authors: Sabine Fuss (Mercator Research Institute on Global Commons and Climate Change), Noah Deich (Center for Carbon Removal), Giana Amador (Center for Carbon Removal), Jan Minx (Mercator Research Institute on Global Commons and Climate Change), Mark G. Lawrence (Institute for Advanced Sustainability Studies, Potsdam), Mercedes Bustamante (Departamento de Ecologia, Universidade de Brasília), Omar Masera (Institute for Ecosystem Research and Sustainability, Universidad Nacional Autónoma de Mexico), Annette Cowie (New South Wales Department of Primary Industries/University of New England), Oliver Geden (German Institute for International and Security Affairs)

\subsection{Introduction}

Carbon dioxide removal (sometimes called carbon removal or (DR) refers to a cluster of technologies, practices and approaches that remove and sequester carbon dioxide :

from the atmosphere. Despite the common denominator of removing carbon dioxide, these technologies can be very different. To put it simply, one can distinguish between biological and engineered options. For some of the

Figure 7.1: Major strategies for negative emission technologies.

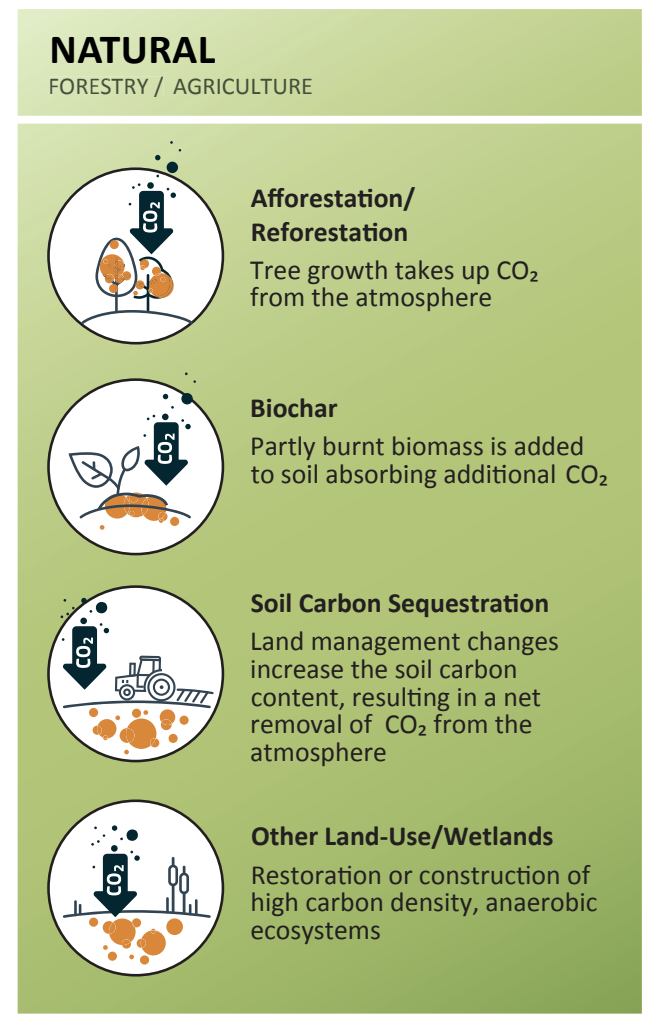

\section{COMBINED \\ NATURAL + TECHNOLOGICAL}

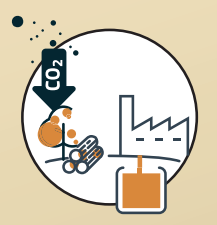

Bioenergy with Carbon Capture and Storage (BECCS) Plants turn $\mathrm{CO}_{2}$ into biomass that fuels energy systems; $\mathrm{CO}_{2}$ from conversion is stored underground

\section{TECHNOLOGICAL ENERGY / INDUSTRY}

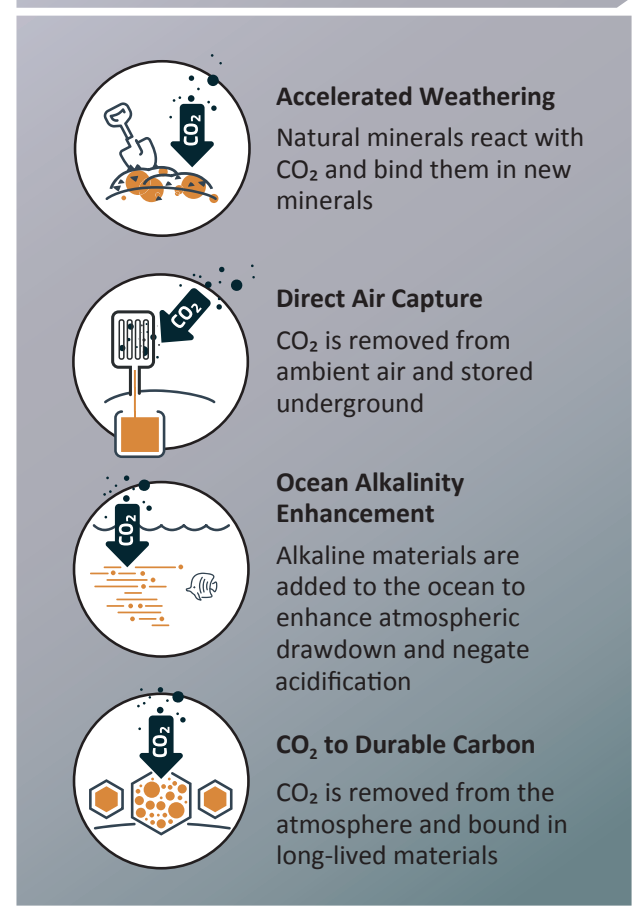

More costly $\leftarrow$ Greater R\&D needs $\leftarrow$ Less vulnerable to reversal $\leftarrow$

Note: This figure includes the major strategies that have been discussed in the literature so far (Minx et al., 2017). 
former (such as afforestation, reforestation or soil carbon management), experience has been accumulated over decades. Conversely, experience is limited with regard to the latter (notably direct air capture, or bioenergy combined with carbon dioxide capture and storage). Some approaches would be more difficult to implement than others, for example, using the ocean as a common-pool resource, which would require coordination on an international scale. The leading technologies and approaches considered here are shown in figure 7.1.

Importantly, carbon dioxide removal is not the same as solar radiation management (Royal Society, 2009). This distinction is critical and was emphasized by the United States National Academy of Sciences, which has reviewed approaches to solar radiation management (USNAS, 2015a) and to carbon dioxide removal (USNAS, 2015b). While solar radiation management may prove important for mitigating climate change in the future (Keith et al., 2017), it is not the subject of this chapter. Instead, this chapter focuses on reducing carbon dioxide concentrations in the atmosphere through active management.

Carbon dioxide removal options have become a common feature in climate change mitigation scenarios that are consistent with the goals of the Paris Agreement (Clarke et al., 2014; van Vuuren et al., 2013; Fuss et al., 2014). Given that carbon budgets are tight and rapidly being depleted (Rogelj et al., 2016; IPCC, 2014), carbon dioxide removal options are more widely used to compensate for temporary budget overshoot.

Carbon dioxide removal and the deployment of negative emissions approaches must be employed in addition to other mitigation options (such as those discussed in Chapter 4). Stated differently, carbon dioxide removal is concerned with the management of overshoot, even in the event that all mitigation options are pursued. For example, limiting deforestation and improving forest management are key undertakings to reduce current emissions and avoid future emissions. However, necessary as they are, these practices are quite different to afforestation, which is the practice of adding forests to areas where there are none today.

In many scenarios, net negative emissions occur in the second half of the $21^{\text {st }}$ Century. However, negative emissions are introduced much earlier, and to a greater extent, in those scenarios. This is done to compensate for residual emissions that are too difficult or too expensive to reduce at the level of climate policy ambition that the scenario seeks to characterize. Taken together, both climate dioxide removal options represent the total or gross negative emissions required in a particular scenario (figure 7.2).

From a wider portfolio of mitigation options, integrated assessment models select negative emissions technologies based on cost-minimization considerations ${ }^{1}$. Naturally, the deployment of negative emissions technologies varies

Figure 7.2: The role of carbon dioxide removal in climate change mitigation.

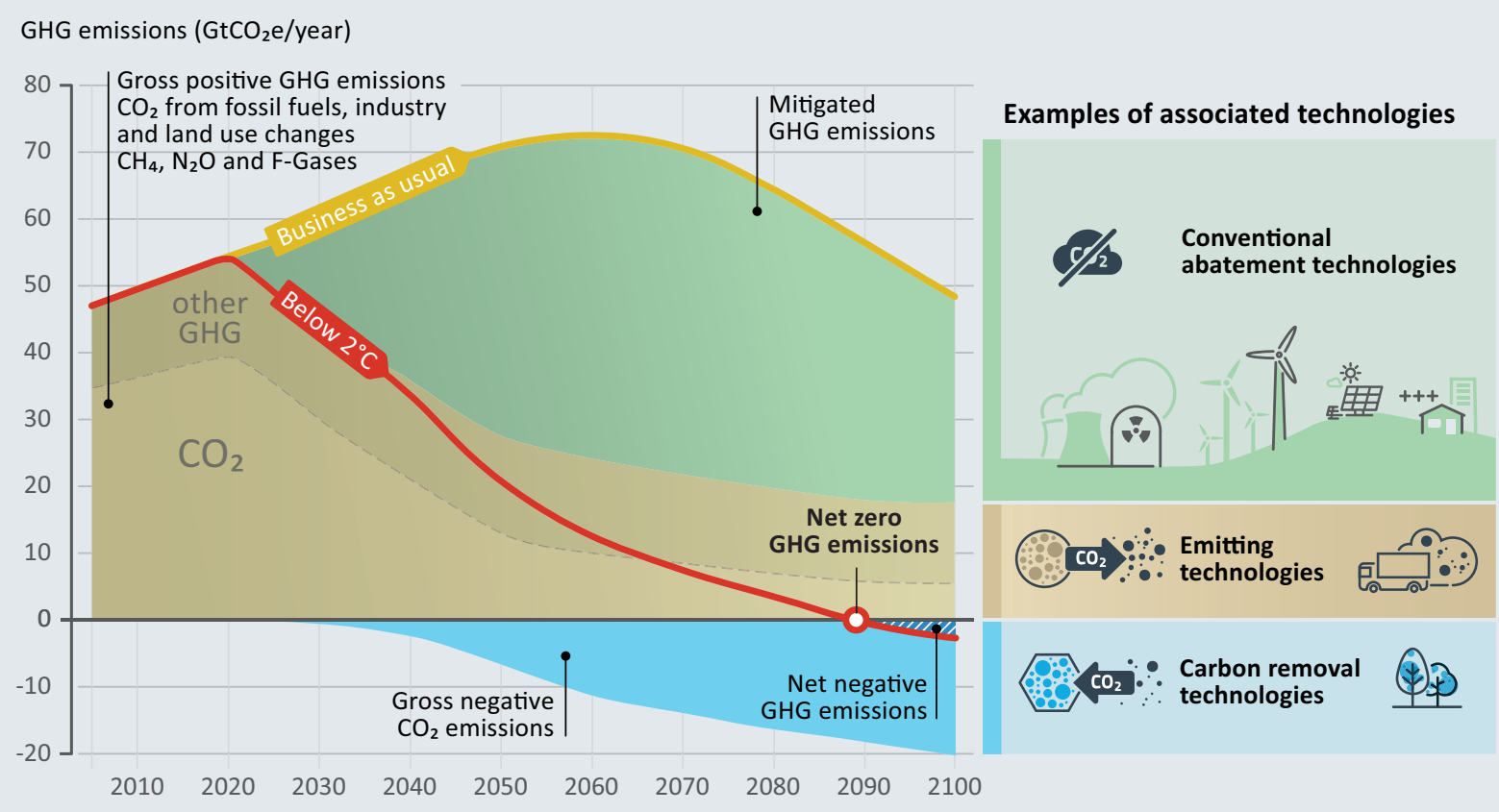

Note: This figure shows emission reductions from conventional mitigation technologies combined with carbon dioxide removal. This exemplary scenario is consistent with an at least 66 percent chance of keeping warming below $2^{\circ} \mathrm{C}$ relative to pre-industrial levels. Emission reductions are shown against a business-as-usual scenario without any additional climate policies. Global net emissions levels turn to net negative towards the very end of the century, but carbon dioxide removal is already being deployed much earlier. Some residual greenhouse gas emissions remain at the end of the century, as they are too difficult to mitigate in the scenario. Note that the scenario used is different from the scenarios used in Chapter 3, which leads to small variations in emission levels and timing of negative emissions. Source: Jérôme Hilaire (Mercator Research Institute on Global Commons and Climate).

1 Specifically, integrated assessment models determine the least-cost pathway for the global economy to meet a given climate target (before additional benefits are accounted for). They do so on the basis of assumptions about technology costs and availability, alongside other macroeconomic factors (for example, demand for energy and food). 
greatly from one scenario to the next, due to differences in scenario design and the specifications of the particular model. Nevertheless, some robust patterns emerge across clusters of scenarios:

- Scenarios consistent with the $1.5^{\circ} \mathrm{C}$ target depend on the large-scale availability of negative emissions technologies. There are no scenarios available that can keep warming below $1.5^{\circ} \mathrm{C}$ by 2100 without removing carbon from the atmosphere via negative emissions technologies (Fuss, 2017; Minx et al., 2017).

- In general, the deployment of negative emissions technologies in the second half of the century occurs on a large scale, and with a very rapid scale-up to $8 \mathrm{GtCO}_{2}$ per year by 2050 (range 5-15). By 2100 the median (2010-2100) removal of carbon dioxide via negative emissions technologies is $810 \mathrm{GtCO}_{2}$ (range 440-1,020). This corresponds to about 20 years of global emissions at current emission rates.

In the $2^{\circ} \mathrm{C}$ scenarios with immediate climate action, the median (2010-2100) deployment of negative emissions technologies is considerably lower: $670 \mathrm{GtCO}_{2}$ (range 320-840). In addition, the scale-up towards mid-century is much slower.

- Delay in adequate near-term climate action swiftly locks $2^{\circ} \mathrm{C}$ pathways deeply into negative emissions. To limit warming to $2^{\circ} \mathrm{C}$, current Nationally Determined Contributions lead to pathways that are fundamentally dependent on the large-scale availability of negative emissions technologies (like $1.5^{\circ} \mathrm{C}$ pathways today, and with similar deployment rates and technology upscaling requirements).

- Compared to emissions pathways that are less efficient in energy use, $1.5^{\circ} \mathrm{C}$ and $2^{\circ} \mathrm{C}$ emissions pathways that feature aggressive energy savings are less dependent on negative emissions technologies.

It is worth noting that a few scenarios can meet the $2^{\circ} \mathrm{C}$ target without the deployment of negative emissions technologies. If the models select these technologies, it is because they represent a cheaper mitigation option overall. This means that even in scenarios that are consistent with the $2^{\circ} \mathrm{C}$ target, there is scope to considerably limit the deployment of negative emissions technologies, compared to what we see in economic optimization scenarios.

\subsection{Land-based carbon dioxide removal options}

Land-based carbon dioxide removal involves technologies, practices and approaches that harness the carbon removal potential of land-based ecosystems, including forests, wetlands, agricultural land and soils. As these systems have been managed by humans for many years, there is a wealth of knowledge that can be readily applied today with confidence. In addition, these approaches present opportunities to meet other global sustainability goals, such as improved water quality, ecosystem restoration, biodiversity preservation, food and nutrition security, job creation and improved crop yields.
For these land-based options to contribute to carbon removal at the scale of gigatonnes, new management approaches that impact large land areas and ecosystems will be required in some cases. In others, traditional, sustainable practices such as agroforestry may need to be applied ${ }^{2}$.

Many substantial uncertainties exist regarding effective carbon dioxide removal rates, the volumes stored, the duration of effective sequestration under a changing climate and the implications for ecosystem services provided by the land in question. In this regard, carbon dioxide removal in these systems may prove very different to other current efforts. Ultimately, each option has its strengths, uncertainties and constraints.

\subsubsection{Afforestation and reforestation}

Afforestation refers to planting trees on land not afforested in recent history (usually 50 years or longer), while reforestation refers to the replanting of trees on more recently deforested land (Hamilton et al., 2010). Agroforestry practices entail the integration of trees into agricultural systems, in combination with crops, livestock or both. Afforestation, and reforestation, and agroforestry projects form part of several voluntary and mandatory carbon-offset trading schemes worldwide (Diaz et al., 2011; Miles and Sonwa, 2015).

Globally, the carbon dioxide removal potential for afforestation and reforestation options is quite significantit has been estimated at between 4 and $12 \mathrm{GtCO}_{2}$ per year (Smith et al., 2016), with other recent estimates even higher, at up to $28 \mathrm{GtCO}_{2}$ per year (Griscom et al., 2017). Preparation and deployment can be done at a relatively modest cost ${ }^{3}$, with the potential for co-benefits. The existence of various projects today, and the experience of forest managers worldwide, provide a high level of technical readiness for afforestation and reforestation options ${ }^{4}$. As such, afforestation and reforestation are considered established carbon dioxide removal options and projects could feasibly be launched soon.

Ultimately, achieving large carbon removal rates and volumes would require very large tracts of land (Houghton et al., 2015; Kriedenweis et al. 2016) and potentially huge volumes of water (Trabucco et al., 2008), although vegetation density is positively correlated with the strength of precipitation sheds and has a moderating effect on the volatility of water availability-in this regard, distant effects might be different and as such, more research is required. Competition for land and water used for food production is a development concern, but could be minimized through agroforestry ${ }^{5}$ or careful selection of appropriate land areas for afforestation and reforestation. There are significant uncertainties around

2 While agroforestry is widely present in the tropics, there are many agroforestry systems in temperate and even boreal regions. For example, according to Aertsens et al. (2013), 90 percent of Europe's mitigation potential in the agriculture sector stems from agroforestry.

For example, Nielsen et al. (2014) report that, within the United States of America, up to $730 \mathrm{MtCO}_{2}$ per year might be sequestered at a carbon price below US\$50 per tonne of carbon.

Political and planning readiness varies between countries.

5 Such competition is avoided in agroforestry systems, which allow integrated management of agricultural landscapes for food production and the delivery of ecosystem services (Zomer et al., 2016; Kimaro et al., 2011; WilliamsGuillén et al., 2008). 
the impacts on non-carbon dioxide greenhouse gases (Benanti et al., 2014), albedo (Kirschbaum et al., 2011; Zhao and Jackson, 2014), evapotranspiration, emissions of volatile organic compounds and other issues ${ }^{6}$. Obstacles may also arise with regard to monitoring, sustaining sequestered carbon in the long term due to sink saturation, changing practices among forest managers and farmers, and creating market and policy contingencies. Despite these uncertainties and obstacles, experience with managing forests stands in our favour for adopting these options, which, as previously mentioned, also have the potential to contribute to other global sustainability goals.

\subsubsection{Other 'natural', land-based solutions}

Other natural, land-based carbon dioxide removal solutions rely on the restoration or construction of high carbon density, anaerobic ecosystems, including "inland organic soils and wetlands on mineral soils, coastal wetlands including mangrove forests, tidal marshes and seagrass meadows, and constructed wetlands for wastewater treatment" (IPCC, 2014). Hereinafter, these solutions are referred to as wetlands. It is increasingly critical to not only preserve existing wetlands, but also to restore and construct these ecosystems for use as carbon dioxide removal solutions.

Peatlands and coastal wetlands store up to 44 to 71 percent of the world's terrestrial biological carbon pool (Zedler and Kercher, 2005). While the carbon stocks in peatlands and coastal wetlands are now vulnerable to reversal (Parish et al., 2008), these ecosystems also have significant carbon sequestration capacity (Page and Hooijer, 2016).

Compared to afforestation and reforestation options, much less is known about wetlands. Roughly one third of global wetland ecosystems had been lost by 2009 (Hu et al., 2017), suggesting there are a number of locations where work could begin. Long-term sequestration rates in wetlands range from 0.1 to 5 tonnes of carbon per hectare and per year, a rate that significantly improves when emissions avoided from (previously degraded) restored wetlands are counted (Parish et al., 2008; Mitsch et al., 2012; Smith et al., 2008). However, estimating global rates and volumes is challenging. Carbon dioxide abatement costs for wetland restoration range from US\$10 to US\$100 per tonne of carbon dioxide (Worrall et al., 2009), suggesting potential low-cost options for projects.

Little is known about the total land and water requirements needed to achieve substantial and sustainable levels of carbon dioxide removal through wetlands. However, noncarbon dioxide greenhouse gases represent a substantial risk. While wetlands store significant amounts of carbon in above- and below-ground biomass, and in soil, they have also historically been a significant source of methane, with estimates ranging from 20 to 25 percent of global methane emissions (Mitsch et al., 2012). As such, restoring some wetlands could induce a short-term net warming effect (Mitsch et al., 2012) due to increased emissions of methane

6 These uncertainties could be reduced or better characterized through a dedicated science programme aimed at understanding the issues across ecosystems, latitudes and climate zones. and nitrous oxide ${ }^{7}$. In addition, while some sites may be suitable for early remediation, in other instances, sites of former wetlands have been converted to ports, industrial sites and other high-value capital assets, which limits the extent to which they can be used for carbon dioxide removal. Griscom et al. (2017) estimate that avoided coastal wetland impacts, avoided peat impacts and peat restoration could deliver $0.3,0.7$ and $0.8 \mathrm{GtCO}_{2}$ per year, respectively, by 2030. As with forest management, wetlands and peatlands have been managed by humans for many years, which provides an opportunity to capitalize on existing knowledge and on the readiness to implement measures (Griscom et al., 2017). There is also the added potential to contribute to other global sustainability goals such as improved water quality, ecosystem restoration, biodiversity preservation and job creation.

\subsubsection{Soil carbon sequestration}

Soil carbon sequestration occurs when a change in land management practices increases the carbon content of soil, thus resulting in a net removal of carbon dioxide from the atmosphere. Since the level of carbon in the soil is a balance of carbon inputs (for example, from litter, residues, roots or manure) and carbon losses (mostly through respiration, which is increased by soil disturbance), practices that either increase inputs or reduce losses can promote soil carbon sequestration. Lal $(2011,2013)$ and Smith et al. $(2008,2014)$ cite a large number of land management practices that can promote soil carbon sequestration, some of which can also promote carbon sequestration in above-ground biomass.

Soil carbon sequestration uses agricultural and land management practices that are generally well known by farmers and land managers, and for the most part, does not require additional machinery or infrastructure. It therefore represents a readily available option to be implemented.

Rates for soil carbon sequestration vary considerably, depending on land management approaches, soil type and climate region (Smith, 2012; Lal, 2013). When scaled globally, the technical potential for soil carbon sequestration is estimated at $4.8 \mathrm{GtCO}_{2}$ e per year (Smith, 2016) ${ }^{8}$. Assuming unit costs between US\$20 and US\$100 per tonne of carbon, the global carbon emissions mitigation potential of soil carbon sequestration ranges between 1.5 and $2.6 \mathrm{GtCO}_{2} \mathrm{e}$ per year (Smith et al., 2008; Smith, 2016). It is worth noting that for some systems, such as croplands and grazing lands, soil carbon sequestration costs range from minus US\$45 to plus US\$10 per tonne of carbon (Smith, 2016), suggesting there are revenues and cost savings to be made from some of these practices ${ }^{9}$. Smith (2016) estimated that carbon dioxide removal through soil carbon sequestration at a rate of

\footnotetext{
Dedicated and sustained research is needed to resolve or reduce these uncertainties.

Other estimates range between $0.4 \mathrm{GtCO}_{2}$ e per year (Powlson et al., 2014) and 11.4 GtCO e per year (Lal, 2011; Lal, 2013; Minasny et al., 2017).

9 Most of the annual estimates are based on sequestration values calculated over 20 years. Given that sinks saturate, annualized sequestration estimates should be multiplied by 20 to derive the total cumulative sequestration potential.
} 
$2.6 \mathrm{GtCO}_{2}$ e per year would save US\$7.7 billion, comprising US\$16.9 billion of savings and US\$9.2 billion of costs.

Although the apparent energy costs for soil carbon sequestration appear low, and in many cases, soil carbon sequestering practices would benefit soil ecosystems and agribusinesses, implementing these practices involves a significant range of potential land requirements (Smith et al., 2010). While emissions from methane may be limited, soil carbon sequestration may result in emissions of nitrous oxide (Smith, 2016). As for wetlands, dedicated and continued research on these uncertainties and challenges could help reduce risks and improve performance.

Barriers to implementation include lack of knowledge among farmers, lack of policy incentives, monitoring and verification of practices and costs and crucially, reversibility of stored carbon. Dedicated pilot projects and programmes could help to identify the measures required to overcome these barriers, with an emphasis on learning-by-doing and resolving key uncertainties through data acquisition and development of practices. Since soils have been managed for millenniums, there is a high level of knowledge and readiness, with the potential to contribute to other global sustainability goals such as improved water quality, ecosystem restoration, biodiversity preservation, job creation and increased yields and food security.

\subsubsection{Biochar}

Biochar is produced through pyrolysis of biomass into a stable, long-lived product, such as charcoal. Biochar is resistant to decomposition (Lehmann et al., 2015) and can stabilize organic matter added to soil (Weng et al., 2017). It can form long-term carbon pools in the soil and provide a range of soil fertility and soil quality co-benefits, such as improved water and nutrient retention, increased soil porosity and higher crop yields.

While biochar can be applied at high rates (Genesio et al., 2012; Zhang et al., 2010), the net benefits of biochar are likely to be higher if applied in low volumes in the most responsive soils ${ }^{10}$. The carbon dioxide removal potential through biochar is high: it has been estimated at between 1.8 and $3.3 \mathrm{GtCO}_{2}$ e per year (Woolf et al., 2010). However, the efficacy of biochar for carbon dioxide removal is disputed ${ }^{11}$. Costs range between US\$18 and US\$166 per tonne of carbon dioxide-equivalent per year (Woolf et al., 2010), although economic benefits and revenues could offset part of this cost.

Although biochar is an established technology, it is not yet widely applied, in part due to costs and the (limited) availability of infrastructure. Additional infrastructure (namely pyrolysis facilities) would be required for large-scale implementation. Indeed, the quantity of biomass available for biochar production is a key factor limiting the global

10 Notably after enhancement through co-composting or nutrient addition (Joseph et al., 2013).

11 Interestingly, biochar can reduce non-carbon dioxide greenhouse gases, notably nitrous oxide (Cayuela et al., 2015). potential for carbon dioxide removal through biochar. Energy and water are also required to produce the crop feedstocks, although producing biochar can also produce power and fuels ${ }^{12}$. While the land use for carbon dioxide removal through biochar appears relatively modest (between 26 and 95 million hectares), estimates are dependent on land and crop quality. Not least, carbon dioxide-reduction benefits may be mitigated by albedo reduction (Bozzi et al., 2015). Although the risks of reversibility and difficulty of monitoring are lower than for soil carbon sequestration, barriers such as limited knowledge of practice or policy support remain.

\subsection{Combined land/technology-based option: bioenergy with carbon dioxide capture and storage}

Bioenergy with carbon dioxide capture and storage removes carbon dioxide from the atmosphere through the cultivation of biomass (bioenergy), and stores carbon dioxide from energy generation in deep, geological formations (carbon dioxide capture and storage), providing net carbon removal. So far, this is the carbon dioxide removal technology that has featured most prominently in the mitigation scenarios by the Intergovernmental Panel on Climate Change (Fuss et al., 2016; Fuss, 2017).

Many integrated assessment models estimate the availability of sustainable bioenergy at 100 exajoules per year (Creutzig et al., 2015; Slade et al., 2014) ${ }^{13}$; fewer models accommodate estimates above 300 exajoules per year.

With regard to carbon dioxide capture and storage, estimates for geological storage capacity are well above 5,000 $\mathrm{GtCO}_{2}$. However, the estimated capacities are not viable in all locations (Scott et al., 2015; De Coninck and Benson, 2014; Lassiter and Misra, 2016; Global CCS Institute, 2016).

The combined potentials of bioenergy and carbon dioxide capture and storage in 2050 are estimated at between 2 and $18 \mathrm{GtCO}_{2}$ per year (Kemper, 2015; USNAS 2015a; McLaren, 2012). To achieve this scale, the demands on land use are significant: a level of carbon dioxide removal consistent with average $2^{\circ} \mathrm{C}$ emissions pathways would require between 0.38 and 0.7 billion hectares of crops purpose-grown for bioenergy with carbon dioxide capture and storage (Smith et al., 2016) ${ }^{14}$. Under more conservative assumptions, the demands on land use would be even higher (Monfreda et al., 2008).

Use of agricultural and forest residue as a feedstock for bioenergy does not require competition for land, although its extraction can adversely impact soil carbon stocks (Smith et al., 2016). The potential competition for land from widespread use of bioenergy with carbon capture and

12 Net energy balances remain controversial and dependent on process, feedstock and products.

13 Roughly, this represents 15 percent of global primary energy consumption today.

14 For comparison, global agriculture today, including both farming and grazing, requires roughly 5 billion hectares of land. 
storage remains a major issue for large-scale bioenergy with carbon capture and storage deployment and policymaking.

In a scenario consistent with the $2^{\circ} \mathrm{C}$ target, infrastructure investment costs associated with bioenergy with carbon dioxide capture and storage in 2050 are estimated at US\$138 billion per year for power and US\$123 billion per year for fuels (Smith et al., 2016). Nonetheless, there are significant variations in unit costs for bioenergy and with carbon dioxide capture and storage, depending on assumptions about feedstock, technology, supply chains and logistics ${ }^{15}$.

For a level of bioenergy with carbon capture and storage deployment consistent with a $2^{\circ} \mathrm{C}$ target, 170 exajoules per year of energy would be generated from bioenergy with carbon capture and storage by 2100 (Smith et al., 2016).

Bioenergy with carbon dioxide capture and storage could have a large impact on water use, requiring about $720 \mathrm{~km}^{3}$ per year or roughly 3 percent of the fresh water currently appropriated for human use (Smith et al., 2016). Non-carbon dioxide greenhouse gas impacts are value-chain specific and uncertain, as are global albedo effects (Bright et al., 2015; Jones et al., 2015). Taken together, these considerations suggest that (i) over the next 10 to 20 years, carbon reduction using combined land- and technology-based options will be challenging; and (ii) there are risks associated with largescale implementation of these options.

Three main barriers stand out with regard to large-scale implementation of bioenergy with carbon dioxide capture and storage. Firstly, carbon dioxide capture and storage and bioenergy enjoy little public acceptance (Benson et al., 2012; Upham and Roberts, 2011; Wallquist et al., 2012; de Best-Waldhober et al., 2009). Secondly, whether there are substantial, or even any carbon reductions when accounting for displaced activities is unclear (Havlík et al., 2011; Frank et al., 2013; Searchinger et al., 2009; Plevin et al., 2010, Creutzig et al., 2015; Popp et al., 2012). Thirdly, the lack of economic incentives and the regulatory barriers related to underground storage hamper large-scale implementation (De Coninck and Benson, 2014) ${ }^{16}$.

McLaren (2012) reports a technological readiness level of 4 to 6 for bioenergy with carbon dioxide capture and storage from combustion and co-firing, and a technological readiness level of 5 to 6 for bioenergy with carbon dioxide capture and storage from ethanol fermentation (technological readiness level 6 corresponds to "prototype demonstration in the 'relevant' real-world environment" and technological readiness level 4 to the stage of "component validation"). Although individually, both bioenergy and carbon dioxide capture and storage are relatively mature technologies, in combination they have seen very little demonstration and

15 Estimates of cost per tonne of carbon dioxide range from US\$60-250 (Kemper, 2015), to US\$70-250 (McLaren, 2012), to as little as US\$15-45 for bioenergy and carbon dioxide capture and storage from ethanol fermentation.

16 Current low carbon prices deter investments in bioenergy with carbon dioxide capture and storage. The withdrawal of public support for these technologies (as was the same effect. deployment, especially at a large scale. Whether bioenergy with carbon dioxide capture and storage can thus be scaled up in the manner required to achieve ambitious climate change targets remains questionable, given the lag in actual carbon dioxide capture and storage deployment, compared to the requirements associated with emissions pathways that are compatible with the $2^{\circ} \mathrm{C}$ target (Peters et al., 2017; Peters and Geden, 2017).

\subsection{Technology-based carbon dioxide removal options}

Man-made technologies to remove carbon dioxide from the air have been in use for many years, mostly in submarine, aerospace and medical applications. Consideration of them as global-scale carbon removal agents is recent (USNAS, 2015a). They offer specific benefits in that they use very little land or water, they do not emit non-carbon dioxide greenhouse gases and they have very high levels of certainty regarding the flux and long-term fate of the carbon dioxide removed. Some approaches also produce materials that can be used commercially, for example, cements and aggregates.

However, many approaches are expensive. Most have not been deployed at scale and have a low level of technical readiness. Investment in developing these options will likely yield breakthroughs in material science and manufacturing, and could spur new industries and a circular carbon economy (McDonough, 2016; Center for Carbon Removal, 2017), as was true for lithium-ion batteries 25 years ago (The Economist, 2017). Nonetheless, among the 23 countries committed to undertaking large-scale research and development programmes in this and related areas, only the United Kingdom has financed technology-based carbon dioxide removal programmes, and at a modest level of $£ 8.6$ million (approximately US\$11.3 million) per year (NERC, 2017).

Each option has strengths, uncertainties and constraints. The low level of readiness facing many technologies is perhaps the most pressing issue.

\subsubsection{Direct air capture}

Direct air capture is the practice of separating carbon dioxide from ambient air, typically through chemical or physical separation (Lackner et al., 1999; Sanz-Peres et al., 2016). Early approaches to this process have been applied in aerospace and submarine settings, to provide environmental controls (Keith et al., 2006). To achieve carbon removal and negative emissions, direct air capture would have to be combined with carbon-dioxide capture and storage or carbon dioxide conversion to long-lived materials (see below) ${ }^{17}$.

To yield negative emissions, direct air capture combined with carbon dioxide capture and storage must be powered predominantly by zero-carbon energy sources (wind, solar,

17 Several companies have fielded direct air capture units (Marshall, 2017; Lassiter and Misra, 2016). Most of these produce fresh water as a by-product (American Physics Society, 2011). Niche applications could include the food and beverage industry, semiconductor manufacturing and remote sites for enhanced oil recovery (Lassiter and Misra, 2016). 
geothermal, hydro and nuclear). Although this approach has a technical potential above $20 \mathrm{GtCO}_{2}$ per year, actual global deployment is likely to result in reductions of between 2 and $5 \mathrm{GtCO}_{2}$ per year (USNAS, 2015a).

Cost remains the largest barrier to deployment. Since direct air capture involves separating carbon dioxide from air, and the partial pressure of carbon dioxide in air is low, costs can be between US\$200 and US\$600 per tonne (American Physics Society, 2011) ${ }^{18}$. Like bioenergy with carbon dioxide capture and storage, direct air capture combined with carbon dioxide capture and storage would require functional scale deployment of carbon dioxide capture and storage, which represents both a potential limit and cause for renewed commitments to the technology (Center for Carbon Removal, 2017).

It is worth noting that it is possible to directly separate dissolved carbon dioxide from ocean water and from air. This could provide an additional benefit as a local or global countermeasure to ocean acidification. However, research on dissolved ocean carbon dioxide is very recent and at very low technical readiness levels (Willauer et al., 2014) ${ }^{19}$.

\subsubsection{Accelerated weathering of minerals}

It has long been known that natural weathering of most rocks (silicates, carbonates and oxides) binds carbon dioxide from the atmosphere (Chamberlain, 1899; Raymo, 1991). Accelerated weathering has been proposed as a means of either drawing carbon dioxide from the air, binding it permanently, or both (Lackner et al., 1995; Chiang and Pan, 2017). Much of this research proposes using rocks that are very rich in iron, calcium and magnesium (ultramafic rocks) as the primary feedstock, and reacting these in situ or ex situ with carbon dioxide to form carbonate rocks and minerals, locking away atmospheric carbon dioxide in the process (Kelemen and Matter, 2008).

While the technical potential of accelerated weathering is, in theory, unlimited (IPCC, 2005), the effective technical potential is not. This is due to the kinetics of most carbon dioxide mineral reactions, which are slow and limit the viable rates for carbon dioxide removal. Not least, the technical potential can be limited by the rate at which the ground material can be applied to land (Smith et al., 2016, Taylor et al., 2016). Global estimates of potential for accelerated weathering of minerals are in the range of 0.7 and $3.7 \mathrm{GtCO}_{2}$ per year (Lenton, 2014; Smith et al., 2016).

While kinetics can be improved by grinding, drilling and deep, in situ injection, adding heat or other energy sources, or adding chemicals (such as strong acids), these approaches dramatically increase costs and can increase the carbon intensity of the overall process ${ }^{20}$. These estimates are poorly

18 Specialized companies claim much lower prices today (a maximum of US\$500 per tonne) and cost reductions of about 50 percent in the next 10 years.

19 Nonetheless, the United States Senate recently asked the National Academies to undertake an assessment on the matter (Whitehouse, 2017).

20 Costs would range between US\$20 and US\$1,000 per tonne of carbon dioxide (USNAS, 2015a). represented in the literature, thus necessitating additional research in this area.

Since carbon dioxide is bound indefinitely in chemical form, there is both high confidence in carbon dioxide retention for many years, and robustness in accounting and validation of carbon storage and removal. For ex situ approaches, revenues from product sales, including agricultural inputs or aggregate and cement for construction offer an additional benefit (Monkman and MacDonald, 2015; $\mathrm{CO}_{2}$ Sciences, 2016) ${ }^{21}$.

\subsubsection{Ocean alkalinity enhancement}

The addition of alkaline materials to sea water enhances the amount of carbon stored in the ocean. It draws carbon dioxide from the atmosphere by shifting the equilibrium between atmospheric carbon dioxide and dissolved inorganic carbon in the ocean, which also serves to counter ocean acidification. While ocean alkalinity enhancement has received very little attention, compared to other carbon dioxide removal options, it has the potential "to sequester hundreds of billions to trillions of tonnes of [carbon]" (Renforth and Henderson, 2017).

Ocean alkalinity can be enhanced in a number of ways:

- Weathering of silicate and carbonate minerals on land, resulting in the introduction of calcium and magnesium ions into ocean waters (Hartmann et al., 2013; Rau et al., 2007).

- Introducing calcium ions into ocean water by adding calcium oxide or calcium hydroxide to sea water, a procedure often referred to as ocean liming (Kheshgi, 1995; Renforth and Kruger, 2013).

- Electrolysis of sea water, often referred to as electrochemical splitting, to increase aqueous sodium hydroxide (House et al., 2007) or to accelerate the dissolution of calcium carbonate (Rau et al., 2004).

Few techno-economic assessments of these approaches exist. Preliminary estimates range from US\$10 to US\$600 per tonne of carbon dioxide for weathering of silicate and carbonate minerals, US\$72 to US\$159 per tonne of carbon dioxide for ocean liming and US\$14 to US\$190 per tonne of carbon dioxide for electrochemical splitting (Renforth and Henderson, 2017).

The availability of suitable minerals close to oceans would limit deployment. Notwithstanding, environmental concerns and governance considerations may prove to be the primary barrier to implementation. Regarding the former, the consequences of increased alkalinity on marine ecosystems are poorly understood (Henderson et al., 2008) 22 . Regarding the latter, the addition of alkaline materials to the ocean would fall within the remit of the International

21 Early niche applications are likely at diamond, base-metal and asbestos mines with tailings of carbon dioxide-reactive rocks that have already been processed for primary mineral extraction.

22 Note that the addition of alkaline materials would counteract ocean acidification. 
Maritime Organization, through the London Protocol to the "Convention on the Prevention of Marine Pollution by Dumping of Wastes and Other Matter" (also known as the "London Convention") ${ }^{23}$.

\subsubsection{Conversion of carbon dioxide to long-lived products}

The concept of using carbon dioxide to produce chemicals and materials was already being developed in the context of chemical research in the 1970s, long before climate change and the possibilities for removing $\mathrm{CO}_{2}$ from the atmosphere entered the public debate (Aresta, 2010; Bruhn et al., 2016). Most of these technologies have not been developed with long-term storage of carbon dioxide in mind. In addition, most materials based on captured carbon dioxide (for example, polyurethane foams or fuels such as ethanol) only have limited lifetimes in the context of the timescales that are relevant to climate change (Aresta, 2013; CLCF, 2011). An exception to this is carbonates, which are used to produce cement-like construction materials in which long-term (decades to centuries) sequestration of carbon dioxide can be achieved (von der Assen, Jung et al., 2013; Bruhn, 2016), as noted above.

Recently, there has been new research and commercial activity focused on converting carbon dioxide directly to other long-lived materials, including polymers, carbon fibre composites, graphene, carbon black and even diamond (ICEF, 2017). Although these companies and research efforts are in their infancy, they have attracted substantial commercial interest. Due to the early stages of development, it is difficult to estimate the upscaling potential of the various approaches. A recent estimate puts the annual market for these materials between 1 and $7 \mathrm{GtCO}_{2}$ per year, although this is contingent on policy- and market-support actions ( $\mathrm{CO}_{2}$ Sciences, 2016).

\subsection{Governance issues for carbon dioxide removal}

Realizing the potential of carbon dioxide removal would require large-scale investment in research (to reduce key uncertainties), and development and deployment incentives (to reduce costs). Governments can play a key role in providing the funding and incentives needed to achieve these investments (Lomax et al., 2015; Peters and Geden, 2017).

Firstly, government policy can work to protect communities from any potential, negative side-effects (environmental, economic, social, political and ethical) associated with largescale deployment of carbon dioxide removal solutions (Buck, 2016). Secondly, governments can set consistent standards for transparency, notably with regard to the measurement and verification of carbon stored from a given carbon dioxide removal solution (Zakkour et al., 2014). Thirdly, they can require that standards accept products arising

23 The London Convention is examining ocean alkalinity enhancement. from carbon dioxide-reduction approaches ${ }^{24}$. And finally, they would have to develop international agreements with regard to the transboundary effects of these technologies (Schäfer et al., 2015)

There is currently limited discussion on carbon dioxide removal issues in most subnational and international climate policy forums. Policymakers might consider giving attention to the importance of carbon dioxide removal, the risks and challenges faced by leading carbon dioxide removal solutions and the policy options for addressing these risks and challenges (Williamson, 2016). This is because, to achieve the objectives of the Paris Agreement, mobilizing a rapid reduction of greenhouse gas emissions will be essential. Carbon dioxide removal can play an important role in meeting these objectives. However, to do so, enabling actions on carbon dioxide removal will be required, including more extensive policy discussions and focus on specific barriers to deployment (Peters and Geden, 2017).

Many key uncertainties can be explored using a learning-bydoing approach, notably by undertaking research and smallscale deployment activities (Lomax et al., 2015). All of the approaches described in this chapter have initiated or can initiate small- and large-scale pilot projects, from which data on cost, performance and improvement opportunities can be drawn (IEA, 2017). Some efforts, such as afforestation or reforestation projects, have begun under the jurisdiction of United Nations programmes that could be expanded or rapidly scaled up. Scenarios that show net emissions turning negative in the second half of the $21^{\text {st }}$ Century can give the false impression that there is no urgency. However, to achieve those scenarios will require significant amounts of gross negative emissions by 2030 at the latest (Rogelj et al., 2015; Anderson and Peters, 2016), and advancing techniques to maturity usually takes decades.

\subsection{Conclusions and recommendations}

Carbon dioxide removal remains an important set of undertakings following the Paris Agreement, to supplement immediate and aggressive mitigation action. In order to achieve the goals of the Paris Agreement, to keep the global mean temperature increase well below $2^{\circ} \mathrm{C}$ (or even below $\left.1.5^{\circ} \mathrm{C}\right)$, carbon dioxide removal is likely a necessary step.

Although there is much ongoing work worldwide on this topic, the field of carbon removal remains very young (particularly for technology-based solutions), with relatively little scholarship on the direct topic of carbon dioxide removal. In some cases, efforts aimed at strengthening approaches to carbon dioxide removal can build on deep understanding and experience from other industries, for example, agribusinesses or heavy industry. Nonetheless, specific questions concerning current and future costs of carbon dioxide removal options, the longevity of carbon retention, the environmental consequences of scale-level

24 For example, the International Civil Aviation Organization (ICAO) standards do not currently accept synthetic fuels made from carbon dioxide derived from direct air capture. 
deployment of carbon dioxide removal and other key questions remain largely unexplored. Critically, only one country in the world (the United Kingdom) has a government programme aimed explicitly at supporting carbon dioxide removal (NERC, 2017).

In light of the above, there are four key recommendations for consideration:

- Governments around the world might carefully assess the potential role of carbon dioxide removal in achieving the goals of the Paris Agreement. They would benefit : from understanding these technologies and the potential ancillary benefits they may provide to commerce and trade, such as improved crop yields.

- Governments and other stakeholders could launch joint research and development programmes on the many pathways for carbon dioxide removal. Such programmes would be appropriate, given that some carbon dioxide removal options are only at the early stages of development, and in light of the role they could play in curbing climate change. Both core scientific undertakings (for example, a decade-long science programme on the carbon cycle in soil) and technology development efforts (focused, for example, on novel materials and processes for direct air capture) could be included, possibly structured around pilot programmes and earlydemonstration activities, where progress can be made quickly and early-action opportunities can be identified and investigated.
Carbon dioxide removal presents specific challenges for life-cycle accounting, which will directly affect accounting standards, industrial standards, industrial and financial practice, and regulation. Emissions trading in particular would be complicated by carbon-negative approaches. Overt and dedicated analysis and efforts would be required to develop, refine and incorporate carbon dioxide removal approaches into these commercial and governmental endeavours.

- Some approaches raise questions around global governance in the near term (for example, ocean alkalinity enhancement vis-a-vis the London Convention). In addition, wide deployment of carbon dioxide removal raises fundamental questions about how to appropriately stabilize atmospheric carbon dioxide concentrations and how to manage interests globally and among nations. Dedicated working groups, perhaps modelled on the Climate and Clean Air Coalition and their work on shortlived climate pollutants, could be formed and begin discussing these issues.

- Since the land-based systems relevant for carbon dioxide removal have been managed by humans for many years, there is a wealth of knowledge that can be readily applied today with confidence. Furthermore, these approaches present opportunities to meet other global sustainability goals, such as improved water quality, ecosystem restoration, biodiversity preservation, food and nutrition security, job creation and improved crop yields. 


\section{References}

\section{Chapter 1}

UNEP (2016). 'The Emissions Gap Report 2016', United Nations Environment Programme (UNEP), Nairobi. Available at: http://www. google.com/url?sa=t\&rct=j\&q=\&esrc=s\&source=web\&cd=2\&ved=0ahUKEwiAncDtsfPWAhViQZoKHZt9CrAQFggwMAE\&url=http \%3A\%2F\%2Fwedocs.unep.org\%2Fbitstream\%2Fhandle\%2F20.500.11822\%2F10016\%2Femission_gap_report_2016.pdf\&usg=A OvVaw3gBleyjAH07zqiljLQw9N2 [Accessed 15 October 2017].

UNEP (2015). 'The Emissions Gap Report 2015', United Nations Environment Programme (UNEP), Nairobi. Available at: http:// uneplive.unep.org/media/docs/theme/13/EGR_2015_Technical_Report_final_version.pdf [Accessed 15 October 2017].

UNFCCC (2017). 'Initial feedback by Fiji and Morocco on the approach to the Facilitative Dialogue 2018 based on their consultations with Parties' United Nations Framework Convention on Climate Change (UNFCCC), Bonn Available at: http://unfccc.int/files/na/ application/pdf/preliminary_ideas.pdf [Accessed 20 October 2017].

UNFCCC (2015). 'The Paris Agreement', The Conference of the Parties. Available at: https://unfccc.int/resource/docs/2015/cop21/ eng/l09r01.pdf [Accessed 15 October 2017].

\section{Chapter 2}

Australian Government (2016) Australia's emissions projections 2016. http://www.environment.gov.au/system/files/resources/ 9437fe27-64f4-4d16-b3f1-4e03c2f7b0d7/files/aust-emissions-projections-2016.pdf: Department of the Environment and Energy, Australia.

Bappenas (2015) Sekretariat RAN-GRK. Available at: http://apki.net/wp-content/uploads/2015/07/Presentasi-INDC-BAPPENASdi-KLHK.pptx.

BP (2017) Statistical review of World Energy 2016, British Petroleum, http://www.bp.com/en/global/corporate/energy-economics/ statistical-review-of-world-energy.html.

Climate Action Tracker (2017a) Action by China and India slows emissions growth, President Trump's policies likely to cause US emissions to flatten. Policy Brief Climate Analytics, Ecofys and NewClimate institute, Available at: http://climateactiontracker. org/assets/publications/briefing_papers/CAT_2017-05-15_Briefing_India-China-USA.pdf [Accessed 7 August 2017].

Climate Action Tracker (2017b) Country assessment: Brazil (updated 17 May, 2017). Climate Action Tracker (Climate Analytics, Ecofys, NewClimate Institute). http://climateactiontracker.org/countries/brazil.html (Accessed 27 August, 2017).

Climate Action Tracker (2017c) Country assessment: China (updated 17 May, 2017). Climate Action Tracker (Climate Analytics, Ecofys, NewClimate Institute). http://climateactiontracker.org/countries/china.html (Accessed 27 August, 2017).

Climate Action Tracker (2017d) Country assessment: India (updated 17 May, 2017). Climate Action Tracker (Climate Analytics, Ecofys, NewClimate Institute). http://climateactiontracker.org/countries/india.html (Accessed 27 August, 2017).

Climate Action Tracker (2017e) Country assessment: Japan (updated 9 May, 2017). Climate Action Tracker (Climate Analytics, Ecofys, NewClimate Institute). http://climateactiontracker.org/countries/japan.html (accessed on 27 August, 2017).

Climate Action Tracker (2017f) Country assessment: South Africa (updated 6 July, 2017). Climate Action Tracker (Climate Analytics, Ecofys, NewClimate Institute). http://climateactiontracker.org/countries/southafrica.html (accessed on 27 August, 2017).

Climate Action Tracker (2017g) http://climateactiontracker.org/.

Climate Advisers (2017) Trumpbacktracker. https://www.climateadvisers.com/trumpbacktracker/.

Climate Transparency (2017) Brown to Green: The G20 transition to a low-carbon economy. Climate Transparency, c/o HumboldtViadrina Governance Platform, Berlin, Germany, www.climate-transparency.org.

Climateinteractive (2017) What Slashing Climate Rules Means For the U.S. Pledge to Paris, Available at: https://www.climateinteractive.org/media-coverage/what-slashing-climate-rules-means-for-the-u-s-pledge-to-paris/

Den Elzen, M., Admiraal, A., Roelfsema, M., Van Soest, H., Hof, A. F. \& Forsell, N. (2016a) Contribution of the G20 economies to the global impact of the Paris agreement climate proposals. Climatic Change, 137, 655-665.

Den Elzen, M. G. J., Fekete, H., Höhne, N., Admiraal, A., Forsell, N., Hof, A. F., Olivier, J. G. J., Roelfsema, M. \& Van Soest, H. (2016b) Greenhouse gas emissions from current and enhanced policies of China until 2030: Can emissions peak before 2030? Energy Policy, 89, 224-236. 
Department Of Environmental Affairs Republic Of South Africa (2011a) South Africa's Second National Communication under the United Nations Framework Convention on Climate Change, Available at: http://unfccc.int/resource/docs/natc/zafnc02.pdf [Accessed 14 October 2016].

Department Of Environmental Affairs Republic Of South Africa (2011b) Explanatory note: Defining South Africa's Peak, Plateau and Decline Greenhouse Gas Emission Trajectory. Available at: http://www.climateaction.org.za/cop17-cmp7/sa-governmentposition-on-climate-change [Accessed 24 October, 2017]

EEA (2014) Trends and projections in Europe 2014. European Environment Agency, EEA Report No 6/2016, http://www.eea.europa. eu/publications/trends-and-projections-in-europe-2014.

EEA (2016a) Total greenhouse gas emissions trends and projections - European Environment Agency [Online]. Available: http:// www.eea.europa.eu/data-and-maps/indicators/greenhouse-gas-emission-trends-6/assessment [Accessed 27 January 2017].

EEA (2016b) Trends and projections in Europe 2016 - Tracking progress towards Europe's climate and energy targets. European Environment Agency, EEA Report No 29/2016, https://www.eea.europa.eu/publications/trends-and-projections-in-europe.

Environment And Climate Change Canada (2017) Canadian Environmental Sustainability Indicators: Progress Towards Canada's Greenhouse Gas Emissions Reduction Target. https://www.ec.gc.ca/indicateurs-indicators/CCED3397-174A-4F0E-825891DCFE295B34/ProgressTowardsCanadaGHGEmissionsTarget_EN.pdf.

FAO (2017) FAOSTAT Production of live animals, crops, consumption of nitrogen fertilisers, burning - savannah. Available at: "http:// www.fao.org/faostat/en/" \ “data" [Accessed 24 October 2017] Figueres, C., Schellnhuber, H. J., Whiteman, G., Rockström, J., Hobley, A. \& Rahmstorf, S. 2017. Three years to safeguard our climate. Nature, 546, 593-595, doi:10.1038/546593a.

Government of Canada (2016) Canada's Second Biennial Report on Climate Change, Environment and Climate Change Canada, https://www.ec.gc.ca/ges-ghg/02D095CB-BAB0-40D6-B7F0-828145249AF5/3001\%20UNFCCC\%202nd\%20Biennial\%20 Report_e_v7_lowRes.pdf.

Government of Japan. (2016) Japan's Second Biennial Report Under the United Nations Framework Convention on Climate Change, Available at: http://unfccc.int/files/national_reports/biennial_reports_and_iar/submitted_biennial_reports/application/pdf/ japan_br2_revised.pdf [Online]. [Accessed].

Government of Russia. (2014) First Biennial Report of the Russian Federation [Online]. UNFCCC, Bonn, available at: http://unfccc. int/files/national_reports/biennial_reports_and_iar/submitted_biennial_reports/application/pdf/1br_rus_unoffical_translation_eng.pdf [Accessed 12 December 2014].

Government of Russia. (2015) Second Biennial Report of the Russian Federation [Online]. UNFCCC, Bonn, available at: http://unfccc. int/resource/docs/2016/trr/rus.pdf. [Accessed 2015].

Government of Brazil (2010) DECREE No. 7390, 9 December 2010. http://www.planalto.gov.br/ccivil_03/_Ato2007-2010/2010/ Decreto/D7390.htm

Government of Mexico (2012a) Mexico. México quinta comunicación nacional ante la Convención Marco de las Naciones Unidas sobre el Cambio Climático.: http://unfccc.int/resource/docs/natc/mexnc5s.pdf.

Government of Mexico (2012b) Programas para mitigar el cambio climático, Available at: http://www2.inecc.gob.mx/publicaciones/libros/685/programas2.pdf [Accessed 10 November 2015].

Grassi, G., House, J., Dentener, F., Federici, S., Den Elzen, M. \& Penman, J. (2017) The key role of forests in meeting climate targets requires science for credible mitigation. Nature Clim. Change, 7, 220-226.

Green, F. and Stern, N. (2017) China's changing economy: implications for its carbon dioxide emissions. Climate Policy, 17, $423-442$.

Hafstead, M. (2017) On Trump, Paris, and Greenhouse Gas Emissions. Retrieved August 7, 2017, from Resources for the Future: http://www.rff.org/blog/2017/trump-paris-and-greenhouse-gas-emissions.

IEA (2015) World Energy Outlook 2016, Paris, France, International Energy Agency.

IEA (2017) IEA finds $\mathrm{CO}_{2}$ emissions flat for third straight year even as global economy grew in 2016, Paris, France, International Energy Agency, https://www.iea.org/newsroom/news/2017/march/iea-finds-co -emissions-flat-for-third-straight-year-evenas-global-economy-grew.html.

Jackson, R. B., Canadell, J. G., Le Quere, C., Andrew, R. M., Korsbakken, J. I., Peters, G. P. \& Nakicenovic, N. (2016) Reaching peak emissions. Nature Clim. Change, 6, 7-10.

Janssens-Maenhout, G., Crippa, M., Guizzardi, D., Muntean, M., Schaaf, E., Dentener, F., Bergamaschi, P., Pagliari, V., Olivier, J. G. J., Peters, J. A. H. W., Van Aardenne, J. A., Monni, S., Doering, U. \& Petrescu, A. M. R. (2017) EDGAR v4.3.2 Global Atlas of the three major Greenhouse Gas Emissions for the period 1970-2012. Earth Syst. Sci. Data Discuss., 2017, 1-55 (in review).

Kuramochi, T., Höhne, N., Hagemann, M., Sterl, S., El-Laboudy, T., Wouters, K., Deng, Y., Blok, K., Hare, B., Schaeffer, M., Cantzler, J., Rocha, M., Deryng, D., Rogelj, J., Sindt, J. \& Yanguas Parra, P. (2016a) The ten most important short-term steps to limit warming to $1.5^{\circ} \mathrm{C}$. Climate Analytics, Ecofys and the Potsdam Institute for Climate Impact Research (PIK).

Kuramochi, T., Höhne, N., Sterl, S., Gonzales-Zuñiga, S., Hans, F., Hagemann, M., Hernandez Legaria, E., Den Elzen, M. G. J., Roelfsema, M., Van Soest, H., Forsell, N. \& Turkovska, O. (2016b) Greenhouse gas mitigation scenarios for major emitting countries: Analysis of current and planned climate policies, and mitigation pledges. Cologne, Germany: NewClimate Institute, PBL, IIASA, http://www.pbl.nl/en/publications/greenhouse-gas-mitigation-scenarios-for-major-emitting-countries.

Ministry of The Environment and Sustainable Development Argentina. (2015) Tercera Comunicación Nacional del Gobierno de la República Argentina a las Partes de la Convención Marco de las Naciones Unidas sobre Cambio Climático [Online]. Secretaría de Ambiente y Desarrollo Sustentable de la Nación. Available: http://unfccc.int/resource/docs/natc/argnc3s.pdf [Accessed 4 August 2016].

Mitra, A., Chitkara, P., Ross, K., Singh, M., Sawhney, S., Keswani, S. \& Batra, P. (2017) Pathways for Meeting India's Climate Goals. Washington DC, USA: World Resource Institute.

NCCS (2013) National Climate Change Strategy. 10-20-40 Vision. Mexico: Federal Government of Mexico.

Olivier, J. G. J., Peters, J. A. H. W. \& Schure, K. M. (2017) Trends in global emissions of $\mathrm{CO}_{2}$ and other greenhouse gases: 2017 Report. PBL report no. 2674, PBL Netherlands Environmental Assessment Agency, Bilthoven, the Netherlands, http://www.pbl.nl/en/ news/newsitems/2017/greenhouse-gas-emission-levels-continued-to-rise-in-2016.

PBL (2017) PBL Climate Pledge NDC tool, www.pbl.nl/indc. PBL Netherlands Environmental Assessment Agency. 
Peters, G. P., Andrew, R. M., Canadell, J. G., Fuss, S., Jackson, R. B., Korsbakken, J. I., Le Quere, C. \& Nakicenovic, N. (2017) Key indicators to track current progress and future ambition of the Paris Agreement. Nature Clim. Change, 7, 118-122.

Planning Commission Government of India (2011) Low Carbon Strategies for Inclusive Growth: An Interim Report. Interim Report of the Expert Group on Low Carbon Strategies for Inclusive Growth, New Delhi, India, http://moef.nic.in/downloads/publicinformation/Interim\%20Report\%20of\%20the\%20Expert\%20Group.pdf.

Planning Commission Government of India (2014) The Final Report of the Expert Group on Low Carbon Strategies for Inclusive Growth. Interim Report of the Expert Group on Low Carbon Strategies for Inclusive Growth, New Delhi, India, http://planningcommission.nic.in/reports/genrep/rep_carbon2005.pdf.

Republic of Korea. (2016) Submission by the Republic of Korea: Intended Nationally Determined Contribution [Online]. UNFCCC. Available: http://www4.unfccc.int/ndcregistry/PublishedDocuments/Republic\%20of\%20Korea\%20First/INDC\%20Submission\%20by\%20the\%20Republic\%20of\%20Korea\%20on\%20June\%2030.pdf [Accessed 28 July 2017].

Republic of Turkey Ministry of Environment and Urbanization (2016) Sixth National Communication of Turkey. Ankara, Turkey.

Reputex (2016) Framing Australia's 2030 energy \& climate policy mix. The contribution of safeguard sectors to Australia's 2030 emissions reduction target. http://www.reputex.com/wp-content/uploads/2016/09/0916_RepuTex-White-Paper_FramingAustralias-energy-policy-mix-to-2030.pdf: MARKET UPDATE | September 2016

Rhodium Group (2017) Taking Stock 2017: Adjusting Expectations for US GHG Emissions. Available at: http://rhg.com/reports/ taking-stock-2017-adjusting-expectations-for-us-ghg-emissions.

Rockström, J., Gaffney, O., Rogelj, J., Meinshausen, M., Nakicenovic, N. \& Schellnhuber, H. J. (2017) A roadmap for rapid decarbonization. Science, 355, 1269.

Sha, F., JI, Z. \& Linwei, L. (2015) An Analysis of China's INDC. Beijing, China: China National Center for Climate Change Strategy and International Cooperation.

Sha, F., JI, Z. \& Linwei, L. (2017) An Analysis of China's INDC (Updated analysis 2017) (MILES report). Beijing, China: China National Center for Climate Change Strategy and International Cooperation.

South Africa. Department of Environmental Affairs (2011) Explanatory note: Defining South Africa's Peak, Plateau and Decline Greenhouse Gas Emission Trajectory. Government of Republic of South Africa.: http://www.climateaction.org.za/cop17-cmp7/sagovernment-position-on-climate-change.

The Law National Information Center. (2016) Presidental Decree 27180 of 24 May, 2016 (enforced 1 June, 2016); partial amendment of the Enforcement Decree of the Framework Act on Low Carbon, Green Growth. The Law National Information Center, Korea [Online]. Ministry of Government Legislation. Available: $h t p: / / w w w . l a w . g o . k r / I s I n f o P . d o ? l s i S e q=183314 \& e f Y d=20160601 \# A J A X$ [Accessed 16 October 2016].

U.S. Department of State (2016) 2016 second biennial report of the United States of America, under the United Nations Framework Convention on Climate Change. US Department of State, Washington, DC, https://unfccc.int/files/national_reports/biennial_ reports_and_iar/submitted_biennial_reports/application/pdf/2016_second_biennial_report_of_the_united_states_.pdf.

UNEP (2016) The Emissions Gap Report 2016: A UNEP Synthesis Report [Online]. United Nations Environment Programme (UNEP), Nairobi. Available: http://www.unep.org/emissionsgapreport2016/ [Accessed 20 October 2017].

UNEP (2015) The Emissions Gap Report 2015: A UNEP Synthesis Report [Online]. United Nations Environment Programme (UNEP), Nairobi. Available: http://www.unep.org/emissionsgapreport2015/ [Accessed].

UNFCCC (2011) Compilation of information on nationally appropriate mitigation actions to be implemented by Parties not included in Annex I to the Convention. FCCC/AWGLCA/2011/INF.1, http://unfccc.int/resource/docs/2011/awglca14/eng/inf01.pdf

WRI (2016) CAIT Indonesia Climate Data Explorer - PINDAI [Online]. Available: http://cait.wri.org/indonesia?lng=en [Accessed 31 October 2016].

WRI CAIT (2017) Climate Analysis Indicators Tool: WRI's Climate Data Explorer. Washington DC, USA: World Resource Institute.

\section{Chapter 3}

Aldy, J. E., Pizer, W. A. \& Akimoto, K. (2016) Comparing emissions mitigation efforts across countries. Climate Policy, 1-15.

Andonova, L. B., Hale, T. N. \& Roger, C. B. (2017) National Policy and Transnational Governance of Climate Change: Substitutes or Complements? International Studies Quarterly, 61, 253-268.

Australian Government (2016) Australia's emissions projections 2016. http://www.environment.gov.au/system/files/ resources/9437fe27-64f4-4d16-b3f1-4e03c2f7b0d7/files/aust-emissions-projections-2016.pdf: Department of the Environment and Energy, Australia.

CAT (2017) Climate Action Tracker. Available at: http://climateactiontracker.org/ [Accessed 7 August 2017].

CDP and We Mean Business (2016) The Business End of Climate Change. Available at: https://newclimateinstitute.files.wordpress. com/2016/06/business-end-of-climate-change.pdf.

CEC (2017) Power Generation Industry Information, CEC (China Electricity Council), Beijing [Online]. [Accessed 08/10/2017].

Central Electricity Authority (2016) Draft National Electricity Plan, Central Elctricity Authority (CEA), Ministry of Power, Government of India, http://www.cea.nic.in/reports/committee/nep/nep_dec.pdf

Chai, Q., Fu, S., XU, H., Li, W. \& Zhong, Y. (2017) The gap report of global climate change mitigation, finance, and governance after the United States declared its withdrawal from the Paris Agreement. Chinese Journal of Population Resources and Environment, 1-13.

Chan, S., Falkner, R., Goldberg, M. \& Van Asselt, H. (2016) Effective and geographically balanced? An output-based assessment of non-state climate actions. Climate Policy, 1-12.

Cheong Wa Dae (2017) Opening remarks by the President Moon Jae-In at the 2nd Annual Meeting of the AllB Board of Governors, 16 June, 2017, Jeju, the Republic of Korea. Cheong Wa Dae (the President's Office of the Republic of Korea). http://men.president.go.kr/activity/speeches.php?srh\%5Bview_mode\%5D=detail\&srh\%5Bseq\%5D=429\&srh\%5Bdetail_no\%5D=4 (accessed 18 July, 2017). 
China Statistic Year Book (2017) China Statistic Year Book 2017, China Statistic Publishing House, Beijing, available at: http://www. stats.gov.cn/tjsj/ndsj/2016/indexeh.htm.

Clarke, L., Jiang, K., Akimoto, K., Babiker, M., Blanford, G., Fisher-Vanden, K., Hourcade, J.-C., Krey, V., Kriegler, E., Löschel, A., Mccollum, D., Paltsev, S., Rose, S., Shukla, P. R., Tavoni, M., Zwaan, B. V. D. \& Vuuren, D. V. (2014) Assessing Transformation Pathways. In: Edenhofer, O., Pichs-Madruga, R., Sokona, Y., Farahani, E., Kadner, S., Seyboth, K., Adler, A., Baum, I., Brunner, S., Eickemeier, P., Kriemann, B., Savolainen, J., Schlömer, S., Stechow, C. V., Zwickel, T. \& Minx, J. C. (eds.) Climate Change 2014: Mitigation of Climate Change. Contribution of Working Group III to the Fifth Assessment Report of the Intergovernmental Panel on Climate Change. Cambridge, United Kingdom and New York, NY, USA: Cambridge University Press.

Climate Action Tracker (2017a) Action by China and India slows emissions growth, President Trump's policies likely to cause US emissions to flatten. Policy Brief Climate Analytics, Ecofys and NewClimate institute, Available at: http://climateactiontracker.org/ assets/publications/briefing_papers/CAT_2017-05-15_Briefing_India-China-USA.pdf [Accessed 7 August 2017].

Climate Action Tracker (2017b) Country assessment: Argentina (updated 17 May, 2017). Climate Action Tracker (Climate Analytics, Ecofys, NewClimate Institute). http://climateactiontracker.org/countries/argentina.html(Accessed 27 August, 2017).

Climate Action Tracker (2017c) Country assessment: Mexico (updated 6 July, 2017). Climate Action Tracker (Climate Analytics, Ecofys, NewClimate Institute). http://climateactiontracker.org/countries/mexico.html [Accessed 30 August, 2017].

Climate Action Tracker (2017d) Country assessment: Russian Federation (updated 11 May, 2017). Climate Action Tracker (Climate Analytics, Ecofys, NewClimate Institute). http://climateactiontracker.org/countries/russianfederation.html (accessed on 27 August, 2017).

Climate Action Tracker (2017e) Country assessment: Saudi Arabia (updated 10 May, 2017). Climate Action Tracker (Climate Analytics, Ecofys, NewClimate Institute). http://climateactiontracker.org/countries/saudiarabia.html (Accessed 27 August, 2017).

Climate Action Tracker (2017f) Country assessment: South Africa (updated 6 July, 2017). Climate Action Tracker (Climate Analytics, Ecofys, NewClimate Institute). http://climateactiontracker.org/countries/southafrica.html (accessed on 27 August, 2017).

Climate Action Tracker (2017g) Country assessment: Turkey (updated 17 May, 2017). Climate Action Tracker (Climate Analytics, Ecofys, NewClimate Institute). http://climateactiontracker.org/countries/turkey.html (Accessed 27 August, 2017).

Climate Action Tracker (2017h) http://climateactiontracker.org/.

Climate Advisers (2017) Trumpbacktracker. https://www.climateadvisers.com/trumpbacktracker/.

Climate Transparency (2017) Brown to Green: The G20 transition to a low-carbon economy. Climate Transparency, c/o HumboldtViadrina Governance Platform, Berlin, Germany, www.climate-transparency.org.

Climate Interactive (2017) Climate Scoreboard. US: Climate Interactive.

Climateinteractive (2017) What Slashing Climate Rules Means For the U.S. Pledge to Paris, Available at: https://www.climateinteractive.org/media-coverage/what-slashing-climate-rules-means-for-the-u-s-pledge-to-paris/

Compact Of Mayors (2015) Climate Leadership at the Local Level: Global Impact of the Compact of Mayors. Available at: https:// data.bloomberglp.com/mayors/sites/14/2016/01/BR_AggregationReport_Final_SinglePages-FINAL-2016.pdf.

Damassa, T., Fransen, T., Haya, B., Ge, M., Pjeczka, K. \& Ross, K. (2015) Interpreting INDCs: Assessing transparency of post-2020 greenhouse gas emissions targets for 8 top-emitting economies. Working Paper. Washington, DC: World Resources Institute. Available online at http://www.wri.org/publication/interpreting-indcs.

Den Elzen, M., Admiraal, A., Roelfsema, M., Van Soest, H., Hof, A. F. \& Forsell, N. (2016a) Contribution of the G20 economies to the global impact of the Paris agreement climate proposals. Climatic Change, 137, 655-665.

Den Elzen, M. G. J., Fekete, H., Höhne, N., Admiraal, A., Forsell, N., Hof, A. F., Olivier, J. G. J., Roelfsema, M. \& Van Soest, H. (2016b) Greenhouse gas emissions from current and enhanced policies of China until 2030: Can emissions peak before 2030? Energy Policy, 89, 224-236.

EEA (2016) Trends and projections in Europe (2016 - Tracking progress towards Europe's climate and energy targets. European Environment Agency, EEA Report No 29/2016, https://www.eea.europa.eu/publications/trends-and-projections-in-europe.

Environment And Climate Change Canada (2017) Canadian Environmental Sustainability Indicators: Progress Towards Canada's Greenhouse Gas Emissions Reduction Target. https://www.ec.gc.ca/indicateurs-indicators/CCED3397-174A-4F0E-825891DCFE295B34/ProgressTowardsCanadaGHGEmissionsTarget_EN.pdf.

Forsell, N., Turkovska, O., Gusti, M., Obersteiner, M., Elzen, M. D. \& Havlik, P. (2016) Assessing the INDCs' land use, land use change, and forest emission projections. Carbon Balance and Management, 11, 26.

Fricko, O., Havlik, P., Rogelj, J., Klimont, Z., Gusti, M., Johnson, N., Kolp, P., Strubegger, M., Valin, H., Amann, M., Ermolieva, T., Forsell, N., Herrero, M., Heyes, C., Kindermann, G., Krey, V., Mccollum, D. L., Obersteiner, M., Pachauri, S., Rao, S., Schmid, E., Schoepp, W. \& Riahi, K. (2017) The marker quantification of the Shared Socioeconomic Pathway 2: A middle-of-the-road scenario for the 21st century. Global Environmental Change, 42, 251-267.

Fuglestvedt, J. S., Shine, K. P., Berntsen, T., Cook, J., Lee, D. S., Stenke, A., Skeie, R. B., Velders, G. J. M. \& Waitz, I. A. (2010) Transport impacts on atmosphere and climate: Metrics. Atmospheric Environment, 44, 4648-4677.

Government of Argentina (2016) Primera Revisión de su Contribución Determinada a Nivel Nacional, http://www4.unfccc.int/ ndcregistry/PublishedDocuments/Argentina\%20First/17112016\%20NDC\%20Revisada\%202016.pdf.

Government of Russia. (2014) First Biennial Report of the Russian Federation [Online]. UNFCCC, Bonn, available at: http://un$\mathrm{fccc}$.int/files/national_reports/biennial_reports_and_iar/submitted_biennial_reports/application/pdf/1br_rus_unoffical_translation_eng.pdf [Accessed 12 December 2014].

Graichen, J., Healy, S., Siemons, A., Höhne, N., Kuramochi, T., Gonzales Zuñiga, S., Sterl, S., Kersting, J. \& Wachsmuth, J. (2017) International Climate Initiatives - A way forward to close the emissions gap? Initiatives' potential and role under the Paris Agreement. Berlin: Öko-Institut. Retrieved from https://www.umweltbundesamt.de/sites/default/files/medien/376/publikationen/ climate_change_22_2017.pdf.

Graichen, J., Healy, S., Siemons, A., Höhne, N., Kuramochi, T., Gonzales Zuñiga, S. \& Wachsmuth, J. (2016) Climate initiatives, national contributions, and the Paris Agreement. Berlin: Öko-Institut. Retrieved from http://www.oeko.de/oekodoc/2554/2016079-de.pdf.

Grassi, G., House, J., Dentener, F., Federici, S., Den Elzen, M. \& Penman, J. (2017) The key role of forests in meeting climate targets requires science for credible mitigation. Nature Clim. Change, 7, 220-226. 
Green, F. and Stern, N. (2017) China's changing economy: implications for its carbon dioxide emissions. Climate Policy, 17, 423-442.

Gütschow, J., Jeffery, L., Gieseke, R. \& Gebel, R. (2017) The PRIMAP-hist national historical emissions time series (1850-2014). V. 1.1. GFZ Data Services. http://doi.org/10.5880/PIK.2017.001.

Hafstead, M. (2017) On Trump, Paris, and Greenhouse Gas Emissions. Retrieved August 7, 2017, from Resources for the Future: http://www.rff.org/blog/2017/trump-paris-and-greenhouse-gas-emissions.

Höglund-Isaksson, L., Purohit, P., Amann, M., Bertok, I., Rafaj, P., Schöpp, W. \& Borken-Kleefeld, J. (2017) Cost estimates of the Kigali Amendment to phase-down hydrofluorocarbons. Environmental Science and Policy, 75, 138-147.

Höhne, N., Fekete, H., Den Elzen, M. G. J., Hof, A. F. \& Kuramochi, T. (2017) Assessing the ambition of post-2020 climate targets: a comprehensive framework. Climate Policy, 1-16.

IEA (2016) World Energy Outlook 2016, Paris, France, International Energy Agency.

IPCC (2014a) Climate Change 2014: Synthesis Report. Contribution of Working Groups I, II and III to the Fifth Assessment Report of the Intergovernmental Panel on Climate Change. In: CORE WRITING TEAM, PACHAURI, R. K. \& MEYER, L. A. (eds.). Geneva, Switzerland: IPCC.

IPCC (2014b) Summary for Policymakers. In: Edenhofer, O., Pichs-Madruga, R., Sokona, Y., Farahani, E., Kadner, S., Seyboth, K., Adler, A., Baum, I., Brunner, S., Eickemeier, P., Kriemann, B., Savolainen, J., Schlömer, S., Stechow, C. V., Zwickel, T. \& Minx, J. C. (eds.) Climate Change 2014: Mitigation of Climate Change. Contribution of Working Group III to the Fifth Assessment Report of the Intergovernmental Panel on Climate Change. Cambridge, United Kingdom, and New York, NY, USA: Cambridge University Press.

Jiang, K.-J., Tamura, K. \& Hanaoka, T. (2017) Can we go beyond INDCs: Analysis of a future mitigation possibility in China, Japan, EU and the U.S. Advances in Climate Change Research, 8, 117-122.

Kitous, A., Keramidas, K., Vandyck, T. \& Saveyn, B. (2016) GECO 016. Global Energy and Climate Outlook. Road to Paris. download at: http://ec.europa.eu/jrc/en/geco: Joint Research Centre.

Kitous, A., Keramidas, K., Vandyck, T., Saveyn, B., Van Dingenen, R., Spadaro, J. \& Holland, M. (2017) Global Energy and Climate Outlook 2017: How climate policies improve air quality. EUR 28798 EN, Publications Office of the European Union, Luxembourg, 2017, ISBN 978-92-79-73864-7, doi:10.2760/474356, JRC107944: Joint Research Centre.

Kuramochi, T., Höhne, N., Sterl, S., Gonzales-Zuñiga, S., Hans, F., Hagemann, M., Hernandez Legaria, E., Den Elzen, M. G. J., Roelfsema, M., Van Soest, H., Forsell, N. \& Turkovska, O. (2016) Greenhouse gas mitigation scenarios for major emitting countries: Analysis of current and planned climate policies, and mitigation pledges. Cologne, Germany: NewClimate Institute, PBL, IIASA, http://www.pbl.nl/en/publications/greenhouse-gas-mitigation-scenarios-for-major-emitting-countries.

Kuramochi, T., Höhne, N., Sterl, S., Lütkehermöller, K. \& Seghers, J.-C. (2017) States, cities and businesses leading the way: a first look at decentralized climate commitments in the US. NewClimate Institute, the Climate group.

Le Quéré, C., Moriarty, R., Andrew, R. M., Canadell, J. G., Sitch, S., Korsbakken, J. I., Friedlingstein, P., Peters, G. P., Andres, R. J., Boden, T. A., Houghton, R. A., House, J. I., Keeling, R. F., Tans, P., Arneth, A., Bakker, D. C. E., Barbero, L., Bopp, L., Chang, J., Chevallier, F., Chini, L. P., Ciais, P., Fader, M., Feely, R. A., Gkritzalis, T., Harris, I., Hauck, J., llyina, T., Jain, A. K., Kato, E., Kitidis, V., Klein Goldewijk, K., Koven, C., Landschützer, P., Lauvset, S. K., Lefèvre, N., Lenton, A., Lima, I. D., Metzl, N., Millero, F., Munro, D. R., Murata, A., Nabel, J. E. M. S., Nakaoka, S., Nojiri, Y., O’brien, K., Olsen, A., Ono, T., Pérez, F. F., Pfeil, B., Pierrot, D., Poulter, B., Rehder, G., Rödenbeck, C., Saito, S., Schuster, U., Schwinger, J., Séférian, R., Steinhoff, T., Stocker, B. D., Sutton, A. J., Takahashi, T., Tilbrook, B., Van Der Laan-Luijkx, I. T., Van Der Werf, G. R., Van Heuven, S., Vandemark, D., Viovy, N., Wiltshire, A., Zaehle, S. \& Zeng, N. (2015) Global Carbon Budget 2015. Earth Syst. Sci. Data, 7, 349-396.

Lee, D. S., Fahey, D. W., Forster, P. M., Newton, P. J., Wit, R. C. N., Lim, L. L., Owen, B. \& Sausen, R. (2009.) Aviation and global climate change in the 21st century. Atmospheric Environment, 43, 3520-3537.

Lee, D. S., Pitari, G., Grewe, V., Gierens, K., Penner, J. E., Petzold, A., Prather, M. J., Schumann, U., Bais, A., Berntsen, T., lachetti, D., Lim, L. L. \& Sausen, R. (2010) Transport impacts on atmosphere and climate: Aviation. Atmospheric Environment, 44, $4678-4734$.

Luderer, G., Kriegler, E., Delsa, L., Edelenbosch, O., Emmerling, J., Krey, V., Mccollum, D., Pachauri, S., Riahi, K., Saveyn, B., Tavoni, M., Vrontisi, Z., Van Vuuren, D., Arent, D., Arvesen, A., Fujimori, S., Iyer, G., Keppo, I., Kermeli, K., Mima, S., Ó, Broin, E., Pietzcker, R., Sano, F., Scholz, Y., Van Ruijven, B. \& Wilson, C. (2016) Deep Decarbonisation Towards $1.5^{\circ} \mathrm{C}-2^{\circ} \mathrm{C}$ Stabilisation - Policy findings from the ADVANCE project (first edition). ADVANCE, http://www.fp7-advance.eu/content/advance-key-findings.

Luderer, G., Pietzcker, R. C., Bertram, C., Kriegler, E., Meinshausen, M. \& Edenhofer, O. (2013) Economic mitigation challenges: how further delay closes the door for achieving climate targets. Environmental Research Letters, 8, 034033.

Michaelowa, K. and Michaelowa, A. (2017) Transnational Climate Governance Initiatives: Designed for Effective Climate Change Mitigation? International Interactions, 43, 129-155

Millar, R. J., Fuglestvedt, J. S., Friedlingstein, P., Rogelj, J., Grubb, M. J., Matthews, H. D., Skeie, R. B., Forster, P. M., Frame, D. J. \& Allen, M. R. (2017) Emission budgets and pathways consistent with limiting warming to $1.5^{\circ} \mathrm{C}$. Nature Geosci, 10, $741-747$.

Ministry of Science And Technology Of Brazil (2016) Third National Communication of Brazil to the United Nations Framework Convention on Climate Change.

Mitra, A., Chitkara, P., Ross, K., Singh, M., Sawhney, S., Keswani, S. \& Batra, P. (2017) Pathways for Meeting India's Climate Goals. Washington DC, USA: World Resource Institute.

Motie-Moe-Molit (2017) Joint press release by Ministry of Trade, Industry, and Energy (MOTIE), Ministry of Environment (MOE), and Ministry of Land, Infrastructure, and Transport (MOLIT) on the occasion of joint report to the President.

Nordhaus, W. D. (2017) Revisiting the social cost of carbon. Proceedings of the National Academy of Sciences, 114, $1518-1523$.

PBL (2017) PBL Climate Pledge NDC tool, www.pbl.nl/indc. PBL Netherlands Environmental Assessment Agency.

REN21 (2017) Renewables 2017: Global Status Report, available at: http://www.ren21.net/gsr-2017/ [Online]. Available: http:// www.ren21.net/gsr-2017/ [Accessed 08/10/2017].

Reputex (2016) Framing Australia's 2030 energy and climate policy mix. The contribution of safeguard sectors to Australia's 2030 emissions reduction target. http://www.reputex.com/wp-content/uploads/2016/09/0916_RepuTex-White-Paper_Framing-Australias-energy-policy-mix-to-2030.pdf: MARKET UPDATE | September 2016

Rhodium GROUP (2017a) Taking Stock 2017: Adjusting Expectations for US GHG Emissions. Available at: http://rhg.com/reports/ taking-stock-2017-adjusting-expectations-for-us-ghg-emissions. 
Rhodium GROUP (2017b) Trump's Regulatory Rollback Begins, Available at: http://rhg.com/notes/trumps-regulatory-rollback-begins.

Riahi, K., Van Vuuren, D. P., Kriegler, E., Edmonds, J., O’neill, B. C., Fujimori, S., Bauer, N., Calvin, K., Dellink, R., Fricko, O., Lutz, W., POPP, A., Cuaresma, J. C., KC, S., Leimbach, M., Jiang, L., Kram, T., Rao, S., Emmerling, J., Ebi, K., Hasegawa, T., Havlik, P., Humpenöder, F., Da Silva, L. A., Smith, S., Stehfest, E., Bosetti, V., Eom, J., Gernaat, D., Masui, T., Rogelj, J., Strefler, J., Drouet, L., Krey, V., Luderer, G., Harmsen, M., Takahashi, K., Baumstark, L., Doelman, J. C., Kainuma, M., Klimont, Z., Marangoni, G., LotzeCampen, H., Obersteiner, M., Tabeau, A. \& Tavoni, M. (2017) The Shared Socioeconomic Pathways and their energy, land use, and greenhouse gas emissions implications: An overview. Global Environmental Change, 42, 153-168.

Rogelj, J., Den Elzen, M., Höhne, N., Fransen, T., Fekete, H., Winkler, H., Schaeffer, R., SHA, F., RIAHI, K. \& MEINSHAUSEN, M. (2016) Paris Agreement climate proposals need a boost to keep warming well below $2^{\circ} \mathrm{C}$. Nature, 534, 631-639.

Rogelj, J., Fricko, O., Meinshausen, M., Krey, V., J, Z. \& Riahi, K. (2017a) Understanding the origin of Paris Agreement emission uncertainties Nature Communications 8,15748 doi: 10.1038/ncomms15748.

Rogelj, J., Hare, W., Chen, C. \& Meinshausen, M. (2011) Discrepancies in historical emissions point to a wider 2020 gap between $2^{\circ} \mathrm{C}$ benchmarks and aggregated national mitigation pledges. Environmental Research Letters.

Rogelj, J., Luderer, G., Pietzcker, R. C., Kriegler, E., Schaeffer, M., Krey, V. \& Riahi, K. (2015) Energy system transformations for limiting end-of-century warming to below $1.5^{\circ} \mathrm{C}$. Nature Climate Change, 5, 519-527.

Rogelj, J., Mccollum, D. L., O'neill, B. C. \& Riahi, K. (2013a) 2020 emissions levels required to limit warming to below $2^{\circ} \mathrm{C}$. Nature Clim. Change, 3, 405-412.

Rogelj, J., Mccollum, D. L., Reisinger, A., Meinshausen, M. \& Riahi, K. (2013b) Probabilistic cost estimates for climate change mitigation. Nature, 493, 79-83.

Rogelj, J., Popp, A., Calvin, K. V., Luderer, G., Emmerling, J., Gernaat, D., Fujimori, S., Strefler, J., Hasegawa, T., Marangoni, G., Krey, V., Kriegler, E., Riahi, K., Van Vuuren, D. P., Doelman, J., Drouet, L., Edmonds, J., Fricko, O., Harmsen, M., Havlík, P., Humpenöder, F., Stehfest, E. \& Tavoni, M. (2017b) Transition pathways towards limiting climate change below $1.5^{\circ} \mathrm{C}$. Nature Climate Change (under review), http://unfccc.int/files/adaptation/application/pdf/2.9_iiasa_rogelj.pdf.

Schneider, L., Day, T., LA Hoz, S. \& Warnecke, C. (2017) Discussion Paper: CDM Supply Potential up to 2020. NewClimate Institute, the Climate group.

SEEG (2017) The System Study Greenhouse Gas Emissions Estimates (SEEG). [Online]. Available: http://seeg.eco.br/en/ [Accessed 21 July 2017].

Sha, F., Ji, Z. and Linwei, L. (2015) An Analysis of China's INDC. Beijing, China: China National Center for Climate Change Strategy and International Cooperation.

Sha, F., Ji, Z. and Linwei, L. (2017) An Analysis of China's INDC (Updated analysis 2017) (MILES report). Beijing, China: China National Center for Climate Change Strategy and International Cooperation.

State CounciL (2013) Air Pollution Prevention Action Plan [Online]. Accessed: 26 October 2017

The Climate Group (2016) Compact of States and Regions - Disclosure report: How leading states, provinces and regions are responding to the Paris Agreement 2016 Edition. Available at: https://www.theclimategroup.org/sites/default/files/compact-ofstates-and-regions-disclosure-report-2015.pdf.

The Representative of The United States of America to the United Nations (2017) Reference: C.N.464.2017.TREATIES-XXVII.7.d (Depositary Notification). United Nations, https://treaties.un.org/doc/Publication/CN/2017/CN.464.2017-Eng.pdf

UNEP (2012) The Emissions Gap Report 2012: A UNEP Synthesis Report. United Nations Environment Programme (UNEP), Nairobi. Available: http://www.unep.org/emissionsgapreport2012/ [accessed 23 September 2017]

UNEP (2015) The Emissions Gap Report 2015: A UNEP Synthesis Report [Online]. United Nations Environment Programme (UNEP), Nairobi. Available: http://www.unep.org/emissionsgapreport2015/ [Accessed 23 September 2017].

UNEP (2016) The Emissions Gap Report 2016: A UNEP Synthesis Report [Online]. United Nations Environment Programme (UNEP), Nairobi. Available: http://www.unep.org/emissionsgapreport2016/ [Accessed 23 September 2017].

UNFCCC (2015) Intended Nationally Determined Contributions (INDCs), http://www4.unfccc.int/submissions/indc/Submission\%20 Pages/submissions.aspx.

Van Vuuren, D. P., Stehfest, E., Gernaat, D., Doelman, J., Van Den Berg, M., Harmsen, M., DE Boer, H. S., Bouwman, L., Daioglou, V., Edelenbosch, O., Girod, B., Kram, T., Lassaletta, L., Lucas, P., Van Meijl, H., Müller, C., Van Ruijven, B., Van Der Sluis, S. \& Tabeau, A. (2017) Energy, land-use and greenhouse gas emissions trajectories under a green growth paradigm. Global Environmental Change, 42, 237-250.

Vandyck, T., Keramidas, K., Saveyn, B., Kitous, A. \& Vrontisi, Z. (2016) A global stocktake of the Paris pledges: Implications for energy systems and economy. Global Environmental Change, 41, 46-63.

Vrontisi, Z., Luderer, G., Saveyn, B., Bertram, C., De Boer, H. S., Drouet, L., Fragkiadakis, K., Fricko, O., Fujimori, S., Guivarch, C., Keramidas, K., Kitous, A., Krey, V., Kriegler, E., Broin, E., Paroussos, L., Riahi, K., Tavoni, M. \& Van Vuuren, D. P. (2016) Report containing an economic analysis of a set of sectoral impacts, Deliverable No. 6.4, ADVANCE, Advanced Model Development and Validation for Improved Analysis of Costs and Impacts of Mitigation Policies, http://www.fp7-advance.eu/sites/default/files/ documents/WP6/D6.4_deliverable_20170619.pdf.

Vrontisi, Z., Luderer, G., Saveyn, B., Bertram, C., De Boer, H. S., Drouet, L., Fragkiadakis, K., Fricko, O., Fujimori, S., Guivarch, C., Keramidas, K., Kitous, A., Krey, V., Kriegler, E., Broin, E., Paroussos, L., Riahi, K., Tavoni, M. \& Van Vuuren, D. P. (2017) A multi-model assessment of the effectiveness of Paris pledges towards a $1.5-2^{\circ} \mathrm{C}$ stabilization, Global Environmental Change (submitted).

Weyant, J. (2017) Some Contributions of Integrated Assessment Models of Global Climate Change. Review of Environmental Economics and Policy, 11, 115-137.

\section{Chapter 4}

Afanador, A., Begemann, E., Bourgault, C., Krabbe, O. and Wouters, K. (2015) The potential of scaling up proven low-carbon solutions. Available at: https://media.sitra.fi/2017/02/28142516/Ecofys_2015_potential_of_scaling_up-low_carbon_solutions.pdf [Accessed 24 October 2017]. 
Akbar, S., Kleiman, G., Menon, S. and Segafredo, L. (2014) Climate-smart development : adding up the benefits of actions that help build prosperity, end poverty and combat climate change : Main report Washington, DC: World Bank Group. Available at: http:// documents.worldbank.org/curated/en/794281468155721244/Main-report [Accessed 24 October 2017]

Alvik, S., Eide, M., Endresen, Ø., Hoffman, P., and Longva, T. (2010) Pathways to Low Carbon Shipping-Abatement Potential Towards 2030. DNV De Norske Veritas.

Arasto, A., K. Onarheim, E., Tsupari, and Kärki, J. (2014) 'Bio-CCS: feasibility comparison of large scale carbon-negative solutions'. Energy Procedia 63, 6756-6769.

Blok, K., and Gardiner, A. (2015) Climate commitments of subnational actors and business - a quantitative assessment of their emission reduction impact. Available at: http://www.unep.org/ourplanet/september-2015/unep-publications/climate-commitments-subnational-actors-and-business-quantitative [Accessed 24 October 2017]

Bloomberg New Energy Finance. (2017) Electric Vehicle Outlook 2017. Available at: https://data.bloomberglp.com/bnef/ sites/14/2017/07/BNEF_EVO_2017_ExecutiveSummary.pdf [Accessed 24 October 2017]

Bonn, A., Reed, M., Evans, C., Joosten, H., Bain, C., Farmer, J., Emmer, I., Birnie, D.. (2014) Investing in nature: Developing ecosystem service markets for peatland restoration. Ecosystem Services, 9: 54-65.

Breyer, C., Bogdanov, D., Gulagi, A., Aghahosseini, A., Barbosa, L.S.N.S., Koskinen, O., Barasa, M., Caldera, U., Afanasyeva, S., Child, M., Farfan, J. and Vainikka, P. (2017) On the role of solar photovoltaics in global energy transition scenarios. Progress in photovoltaics: research and applications. 25(8): 727-745.

Bouman, E., Lindstad, E., Rialland, A., Stromann, A. (2017) State-of-the-art technologies, measures, and potential for reducing GHG emissions from shipping - A review. Transportation Research Part D: Transport and Environment. 52: 408-421.

BLE (2016) Evaluations und Erfahrungsbericht für das Jahr 2015, Biomassestrom-Nachhaltigkeitsverordnung and BiokraftstoffNachhaltigkeitsverordnung. Bonn Germany: Bundesanstalt für Landwirtschaft und Ernährung.

C40 (2014) Advancing climate ambition: cities as partners in global climate action. Available at http://c40-production-images. s3.amazonaws.com/researches/images/25_Advancing_Climate_Ambition.original.pdf?1412878084 [Accessed 24 October 2017]

Chen, X., Luo, Y., Zhou, Y., and Lu, M. (2016) Carbon Sequestration Potential in Stands under the Grain for Green Program in Southwest China. PLOS ONE, 11(3): 1-17.

Clarke, L., Jiang, K., Akimoto, K., Babiker, M., Blanford, G., Fisher-Vanden, K., Hourcade, J.-C., Krey, V., Kriegler, E., Löschel, A., McCollum, D., Paltsev, S., Rose, S., Shukla, P.R., Tavoni, M., Van der Zwaan, B., Van Vuuren, D. (2014) Assessing Transformation Pathways. In: Climate Change 2014: Mitigation of Climate Change. Contribution of Working Group III to the Fifth Assessment Report of the Intergovernmental Panel on Climate Change. Cambrigde and New York: Cambridge University Press.

CLASP (2011) Opportunities for success and $\mathrm{CO}_{2}$ savings from appliance energy efficiency harmonisation. Available at http://clasp. ngo/Resources/Resources/PublicationLibrary/2011/Opportunities-for-appliance-EE-harmonization\#file [Accessed 24 October 2017]

Climate Action Tracker (2016) 10 Steps: the ten most important short-term steps to limit warming to $1.5^{\circ} \mathrm{C}$. Available at http://climateactiontracker.org/assets/publications/publications/CAT_10_Steps_for_105.pdf [Accessed 24 October 2017]

Creutzig, F., Agoston, P., Goldschmidt, J., Luderer, G., Nemet, G., and Pietzcker, R. (2017) The underestimated potential of solar energy to mitigate climate change. Nature Energy (2) doi:10.1038/nenergy.2017.140

Deng, Y., Blok, K., and Leun, K. (2012) Transition to a fully sustainable global energy system. Energy Strategy Reviews, 1(2): 1-13.

Dimassi, B., Mary, B., Wylleman, R., Labreuche, J., Couture, D., Piraux, F., and Cohan, J. (2014) Long-term effect of contrasted tillage and crop management on soil carbon dynamics during 41 years. Agriculture, Ecosystems and Environment, 136-146.

Ecofys (2017) A role for rapeseed biodiesel in greening EU transport. Utrecht: Ecofys (forthcoming).

Eide, M., Longva, T., Hoffmann, P., Endresen, $\varnothing$., and Dalsøren , S. (2011) Future cost scenarios for reduction of ship $\mathrm{CO}_{2}$ emissions. Maritime Policy and Management, 11-37.

Faber, J., Wang., H., Nelissen, D., Russell, B., and Amand, D. (2011) Marginal abatement costs and cost effectiveness of energyefficiency measures. Institute of Marine Engineering, Science and Technology.

Fischedick. (2014) Industry. New York: Cambridge University Press.

GBPN (2013) What is a deep renovation definition? Available at http://www.gbpn.org/sites/default/files/08.DR_TechRep.low_.pdf [Accessed 24 October 2017]

GCEM (2015) Raising Ambition to Reduce International Aviation and Maritime Emissions. Contributing paper for Seizing the Global Opportunity: Partnerships for Better Growth and a Better Climate. New Climate Economy, London and Washington, DC. Available at: http://newclimateeconomy.report/misc/working-papers. [Accessed 24 October 2017]

GCEM (2015) New Climate Economy Technical Note: Abatement Reduction Potential. Available at: http://newclimateeconomy. report/workingpapers/wp-content/uploads/sites/5/2016/04/NCE-technical-note-emission-reduction-potential_final.pdf [Accessed 24 October 2017]

GWEC (2016) Global Wind Report 2016. Available at http://gwec.net/publications/global-wind-report-2/global-wind-report-2016/ [Accessed 24 October 2017]

Hawken, P. (2017) Drawdown: The Most Comprehensive Plan Ever Proposed to Reverse Global Warming. New York: Penguin Random House LLC.

Herzog, H., Smekens K., Dadhich, P., Dooley, J., Fujii, Y., Hohmeyer, O., and Riahi K. (2005) Costs and Economic Potential, in: IPCC Special Report on Carbon Dioxide Capture and Storage. Cambridge, United Kingdom and New York, NY, USA: Cambridge University Press.

Hoffmann, P., Eide, M., and Endresen, $\varnothing$. (2012) Effect of proposed $\mathrm{CO}_{2}$ emission reduction scenarios on capital expenditure. Maritime Policy and Management, 443-460.

ICAO (2013) Environmental Report 2013. Available at http://cfapp.icao.int/Environmental-Report-2013/files/assets/basic-html/index.html\#1 [Accessed 24 October 2017].

ICCT (2012) Global Transportation Energy and Climate Roadmap. Availabel at: http://www.theicct.org/publications/global-transportation-energy-and-climate-roadmap [Accessed 24 October 2017]. 
ICCT (2017) Technology uptake, costs, and benefits under a next-phase passenger car efficiency program in Brazil. Available at: http://www.theicct.org/publications/technology-uptake-costs-and-benefits-under-next-phase-passenger-car-efficiency-program [Accessed 24 October 2017].

IEA (2016) World Energy Outlook 2016. Paris: International Energy Agency.

IEA (2017) Enery Technology Perspectives 2017. Paris: International Energy Agency.

IPCC. (2001) Climate Change 2001: Synthesis Report. A Contribution of Working Groups I, II, and III to the Third Assessment Report of the Integovernmental Panel on Climate Change. Cambrigde and New York: Cambridge University Press.

IPCC (2007) Fourth Assessment Report of the Intergovernmental Panel on Climate Change. Geneva: IPCC.

IPCC (2014) Climate Change 2014: Mitigation of Climate Change. Geneva: IPCC.

IRENA (2016) Roadmap for a Renewable Energy Future. Bonn: IRENA Innovation and Technology Centre.

IRENA (2017) 'Renewable Energy Auctions: Analysing 2016'. IRENA, Abu Dhabi. Available at http://www.irena.org/DocumentDownloads/Publications/IRENA_REAuctions_summary_2017.pdf

Johnson, N., Parker, N., and J.Ogden. (2014) How negative can biofuels with CCS take us and at what cost? . Energy Procedia 63: $6770-6791$.

Joosten, H., Tapio-Biström, M.-L., and Tol, S. (2012) Peatlands - guidance for climate change mitigation through conservation, rehabilitation and sustainable use. Available at: http://www.fao.org/3/a-an762e.pdf [Accessed 24 October 2017].

Kim, K., and Zsuffa, L. (1994) Reforestation of South Korea: The history and analysis of a unique case in forest tree improvement and forestry. The Forestry Chronicle, 58-64.

Klimont, Z., and Höglund-Isaksson, L. (2017) Personal communication. IIASA.

Lazard (2016) Levelized Cost of Energy Analysis 10.0. Available at: https://www.lazard.com/media/438038/levelized-cost-of-energyv100.pdf [Accessed 24 October 2017].

Lundqvist, J. (2009) Losses and waste in the global crisis. Rev. Environ. Sci. Biotechnnol., 121-123

Mac Dowell N, and Fajardy, M. (2017) Inefficient power generation as an optimal route to negative emissions via BECCS? Environmental Research Letters 12 (4): 1-11.

McGlashan, N., Workman, M., Caldecott, B., and Shah, N. (2012) Negative Emissions Technologies. Grantham Institute for Climate Change Briefing paper No 8.

Messinger, J. and DeWitt, S. (2015) Bonn Challenge on track to meet land restoration goal by 2020. Available at: http://www.wri. $\mathrm{org} / \mathrm{blog} / 2015 / 03 /$ bonn-challenge-track-meet-land-restoration-goal-2020-0 [Accessed 24 October 2017]

Molenbroek, E., Smith, M., Surmeli, N., Schimschär, S., Waide, P., Tait, J., and McAllister, C. (2015) Savings and benefits of global regulations for energy efficient products. Brussels, Belgium: European Commission.

Nelleman, C., MacDevette, M., Manders, T., Eickhout, B., Svihus, B., and Prins, A. (2009) The environmental Food Crisis - The Environment's Role in Averting Future Food Crises. A UNEP Rapid Response Assessment. Arendal, Norway: United Nations Environmental Programme, GRID.

Nelson, G., Rosegrant, M., Palazzo, A., Gray, I., Ingersoll, C., Robertson, R., Tokzog S., Zhu T., Sulser T.B., Ringer, C., Mgansi, S. and You, L. (2010) Food Security, Farming, and Climate Change to 2050: Scenarios, Results, Policy Options. Washington, DC: International Food Policy Research Institute.

Papaefthymiou, G., Grave, K., and Dragoon, K. (2014) Flexibility options in electricity systems. Available at: https://www.ecofys.com/ files/files/ecofys-eci-2014-flexibility-options-in-electricity-systems.pdf [Accessed 24 October 2017]

Purohit, P., and Höglund-Isaksson, L. (2017) Global emissions of fluorinated greenhouse gases 2005-2050 with abatement potentials and costs. Atmos. Chem. Phys., 17, 2795-2816. doi:10.5194/acp-17-2795-2017

REN21 (2017) Global Status Report. Available at http://www.ren21.net/status-of-renewables/global-status-report/ [Accessed 24 October 2017]Renforth, P., Washbourne, C.-L., Taylder, J., and Manning, D.A.C. (2012) Silicate Production and Availability for Mineral Carbonation. Environmental Science and Technology, 45 (6), 2035-2041Saygin, D., E. Worrell, M.K. Patel, D.J. Gielen. (2011) Benchmarking the energy use of energy-intensive industries in industrialized and in developing countries. Energy (36): $6661-6673$.

SITRA (2015) Green to Scale. Available at https://media.sitra.fi/2017/02/28142523/Selvityksia105.pdf [Accessed 24 October 2017].

Smith (2016) Soil carbon sequestration and biochar as negative emission technologies. Global Change Biology, 1315-1324.

Smith, P., Martino, D., Cai, Z., Gwary, D., Janzen, H., Pushpam, K., McCarl, B., Ogle, S., O’Mara, F., Rice, C., Scholes, B., Sirotenko, O. (2008) Greenhouse gas mitigation in agriculture. Phil. Trans. R. Soc. B, 789-813.

Smith, P. Smith, P., Martino, D., Cai, Z., Gwary, D., Janzen, H., Pushpam, K., McCarl, B., Ogle, S., O'Mara, Frank, Rice, Charles, Scholes, Bob, Sirotenko, Oleg, (2007) Agriculture. In Climate Change 2007: Mitigation. Contribution of Working Group III to the Fourth Assessment Report of the, Cambridge: Cambridge University Press.

Smith, P., M. Bustamante, H.Ahammad, H. Clark, H. Dong, E. Elsiddig, H. Haberl, R. Harper, J. House,, M. Jafari, O. Masera, C. Mbow, N. Ravindranath, C. Rice, C. Robledo, A. Romanovskaya, F. Sperling, F. Tubiello. (2014) Agriculture, Forestry and Other Land Use (AFOLU) In: Climate Change 2014: Mitigation of Climate Change. Contribution of Working Group III to the Fifth Assessment Report of the Intergovernmental Panel on Climate Change. Cambridge and New York: Cambridge University Press.

Stehfest, E., Van den Berg, M., Woltjer, G., and Westhoek, G. (2013) Options to reduce the environmental effects of livestock production - Comparison of two economic models. Agricultural Systems, 38-53.

Teske, S., Sawyer, S., Schäter, O., Pregger, T., Simon, S., and Naegler, T. (2015) Energy [R]evolution a Sustainable World Energy Outlook 2015. Hamburg: Greenpeace International.

UNEP (2011) Bridging the Emission Gap. Nairobi: United Nations Environment Programme. Available at: https://www.ecofys.com/ files/files/unep_bridging\%20the\%20emissions\%20gap.pdf [Accessed 24 October 2017]

UNEP (2012) The Emissions Gap Report 2012. Nairobi: United Nations Environment Programme (UNEP). http://apps.unep.org/redirect.php?file=/publications/pmtdocuments/-The\%20emissions\%20gap\%20report\%202012_\%20a\%20UNEP\%20synthesis\%20 reportemissionGapReport2012.pdf [Accessed 24 October 2017] 
UNEP (2013) The Emissions Gap Report 2013. Nairobi: United Nations Environment Programme (UNEP). Available at: http://www. unep.org/sites/default/files/EGR2013/EmissionsGapReport_2013_high-res.pdf [Acessed 24 October 2017]

UNEP (2014) The Emissions Gap Report 2014. Nairobi: United Nations Environment Programme (UNEP). Available at: http://wedocs.unep.org/bitstream/handle/20.500.11822/9345/-The\%20Emissions\%20Gap\%20Report\%202014\%3a\%20a\%20UNEP\%20 synthesis\%20report-November\%202014EGR_2014_Lowres.pdf?sequence=3\&isAllowed=y [Accessed 24 October 2017]

UNEP (2014) Green paper Policy Options to Accelerate the Global Transition to Advanced Lighting. Nairobi: United Nations Environment Programme (UNEP).

UNEP (2016) Emission Gap Report 2016. Nairobi: United Nations Environment Programme (UNEP). Available at: https://www. google.dk/url?sa=t\&rct=j\&q=\&esrc=s\&source=web\&cd=2\&cad=rja\&uact=8\&ved=0ahUKEwignN39p4vXAhXpDZoKHdh9BgUQ FggwMAE\&url=http\%3A\%2F\%2Fwedocs.unep.org\%2Fbitstream\%2Fhandle\%2F20.500.11822\%2F10016\%2Femission_gap_report_2016.pdf\&usg=AOvVaw3gBleyjAH07zqiljLQw9N2 [Accessed 24 October 2017.

UNEP (2017) Accelerating the global adoption of energy-efficient lighting. Available at: http://www.enlighten-initiative.org/Portals/0/documents/global-forum/Green_Paper_FINAL\%2Oreduced.pft [Accessed 24 October 2017]

USEPA (2012) Global Anthropogenic Non-CO Greenhouse Gas Emissions: 1990 - 2030. United States: Environmental Protection Agency.

USEPA (2013) Global Mitigation of Non-CO Greenhouse Gases: 2010-2030. United States: Environmental Protection Agency.

Verdone, M., Olsen, N., Wylie, P., Saint Laurent, C., and Maginnis, M. (2015) Making the case for forest landscape restoration. White paper, initial working draft for future discussion. Post-Bonn Challenge 2.0 Ministerial Event, 20-21 March 2015. IUCN.

Wagner, N. (2017) Personal communication from Mr. N. Wagner, IRENA, September 2017.

Wichtmann, W., Schröder, C., and Joosten, H. (2016) Paludiculture - productive use of wet peatlands. Climate protection - biodiversity - regional economic benefits. Stuttgart: Schweizerbart Science Publishers.

Woolf, D., Amonette, J., Alayne Street-Perrott, F., Lehmann, J., and Joseph, S. (2010) Sustainable biochar to mitigate global climate change. Nature Communications, 1-56.

Worell, E., and Carreon, J. (2017) Energy demand for materials in an international context. Utrecht: The Royal Society.

World Bank (2016) The Cost of Fire: An Economic Analysis of Indonesia's 2015 Fire Crisis. Jakarta: World Bank.

\section{Chapter 5}

ADB (2017). 'Poverty in India.' Basic Statistics. Asian Development Bank. Available at: https://www.adb.org/countries/india/ poverty[Accessed 19 October 2017]

Annaluru, R., and Garg, A. (2017). Managing the Power Grid Ramping Challenges Critical to Success of India's Renewable Energy Targets. Working paper No 2017-08-01. Indian Institute of Management Ahmedabad. Available at: https://web.iima.ac.in/assets/snippets/workingpaperpdf/14473831782017-08-01.pdf [Accessed October 19 2017]

Arent, D., Arndt, C., Miller, M., Zinaman, O., and Tarp, F. (2017). 'The Political Economy of Clean Energy Transitions.' Oxford University Press.

Audoly, R., Vogt-Schilb, A. and Guivarch, C. (2014). 'Pathways toward Zero-Carbon Electricity Required for Climate Stabilization.' World Bank Policy Research Working Paper 7075.

Australian Government. (2017). 'Australian Mineral Commodities: Coal.' Department of Industry, Innovation and Science. Available at:https://www.industry.gov.au/resource/Mining/AustralianMineralCommodities/Pages/Coal.aspx [Accessed 19 October 2017]

Bach, S., Kohlhaas, M., Meyer, B., Praetorius, B. and Welsch, H. (2002). 'The Effects of Environmental Fiscal Reform in Germany: A Simulation Study.' Energy Policy 30 (9): pp. 803-811.

Baker, L., and Burton, J. in press. 'The Politics of Procurement and the Low Carbon Transition in South Africa.' In: Elgar, E. Handbook of the International Political Economy of Energy and Natural Resources.

Sharma, B. K. and Das Kundu, N. (2016). China's One Belt One Road: Initiative, Challenges and Prospects. Vij Books India Pvt Ltd. Available at:https://books.google.dk/books?isbn=9385563602 [Accessed 19 October 2017]

Bauer, N., Mouratiadou, I., Luderer, G., Baumstark, L., Brecha, R. J., Edenhofer, O., and Kriegler, E. (2016). 'Global Fossil Energy Markets and Climate Change Mitigation-an Analysis with REMIND.' Climatic Change 136 (1): pp. 69-82.

Bazilian, M., and Onyeji, I. (2012). 'Fossil Fuel Subsidy Removal and Inadequate Public Power Supply: Implications for Businesses.' Energy Policy 45: pp. 1-5.

Bertram, C., Johnson, N., Luderer, G., Riahi, K., Isaac, M. and Eom, J. (2015). 'Carbon Lock-in through Capital Stock Inertia Associated with Weak near-Term Climate Policies.' Technological Forecasting and Social Change 90, Part A (January): pp. 62-72. Bertram, C., Luderer, G., Pietzcker, R. C., Schmid, E., Kriegler, E., and Edenhofer, O. (2015). 'Complementing Carbon Prices with Technology Policies to Keep Climate Targets within Reach.' Nature Climate Change 5 (3): pp. 235-39.

BNEF (2017). 'New Energy Outlook.' Bloomberg New Energy Finance. https://about.bnef.com/new-energy-outlook/

Bouzarovski, S. and Tirado Herrero, S. (2017). 'Geographies of Injustice: The Socio-Spatial Determinants of Energy Poverty in Poland, the Czech Republic and Hungary.' Post-Communist Economies 29 (1): pp. 27-50.

Branger, F. and Quirion, P. (2014). 'Climate Policy and the 'Carbon Haven' Effect.' Wiley Interdisciplinary Reviews: Climate Change 5 (1): pp. 53-71. doi:10.1002/wcc.245.

Brenner, M., Riddle, M. and Boyce, J.K. (2007). 'A Chinese Sky Trust?: Distributional Impacts of Carbon Charges and Revenue Recycling in China.' Energy Policy 35 (3): pp. 1771-1784.

Breyer, C., Bogdanov, D., Gulagi, A., Aghahosseini, A., Barbosa, L. S.N.S., Koskinen, O., Maulidi Barasa, M. (2017). ‘On the Role of Solar Photovoltaics in Global Energy Transition Scenarios.' Progress in Photovoltaics: Research and Applications 25: pp. $727-745$. doi:10.1002/pip.2885.

Burton, J., Caetano, T., Hughes, A., Merven, B., Ahjum, F. and McCall, B. (2016). 'The Impact of Stranding Power Sector Assets in South Africa: Using a Linked Model to Understand Economy-Wide Implications.' Cape Town: Energy Research Centre, University of Cape Town. 
Burtraw, D., Sweeney, R. and Walls, M. (2009). 'The Incidence of U.S. Climate Policy: Alternative Uses of Revenues from a Cap-andTrade Auction.' National Tax Journal 62 (3): pp. 497-518.

Caldecott, B. (2017). 'Introduction to Special Issue: Stranded Assets and the Environment.' Journal of Sustainable Finance \& Investment 7 (1): pp. 1-13.

Caldecott, B., Sartor, O. and Spencer, T. (2017). 'Lessons from Previous Coal Transitions: High-Level Summary for Decision-Makers.' London: IDDRI \& Climate Strategies. http://www.iddri.org/Publications/Rapports-and-briefing-papers/COAL_SynthesisReport_ v04.pdf

Callan, T., Lyons, S., Scott, S., Tol, R. S. J. and Verde, S. (2009). 'The Distributional Implications of a Carbon Tax in Ireland.' Energy Policy 37 (2): pp. 407-412.

Cameron, L., and van der Zwaan, B. (2015). 'Employment Factors for Wind and Solar Energy Technologies: A Literature Review.' Renewable and Sustainable Energy Reviews 45 (May): pp. 160-172.

Carbon Tracker Initiative. (2015). 'The \$2 Trillion Stranded Assets Danger Zone: How Fossil Fuel Firms Risk Destroying Investor Returns.' London. https://www.carbontracker.org/reports/stranded-assets-danger-zone/

CEC. (2017). 'Briefing on the Power Sector's Status during January - June 2017.' China Electricity Council. http://www.cec.org.cn/ guihuayutongji/gongxufenxi/dianliyunxingjiankuang/2017-07-19/171012.html

Central Electricity Authority Government of India. (2016). 'Draft National Electricity Plan (Volume 1) Generation.' http://www.cea. nic.in/reports/committee/nep/nep_dec.pdf

Chen, H. (2017). 'Why Are G20 Governments Financing Coal Over Renewables?' National Resources Defense Council (NRDC) Expert Blog. July 17. https://www.nrdc.org/experts/han-chen/why-are-g20-governments-financing-coal-over-renewables

Chong, C., Ma, L., Li, Z., Ni, W and Song, S. (2015). 'Logarithmic Mean Divisia Index (LMDI) Decomposition of Coal Consumption in China Based on the Energy Allocation Diagram of Coal Flows.' Energy 85 (June): pp. 366-378.

Citi GPS. (2015). 'Energy 2030: Financing a Greener Future. Financing Green Energy in a Low Fossil Fuel Price World and Managing Stranded Asset Risk.' Citi Global Perspectives \& Solutions. https://ir.citi.com/BOkALUJBhr6ezsrQxov5ZpfX3D8UkGSU7cyUzHOPU zfK\%2FaozVshGqUWCOwuxH0eFBsfY5BSB8aM\%3D

Clarke, L., Jiang, K., Akimoto, K., Babiker, M., Blanford, G., Fisher-Vanden, K. and van Vuuren, D. P. (2014). Assessing Transformation Pathways. In: Climate Change 2014: Mitigation of Climate Change. Contribution of Working Group III to the Fifth Assessment Report of the Intergovernmental Panel on Climate Change. Cambridge, New York. Cambridge University Press.

Coady, D., Parry, I., Sears, L. and Shang, B. (2016). 'How Large Are Global Fossil Fuel Subsidies?' World Development.

Coady, D., Parry, I. and Shang, B. (2017). 'Energy Price Reform: A Guide for Policymakers.' CESifo Working Paper Series No. 6342.

Collier, P., and Venables, A. J. (2014). 'Closing Coal: Economic and Moral Incentives.' Oxford Review of Economic Policy 30 (3): pp. 492-512.

Coons, C. (2015). 'Master Limited Partnership Parity Act Section-by-Section.' http://www.mlpassociation.org/wp-content/uploads/ 2015/09/MLP_Section-by-Section-114th_-Congress.pdf

Cramton, P, MacKay, D. J. C., Ockenfels, A. and Stoft, S. eds. (2017). Global Carbon Pricing: The Path to Climate Cooperation. Cambridge, MA, USA: MIT Press.

Creutzig, F., Agoston, P., Goldschmidt, J. C., Luderer, G., Nemet, G. and Pietzcker, R. C. (2017). 'The Underestimated Potential of Solar Energy to Mitigate Climate Change.' Nature Energy 2 (9):

CSIR. (2016). 'Least-Cost Electricity Mix for South Africa by 2040: Scenarios for South Africa's Future Electricity Mix.' Pretoria: South Africa: Council of Scientific \& Industrial Research (CSIR) Energy Centre.

Danish Energy Agency. (2017). 'Annual and Monthly Statistics.' https://ens.dk/en/our-services/statistics-data-key-figures-andenergy-maps/annual-and-monthly-statistics

Davis, S. J., Caldeira, K. and Matthews, H. D. 2010. 'Future $\mathrm{CO}_{2}$ Emissions and Climate Change from Existing Energy Infrastructure.' Science 329 (5997): pp. 1330-1333.

Davis, S. J., and Socolow R.H. (2014). 'Commitment Accounting of $\mathrm{CO}_{2}$ Emissions.' Environmental Research Letters 9 (8).

DoE. 2017a. 'Siting and Regulating Carbon Capture, Utilization and Storage Infrastructure.' Workshop Report. Washington, DC: U.S. Dept. of Energy.

DoE. 2017b. 'Staff Report to the Secretary on Electricity Markets and Reliability.' Washington DC: U.S. Dept. of Energy. https://energy.gov/sites/prod/files/2017/08/f36/Staff\%20Report\%20on\%20Electricity\%20Markets\%20and\%20Reliability_0.pdf

Dolphin, G., Pollitt, M. and Newbery, D. (2016). 'Political Economy of Carbon Pricing Policies: Insights from a Panel of Countries.' In Energy: Expectations and Uncertainty, 39th IAEE International Conference, Jun 19-22, (2016). International Association for Energy Economics.

Edenhofer, O., Steckel, J. C., Jakob, M. and Bertram, C. (2017). 'Reports of Coal's Terminal Decline May Be Exaggerated.' MCC Working Paper.

Enerdata. (2015). 'Indonesia Releases Its 35 GW Power Capacity Addition Plan.' http://www.enerdata.net/enerdatauk/press-andpublication/energy-news-001/indonesia-releases-its-35-gw-power-capacity-addition-plan_32605.html

Eskom. (2017). 'Integrated Report 2017.' http://www.eskom.co.za/IR2017/Documents/Eskom_integrated_report_2017.pdf

Fay, M., Hallegatte, S., Vogt-Schilb, A., Rozenberg, J., Narloch, U. and Kerr, T. (2015). Decarbonizing Development: Three Steps to a Zero-Carbon Future. Washington DC, USA: World Bank Publications.

Fothergill, S. (2017). 'Coal Transition in the United Kingdom.' An Historical Case Study for the Project 'Coal Transitions: Research and Dialogue on the Future of Coal.' IDDRI and Climate Strategies. www.iddri.org/Publications/Rapports-and-briefing-papers/ COAL_UK_v04.pdf

Galgóczi, B. (2014). 'The Long and Winding Road from Black to Green: Decades of Structural Change in the Ruhr Region.' International Journal of Labour Research 6 (2): pp. 217-240.

Garg, A., Mohan, P., Kankal, B., Shukla, S. and Vishwanathan, S. (2017). High-Impact Opportunities for Energy Efficiency in India. Copenhagen: Copenhagen Centre on Energy Efficiency, UNEP DTU. ISBN: 978-87-93458-14-7

Garg, A., and Shukla, P. R. (2009). 'Coal and Energy Security for India: Role of Carbon Dioxide $\left(\mathrm{CO}_{2}\right)$ Capture and Storage (CCS).' Energy Journal 34 (8): pp. 1032-1041. 
Gerdes, J. (2016). Quitting Carbon: How Denmark Is Leading the Clean Energy Transition and Winning the Race to the Low-Carbon Future.

Gol. (2017). India's Intended Nationally Determined Contribution: Working Towards Climate Justice. New Delhi: Government of India. http://www4.unfccc.int/submissions/INDC/Published\%20Documents/India/1/INDIA\%20INDC\%20TO\%20UNFCCC.pdf

Gonzalez, F. (2012). 'Distributional Effects of Carbon Taxes: The Case of Mexico.' Energy Economics 34 (6): pp. $2102-2115$. doi:10.1016/j.eneco.2012.03.007.

Goulder, L. H., and Schein, A. R. (2013). 'Carbon Taxes versus Cap and Trade: A Critical Review.' Climate Change Economics 4 (3): 1350010. doi:10.1142/S2010007813500103.

Government of Alberta. (2015). 'Phasing Out Coal Pollution - Alberta Climate Leadership Plan.' Edmonton. http://www.alberta.ca/ climate-coal-electricity.cfm

Graichen, P., Kleiner, M. M. and Buck, M. (2016). 'Energy Transition in the Power Sector in Europe: State of Affairs in 2015: Review of the Developments and Outlook for 2016.' Agora Energiewende.

Arze del Granado, F.J., Coady, D., Gillingham, R. (2012). 'The Unequal Benefits of Fuel Subsidies: A Review of Evidence for Developing Countries.' World Development 40 (11): pp. 2234-2248.

Great Plains Institute. (2016). 'Putting the Puzzle Together: State and Federal Policy Drivers for Growing America's Carbon Capture \& $\mathrm{CO}_{2}$-EOR Industry.' Great Plains Institute. http://www.betterenergy.org/sites/default/files/PolicyDriversCO_EOR\%20V1.1_0.pdf

Green, F., and Stern, N. (2017). 'China's Changing Economy: Implications for Its Carbon Dioxide Emissions.' Climate Policy 17 (4): pp. 423-442.

Guivarch, C., and Hood, C. 2011. 'Early Retirement of Coal-Fired Generation in the Transition to Low-Carbon Electricity Systems.' In: Climate \& Electricity Annual 2011 Data and Analyses. Paris: International Energy Agency.

Hallegatte, S., Bangalore, M., Bonzanigo, L., Fay, M., Kane, T., Narloch, U., Rozenberg, J., Treguer, D. and Vogt-Schilb, A. (2016). Shock Waves: Managing the Impacts of Climate Change on Poverty. Washington DC: World Bank Publications.

Hao, Y., Liu, Y., Weng, J., and Gao, Y. (2016). 'Does the Environmental Kuznets Curve for Coal Consumption in China Exist? New Evidence from Spatial Econometric Analysis.' Energy 114 (November): pp. 1214-1223.

Hart, M, Bassett, L. and Johnson, B. (2017). 'Everything You Think You Know About Coal in China Is Wrong.' Issue Brief. Energy and Environment. Center for American Progress. https://www.americanprogress.org/issues/green/reports/2017/05/15/432141/ everything-think-know-coal-china-wrong/

Healy, N., and Barry, J. (2017). 'Politicizing Energy Justice and Energy System Transitions: Fossil Fuel Divestment and a 'Just Transition." Energy Policy 108 (September): pp. 451-459.

Heede, R. (2014). 'Tracing Anthropogenic Carbon Dioxide and Methane Emissions to Fossil Fuel and Cement Producers, 18542010.' Climatic Change 122 (1-2): pp. 229-241.

Heede, R., and Oreskes, N. (2016). 'Potential Emissions of $\mathrm{CO}_{2}$ and Methane from Proved Reserves of Fossil Fuels: An Alternative Analysis.' Global Environmental Change 36: pp. 12-20.

Hirth, L., and Steckel, J.C. (2016). 'The Role of Capital Costs in Decarbonizing the Electricity Sector.' Environmental Research Letters 11. doi:doi:10.1088/1748-9326/11/11/114010.

Hirth, L., Ueckerdt, F. and Edenhofer, O. (2015). 'Integration Costs Revisited - An Economic Framework for Wind and Solar Variability.' Renewable Energy 74 (February): pp. 925-939.

Hirth, L., Ueckerdt, F. and Edenhofer, O. (2016). 'Why Wind Is Not Coal: On the Economics of Electricity Generation.' The Energy Journal 37 (3).

Houser, T., Bordoff, J. and Marsters, P. (2017). 'Can Coal Make a Comeback?' New York, NY: Columbia University. Center on Global Energy Policy. https://www.eenews.net/assets/2017/04/27/document_gw_06.pdf

IEA. (2016). World Energy Outlook (2016). International Energy Agency. Paris: IEA. http://www.oecd-ilibrary.org/energy/worldenergy-outlook-2016_weo-2016-en

IEA. (2017). Tracking Progress: Renewable Power. Paris: IEA. https://www.iea.org/etp/tracking2017/renewablepower

IEA/OECD. (2016). Coal Information (2016). Paris, France: International Energy Agency, OECD Publishing. http://www.oecd-ilibrary. org/energy/coal-information-2016_coal-2016-en

IEA-RETD. (2016). 'RE-TRANSITION - Transitioning to Policy Frameworks for Cost-Competitive Renewables.' Utrecht: IEA Technology Collaboration Programme for Renewable Energy Technology Deployment (IEA-RETD).

International Labour Organization. (2015). Guidelines for a Just Transition towards Environmentally Sustainable Economies and Societies for All. Geneva: International Labour Organization. http://www.ilo.org/wcmsp5/groups/public/---ed_emp/---emp_ent/ documents/publication/wcms_432859.pdf

IPCC. (2014). Climate Change 2014: Mitigation of Climate Change. Contribution of Working Group III to the Fifth Assessment Report of the Intergovernmental Panel on Climate Change. Edited by Edenhofer, Ottmar, Ramón Pichs-Madruga, Youba Sokona, Ellie Farahani, Susanne Kadner, Anna Adler, and Kristin Seyboth. Cambridge, United Kingdom and New York, NY, USA: Cambridge University Press.

Iqtiyanillham, N., Hasanuzzaman, M. and Hosenuzzaman, M. (2017). 'European Smart Grid Prospects, Policies, and Challenges.' Renewable and Sustainable Energy Reviews 67: pp. 776-790.

IRENA. 2017a. 'Geothermal Power. Technology Brief.' Abu Dhabi: International Renewable Energy Agency. http://www.irena.org/ DocumentDownloads/Publications/IRENA_Geothermal_Power_2017.pdf

IRENA. 2017b. 'Stranded Assets and Renewables: How the Energy Transition Affects the Value of Energy Reserves, Buildings and Capital Stock.' Abu Dhabi: International Renewable Energy Agency (IRENA). http://www.irena.org/DocumentDownloads/Publications/IRENA_REmap_Stranded_assets_and_renewables_2017.pdf

Iyer, G. C., Clarke, L. E., Edmonds, J.E., Flannery, B. P., Hultman, N.E., McJeon, H. C. and Victor, D. G. (2015). 'Improved Representation of Investment Decisions in Assessments of $\mathrm{CO}_{2}$ Mitigation.' Nature Climate Change 5 (5): pp. 436-440.

Jakob, M., Chen, C., Fuss, S., Marxen, A. and Edenhofer, O. (2015). 'Development Incentives for Fossil Fuel Subsidy Reform.' Nature Climate Change 5 (8): pp. 709-712. 
Jakob, M., Chen, C., Fuss, S., Marxen, A., Rao, N. D. and Edenhofer, O. (2016). 'Carbon Pricing Revenues Could Close Infrastructure Access Gaps.' World Development 84 (August): pp. 254-265.

Jakob, M., and Steckel, J.C. (2016). 'Implications of Climate Change Mitigation for Sustainable Development.' Environmental Research Letters 11 (10): 104010.

Johnson, N., Krey, V., McCollum, D. L., Rao, S., Riahi, K. and Rogelj, J. (2015). 'Stranded on a Low-Carbon Planet: Implications of Climate Policy for the Phase-out of Coal-Based Power Plants.' Technological Forecasting and Social Change 90, Part A (January): pp. 89-102.

Jonek Kowalska, I. (2015). 'Challenges for Long-Term Industry Restructuring in the Upper Silesian Coal Basin: What Has Polish Coal Mining Achieved and Failed from a Twenty-Year Perspective?' Resources Policy 44 (June): pp. 135-149.

Jordaan, S. M., Romo-Rabago, E., McLeary, R., Reidy, L., Nazari, J., and Herremans, I.M. (2017). 'The Role of Energy Technology Innovation in Reducing Greenhouse Gas Emissions: A Case Study of Canada.' Renewable and Sustainable Energy Reviews 78 (October): pp. 1397-1409. doi:10.1016/j.rser.2017.05.162.

Jotzo, F., Jordan, T. and Fabian, N. (2012). 'Policy Uncertainty about Australia's Carbon Price: Expert Survey Results and Implications for Investment.' Australian Economic Review 45 (4): pp. 395-409.

Kalkuhl, M., and Brecha, R.J. (2013). 'The Carbon Rent Economics of Climate Policy.' Energy Economics 39: pp. 89-99.

Kern, F., and Rogge, K. S. (2016). 'The Pace of Governed Energy Transitions: Agency, International Dynamics and the Global Paris Agreement Accelerating Decarbonisation Processes?' Energy Research \& Social Science 22 (December): pp. 13-17.

Khosla, R., Dukkipati, S., Dubash, N.K., Sreenivas, A. and Cohen, B. (2015). 'Towards Methodologies for Multiple Objective-Based Energy and Climate Policy.' Economic \& Political Weekly 50 (49): pp. 49-59.

Kim, S. E., Urpelainen, J. and Yang, J. (2016). 'Electric Utilities and American Climate Policy: Lobbying by Expected Winners and Losers.' Journal of Public Policy 36 (2): pp. 251-275.

Kolstad, C. D., Urama, K., Broome, J., Bruvoll, A., Cariño-Olvera, M., Fullerton, D., Gollier, C. (2014). 'Social, Economic and Ethical Concepts and Methods.' In: Climate Change 2014: Mitigation of Climate Change, pp. 173-248. Cambridge, United Kingdom and New York, NY, USA: Cambridge University Press. http://lup.lub.lu.se/record/5104578.

Kriegler, E., Weyant, J.P., Blanford, G. J., Krey, V., Clarke, L., Edmonds, J., Fawcett, A. (2014). 'The Role of Technology for Achieving Climate Policy Objectives: Overview of the EMF 27 Study on Global Technology and Climate Policy Strategies.' Climatic Change 123 (3-4): pp. 353-367.

Lazarus, M., Erickson, P. and Tempest, K. (2015). 'Supply-Side Climate Policy: The Road Less Taken.' Stockholm Environment Institute, Working Paper, No. SEI-WP-2015-13 (October).

Liang, Q. and Wei, Y. (2012). 'Distributional Impacts of Taxing Carbon in China: Results from the CEEPA Model.' Applied Energy 92 (April): pp. 545-551.

Lindebjerg, E. S., Peng, W., and Yeboah, S. (2015). 'Do Policies for Phasing out Fossil Fuel Subsidies Deliver What They Promise? Social Gains and Repercussions in Iran, Indonesia and Ghana.' United Nations Research Institute for Social Development (UNRISD) Working Paper.

Löffler, K., Hainsch, K., Burandt, T., Oei, P., Kemfert, C. and von Hirschhausen, C. (2017). 'Designing a Global Energy System Based on 100\% Renewables for 2050 - GENeSYS-MOD: An Application of the Open-Source Energy Modelling System (OSeMOSYS).' DIW Discussion Paper, DIW Discussion Paper 1678.

Louie, E. P., and Pearce, J.M. (2016). 'Retraining Investment for U.S. Transition from Coal to Solar Photovoltaic Employment.' Energy Economics 57 (June): pp. 295-302.

Luderer, G., Pietzcker, R. C., Carrara, Bertram, C., Kriegler, E., Meinshausen, M. and Edenhofer, O. (2013). 'Economic Mitigation Challenges: How Further Delay Closes the Door for Achieving Climate Targets.' Environmental Research Letters 8 (3): 34033.

Luderer, G., Pietzcker, R. C., Carrara, S., Sytze de Boer, H., Fujimori, S., Johnson, N., Mima, S. and Arent, D. (2017). 'Assessment of Wind and Solar Power in Global Low-Carbon Energy Scenarios: An Introduction.' Energy Economics 64 (May): pp. 542-551.

Marcinkiewicz, K., and Tosun, J. (2015). 'Contesting Climate Change: Mapping the Political Debate in Poland.' East European Politics 31 (2): pp. 187-207. doi:10.1080/21599165.2015.1022648.

Matthes, F. C. (2017). 'Energy Transition in Germany: A Case Study on a Policy-Driven Structural Change of the Energy System.' Evolutionary and Institutional Economics Review 14 (1): pp. 141-169.

Matthes, F. C., Fabra, N., Newbery, D., Colombier, M., Mathieu, M. and Rüdinger, A. (2015). 'The Energy Transition in Europe: Initial Lessons from Germany, the UK and France.' Centre on Regulation in Europe (CERRE).

McGlade, C., and Ekins, P. (2015). 'The Geographical Distribution of Fossil Fuels Unused When Limiting Global Warming to $2^{\circ} \mathrm{C}$.' Nature 517 (7533): pp. 187-190. doi:10.1038/nature14016.

Meadowcroft, J., Stephens, J., Wilson, E. and Rowlands, I. (2017). 'Social Dimensions of Smart Grid: Regional Analysis in Canada and the United States. Introduction to Special Issue of Renewable and Sustainable Energy Reviews.' Renewable and Sustainable Energy Reviews In press.

Meinshausen, M., Meinshausen, N., Hare, W., Raper, S. C. B., Frieler, K., Knutti, R., Frame, D. J. and Allen, M. R. (2009). 'GreenhouseGas Emission Targets for Limiting Global Warming to $2^{\circ}{ }^{\circ}$.' Nature 458 (7242): pp. 1158-1162. doi:10.1038/nature08017.

MEMR. (2016). 'Statistik Ketenagalistrikan (Electricity Statistics) 2015.' Jakarta: Directorate General Electricity Ministry of Energy and Mineral Resources of Indonesia.

MEMR. (2017). 'Electric ity Supply Business Plan (Rencana Umum Penyediaan Tenaga Listrik) 2017 - 2026.' Jakarta: Directorate General Electricity Ministry of Energy and Mineral Resources of Indonesia.

Mendelevitch, R., Richter, P. and Jotzo, F. (2015). 'Market Power Rents and Climate Change Mitigation: A Rationale for Coal Export Taxes?' Conference Paper.

Metcalf, G. E. (1999). 'A Distributional Analysis of Green Tax Reforms.' National Tax Journal 52 (4): pp. 655-682.

Miller, C. A., Richter, J. and O'Leary, J. (2015). 'Socio-Energy Systems Design: A Policy Framework for Energy Transitions.' Energy Research \& Social Science 6 (March): pp. 29-40.

Ministry of Power Government of India. n.d. LOK SABHA STARRED QUESTION NO.164 ANSWERED ON 28.07.2016. 
Mondal, D. (2017). 'Electricity May Get Costlier as States Demand Higher Royalty on Coal: India Ratings.' ET Energy World. January 18. http://energy.economictimes.indiatimes.com/news/coal/electricity-may-get-costlier-as-states-demand-higherroyalty-on-coal-india-ratings/56649160

Morgan, E. (2017). 'Electricity Prices Could Double with New Coal-Fired Stations, Energy Experts Say.' ABC. http://www.abc.net. au/news/2017-02-02/coal-power-stations-could-double-the-cost-of-electricity/8234240

NDRC. (2016). 'First Biennial Update Report on Climate Change of China.' China's official submission to the UNFCCC. National Development and Reform Commission. http://unfccc.int/files/national_reports/non-annex_i_parties/biennial_update_reports/application/pdf/pr_china-_bur-chinese+en.pdf

Nemet, G. F., Jakob, M., Steckel, J. C. and Edenhofer, O. (2017). 'Addressing Policy Credibility Problems for Low-Carbon Investment.' Global Environmental Change 42 (January): pp. 47-57. doi:10.1016/j.gloenvcha.2016.12.004.

Nordhaus, W. D. (1991). 'A Sketch of the Economics of the Greenhouse Effect.' The American Economic Review 81 (2): pp. 146-150.

OCl. (2016). 'The Sky's Limit. Why the Paris Climate Goals Require a Managed Decline of Fossil Fuel Production.' Oil Change International. http://priceofoil.org/content/uploads/2016/09/OCI_the_skys_limit_2016_FINAL_2.pdf

OECD. (2017). Investing in Climate, Investing in Growth. OECD Publishing, Paris. http://www.oecd-ilibrary.org/economics/investing-in-climate-investing-in-growth_9789264273528-en

Oei, P., and Mendelevitch, R. (2016). 'European Scenarios of $\mathrm{CO}_{2}$ Infrastructure Investment until 2050.' The Energy Journal 37: pp. 171-194.

Olivier, J. G. J., Greet Janssens-Maenhout, Marilena Muntean, and Jeroen Peters. (2016). 'Trends in Global CO Emissions: 2016 Report.' PBL publication number: 2315. JRC Science for Policy Report: 103428. The Hague: PBL Netherlands Environmental Assessment Agency. European Commission, Joint Research Centre.

Ondraczek, J., Komendantova, N. and Patt, A. (2015). 'WACC the Dog: The Effect of Financing Costs on the Levelized Cost of Solar PV Power.' Renewable Energy 75: pp. 888-898.

Oosterhuis, F., and ten Brink, P. eds. (2014). Paying the Polluter: Environmentally Harmful Subsidies and Their Reform. Cheltenham, UK ; Northampton, MA, USA: Edward Elgar Publishing.

Park, A., and Lappas, P. (2017). 'Evaluating Demand Charge Reduction for Commercial-Scale Solar PV Coupled with Battery Storage.' Renewable Energy 108 (August): pp. 523-532.

Parry, I. W. H., and Williams III, R.C. (2010). 'What Are the Costs of Meeting Distributional Objectives for Climate Policy?' The B.E. Journal of Economic Analysis \& Policy 10 (2): pp. 1935-1682.

Pearce, D. (1991). 'The Role of Carbon Taxes in Adjusting to Global Warming.' The Economic Journal 101 (407): pp. 938-948.

Perrier, Q., and Quirion, P. (2016). 'La transition énergétique est-elle favorable aux branches à fort contenu en emploi ? Une approche input-output pour la France.' Working Paper 2016.09. French Association of Environmental and Resource Economists (FAERE) http://faere.fr/pub/WorkingPapers/Perrier_Quirion_FAERE_WP2016.09.pdf

Pfeiffer, A., Millar, M., Hepburn, C. and Beinhocker, E. (2016). 'The ' $2{ }^{\circ} \mathrm{C}$ Capital Stock' for Electricity Generation: Committed Cumulative Carbon Emissions from the Electricity Generation Sector and the Transition to a Green Economy.' Applied Energy 179 (October): pp. 1395-1408.

Pigou, A. C. (1920). The Economics of Welfare. Macmillan \& Co., London.

Portman, R. (2017). 'Portman, Bennet Introduce Bill to Help Finance Carbon Capture and Storage Projects.' Press release. https://www.portman.senate.gov/public/index.cfm/2017/4/portman-bennet-introduce-bill-to-help-finance-carbon-captureand-storage-projects

Porto, G.G. (2012). 'The Cost of Adjustment to Green Growth Policies: Lessons from Trade Adjustment Costs.' World Bank Policy Research Working Paper No. 6237. http://papers.ssrn.com/abstract=2165675

PWC Indonesia and ICMA. (2016). 'Supplying and Financing Coal-fired Power Plants in 35 GW Programme.' http://www.apbi-icma. org/wp-content/uploads/2016/03/03-03-2016-APBI-PwC-Report-on-Supplying-and-Financing-the-35-GW-program-FINALFINAL-rev-8-32016.pdf

Ragwitz, M., Schade, W., Breitschopf, B., Walz,R., Helfrich, N., Rathmann, M., Resch, G., Panzer, C., Faber, T. and Haas, R. (2009). 'EmployRES. The Impact of Renewable Energy Policy on Economic Growth and Employment in the European Union. Final Report, Contract No.' TREN.

Rausch, S., Metcalf, G. E. and Reilly, J.M. 2011. 'Distributional Impacts of Carbon Pricing: A General Equilibrium Approach with Micro-Data for Households.' Energy Economics, Supplemental Issue: Fourth Atlantic Workshop in Energy and Environmental Economics, 33, Supplement 1 (December): S20-33.

Reddy, B. S. (2016). 'India's Energy System Transition-Survival of the Greenest.' Renewable Energy 92: pp. $293-302$.

Ren, P., Liu, C. and Zhang, L. (2017). 'China's Involvement in Coal-Fired Power Projects along the Belt and Road.' Global Environmental Institute. http://www.geichina.org/_upload/file/report/China's_Involvement_in_Coal-fired_Power_Projects_OBOR_EN.pdf

Renn, O., and Marshall, J.P. (2016). 'Coal, Nuclear and Renewable Energy Policies in Germany: From the 1950s to the 'Energiewende." Energy Policy 99 (December): pp. 224-232.

Rentschler, J. (2015). Incidence and Impact: A Disaggregated Poverty Analysis of Fossil Fuel Subsidy Reform. OIES working Paper: SP 36. Oxford: Oxford Institute for Energy Studies.

Rentschler, J and Bazilian, M. (2016). 'Reforming Fossil Fuel Subsidies: Drivers, Barriers and the State of Progress.' Climate Policy, 17 (7): pp. 891-914.

Riahi, K., Kriegler, E., Johnson, N., Bertram, C., den Elzen, M., Eom, J., Schaeffer, M. (2015). 'Locked into Copenhagen Pledges Implications of Short-Term Emission Targets for the Cost and Feasibility of Long-Term Climate Goals.' Technological Forecasting and Social Change 90, Part A (January): pp. 8-23.

Rifkin, J. 2011. The Third Industrial Revolution: How Lateral Power Is Transforming Energy, the Economy, and the World. St. Martin's Press. http://www.ebooks.com/731631/the-third-industrial-revolution/rifkin-jeremy/

Robles, M., Rubio, M. G., and Stampini, M.S. (2015). 'Have Cash Transfers Succeeded in Reaching the Poor in Latin America and the Caribbean?' Inter-American Development Bank (IDB). http://publications.iadb.org/handle/11319/7223 
Rogelj, J., Luderer, G., Pietzcker, R. C., Kriegler, E., Schaeffer, M., Krey, V., and Riahi, K. (2015). 'Energy System Transformations for Limiting End-of-Century Warming to below $1.5^{\circ} \mathrm{C}$.' Nature Climate Change 5 (6): pp. 519-527. doi:10.1038/nclimate2572.

Rogelj, J., McCollum, D. L., O’Neill, B.C. and Riahi, K. (2013). '2020 Emissions Levels Required to Limit Warming to below 2? C.' Nature Climate Change 3 (4): pp. 405-412.

Rozenberg, J., Vogt-Schilb, A. and Hallegatte, S. (2017). 'Instrument Choice and Stranded Assets in the Transition to Clean Capital.' Inter-American Development Bank (IDB).

Sachs, J., Guerin, E., Mas, C., Schmidt-Traub, G., Tubiana, L., Waisman, H., Colombier, M. (2014). 'Pathways to Deep Decarbonization: 2014 Report.' INIS-FR--15-0191. France: SDSN/IDDRI.

Sdralevich, C.A., Sab, R., Zouhar, Y. and Albertin, G. (2014). Subsidy Reform in the Middle East and North Africa: Recent Progress and Challenges Ahead. International Monetary Fund.

Shearer, C., Ghio, N., Myllyvirta, L., Yu, A. and Nace, T. (2017). 'Boom and Bust 2017 - Tracking the Global Coal Plant Pipeline.' Coalswarm / Sierra Club / Greenpeace.

Singh, R. K. (2016). 'India Seeks to Shut 12\% of Power Capacity in Anti-Pollution Move.' Live Mint, May 8.http://www.livemint.com/ Industry/QkD9eo3IrSVj1sxV3ubB9K/India-seeks-to-shut-12-of-power-capacity-in-antipollution.html

Sovacool, B. (2017). 'Reviewing, Reforming, and Rethinking Global Energy Subsidies: Towards a Political Economy Research Agenda.' Ecological Economics 135 (February): 150-163. doi:http://dx.doi.org/10.1016/j.ecolecon.2016.12.009.

Sovacool, B. K., Heffron R. J., McCauley, D. and Goldthau. A. (2016). 'Energy Decisions Reframed as Justice and Ethical Concerns.' Nature Energy 1: 16024.

Steckel, J. C., Edenhofer, O and Jakob, M. (2015). 'Drivers for the Renaissance of Coal.' Proceedings of the National Academy of Sciences 112 (29): E3775-81. doi:10.1073/pnas.1422722112.

Steckel, J. C., Jakob, M., Flachsland, C., Kornek, U., Lessmann, K., and Edenhofer, O. (2017). 'From Climate Finance toward Sustainable Development Finance.' Wiley Interdisciplinary Reviews: Climate Change 8 (1).

Sterner, T., ed. (2012). Fuel Taxes and the Poor: The Distributional Effects of Gasoline Taxation and Their Implications for Climate Policy. New York: RFF Press.

Stiglitz, J. and Stern, N. (2017). Report of the High-Level Commission on Carbon Prices. Washington: World Bank Group: Carbon Pricing Leadership Coalition.

Suwala, W. 2010. 'Lessons Learned from the Restructuring of Poland's Coal-Mining Industry.' Global Subsidies Initiative (GSI), International Institute for Sustainable Development (IISD).

Swartz, J. (2016). 'China's National Emissions Trading System: Implications for Carbon Markets and Trade.' Issue Paper No. 6. International Centre for Trade and Sustainable Development (ICTSD).

Symons, E., Proops, J. and Gay, P. (1994). 'Carbon Taxes, Consumer Demand and Carbon Dioxide Emissions: A Simulation Analysis for the UK.' Fiscal Studies 15 (2): pp. 19-43.

Szpor, A. (2017). 'Coal Transition in Poland.' IDDRI and Climate Strategies. www.iddri.org/Publications/Rapports-and-briefing-papers/COAL_PL_v04.pdf

Szulecki, K., Fischer, S., Gullberg, A.T. and Sartor, O. (2016). 'Shaping the 'Energy Union': between National Positions and Governance Innovation in EU Energy and Climate Policy.' Climate Policy 16 (5): pp. 548-567.

Torvanger, A., Narbel, P., Pillay, K. and Clapp, C. (2016). 'Instruments to Incentivize Private Climate Finance for Developing Countries.' CICERO Report.

Trebilcock, C. 1981. The Industrialization of the Continental Powers, 1780-1914. Longman London.

Trebilcock, M. J. (2014). Dealing with Losers: The Political Economy of Policy Transitions. Oxford University Press, USA.

United Nations. (2015). 'Adoption of the Paris Agreement.' Framework Convention on Climate Change. http://unfccc.int/resource/ docs/2015/cop21/eng/l09r01.pdf

US Senate. (2017). 'S.1535 - FUTURE Act.' Washington, DC. https://www.congress.gov/bill/115th-congress/senate-bill/1535/text

Vogt-Schilb, A. and Hallegatte, S. (2017). 'Climate Policies and Nationally Determined Contributions: Reconciling the Needed Ambition with the Political Economy.' WIREs Energy Environment 6 (6). doi:10.1002/wene.256.

Wei, M., Patadia, S. and Kammen, D. M. (2010). 'Putting Renewables and Energy Efficiency to Work: How Many Jobs Can the Clean Energy Industry Generate in the U.S.?' Energy Policy 38 (2): pp. 919-931.

West, J. J., Smith, S. J., Silva, R. A., Naik, V., Zhang, Y., Adelman, Z., Fry, M. M., Anenberg, S., Horowitz, L.W. and Lamarque, J. (2013). 'Co-Benefits of Mitigating Global Greenhouse Gas Emissions for Future Air Quality and Human Health.' Nature Climate Change 3 (10): pp. 885-889. doi:10.1038/nclimate2009.

White House. (2015). 'The Budget of the U.S. Government Fiscal Year2015.' Washington, DC.

White House . (2016). "The Budget of the U.S. Government Fiscal Year 2016." Washington, DC.

Widera, M., Kasztelewicz, Z. and Ptak, M. (2016). 'Lignite Mining and Electricity Generation in Poland: The Current State and Future Prospects.' Energy Policy 92: pp. 151-157.

Williams, J. H., DeBenedictis, A., Ghanadan, R., Mahone, A., Moore, J., Morrow III, W.R., Price, S. and. Torn, M.S. (2012). 'The Technology Path to Deep Greenhouse Gas Emissions Cuts by 2050: The Pivotal Role of Electricity.' Science 335 (6064): pp. 53-59.

World Bank. (2015). The State of Social Safety Nets (2015). Washington DC: The World Bank. http://elibrary.worldbank.org/doi/ book/10.1596/978-1-4648-0543-1

World Bank, and Ecofys. (2016). 'Carbon Pricing Watch 2016: An Advance Brief from the State and Trends of Carbon Pricing 2016 Report, to Be Released Late 2016.' Washington, DC: World Bank Group. http://documents.worldbank.org/curated/ en/2016/05/26379305/carbon-pricing-watch-2016-advance-brief-state-trends-carbon-pricing-2016-report-released-late-2016

Wynn, G. (2016). 'The Dutch Coal Mistake: How Three Brand-New Power Plants in the Netherlands Are Already at Risk of Becoming Stranded Assets.' Cleveland: Institute for Energy Economics and Financial Analysis (IEEFA) http://ieefa.org/wp-content/uploads/2016/11/The-Dutch-Coal-Mistake_November-2016.pdf

Zhang, C. (2017). 'China Takes Another Step to Reduce Coal-Fired Power.' ChinaDialogue, March 20. https://www.chinadialogue. net/article/show/single/en/9678-China-takes-another-step-to-reduce-coal-fired-power 
Zhou, Y., Li, H., Wang, K. and Bi, J. (2016). 'China's Energy-Water Nexus: Spillover Effects of Energy and Water Policy.' Global Environmental Change 40 (September): pp. 92-100.

\section{Chapter 6}

Aggarwal, R.K. and Chandel, S.S. (2004) 'Review of Improved Cookstoves Programme in Western Himalayan State of India'. Biomass and Bioenergy, 27(2):131-144. Available at: https://www.cabdirect.org/cabdirect/abstract/20043106078 [Accessed 18 October 2017]. doi:10.1016/j.biombioe.2004.01.001

Allen, M.R., Fuglestvedt, J.S., Shine, K.P., Reisinger, A., Pierrehumbert, R.T. and Forster, P.M. (2016) 'New use of global warming potentials to compare cumulative and short-lived climate pollutants'. Nature Climate Change, 6:773-776. Available at: http://www. sequoiaforestkeeper.org/pdfs/attachments/Allen_et_al_on_SLCP_GWP_2016.pdf [Accessed 18 October 2017].

Amann, M., Klimont, Z. and Wagner, F. (2013) 'Regional and Global Emissions of Air Pollutants: Recent Trends and Future Scenarios'. Annual Review of Environment and Resources, 38:31-55. Available at: http://pure.iiasa.ac.at/10315/ [Accessed 18 October 2017]-

Bond, T.C., Doherty, S.J., Fahey, D.W., Forster, P.M., Berntsen, T., DeAngelo, B.J., Flanner, M.G., Ghan, S., Kärcher, B., Koch, D., Kinne, S., Kondo, Y., Quinn, P.K., Sarofim, M.C., Schultz, M.G., Schulz, M., Venkataraman, C., Zhang, H., Zhang, S., Bellouin, N., Guttikunda, S.K., Hopke, P.K., Jacobson, M.Z., Kaiser, J.W., Klimont, Z., Lohmann, U., Schwarz, J.P., Shindell, D., Storelvmo, T., Warren, S.G. and Zender, C.S. (2013) 'Bounding the role of black carbon in the climate system: A scientific assessment'. Journal of Geophysical Research: Atmospheres, 118(11):5380-5552. Available at: https://experts.illinois.edu/en/publications/bounding-the-role-ofblack-carbon-in-the-climate-system-a-scienti [Accessed 18 October 2017].

Brander, M., Sood, A., Wylie, C., Haughton, A. and Lovell, J. (2011) 'Technical Paper - Electricity-specific Emission Factors for Grid Electricity'. Ecometrica. Available at: https://ecometrica.com/assets/Electricity-specific-emission-factors-for-grid-electricity.pdf [Accessed 18 October 2017].

CAI-Asia (2011) Factsheet No. 17- Roadmap for Cleaner Fuels and Vehicles in Asia. Manila: Clean Air Initiative for Asian Cities Center. Available at: http://cleanairasia.org/wp-content/uploads/portal/files/documents/16_Roadmap_to_Cleaner_Fuels_and_Vehicles_in_Asia_0.pdf [Accessed 18 October 2017].

Cardenas, B., Maiz, P., Márquez, R.O., Munguia, J.L., Angeles, F., Baum, E. and Molina, L.T. (2012) Determining Emissions of Black carbon, greenhouse gases and other pollutants from artisanal brick production in Mexico. Clean Air Task Force and MCE2.

Chambliss, S., Miller, J., Facanho, C., Minjares, R., Blumberg, K., 2013. The impact of stringent fuel and vehicle standards on premature mortality and emisisons. International Council on Clean Transportation (ICCT), Washington D.C., USA.

Cherian, A. (2015) Energy and Global Climate Change: Bridging the Sustainable Development Divide. Chichester: John Wiley \& Sons Ltd.

Christian, T.J., Yokelson, R.J., Cárdenas, B., Molina, L.T., Engling, G. and Hsu, S.-C. (2010) 'Trace gas and particle emissions from domestic and industrial biofuel use and garbage burning in central Mexico'. Atmospheric Chemistry and Physics, 10(2):565-584. Available at: https://www.atmos-chem-phys.net/10/565/2010/acp-10-565-2010.html [Accessed 18 October 2017].

Coan, J. (2012) Vehicle emissions standards are a regulatory success story. Fuelfix. Available at: http://fuelfix.com/blog/2012/05/18/ vehicle-emissions-standards-a-regulatory-success-story/ [Accessed 18 October 2017].

Conrad, B.M. and Johnson, M.R. (2017) 'Field Measurements of Black Carbon Yields from Gas Flaring'. Environmental Science and Technology, 51(3):1893-1900. Available at: http://pubs.acs.org/doi/abs/10.1021/acs.est.6b03690 [Accessed 18 October 2017].

Crippa, M., Janssens-Maenhout, G., Dentener, F., Guizzardi, D., Sindelarova, K., Muntean, M., Van Dingenen, R. and Granier, C. (2016) 'Forty years of improvements in European air quality: regional policy-industry interactions with global impacts'. Atmospheric Chemistry and Physics, 16:3825-3841. Available at: https://www.atmos-chem-phys.net/16/3825/2016/ [Accessed 18 October 2017].

DieselNet (2015). Summary of worldwide engine emission standards. Emission Standards.

EC-JRC/PBL (2013) EDGAR version 4.2FT2010-Emission Database for Global Atmospheric Research.

Etminan, M., Myhre, G., Highwood, E. and Shine, K.P. (2016) 'Radiative forcing of carbon dioxide, methane, and nitrous oxide: A significant revision of the methane radiative forcing'. Geophysical Research Letters, 43:614-623. Available at: http://centaur. reading.ac.uk/68557/1/grl_etminan.pdf [Accessed 18 October 2017].

Evans, M., Kholod, N., Malyshev, V., Tretyakova, S., Gusev, E., Yu, S. and Barinov, A. (2015) 'Black carbon emissions from Russian diesel sources: case study of Murmansk'. Atmospheric Chemistry and Physics, 15:8349-8359. Available at: https://www.atmoschem-phys.net/15/8349/2015/ [Accessed 18 October 2017].

FAO (2013) Mitigation of greenhouse gas emissions in livestock production - a review of technical options for non-CO, emissions. Rome: Food and Agriculture Organization (FAO) of the United Nations. Available at: http://www.fao.org/docrep/018/i3288e/ i3288e.pdf [Accessed 18 October 2017].

GACC (2015). Five Years of Imapct 2010-2015. Our Story. Our Progress. Our Aspiration. Washington: Global Alliance for Clean Cookstoves (GACC). Available at: http://cleancookstoves.org/resources/reports/fiveyears.html [Accessed 18 October 2017].

Gasser, T., Peters, G.P., Fuglestvedt, J.S., Collins, W.J., Shindell, D.T. and Ciais, P. (2017) 'Accounting for the climate-carbon feedback in emission metrics'. Earth System Dynamics, 8:235-253. Available at: https://www.earth-syst-dynam.net/8/235/2017/esd-201655.pdf [Accessed 18 October 2017].

Geoffroy, O., Saint-Martin, D., Bellon, G., Voldoire, A., Olivié, D.J.L. and Tytéca, S. (2013) 'Transient Climate Response in a Two-Layer Energy-Balance Model. Part II: Representation of the Efficacy of Deep-Ocean Heat Uptake and Validation for CMIP5 AOGCMs'. Journal of Climate, 23:1859-1876. Available at: http://journals.ametsoc.org/doi/ref/10.1175/JCLI-D-12-00196.1 [Accessed 18 October 2017].

GOI (2014) Auto Fuel Vision and Policy 2025. Report of the Expert Committee. Government of India (GOI). Available at: http://www. petroleum.nic.in/sites/default/files/autopol.pdf [Accessed 18 October 2017].

Griggs, D., M. Stafford Smith, J. Rockström, M. C. Öhman, O. Gaffney, G. Glaser and P. Shyamsundar (2014) 'An integrated framework for sustainable development goals'. Ecology and Society, 19(4):49. Available at: https://www.ecologyandsociety.org/vol19/iss4/ art49/ [Accessed 18 October 2017]. 
Haines, A., et al. (under review) 'Short-lived climate pollutant mitigation and the sustainable development goals'. Nature Climate Change.

Hoesly, R.M., Smith, S.J., Feng, L., Klimont, Z., Janssens-Maenhout, G., Pitkanen, T., Seibert, J.J., Vu, L., Andres, R.J., Bolt, R.M., Bond, T.C., Dawidowski, L., Kholod, N., Kurokawa, J.-I., Li, M., Liu, L., Lu, Z., Moura, M.C.P., O'Rourke, P.R. and Zhang, Q. (2017). 'Historical (1750-2014) anthropogenic emissions of reactive gases and aerosols from the Community Emission Data System (CEDS)'. Geoscientific Model Development Discussions, 1-41. Available at: https://www.geosci-model-dev-discuss.net/gmd-2017-43/ [Accessed 18 October 2017].

Höglund-Isaksson, L. (2017) 'Bottom-up simulations of methane and ethane emissions from global oil and gas systems 1980 to 2012'. Environmental Research Letters, 12(2). Available at: http://iopscience.iop.org/article/10.1088/1748-9326/aa583e [Accessed 18 October 2017].

Höglund-Isaksson, L. (2012) 'Global anthropogenic methane emissions 2005-2030: technical mitigation potentials and costs'. Atmospheric Chemistry and Physics, 12(19):9079-9096. Available at: https://www.atmos-chem-phys.net/12/9079/2012/acp-129079-2012.html [Accessed 18 October 2017].

Höglund-Isaksson, L., Purohit, P., Amann, M., Bertok, I., Rafaj, P., Schöpp, W. and Borken-Kleefeld, J. (2017) 'Cost estimates of the Kigali Amendment to phase-down hydrofluorocarbons'. Environmental Science \& Policy, 75:138-147.

Hu, A., Xu, Y., Tebaldi, C., Washington, W.M. and Ramanathan, V. (2013) 'Mitigation of short-lived climate pollutants slows sealevel rise'. Nature Climate Change, 3:730-734. Available at: http://www.nature.com/nclimate/journal/v3/n8/full/nclimate1869. html?foxtrotcallback=true [Accessed 18 October 2017].

Huang, K., Fu, J.S., Prikhodko, V.Y., Storey, J.M., Romanov, A., Hodson, E.L., Cresko, J., Morozova, I., Ignatieva, Y. and Cabaniss, J. (2015) 'Russian anthropogenic black carbon: Emission reconstruction and Arctic black carbon simulation'. Journal of Geophysical Research: Atmospheres, 120(11):306-11.

IEA (2016) World Energy Outlook Special Report: Energy and Air Pollution. Paris: International Energy Agency (IEA). Available at: https://www.iea.org/publications/freepublications/publication/WorldEnergyOutlookSpecialReport2016EnergyandAirPollution. pdf [Accessed 18 October 2017].

IEA (2012) Energy Technology Perspectives 2012 - Pathways to a Clean Energy System. Paris: International Energy Agency (IEA). Available at: https://www.iea.org/publications/freepublications/publication/ETP2012_free.pdf [Accessed 18 October 2017].

INDC-Mexico (2015). Intended Nationally Determined Contribution, Mexico. Government of Mexico.

Jacobson, A., Lam, N.L., Bond, T.C. and Hultman, N. (2013) Black Carbon and Kerosene Lighting: An Opportunity for Rapid Action on Climate Change and Clean Energy for Development. Washington, D.C.: The Bookings Institution. Available at: https://www. brookings.edu/wp-content/uploads/2016/06/04_climate_change_clean_energy_development_hultman.pdf [Accessed 18 October 2017].

Karekezi, S., K. Lata, and S. T. Coelho (2006) 'Traditional biomass energy: improving its use and moving to modern energy use'. Renewable Energy, 1:231-261.Kholod, N., Evans, M. and Kuklinski, T. (2016) 'Russia's black carbon emissions: focus on diesel sources'. Atmospheric Chemistry and Physics, 16(17):11267-11281. Available at: https://www.atmos-chem-phys.net/16/11267/2016/ [Accessed 18 October 2017].

Klimont, Z., Kupiainen, K., Heyes, C., Purohit, P., Cofala, J., Rafaj, P., Borken-Kleefeld, J. and Schöpp, W. (2017) ‘Global anthropogenic emissions of particulate matter including black carbon'. Atmospheric Chemistry and Physics, 17(14):8681-8723. Available at: https://www.atmos-chem-phys.net/17/8681/2017/ [Accessed 18 October 2017].

Kodjak, D. (2015) Policies to reduce fuel consumption, air pollution, and carbon emissions from vehicles in G20 nations. Washington, D.C.: International Council on Clean Transportation (ICCT). Available at: http://www.theicct.org/publications/policies-reducefuel-consumption-air-pollution-and-carbon-emissions-vehicles-g20 [Accessed 18 October 2017].

Kondo, Y., Oshima, N., Kajino, M., Mikami, R., Moteki, N., Takegawa, N., Verma, R.L., Kajii, Y., Kato, S. and Takami, A. (2011) 'Emissions of black carbon in East Asia estimated from observations at a remote site in the East China Sea'. Journal of Geophysical Research: Atmospheres, 116(D16). Available at: http://onlinelibrary.wiley.com/doi/10.1029/2011JD015637/abstract. [Accessed 18 October 2017].

Kurokawa, J., Ohara, T., Morikawa, T., Hanayama, S., Janssens-Maenhout, G., Fukui, T., Kawashima, K. and Akimoto, H. (2013) 'Emissions of air pollutants and greenhouse gases over Asian regions during 2000-2008: Regional Emission inventory in ASia (REAS) version 2'. Atmospheric Chemistry and Physics, 13(21):11019-11058. Available at: https://www.atmos-chem-phys. net/13/11019/2013/acp-13-11019-2013.html [Accessed 18 October 2017].

Lam, N.L., Chen, Y., Weyant, C., Venkataraman, C., Sadavarte, P., Johnson, M.A., Smith, K.R., Brem, B.T., Arineitwe, J., Ellis, J.E. and Bond, T.C. (2012) 'Household Light Makes Global Heat: High Black Carbon Emissions From Kerosene Wick Lamps'. Environmental Science \& Technology, 46(24):13531-13538. Available at: https://www.ncbi.nlm.nih.gov/pubmed/23163320 [Accessed 18 October 2017].

Lamarque, J.-F., Bond, T.C., Eyring, V., Granier, C., Heil, A., Klimont, Z., Lee, D., Liousse, C., Mieville, A., Owen, B., Schultz, M.G., Shindell, D.T., Smith, S.J., Stehfest, E., Van Aardenne, J.A., Cooper, O.R., Kainuma, M., Mahowald, N., McConnell, J.R., Naik, V., Riahi, K. and Van Vuuren, D.P.V. (2010) 'Historical (1850-2000) gridded anthropogenic and biomass burning emissions of reactive gases and aerosols: Methodology and application'. Atmospheric Chemistry and Physics, 10:7017-7039.

Lu, Z., Zhang, Q. and Streets, D.G. (2011) 'Sulfur dioxide and primary carbonaceous aerosol emissions in China and India, 19962010'. Atmospheric Chemistry and Physics, 11(18):9839-9864. Available at: https://www.atmos-chem-phys.net/11/9839/2011/ acp-11-9839-2011.html [Accessed 18 October 2017].

Maithel, S., Lalchandani, D., Malhotra, G., Bhanware, P., Uma, R., Ragavan, S., Athalye, V., Bindiya, K., Reddy, S., Bond, T.C., Weyant, C., Baum, E., Kim Thoa, V.T., Thu Phuong, N. and Kim Thanh, T. (2012) Brick Kilns Performance Assessment; A Roadmap for Cleaner Brick Production in India. Shakti Sustainable Energy Foundation and Climate Works Foundation.

Malley, C.S., Henze, D.K., Kuylenstierna, J.C.I., Vallack, H.W., Davila, Y., Anenberg, S.C., Turner, M.C. and Ashmore, M.R. (2017) ‘Updated global estimates of respiratory mortality in adults $\geq 30$ years of age attributable to long-term ozone exposure'. Environmental Health Perspectives, 125(8). Available at: https://www.ncbi.nlm.nih.gov/pubmed/28858826 [Accessed 18 October 2017].

MoRTH (2016) Government decides to directly shift from BS-IV to BS-VI emission norms. New Delhi: Ministry of Road Transport \& Highways (MoRTH), Government of India. 
Myhre, G., Shindell, D., Bréon, F.M., Collins, W., Fuglestvedt, J., Huang, J., Koch, D., Lamarque, J.F., Lee, D., Mendoza, B., Nakajima, T., Robock, A., Stephens, G., Takemura, T. and Zhang, H. (2013) Anthropogenic and Natural Radiative Forcing, in: Climate Change 2013: The Physical Science Basis. New York: Contribution of Working Group I to the Fifth Assessment Report of the Intergovernmental Panel on Climate Change. Cambridge University Press, Cambridge, United Kingdom. Available at: https://www.ipcc.ch/ pdf/assessment-report/ar5/wg1/WG1AR5_Chapter08_FINAL.pdf [Accessed 18 October 2017].

Pine, K., Edwards, R., Masera, O., Schilmann, A., Marrón-Mares, A. and Riojas-Rodríguez, H., (2011) 'Adoption and use of improved biomass stoves in Rural Mexico'. Energy for Sustainable Development, 15(2):176-183. Available at: https://asu.pure.elsevier. com/en/publications/adoption-and-use-of-improved-biomass-stoves-in-rural-mexico [Accessed 18 October 2017].

Purohit, P. and Höglund-Isaksson, L. (2017) 'Global emissions of fluorinated greenhouse gases 2005-2050 with abatement potentials and costs'. Atmospheric Chemistry and Physics, 17(4):2795-2816. Available at: https://www.atmos-chem-phys. net/17/2795/2017/ [Accessed 18 October 2017].

Rao, S., Klimont, Z., Smith, S.J., Van Dingenen, R., Dentener, F., Bouwman, L., Riahi, K., Amann, M., Bodirsky, B.L., van Vuuren, D.P., Aleluia Reis, L., Calvin, K., Drouet, L., Fricko, O., Fujimori, S., Gernaat, D., Havlik, P., Harmsen, M., Hasegawa, T., Heyes, C., Hilaire, J., Luderer, G., Masui, T., Stehfest, E., Strefler, J., van der Sluis, S. and Tavoni, M. (2017) 'Future air pollution in the Shared Socioeconomic Pathways'. Global Environmental Change, 42:346-358.

Riahi, K., van Vuuren, D.P., Kriegler, E., Edmonds, J., O’Neill, B.C., Fujimori, S., Bauer, N., Calvin, K., Dellink, R., Fricko, O., Lutz, W., Popp, A., Cuaresma, J.C., KC, S., Leimbach, M., Jiang, L., Kram, T., Rao, S., Emmerling, J., Ebi, K., Hasegawa, T., Havlik, P., Humpenöder, F., Da Silva, L.A., Smith, S., Stehfest, E., Bosetti, V., Eom, J., Gernaat, D., Masui, T., Rogelj, J., Strefler, J., Drouet, L., Krey, V., Luderer, G., Harmsen, M., Takahashi, K., Baumstark, L., Doelman, J.C., Kainuma, M., Klimont, Z., Marangoni, G., Lotze-Campen, H., Obersteiner, M., Tabeau, A., Tavoni, M., 2017. The Shared Socioeconomic Pathways and their energy, land use, and greenhouse gas emissions implications: An overview. Global Environmental Change 42, 153-168. doi:10.1016/j.gloenvcha.2016.05.009

Rogelj, J., Schaeffer, M., Meinshausen, M., Shindell, D.T., Hare, W., Klimont, Z., Velders, G.J.M., Amann, M. and Schellnhuber, H.J. (2014) 'Disentangling the effects of $\mathrm{CO}_{2}$ and short-lived climate forcer mitigation'. Proceedings of the National Academy of Sciences, 111:16325-16330. Available at: http://pure.iiasa.ac.at/10817/ [Accessed 18 October 2017].

Ruiz-Mercado, I., Masera, O., Zamora, H. and Smith, K.R. (2011) 'Adoption and sustained use of improved cookstoves'. Energy Policy, 39:7557-7566. Available at: http://citeseerx.ist.psu.edu/viewdoc/download?doi=10.1.1.394.2048\&rep=rep1\&type=pdf [Accessed 18 October 2017].

Sabel, C.F. and Victor, D.G. (2015) 'Governing global problems under uncertainty: making bottom-up climate policy work'. Climatic Change, 136:1-13. Available at: https://ai2-s2-pdfs.s3.amazonaws.com/1e77/b22f9eafa83e6f060517ff890461ceee0a7d.pdf [Accessed 18 October 2017].

Saikawa, E. (2013) 'Policy Diffusion of Automobile Emission Standards: Is there a Race to the Top?' World Politics, 65: 1-33. Available at: https://globalchange.mit.edu/publication/15932 [Accessed 18 October 2017].

Schmale, J., Shindell, D., von Schneidemesser, E., Chabay, I. and Lawrence, M.G. (2014) 'Air pollution: Clean up our skies'. Nature, 515:335-337. Available at: http://publications.iass-potsdam.de/pubman/faces/viewltemFullPage.jsp?itemld=escidoc\%3A7189 05\%3A4\&view=EXPORT [Accessed 18 October 2017].

Shah, N., Wei, M., Letschert, V. and Phadke, A. (2015) Benefits of Leapfrogging to Superefficiency and Low-Global Warming Potential Refrigerants in Room Air Conditioning. Berkeley: Ernest Orlando Lawrence Berkeley National Laboratory.

Shen, G., Wei, S., Wang, Wen, Zhang, Y., Ming, Y., Wang, B., Wang, R., Li, W., Shen, H., Huang, Y., Yang, Y., Wang, Wei, Wang, Xilong, Wang, Xuejun and Tao, S. (2012) 'Emission factors, size distributions, and emission inventories of carbonaceous particulate matter from residential wood combustion in rural China'. Environmental Science \& Technology, 46:4207-4214.

Shindell, D., Borgford-Parnell, N., Brauer, M., Haines, A., Kuylenstierna, J.C.I., Leonard, S.A., Ramanathan, V., Ravishankara, A., Amann, M. and Srivastava, L. (2017a) 'A climate policy pathway for near- and long-term benefits'. Science, 356:493-494. Available at: https://www.ncbi.nlm.nih.gov/pubmed/28473553 [Accessed 18 October 2017].

Shindell, D., Fuglestvedt, J.S. and Collins, W.J. (2017b) 'The social cost of methane: Theory and applications'. Faraday Discussions, 200:429-451. Available at: http://pubs.rsc.org/en/content/articlelanding/2017/fd/c7fd00009j\#!divAbstract [Accessed 18 October 2017].

Shindell, D., Kuylenstierna, J.C.I., Vignati, E., Van Dingenen, R., Amann, M., Klimont, Z., Anenberg, S.C., Muller, N., JanssensMaenhout, G., Raes, F., Schwartz, J., Faluvegi, G., Pozzoli, L., Kupiainen, K., Höglund-Isaksson, L., Emberson, L., Streets, D., Ramanathan, V., Hicks, K., Oanh, N.T.K., Milly, G., Williams, M., Demkine, V. and Fowler, D. (2012) 'Simultaneously mitigating nearterm climate change and improving human health and food security'. Science, 335:183-189. Available at: https://www.ncbi.nlm. nih.gov/pubmed/22246768 [Accessed 18 October 2017].

Sinton, J.E., Smith, K.R., Peabody, J.W., Yaping, L., Xiliang, Z., Edwards, R. and Quan, G. (2004) 'An assessment of programs to promote improved household stoves in China'. Energy for Sustainable Development, 8:33-52.

Smith, S.J. and Mizrahi, A. (2013) 'Near-term climate mitigation by short-lived forcers'. Proceedings of the National Academy of Sciences, 110(35):14202-14206. Available at: http://www.pnas.org/content/110/35/14202.abstract [Accessed 18 October 2017].

Stehfest, E., Bouwman, L., Vuuren, D.P., Elzen, M.G.J., Eickhout, B. and Kabat, P. (2009) 'Climate benefits of changing diet'. Climatic Change, 95(1-2):83-102. Available at: https://link.springer.com/article/10.1007/s10584-008-9534-6 [Accessed 18 October 2017].

Stockwell, C. E., Christian, T. J., Goetz, J. D., Jayarathne, T., Bhave, P. V., Praveen, P. S., Adhikari, S., Maharjan, R., DeCarlo, P. F., Stone, E. A., Saikawa, E., Blake, D. R., Simpson, I. J., Yokelson, R. J., and Panday, A. K.: Nepal Ambient Monitoring and Source Testing Experiment (NAMaSTE): emissions of trace gases and light-absorbing carbon from wood and dung cooking fires, garbage and crop residue burning, brick kilns, and other sources, Atmos. Chem. Phys., 16, 11043-11081, https://doi.org/10.5194/acp-1611043-2016, 2016.

Stohl, A., Aamaas, B., Amann, M., Baker, L.H., Bellouin, N., Berntsen, T.K., Boucher, O., Cherian, R., Collins, W., Daskalakis, N., Dusinska, M., Eckhardt, S., Fuglestvedt, J.S., Harju, M., Heyes, C., Hodnebrog, Ø., Hao, J., Im, U., Kanakidou, M., Klimont, Z., Kupiainen, K., Law, K.S., Lund, M.T., Maas, R., Maclntosh, C.R., Myhre, G., Myriokefalitakis, S., Olivié, D., Quaas, J., Quennehen, B., Raut, J.-C., Rumbold, S.T., Samset, B.H., Schulz, M., Seland, $\varnothing$., Shine, K.P., Skeie, R.B., Wang, S., Yttri, K.E. and Zhu, T. (2015) 'Evaluating the climate and air quality impacts of short-lived pollutants'. Atmospheric Chemistry and Physics, 15(18):10529-10566. Available at: https://www.atmos-chem-phys.net/15/10529/2015/acp-15-10529-2015.html [Accessed 18 October 2017]. 
Stohl, A., Klimont, Z., Eckhardt, S., Kupiainen, K., Shevchenko, V.P., Kopeikin, V.M. and Novigatsky, A.N. (2013) 'Black carbon in the Arctic: the underestimated role of gas flaring and residential combustion emissions'. Atmospheric Chemistry and Physics, 13(17):8833-8855. Available at: https://www.atmos-chem-phys.net/13/8833/2013/acp-13-8833-2013.html [Accessed 18 October 2017].

Thomas, E., Wickramasinghe, K., Mendis, S., Roberts, N. and Foster, C. (2015) 'Improved stove interventions to reduce household air pollution in low and middle income countries: a descriptive systematic review'. BMC Public Health, 15:650. Available at: https:// www.ncbi.nlm.nih.gov/pubmed/26169364 [Accessed 18 October 2017].

UNEP/WMO (2011) Integrated Assessment of Black Carbon and Tropospheric Ozone. Nairobi: United Nations Environment Programme (UNEP) and World Meterorological Organization (WMO). Available at: https://wedocs.unep.org/rest/bitstreams/12809/ retrieve [Accessed 18 October 2017].

US EPA (2017) History of Reducing Air Pollution from Transportation in the United States (U.S.). Washington, DC: United States Environmental Protection Agency (USEPA). Available at: https://www.epa.gov/air-pollution-transportation/accomplishments-andsuccess-air-pollution-transportation [Accessed 18 October 2017].

US EPA (2013) Global Mitigation of Non-CO Greenhouse Gases: 2010-2030. Washington, DC: United States Environmental Protection Agency (USEPA). Available at: https://nepis.epa.gov/Exe/ZyNET.exe/P100GYHT.TXT?ZyActionD=ZyDocument\&Client=EPA\& Index $=2011+$ Thru+2015\&Docs $=\& Q u e r y=\& T i m e=\&$ EndTime $=\&$ SearchMethod $=1 \&$ TocRestrict $=$ n $\&$ Toc $=\&$ TocEntry $=\& Q F i e l d=\& Q F$ ieldYear $=\& Q$ FieldMonth $=\& Q F i e l d D a y=\&$ IntQFieldOp $=0 \&$ ExtQFieldOp $=0 \& X m \mid Q u e r y=\& F i l e=D \% 3 \mathrm{~A} \% 5 \mathrm{Czy}$ files\%5CIndex\%20Data \%5C11thru15\%5CTxt\%5C00000008\%5CP100GYHT.txt\&User=ANONYMOUS\&Password=anonymous\&SortMethod=h\%7C-\&Maxi mumDocuments=1\&FuzzyDegree=0\&ImageQuality=r75g8/r75g8/x150y150g16/i425\&Display=hpfr\&DefSeekPage=x\&SearchBa ck=ZyActionL\&Back=ZyActionS\&BackDesc=Results\%20page\&MaximumPages=1\&ZyEntry=1\&SeekPage=x\&ZyPURL [Accessed 18 October 2017].

US EPA (2012) Global Anthropogenic Non-CO Greenhouse Gas Emissions: 1990 - 2030. Washington, DC: United States Environmental Protection Agency (EPA). Available at: https://www.epa.gov/sites/production/files/2016-08/documents/epa_global_ nonco2_projections_dec2012.pdf [Accessed 18 October 2017].

US EPA (2002) Building owners save money, save the Earth: replace your CFC air conditioning chiller. Washington, DC: United States Environmental Protection Agency (EPA). Available at: https://nepis.epa.gov/Exe/ZyNET.exe/00000LZT.TXT?ZyActionD=ZyDocum ent\&Client=EPA\&Index=2000+Thru+2005\&Docs=\&Query=\&Time $=\& E n d T i m e=\& S e a r c h M e t h o d=1 \&$ TocRestrict $=$ n\&Toc $=\&$ TocEnt

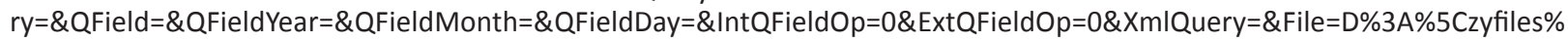
5CIndex\%20Data\%5C00thru05\%5CTxt\%5C00000004\%5C00000LZT.txt\&User=ANONYMOUS\&Password=anonymous\&SortMeth od=h\%7C-\&MaximumDocuments=1\&FuzzyDegree=0\&ImageQuality=r75g8/r75g8/x150y150g16/i425\&Display=hpfr\&DefSeekP age $=x \&$ SearchBack=ZyActionL\&Back=ZyActionS\&BackDesc=Results\%20page\&MaximumPages=1\&ZyEntry=1\&SeekPage=x\&ZyP URL [Accessed 18 October 2017].

Velders, G.J.M., Fahey, D.W., Daniel, J.S., Andersen, S.O. and McFarland, M. (2015) 'Future atmospheric abundances and climate forcings from scenarios of global and regional hydrofluorocarbon (HFCs) emissions'. Atmospheric Environment, 123:200-209. Available at: http://www.sciencedirect.com/science/article/pii/S135223101530488X [Accessed 18 October 2017].

Velders, G.J.M., Solomon, S. and Daniel, J.S. (2014) 'Growth of climate change commitments from HFC banks and emissions'. Atmospheric Chemistry and Physics, 14(9):4563-4572. Available at: https://www.atmos-chem-phys.net/14/4563/2014/ [Accessed 18 October 2017].

Venkataraman, C., Sagar, A.D., Habib, G. and Smith, K.R. (2010) 'The Indian National Initiative for Advanced Biomass Cookstoves: The benefits of clean combustion'. Energy for Sustainable Development, 14:63-72. Available at: http://citeseerx.ist.psu.edu/ viewdoc/download?doi=10.1.1.648.7301\&rep=rep1\&type=pdf [Accessed 18 October 2017].

Victor, D.G., Zaelke, D., Ramanathan, V., 2015. Soot and short-lived pollutants provide political opportunity. Nature Clim. Change 5, 796-798. doi:10.1038/nclimate2703

Wang, R., Tao, S., Shen, H., Huang, Y., Chen, H., Balkanski, Y., Boucher, O., Ciais, P., Shen, G., Li, W., Zhang, Y., Chen, Y., Lin, N., Su, S., Li, B., Liu, J. and Liu, W. (2014) 'Trend in global black carbon emissions from 1960 to 2007'. Environmental Science \& Technology, 48:6780-6787. Available at: https://www.ncbi.nlm.nih.gov/pubmed/24825392 [Accessed 18 October 2017].

Weyant, C., Athalye, V., Ragavan, S., Rajarathnam, U., Lalchandani, D., Maithel, S., Baum, E. and Bond, T.C. (2014) 'Emissions from South Asian Brick Production'. Environmental Science \& Technology, 48:6477-6483. Available at: https://www.ncbi.nlm.nih.gov/ pubmed/24735080 [Accessed 18 October 2017].

Weyant, C.L., Shepson, P.B., Subramanian, R., Cambaliza, M.O.L., Heimburger, A., McCabe, D., Baum, E., Stirm, B.H. and Bond, T.C. (2016) 'Black Carbon Emissions from Associated Natural Gas Flaring'. Environmental Science \& Technology, 50:2075-2081. Available at: https://www.ncbi.nlm.nih.gov/pubmed/26764563 [Accessed 18 October 2017].

WHO(2016) Burning Opportunity:Clean Household Energyfor Health, Sustainable Development, and Wellbeing of Womenand Children. Geneva: World Health Organization (WHO). Available at: http://apps.who.int/iris/bitstream/10665/204717/1/9789241565233_ eng.pdf [Accessed 18 October 18 2017].

Wickramasinghe, A. (2011). 'Energy access and transition to cleaner cooking fuels and technologies in Sri Lanka: Issues and policy limitations'. Energy Policy, 39:7567-7574. Available at: http://agris.fao.org/agris-search/search.do?recordID=US201600071626 [Accessed 18 October 2017].

Wiedinmyer, C., Yokelson, R.J. and Gullett, B.K. (2014) ‘Global Emissions of Trace Gases, Particulate Matter, and Hazardous Air Pollutants from Open Burning of Domestic Waste'. Environmental Science \& Technology, 48:9523-9530. Available at: http://pubs. acs.org/doi/abs/10.1021/es502250z [Accessed 18 October 2017].

Winiger, P., Andersson, A., Eckhardt, S., Stohl, A., Semiletov, I.P., Dudarev, O.V., Charkin, A., Shakhova, N., Klimont, Z., Heyes, C. and Gustafsson, Ö. (2017) 'Siberian Arctic black carbon sources constrained by model and observation'. Proceeding of the National Academy of Sciences, 114:E1054-E1061. Available at: https://www.ncbi.nlm.nih.gov/pubmed/28137854 [Accessed 18 October 2017].

Xu, Y. and Ramanathan, V. (2017) 'Well below $2^{\circ} \mathrm{C}$ : Mitigation strategies for avoiding dangerous to catastrophic climate changes'. Proceedings of the National Academy of Sciences, 114: 10315-10323. Available at: http://www.pnas.org/content/114/39/10315. abstract [Accessed 18 October 2017]. 
Xu, Y., Zaelke, D., Velders, G.J.M. and Ramanathan, V. (2013) 'The role of HFCs in mitigating 21st century climate change'. Atmospheric Chemistry and Physics, 13:6083-6089. Available at: https://www.atmos-chem-phys.net/13/6083/2013/ [Accessed 18 October 2017].

Zeiger, B., Gschrey, B. and Schwarz, W. (2014) Alternatives to HCFCS/HFCs in developing countries with a focus on high ambient temperatures. Frankfurt/Main: Öko-Recherche.

\section{Chapter 7}

Aertsens, J., De Nocker, L., \& Gobin, A. (2013). Valuing the carbon sequestration potential for European agriculture. Land Use Policy, 31, 584-594.

American Physics Society Panel on Public Affairs (2011) Direct Air Capture of $\mathrm{CO}_{2}$ Using Chemicals, 87 p. https://www.aps.org/ policy/reports/assessments/upload/dac2011.pdf

Anderson K., Peters G, 2016, The trouble with negative emissions, Science, 354/6309, pp 182-183, DOI: 10.1126/science.aah4567 Aresta (2010): Carbon dioxide as chemical feedstock, Wiley, Weinheim.

Aresta (2013): M. Aresta, A. Dibenedetto \& A. Angelini: The changing paradigm in $\mathrm{CO}_{2}$ utilization, Journal of $\mathrm{CO}_{2}$ Utilization, 3, 65-73.

Basso, A.S., Miguez, F.E., Laird, D.A., et al. (2013). Assessing potential of biochar for increasing water-holding capacity of sandy soils. GCB Bioenergy, 5(2), pp.132-143.

Benanti, G., Saunders, M., Tobin, B., \& Osborne, B. (2014). Contrasting impacts of afforestation on nitrous oxide and methane emissions. Agricultural and forest meteorology, 198, 82-93.

Benson, S. M., and Coauthors, 2012: Chapter 13 - Carbon Capture and Storage. Cambridge University Press, Cambridge, UK and New York, NY, USA and the International Institute for Applied Systems Analysis, Laxenburg, Austria, 993-1068 www.globalenergyassessment.org.

Berthrong, S. T., Jobbagy, E. G., \& Jackson, R. B. (2009). A global meta-analysis of soil exchangeable cations, pH, carbon, and nitrogen with afforestation. Ecological Applications, 19(8), 2228-2241.

Bozzi, E., Genesio L., Toscano P, Pieri M, Miglietta F, 2015 Mimicking biochar-albedo feedbackin complex Mediterranean landscapes, Envir. Res. Letters 10/084014

Bright, R. M., K. Zhao, R. B. Jackson, and F. Cherubini, 2015: Quantifying surface albedo and other direct biogeophysical climate forcings of forestry activities. Glob. Chang. Biol., 21, 3246-3266, doi:10.1111/gcb.12951.

Bruhn et al. (2016): T. Bruhn, H. Naims, B. Olfe-Kräutlein: Separating the debate on $\mathrm{CO}_{2}$ utilisation from carbon capture and storage', Environmental Science \& Policy, 60, 38-43.

Buck, H. J., 2016, Rapid scale-up of negative emissions technologies: social barriers and social implications, Clim. Change, (2016) 139: 155. Doi:10.1007/s10584-016-1770-6

Cayuela, M.L., Jeffery, S, and Van Zwieten L, (2015). The molar H:Corg ratio of biochar is a key factor in mitigating N2O emissions from soil. Agriculture Ecosystems and Environment 202, 135-138.

Center for Carbon Removal, 2015, Direct Air Capture explained in 10 questions, http://www.centerforcarbonremoval.org/blogposts/2015/9/20/direct-air-capture-explained-in-10-questions

Center for Carbon Removal, 2017, Carbon removal polices: opportunity for federal action, 39p. http://www.centerforcarbonremoval.org/s/Carbon-Removal-Policy-Opportunities-for-Action.pdf

Chamberlain TC, 1899, "An Attempt to Frame a Working Hypothesis of the Cause of Glacial Periods on an Atmospheric Basis". Journal of Geology. 7: 575, 667, 751

Chiang PC., Pan SY.,2017, CO 2 Mineralization and Utilization via Accelerated Carbonation. In: Carbon Dioxide Mineralization and Utilization. Springer, Singapore https://doi.org/10.1007/978-981-10-3268-4_3

Clarke, L., K. Jiang, K. Akimoto, M. Babiker, G. Blanford, K. Fisher-Vanden, J.-C. Hourcade, V. Krey, E. Kriegler, A. Löschel, D. McCollum, S. Paltsev, S. Rose, P. R. Shukla, M. Tavoni, B. van der Zwaan, and D. P. van Vuuren. 2014. Assessing Transformation Pathways. In Climate Change 2014: Mitigation of Climate Change. Contribution of Working Group III to the Fifth Assessment Report of the Intergovernmental Panel on Climate Change [Edenhofer, O., R. Pichs-Madruga, Y. Sokona, E. Farahani, S. Kadner, K. Seyboth, A. Adler, I. Baum, S. Brunner, P. Eickemeier, B. Kriemann, J. Savolainen, S. Schlömer, C. von Stechow, T. Zwickel and J.C. Minx (eds.)]. Cambridge University Press, Cambridge, United Kingdom and New York, NY, USA.

CLCF (2011): The Centre for Low Carbon Futures, Carbon Capture and Utilisation in the green economy: Using $\mathrm{CO}_{2}$ to manufacture fuel, chemicals and materials. http://www.policyinnovations.org/ideas/policy_library/data/01612/_res/id=sa_File1/CCU.pdf

$\mathrm{CO}_{2}$ Sciences, 2016, Global Roadmap for Implementing $\mathrm{CO}_{2}$ Utilization, Innovation for Cool Earth Forum, 61p, https://assets.contentful.com/xg0gv1arhdr3/27vQZEvrxaQiQEAsGyoSQu/44ee0b72ceb9231ec53ed180cb759614/CO_U_ICEF_Roadmap_FINAL_2016_12_07.pdf

Coninck, H. De, and S. M. Benson, 2014: Carbon Dioxide Capture and Storage: Issues and Prospects. Annu. Rev. Environ. Resour., 39, 243-70, doi:10.1146/annurev-environ-032112-095222.

Creutzig, F., Ravindranath, N. H., Berndes, G., Bolwig, S., Bright, R., Cherubini, F., ... Masera, O. (2015). Bioenergy and climate change mitigation: an assessment. GCB Bioenergy, 7(5), 916-944. https://doi.org/10.1111/gcbb.12205

de Best-Waldhober, M., D. Daamen, and A. Faaij, 2009: Informed and uninformed public opinions on $\mathrm{CO}_{2}$ capture and storage technologies in the Netherlands. Int. J. Greenh. Gas Control, 3, 322-332, doi:10.1016/j.ijggc.2008.09.001.

De Coninck, H., Benson, S. (2014). Carbon Dioxide Capture and Storage: Issues and Prospects. Annu. Rev. Environ. Resour. 2014. 39:243-70.

Diaz, D., Hamilton, K., Johnson, E., 2011. State of the Forest Carbon Markets 2011: From Canopy to Currency. Ecosystem Marketplace Report. Forest Trends, Washington, DC.

Field, C. B., \& Mach, K. J. (2017). Rightsizing carbon dioxide removal. Science, 356(6339), 706-707.

Frank, S., H. Böttcher, P. Havlík, H. Valin, A. Mosnier, M. Obersteiner, E. Schmid, and B. Elbersen, 2013: How effective are the sustainability criteria accompanying the European Union 2020 biofuel targets? GCB Bioenergy, 5, 306-314, doi:10.1111/j.17571707.2012.01188.x. http://doi.wiley.com/10.1111/j.1757-1707.2012.01188.x (Accessed July 6, 2017). 
Fuss, S. 2017. The 1.5C target, political implications, and the role of BECCS. Oxford Research Encyclopedia of Climate ScienceClimate Science, DOI: $10.1093 /$ acrefore/9780190228620.013.585

Fuss, S., and Coauthors, 2016: Research priorities for negative emissions. Environ. Res. Lett., 11, 115007, doi:10.1088/17489326/11/11/115007.

Fuss, S., J. G. Canadell, G. P. Peters, M. Tavoni, R. M. Andrew, P. Ciais, R. B. Jackson, C. D. Jones, F. Kraxner, N. Nakicenovic, C. Le Quere, M. R. Raupach, A. Sharifi, P. Smith, and Y. Yamagata. 2014. Betting on negative emissions. Nature Clim. Change 4(10): 850-853.

Genesio, L., Miglietta, F., Lugato, E., Baronti, S., Pieri, M., Vaccari, FP. (2012) Surface albedo following biochar application in durum wheat. Environmental Research Letters (2012): 1-8. IOP Science. http://iopscience.iop.org/1748-9326/7/1/014025.

Global CCS Institute, 2016, The Global Status of CCS, 2016: Summary Report, Australia, https://hub.globalccsinstitute.com/sites/ default/files/publications/201158/global-status-ccs-2016-summary--report.pdf

Griscom, B.W., Adams, J., Ellis, P., Houghton, R.A., Lomax, G., Miteva, D.A., Schlesinger, W.H., Shoch, D., Siikamäki, J., Woodbury, P., Zganjar, C., Blackman, A., Campari, J., Conant, R.T., Delgado, C., Elias, P., Hamsik, M., Kiesecker, J., Landis, E., Polasky, S., Potapov, P., Putz, F.E., Sanderman, J., Silvius, M., Smith, P., Wollenberg, E. \& Fargione, J. 2017. Natural pathways to climate mitigation. Proceedings of the National Academy of Sciences, USA (in press).

Hamilton, K., Chokkalingam, U., Bendana, M., 2010. State of the Forest Carbon Markets 2009: Taking Root and Branching Out. Ecosystem Marketplace Report. Forest Trends, Washington, DC.

Hartmann J., West A.J., Renforth P, Kohler P, DeLaRocha C.L., Wolf-Gladrow D.A., Durr H.H., Scheffran J, 2013, Enhanced chemical weathering as a geoengineering strategy to reduce atmospheric carbon dioxide, supply nutrients, and mitigate ocean acidification, Reviews in Geophysics 51(2) pp 113-149, DOI: 10.1002/rog.20004

Havlík, P., and Coauthors, 2011: Global land-use implications of first and second generation biofuel targets. Energy Policy, 39, 5690-5702, doi:10.1016/j.enpol.2010.03.030.

Henderson G., Rickaby R., Bouman H., 2008, Decreasing atmospheric $\mathrm{CO}_{2}$ by increasing ocean alklainity, https://www.earth.ox.ac. uk/ gideonh/reports/Cquestrate_report.pdf

Houghton, R. A., Byers, B., \& Nassikas, A. A. (2015). A role for tropical forests in stabilizing atmospheric $\mathrm{CO}_{2}$. Nature Climate Change, 5(12), 1022-1023.

House KZ, House CH, Schrag DP, Aziz MJ (2007) Electrochemical acceleration of chemical weathering as an energetically feasible approach to mitigating anthropo- genic climate change. Environ Sci Technol 41(24):8464-8470

Hu, S., Niu, Z., Chen, Y., Li, L., Zhang, H. (2017). Global wetlands: potential distribution, wetland loss, and status. Science of the Total Environment 586: 319-327.

ICEF, 2017, Carbon Dioxide Utilization ( $\left.\mathrm{CO}_{2} \mathrm{U}\right)$ : ICEF Roadmap 1.0,

International Energy Agency, 2017, Energy Technology Perspectives 2017. Catalysing Energy Technology Transformations, Paris (ISBN 978-92-64-27050-3)

IPCC 2014, 2013 Supplement to the 2006 IPCC Guidelines for National Greenhouse Gas Inventories: Wetlands, Hiraishi, T., Krug, T., Tanabe, K., Srivastava, N., Baasansuren, J., Fukuda, M. and Troxler, T.G. (eds). Published: IPCC, Switzerland.

IPCC, 2005 - Bert Metz, Ogunlade Davidson, Heleen de Coninck, Manuela Loos and Leo Meyer (Eds.). Cambridge University Press, UK. pp 431. https://www.ipcc.ch/pdf/special-reports/srccs/srccs_wholereport.pdf

IPCC. 2014. Climate Change 2014: Synthesis Report. Contribution of Working Groups I, II and III to the Fifth Assessment Report of the Intergovernmental Panel on Climate Change. Geneva, Switzerland: IPCC.

Jones, A. D., K. V. Calvin, W. D. Collins, and J. Edmonds, 2015: Accounting for radiative forcing from albedo change in future global land-use scenarios. Clim. Change, 131, 691-703, doi:10.1007/s10584-015-1411-5.

Joseph, S., Graber, E.R., Chia, C., Munroe, P., Donne, S., Thomas, T., Nielsen, S., Marjo, C., Rutlidge, H., Pan, G.X. and Li, L., 2013. Shifting paradigms: development of high-efficiency biochar fertilizers based on nano-structures and soluble components. Carbon Management, 4(3), pp.323-343.)

Keith, D.W. 2017. Toward a Responsible Solar Geoengineering Research Program. Issues in Science and Technology 33(3), 71-77.

Keith, D.W., Ha-Duong M., Stolaroff J.K., 2006, Climate Strategy with $\mathrm{CO}_{2}$ Capture from the Air, Climate Change, v.74 17-45, DOI: 10.1007/s10584-005-9026-x

Kelemen PB, Matter J, 2008, In situ carbonation of peridotite for $\mathrm{CO}_{2}$ storage. PNAS 105(45) pp 17295-17300

Kemper, J., 2015: Biomass and carbon dioxide capture and storage: A review. Int. J. Greenh. Gas Control, 40, 401-430, doi:10.1016/j. ijggc.2015.06.012.

Kheshgi, H. S. 1995. Sequestering atmospheric carbon dioxide by increasing ocean alkalinity. Energy, 20(9), 915-922.

Kimaro, A.A., Isaac, M.E. \& Chamshama, S.A.O. (2011) Carbon pools in tree biomass and soils under rotational woodlot systems in Eastern Tanzania. In: "Carbon Sequestration Potential of Agroforestry Systems", ed. Kumar, B.M. \& Nair, P.K.R., Springer, Dordrecht, NL. pp. 129-143.

Kirschbaum, M. U. F., Whitehead, D., Dean, S. M., Beets, P. N., Shepherd, J. D., \& Ausseil, A. G. (2011). Implications of albedo changes following afforestation on the benefits of forests as carbon sinks. Biogeosciences, 8(12), 3687.

Lackner K.S., Ziock H., Grimes P., 1999, Carbon Dioxide Extraction from Air: Is It an Option? In Proceedings of the 24th Annual Technical Conference on Coal Utilization \& Fuel Systems, Clearwater, FL.; pp 885- 896

Lackner KS, Wendt CH, Butt DP, Joyce EL, Sharp DH (1995) Carbon dioxide disposal in carbonate minerals, Energy 11(20) pp. 11531170

Lal, R (2011) Sequestering carbon in soils of agro-ecosystems. Food Policy 36, Supplement 1, pp. S33-S39

Lal, R. (2013) Intensive Agriculture and the Soil Carbon Pool. Journal of Crop Improvement, 27(6), pp.735-751

Lassiter III J.B., Misra S., 2016, Carbon Engineering, Harvard Business School case study, 9-814-040.

Lehmann J., Czimczik, C., Laird, D., Sohi, S. (2015) Stability of biochar in soil. In: Biochar for Environmental Management: Science, Technology and Implementation (eds. Lehmann, J., Joseph, S.), pp. 235-282, Taylor and Francis, London, UK.

Lehmann, J. and Joseph, S. (2009) Biochar for Environmental Management: Science and Technology. Earthscan Books Ltd., London, UK. 
Lenton, T. M. (2014) The Global Potential for Carbon Dioxide Removal. In Geoengineering of the Climate System (eds Harrison, R. M. and Hester, R. E.), Royal Society of Chemistry, 2014, pp. 52-79.

Li, D., Niu, S., and Luo, Y. (2012). Global patterns of the dynamics of soil carbon and nitrogen stocks following afforestation: a metaanalysis. New Phytologist, 195(1), 172-181.

Lomax, G., M. Workman, T. Lenton, N. Shah, 2015, Reframing the policy approach to greenhouse gas removal technologies, Energy Policy, 78 (2015) 125-136, doi:10.1016/j.enpol.2014.10.002

Marshall C., 2017, "In Switzerland, a giant new machine is sucking carbon directly from the air", E\&E News, June 1 (reprinted in Science: doi:10.1126/science.aan6915)

McDonough W., 2016, Carbon is not the Enemy, Nature 539, pp 349-351

McLaren, D., 2012: A comparative global assessment of potential negative emissions technologies. Spec. Issue Negat. Emiss. Technol., 90, 489-500, doi:10.1016/j.psep.2012.10.005.

Miles L. and Sonwa D.J. et al. 2015 UNEP Emissions Gap Report, Chapter 6: Mitigation potential from forest-related activities and incentives for enhanced ac on in developing countries

Minasny, B. et al. (2017) Soil carbon 4 per mille. Geoderma 292 (2017)59-86

Minx, J.C.; Lamb, W.; Callaghan, M.; Bornmann, L.; Fuss, S. 2017. Fast growing research on negative emissions. Envir. Res. Letters 12/035007

Mitsch, William J., et al. (2012). Wetlands, carbon, and climate change. Landscape Ecology 28.4: 583-597.

Monfreda, C., N. Ramankutty, and J. A. Foley, 2008: Farming the planet: 2. Geographic distribution of crop areas, yields, physiological types, and net primary production in the year 2000. Global Biogeochem. Cycles, 22, doi:10.1029/2007GB002947.

Monkman S., MacDonald M., 2015, Case studies for $\mathrm{CO}_{2}$ utilization in concrete, Spec. Publication 303, American Concrete Institute, pp. 33-44

Naims (2016): H. Naims, Economics of carbon dioxide capture and utilization - A supply and demand perspective. Environmental Science and Pollution Research, 1-16.

NERC, 2017, Greenhouse Gas Removal from the Atmosphere, Program Overview, http://www.nerc.ac.uk/research/funded/programmes/ggr/\#xcollapse2

Nielsen, Anne Sofie Elburg; Plantinga, Andrew J.; Alig, Ralph J. 2014. New cost estimates for carbon sequestration through afforestation in the United States. Gen. Tech. Rep. PNW-GTR-888. Portland, OR: U.S. Department of Agriculture, Forest Service, Pacific Northwest Research Station. $35 \mathrm{p}$.

Page S.E., Hooijer A. 2016 In the line of fire: the peatlands of Southeast Asia. Phil. Trans. R. Soc. B 371: 20150176. http://dx.doi. org/10.1098/rstb.2015.0176

Parish, F., Sirin, A., Charman, D.J., Joosten, H., Minayeva, T., Silvius, M., Stringer, L. (2008). Assessment on Peatlands, Biodiversity and Climate Change: Main Report. Global Environment Centre, Kuala Lumpur and Wetlands International, Wageningen.

Peters, G. P., R. M. Andrew, J. G. Canadell, S. Fuss, R. B. Jackson, J. I. I. Korsbakken, C. Le Quéré, and N. Nakicenovic, 2017: Key indicators to track current progress and future ambition of the Paris Agreement. Nat. Clim. Chang., 7, 118-122, doi:10.1038/ nclimate3202.

Peters, G.P., O. Geden, 2017: Catalysing a political shift from low to negative carbon. Nat. Clim. Chang., 7, 619-621, doi:10.1038/ nclimate3369.

Plevin, R. J., M. O'Hare, A. D. Jones, M. S. Torn, and H. K. Gibbs, 2010: Greenhouse Gas Emissions from Biofuels' Indirect Land Use Change Are Uncertain but May Be Much Greater than Previously Estimated. Environ. Sci. Technol., 44, 8015-8021, doi:10.1021/ es101946t. http://pubs.acs.org.globalproxy.cvt.dk/doi/full/10.1021/es101946t.

Popp, A., Krause, M., Dietrich, J. P., Lotze-Campen, H., Leimbach, M., Beringer, T., \& Bauer, N. (2012). Additional $\mathrm{CO}_{2}$ emissions from land use change - Forest conservation as a precondition for sustainable production of second generation bioenergy. Ecological Economics, 74, 64-70. https://doi.org/10.1016/j.ecolecon.2011.11.004

Powlson, DS, Stirling, CM, Jat, ML, Gerard, BG, Palm, CA, Sanchez, PA, Cassman, KG (2014) Limited potential of no-till agriculture for climate change mitigation. Nature Climate Change 4, 678-683 (2014) doi:10.1038/nclimate2292

Rau G., Knauss K.G., Lander W.H., Caldeira K., 2004, $\mathrm{CO}_{2}$ mitigation via accelerated limestone weathering, Am. Chem. Soc., Div. Fuel Chem. 2004, 49 (1), 376

Rau GH, Knauss KG, Langer WH, Caldeira K, 2007, Reducing energy-related $\mathrm{CO}_{2}$ emissions using accelerated weathering of limestone, Energy 32, pp. 1471-1477, DOI: 10.1016/j.energy.2006.10.011

Raymo, M.E., 1991, Geochemical evidence supporting T.C. Chamberlain's theory of glaciation, Geology 19(4) 344-347 https://doi. org/10.1130/0091-7613(1991)019<0344:GESTCC>2.3.CO;2

Renforth P, Kruger T, 2013, Coupling mineral carbonation and ocean liming, Energy Fuels 27(8), pp. 4199-4207 DOI: 10.1021/ ef302030w

Renforth P., Henderson G., 2017, Assessing ocean alkalinity for carbon sequestration, Reviews in Geophysics 55, 10.1002/2016RG000533

Rogelj, J., G. Luderer, R. C. Pietzcker, E. Kriegler, M. Schaeffer, V. Krey, and K. Riahi. 2015. Energy system transformations for limiting end-of-century warming to below 1.5 [deg]C. Nature Clim. Change 5(6): 519-527.

Rogelj, J., M. den Elzen, N. Höhne, T. Fransen, H. Fekete, H. Winkler, R. Schaeffer, F. Sha, K. Riahi, and M. Meinshausen. 2016. Paris Agreement climate proposals need a boost to keep warming well below $2^{\circ} \mathrm{C}$. Nature 534(7609): 631-639.

Royal Society 2009. Geoengineering the climate Science, governance and uncertainty. Royal Society Policy document 10/09 Issued: September 2009 RS1636. ISBN: 978-0-85403-773-5.

Sanz-Perez E.S., Murdock C.R., Didas S.A., Jones C.W., 2016, Direct Air Capture of CO from Ambient Air, Chem. Rev., v. 116 (19), pp 11840-11876 
Schäfer, S.; Lawrence, M.; Stelzer, H.; Born, W.; Low, S.; Aaheim, A.; Adriázola, P.; Betz, G.; Boucher, O.; Carius, A.; Devine-Right, P.; Gullberg, A. T.; Haszeldine, S.; Haywood, J.; Houghton, K.; Ibarrola, R.; Irvine, P.; Kristjansson, J.-E.; Lenton, T.; Link, J. S. A.; Maas, A.; Meyer, L.; Muri, H.; Oschlies, A.; Proelß, A.; Rayner, T.; Rickels, W.; Ruthner, L.; Scheffran, J.; Schmidt, H.; Schulz, M.; Scott, V.; Shackley, S.; Tänzler, D.; Watson, M.; Vaughan, N., 2015, The European Transdisciplinary Assessment of Climate Engineering (EUTRACE):Removing Greenhouse Gases from the Atmosphere and Reflecting Sunlight away from Earth. http://www.iass-potsdam.de/sites/default/files/files/eutrace_report_digital_second_edition_0.pdf

Scott, V., R. S. Haszeldine, S. F. B. Tett, and A. Oschlies, 2015: Fossil fuels in a trillion tonne world. Nat. Clim. Chang., 5, $419-423$.

Searchinger, T. D., and Coauthors, 2009: Fixing a Critical Climate Accounting Error. Science (80-. )., 326, 527-528, doi:10.1126/science.1178797.

Slade, R., A. Bauen, and R. Gross, 2014: Global bioenergy resources. Nat. Clim. Chang., 4, 99-105.

Smith, P. (2012) Soils and climate change. Current Opinion in Environmental Sustainability 4, 539-544.

Smith P., Bustamante, M., Ahammad, H., Clark, H., Dong, H., Elsiddig, E.A., Haberl, H., Harper, R., House, J., Jafari, M., Masera, O., Mbow, C., Ravindranath, N.H., Rice, C.W., Robledo Abad, C. Romanovskaya, A., Sperling, F. \& Tubiello, F. (2014) Agriculture, Forestry and Other Land Use (AFOLU). In: "Climate Change 2014: Mitigation of Climate Change. Contribution of Working Group III to the Fifth Assessment Report of the Intergovernmental Panel on Climate Change" pp. 811-922 (ed. Edenhofer, O., R. PichsMadruga, Y. Sokona, E. Farahani, S. Kadner, K. Seyboth, A. Adler, I. Baum, S. Brunner, P. Eickemeier, B. Kriemann, J. Savolainen, S. Schlömer, C. von Stechow, T. Zwickel \& J. Minx). Cambridge University Press, Cambridge, United Kingdom and New York, NY, USA. Smith, P. (2016) Soil carbon sequestration and biochar as negative emission technologies. Global Change Biology 22, $1315-1324$.

Smith, P., and Coauthors, 2016: Biophysical and economic limits to negative $\mathrm{CO}_{2}$ emissions. Nat. Clim. Chang., 6, 42-50, doi:10.1038/ nclimate2870.

Smith, P., Gregory, P., van Vuuren, D. et al. (2010) Competition for land. Philosophical Transactions of the Royal Society, B. 365, 2941-2957.

Smith, P., Martino, D., Cai, Z., Gwary, D., Janzen, H., Kumar, P., McCarl, B., Ogle, S., O’Mara, F., Rice, C., Scholes, B., Sirotenko, O., Howden, M., McAllister, T., Pan, G., Romanenkov, V., Schneider, U., Towprayoon, S., Wattenbach, M., Smith, J. (2008). Greenhouse gas mitigation in agriculture. Philosophical transactions of the Royal Society, Series B 363(1492), 789-813.

Taylor, L.L., Quirk, J., Thorley, R.M.S. et al., 2016. Nature Climate Change, 6, 402-406.

The Economist, 2017, Electrifying Everything, Economist Magazine, Aug. 12th

Trabucco, A., Zomer, R. J., Bossio, D. A., van Straaten, O., \& Verchot, L. V. (2008). Climate change mitigation through afforestation/reforestation: a global analysis of hydrologic impacts with four case studies. Agriculture, ecosystems \& environment, 126(1), 81-97.

Upham, P., and T. Roberts, 2011: Public perceptions of CCS: Emergent themes in pan-European focus groups and implications for communications. Int. J. Greenh. Gas Control, 5, 1359-1367, doi:10.1016/j.ijggc.2011.06.005.

USNAS 2015a. Climate Intervention: Carbon Dioxide Removal and Reliable Sequestration. US National Academy of Sciences, Washington D.C.

USNAS 2015b. Climate Intervention: Reflecting Sunlight to Cool Earth. US National Academy of Sciences, Washington D.C.

van Vuuren, D. P., S. Deetman, J. van Vliet, M. van den Berg, B. J. van Ruijven, and B. Koelbl. 2013. The role of negative $\mathrm{CO}_{2}$ emissions for reaching $2^{\circ} \mathrm{C}$-insights from integrated assessment modelling. Climatic Change 118(1): 15-27.

von der Assen, N., Jung, J. \& Bardow, A. (2013) Life-cycle assessment of carbon dioxide capture and utilization: avoiding the pitfalls. Energy Environ. Sci., 6, 2721-2734.

Wallquist, L., S. L. O. Seigo, V. H. M. Visschers, and M. Siegrist, 2012: Public acceptance of CCS system elements: A conjoint measurement. Int. J. Greenh. Gas Control, 6, 77-83, doi:10.1016/j.ijggc.2011.11.008.

Weng, Z.H., Van Zwieten, L., Singh, B.P., Tavakkoli, E., Joseph, S., Macdonald, L.M., Rose, T.J., Rose, M.T., Kimber, S.W., Morris, S. and Cozzolino, D., (2017). Biochar built soil carbon over a decade by stabilizing rhizodeposits. Nature Climate Change 7, 371-376.

Willauer H., DiMascio F., Hardy D.R., Williams F.W., 2014, Feasibility of $\mathrm{CO}_{2}$ Extraction from Seawater and Simultaneous Hydrogen Gas Generation Using a Novel and Robust Electrolytic Cation Exchange Module Based on Continuous Electrodeionization Technology, Industrial \& Chem. Res. 53, 12192-12200, dx.doi.org/10.1021/ie502128x.

Williams-Guillén, K., Perfecto, I \& Vandermeer, J. (2008) Bats Limit Insects in a Neotropical Agroforestry System. Science, $320,70$.

Williamson P., 2016, Scrutinize $\mathrm{CO}_{2}$ removal methods. Nature, 530: 153-155.

Woolf, D., Amonette, JE., Street-Perrott. A., Lehmann, J., Joseph, S. (2010) Sustainable biochar to mitigate global climate change. Nature Communications 1, Article 56, doi:10.1038/ncomms1053 (2010).

Worrall, F., Evans, M.G., Bonn, A., Reed, M.S., Chapman, D., Holden, J. (2009). Can carbon offsetting pay for upland ecological restoration? The Science of the Total Environment 408(1), 26-36.

Zakkour, P., J. Kemper, T. Dixon, 2014: Incentivising and accounting for negative emission technologies, Energy Procedia, 63 (2014) 6824 - 6833, doi: 10.1016/j.egypro.2014.11.716.

Zedler, Joy B., and Suzanne Kercher. (2005). Wetland resources: status, trends, ecosystem services, and restorability. Annu. Rev. Environ. Resour. 30: 39-74.

Zhang, A., Cui, LQ., Pan, G., Li, LQ., Hussain, Q., Zhang, XH., Zheng, JW., Crowley, D. (2010) Effect of biochar amendment on yield and methane and nitrous oxide emissions from a rice paddy from Tai Lake Plain, China. Agriculture, Ecosystems \& Environment $139,469-475$.

Zhao, K., \& Jackson, R. B. (2014). Biophysical forcings of land-use changes from potential forestry activities in North America. Ecological Monographs, 84(2), 329-353.

Zomer, R.J., Neufeldt, H., Xu, J.C., Ahrends, A., Bossio, D., Trabucco, A., van Noordwijk, M. \& Wang, M.C. (2016) Global Tree Cover and Biomass Carbon on Agricultural Land: The contribution of agroforestry to global and national carbon budgets. Scientific Reports 2016, 6: 29987. doi: 10.1038/srep29987. 




\section{UN environment}

\section{United Nations}

Environment Programme

United Nations Avenue, Gigiri

P O Box 30552, 00100 Nairobi, Kenya

Tel +254207621234 | publications@unenvironment.org

www.unenvironment.org

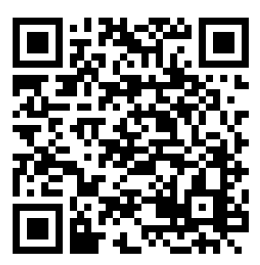

